\title{
HANFORD TANK FARM INTERIM STORAGE PHASE PROBABILISTIC RISK ASSESSMENT OUTLINE (5/19/94)
}

1 EXECUTIVE SUMMARY

2 INTRODUCTION

2.1 Project Background

2.2 Project Scope

2.3 Summary of PRA Methodology

2.4 Organization of Report

3 IDENTIFICATION OF INITIATING EVENTS

3.1 Master Logic Diagram

3.2 Initiating Event Grouping

3.3 Review of Previous Studies

4 ACCIDENT SEQUENCE MODELING AND QUANTIFICATION

4.1 Technical Approach

4.1.1 Accident Sequence Modeling Methods

4.1.1.1 Event Sequence Diagram Development

4.1.1.2 Event Tree Construction

4.1.1.3 End State Assignment

4.1.2 Accident Sequence Quantification

4.2 Hanford Tank Farm Accident Sequence Analysis and Modeling

4.2.1 Flammable Gas Accumulation

4.2.1.1 Tank Susceptibility Evaluation (for each IE)

4.2.1.2 Initiating Event Frequency Quantification (for each IE)

4.2.1.3 Accident Sequence Model (for each IE)

4.2.2 Tank Shell Breach

4.2.3 Tank Dome Breach

4.2.4 Ventilation Line Breach

4.2.5 Ventilation Exhaust HEPA Filter Failure

4.2.6 Ventilation Drainage System Leak

4.2.7 Loss of Active Ventilation Flow 


\section{DISCLAIMER}

Portions of this document may be illegible in electronic image products. Images are produced from the best available original document. 
HANFORD TANK FARM INTERIM STORAGE PHASE PROBABILISTIC RISK ASSESSMENT OUTLINE (5/19/94, continued)

4.2.8 Loss of Tank Mixing

4.2.9 Uncontrolled Heatup of Tank Waste

4.2.10 Water Intrusion

4.2.11 Waste Transfer

4.2.12 Criticality Events

4.2.13 Seismic Events

4.2.14 Aircraft Crash

4.3 Accident Sequence Quantification

4.3.1 Summary of Quantification Inputs

4.3.2 Accident Sequence Results

4.3.3 Release Category Frequencies

4.3.4 Release Category Results Sorted by Initiating Event

4.3.5 Release Category Results Sorted by Accident Sequences

4.3.6 Release Category Results Sorted by Important Top Events

5 SOURCE TERM ANALYSIS

5.1 Overview

5.2 Release Category Definitions

5.3 Waste Characterization

5.4 Airborne Source Terms

5.5 Liquid Pathway Source Terms

5.6 Summary of Source Terms

6 CONSEQUENCE ANALYSIS

6.1 Overview

6.2 Atmospheric Dispersion and Dose Assessment Models

6.3 Liquid Pathway Dose Assessment Model

6.4 Dose/Health Consequences for Release Categories

6.5 Economic Consequences for Release Categories 


\title{
HANFORD TANK FARM INTERIM STORAGE PHASE PROBABILISTIC RISK ASSESSMENT OUTLINE (5/19/94, continued)
}

\section{RESULTS AND CONCLUSIONS}

7.1 Release Category Frequencies

7.2 Conditional Risk Curves

7.3 Total Risk Curves

7.4 Observations and Conclusions

\section{APPENDIX A. GLOSSARY OF TERMS}

APPENDIX B. EQE STRUCTURAL ANALYSIS

\author{
APPENDIX C. EXTERNAL EVENTS ANALYSIS
}

\author{
APPENDIX D. DATA ANALYSIS
}

APPENDIX E. TANK STATUS DATABASE

\section{DISCLAIMER}

This report was prepared as an account of work sponsored by an agency of the United States Government. Neither the United States Government nor any agency thereof, nor any of their employees, makes any warranty, express or implied, or assumes any legal liability or responsibility for the accuracy, completeness, or usefulness of any information, apparatus, product, or process disclosed, or represents that its use would not infringe privately owned rights. Reference herein to any specific commercial product, process, or service by trade name, trademark, manufacturer, or otherwise does not necessarily constitute or imply its endorsement, recommendation, or favoring by the United States Government or any agency thereof. The views and opinions of authors expressed herein do not necessarily state or reflect those of the United States Government or any agency thereof.



\section{CIETEIBUTION OF THIS DOCUMENT IS UR}




\subsection{INTRODUCTION}

\subsection{PROJECT BACKGROUND}

This report is the second in a series examining the risks for the high level waste (HLW) storage facilities at the US Department of Energy (DOE) Hanford Site. The first phase of the HTF PSA effort (Ref. 2-1) addressed risks from tank 101-SY, only. Tank 101-SY was selected as the initial focus of the PSA because of its propensity to periodically release (burp) a mixture of flammable and toxic gases. This has caused tank 101-SY to be the subject of intense observation and study and to be considered one of the most serious risk problems on the site. This report expands the evaluation of tank 101SY to all 177 storage tanks.

The HLW storage facilities consist of 177 underground tanks plus asssociated support and waste transfer systems, located in the 200 east and 200 west areas of the US Department of Energy (DOE) Hanford Site. The 177 tanks are arranged into 18 farms and contain the HLW accumulated over 50 years of weapons material production work at Hanford. Because the Hanford site is no longer in production, the primary focus of current activities is environmental remediation and restoration directed toward long-term site closure. A centerpiece of the remediation activity is the effort toward developing a permanent method fro disposing of the HLW tank's highly radioactive contents. Because these activities are expected to take several decades to complete and because resources are limited, it was deemed advisable to prioritize the HLW tank's activities on a risk basis. One approach to risk based priorirization is to perform a PSA for the whole HLW tank farm complex to identify the highest risk tanks so that remediation planners and managers will have a more rational basis for allocating limited funds to the more critical areas. 


\subsection{PROJECT SCOPE}

The ultimate objective of the work described in this report is to develop risk profile for the entire Hanford HLW tank farm complex. In practice, such a large objective must be achieved through the completion of successive, well defined and manageable pieces. This report represents the second increment of a multi-phase HTF PSA effort.

To comprehensively define the scope of this report and the overall HTF PSA effort, three dimensions were defined to describe the scope of the risks evaluated in the HTF PSA:

1. The time span of the events included in the PSA

2. The time span of the consequences included in the PSA

3. The consequence measures used as risk indices

For many PSA's there is no difference between the time of the events and the consequences. At Hanford, however, radionuclides and hazardous chemicals released into the soil may remain there for hundreds or thousands of years before re-emerging to produce unwanted consequences.

PSA's typically use estimates of the frequency of severe accidents and/or health effects resulting from accidents to measure risk. At Hanford, the cost effectiveness of proposed storage and remediation schemes will also be a significant factor in the overall risk management of the site. Therefore, measures of economic risk are also included in this evaluation.

The next three sub-sections discuss each of the scope dimensions in detail and support the integrated scope description presented in the final sub-section.

\subsubsection{TIME SPAN OF THE EVENTS INCLUDED IN THE PSA}

The life cycle of the Hanford Tank Farms can be described in terms of the four era's or phases that are discussed below. Each era presents different potential health and economic risks. It is recognized that the boundaries between these era's cannot be neatly delineated at any one point in time. They will necessarily overlap and be of different duration's for different tanks. None the less, these era's provide a useful basis for describing the scope of this and future risk assessment activities.

\section{Production Era}

This is the period of plutonium production that began in 1943 and continued for approximately 50 years, until present time. This era includes the direct loading of wastes from separation and purification processing to the tank farms as well as the infarm processing and evaporation of wastes.

Releases of radionuclides and hazardous chemicals did occur in this era to both the atmosphere and the soil. Acute health effects from these releases, if known, are already realized and are not considered further in this analysis. Delayed consequences from hazardous materials still in the soil beneath the site are possible. 


\section{Interim Storage Era}

This is the period of time between the interim stabilization of non-watchlist tank wastes and the final stabilization for long term storage in place or removal of the wastes for processing. Risks from activities to stabilize watchlist tanks and maintain and characterize all tanks are included in this era. Additions of new waste from site wide clean up activities will contiriue through this era which is expected to last 10 to 20 years.

\section{Remediation Era}

This is the period where tank wastes are prepared for final, long term storage. Activities in this era are expected to take 20 to 30 years and may range from minimal action to removal of all tank wastes for processing and disposal.

\section{Long Term Storage Era}

Even the most ambitious proposals for remediation of the HTF include long term storage of at least low level wastes on site. Long term storage should begin within 30 to 50 years from now and extend indefinitely.

\subsubsection{THE TIME SPAN OF THE CONSEQUENCES INCLUDED IN THE PSA}

Radionuclides and hazardous chemicals released into the soil at Hanford may remain there for hundreds or thousands of years before possibly re-emerging to produce unwanted consequences. Factors influencing the timing of the consequence realization include the time, magnitude and location of the initial release as well as future restrictions on public access to the Hanford site.

Figure 2-1 shows a map of the Hanford Nuclear Reservation as it exists today and the location of the $\mathbf{2 0 0}$ or tank farm area within the reservation. Radionuclide or hazardous chemical releases from the tank farm area must travel at least 2 miles to reach the nearest point of public access, highway 240 , and at least 8 miles to cross the nearest point of the site boundary. With these boundaries, hazardous compounds released into the soil may bind with minerals and become immobile or decay and dilute sufficiently before reaching the site boundary so that their potential health risks are negligible. If the boundaries of the site should be moved in the future and the general public allowed closer access to the tank farms, potential health effects from future, or past, releases could be increased. This is especially true if water wells are dug on site, allowing a new more direct exposure path to be formed. Thus, changes in site use restrictions could impact the magnitude of future consequences predicted from past or future ground water contamination.

\subsubsection{CONSEQUENCE MEASURES INCLUDED IN THE PSA}

\subsubsection{HEALTH EFFECTS RISK}

Potential health effects from exposure to radionuclides and hazardous chemicais are included in the HTF PSA. As described in report section 6, radionuclide exposure is measured in person-rem and converted to health effects through the use of generally 
accepted models. Hazardous chemical exposure is measured by the estimated peak concentration of the chemical in the environment and is generally not converted into potential health effects.

Potential health risks from atmospheric releases are calculated for onsite worker and the offsite population. The sources of risk included in the HTF PSA include exposure from accidental releases and their clean-up. Normal occupational exposure is limited by regulations and is assumed to present negligible health risk. Delayed doses to the public from subterranean liquid releases are also calculated but reported separately due to the difference in time and the fact that any consequences will be realized by different individuals.

\subsubsection{ECONOMIC RISK}

Decisions on alternative strategies for storage and remediation of the HTF will consider costs as well as possible health effects. The measure of economic risk is, of course, dollars and procedures for incorporating time-value effects in decision making are well known. The systematic inclusion of uncertainty in economic analysis is much less prevalent.

When viewed from the decision making perspective, the sources of economic risk include uncertainty about the cost of planned activities as well as direct and indirect costs from accidents. However, because this analysis is focused on possible accidents during interim storage, onsite cleanup costs resulting from accidents is the only economic parameter evaluated at this time. Specific clean-up costs evaluated include the collection and disposal of contaminated soil, the repair of damaged tanks or the interdiction and treatment of contaminated ground water.

\subsubsection{INTEGRATED PSA SCOPE DESCRIPTION}

The timing of potential HTF events and consequence discussed above can be joined to define the time span of coverage of the PSA. Because of the potential delay between the time hazardous materials are released into the soil and the time at which they may produce health consequences, a two dimensional concept of time is needed to describe the scope of coverage of the PSA. Figure 2-2 provides a graphical representation of this concept. The time of risk producing events represented by the life cycle era's of the HTF are presented along the top axis from left to right. The vertical axis depicts the time at which consequences from a release are realized. For acute health effects from atmospheric releases there is no delay between the time of release and time of consequence. For releases into the soil, however, there is a potential delay from the time of release until the material migrates off site or the site boundaries are changed allowing public access to already contaminated areas. Using these two axes, nine hypothetical regions are defined for potential risk evaluation.

Region 1 represents the completed production era for which acute consequences have already been realized. Regions 2 and 3 represent the potential future consequences from releases that occurred during the production era. These potential future consequences are arbitrarily divided into time spans with and without continued restriction of public site access. Regions 4,6 and 8 represent the potential future 
consequences from events occurring during the interim storage, remediation and long term storage era's while site use restriction is continued. Regions 5, 7 and 9 represent the potential consequences from events occurring in these era's after the expiration of site use restrictions.

The first phase of the HTF PSA effort (Ref. 2-1) addressed health and economic risks for time scope region 4 (interim storage) from tank 101-SY, only. Tank 101-SY was selected as the initial focus of the PSA because of its propensity to periodically release (burp) a mixture of flammable and toxic gases. This has caused tank 101-SY to be the subject of intense observation and study and to be considered one of the most serious risk problems on the site. This report expands the evaluation of time scope region 4 to all 177 storage tanks. Later phases will address regions 6 (remediation), 8 (long term storage) and possible changes in site usage (time scope regions $3,5,7$, and 9).

The consequence measures important for this phase of the HTF PSA include health risks to onsite workers and the offsite public from accidental atmospheric and subterranean liquid releases from the tanks. For the interim storage period covered in this analysis, the primary economic risk present is the cost of clean-up for accidental releases. Figure 2-3 presents a matrix integrating the time scope regions included in each phase of the HTF PSA with the important consequence measures to define the total scope of the PSA. 


\subsection{SUMMARY OF PSA METHODOLOGY}

The purpose of performing a PSA is to answer the following questions that are fundamental to a quantitative risk assessment:

1. What can go wrong during Hanford Tank Farm (HTF) interim storage operations or maintenance that could result in an accident sequence that could produce a radionuclide or toxic gas release?

2. How likely are these sequences to occur during the tanks' lifetime?

3. What is the level of damage to the tanks and to the environment that could result if a release occurs?

To answer the above questions, a scenario-based approach has been developed and applied for the HTF PSA. The first question is answered by defining a structured set of potential accident scenarios that systematically account for design and operating features specific to the HTF. The second question is answered by calculating the frequency of occurrence of each scenario identified in answer to question 1. The third question is answered by developing the key characteristics of radioactive or hazardous chemical releases that could result from the scenarios identified and calculating the consequences such as public health effects and property damage that could result from these releases.

The scenario definition process begins with the identification of specific initiators that can divert the normal or planned course of events toward a sequence of events that can result in unwanted consequences. Initiators are identified from qualitative evaluation tools such as hazard and operability studies (HAZOP's), preliminary hazard analyses (PHA's), failure mode and effects analyses (FEMA's) and through the construction of a master logic diagram (MLD). Each possible scenario that could result from an initiating event is then defined in terms of the specific ways that the tanks can respond to the initiator and the subsequent events along the sequence. The event sequences also consider all accident phenomena that could influence the ultimate severity of release. Flow charts called event sequence diagrams (ESD's) are used to graphically display how the progression of the accident sequence is modeled. ESD's facilitate communication with facility personnel and serve as the basis for the construction of an integrated event tree-fault tree quantification model. The scenario definition is completed by assigning each accident sequence to a release category that defines the ultimate response of the tanks and the nature of the resulting radioactive material or toxic gas release.

The quantification process is accomplished using data from actual experience and a wide variety of models that interpret and combine the data into failure frequencies of the events questioned in the accident sequence model. Quantification of risk implies telling the truth about our confidence in the frequencies of events, which means displaying frequency uncertainties. This is done using probability distributions for all measurable quantities and expressing modeling uncertainties explicitly. Many sources of uncertainty are addressed in the development of the parameters used to quantify the frequency of accident sequences. These include the source of generic data, plant-to- 
plant variability in the application of generic data, sample size for plant-specific applications, accident progression phenomenological questions, etc. The resulting state of knowledge or confidence in each parameter is expressed by deriving a probability distribution for that parameter. The basic data distributions and selected modeling uncertainties are then propagated through the quantification models and the important event sequences to obtain uncertainties in the overall results.

For each important release category, the frequency and magnitude of the release are combined with site specific meteorology, hydrology and population data to estimate the potential for health impacts on the surrounding population. The final results of the PSA are displayed in the form of risk curves similar to the example shown in Figure 2-4. For each level of damage shown on the $x$-axis of Figure 2-4, the curve indicates the frequency of all scenarios exceeding that level of damage.

A key goal for development of the risk model is to provide a structure that integrates the quantification of risk from all causes into a single, comprehensive, yet manageable package. For the HTF PSA risk model, key characteristics needed in the risk model include:

- Many diverse initiating events.

- Multiple end states with significantly different potential consequences.

- Results for the total risk from all storage tanks as well as individual tanks and groups of like tanks.

Typically, risk models examine only one facility, and some assess only one end state for one facility; e.g., core damage for a reactor. Thus, the challenge for developing an integrated HTF risk model is to incorporate the added complexity required for multiple end states and 177 tanks while, at the same time, keeping the size of the model reasonable. To accomplish this, an approach using separate initiating event models integrated through a common set of release categories for source term development and consequence analysis was adopted. The general structure of the HTF PSA risk model is shown in Figure 2-5. Each element shown in Figure 2-5 will be further defined and amplified in subsequent sections. 


\subsection{ORGANIZATION OF THIS REPORT}

The balance of this report describes the details of the HTF PSA model development and quantification. Section 3 presents the qualitative identification of generic initiators that could threaten to produce releases from one or more tanks. In section 4 a detailed accident sequence model is developed for each initiating event group. The accident sequence models present a complete level 1 evaluation for each initiator including a discussion of the susceptibility of different tanks to the initiator and the development and quantification of appropriate accident sequence models. Section 5 defines the release categories to which the scenarios are assigned in the accident sequence model and presents analyses of the airbome and liquid source terms resulting from different release scenarios. The conditional consequences measured by worker or public exposure to radionuclides or hazardous chemicals and economic costs of cleanup and repair are analyzed in section 6 . Finally, in section 7 , the results from all the previous sections are integrated to produce unconditional risk curves in frequency of exceedance format. Details of many supporting deterministic and probabilistic analyses are presented in the appendicies.

\section{References:}

2.1. Risk Assessment for Hanford High-Level Waste tank 101-SY, D. R. MacFariane, et al, July 1993, LANL- 


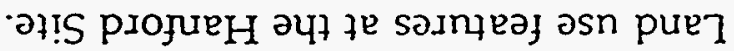

$$
\begin{aligned}
& 81.3 \\
& 1-2
\end{aligned}
$$

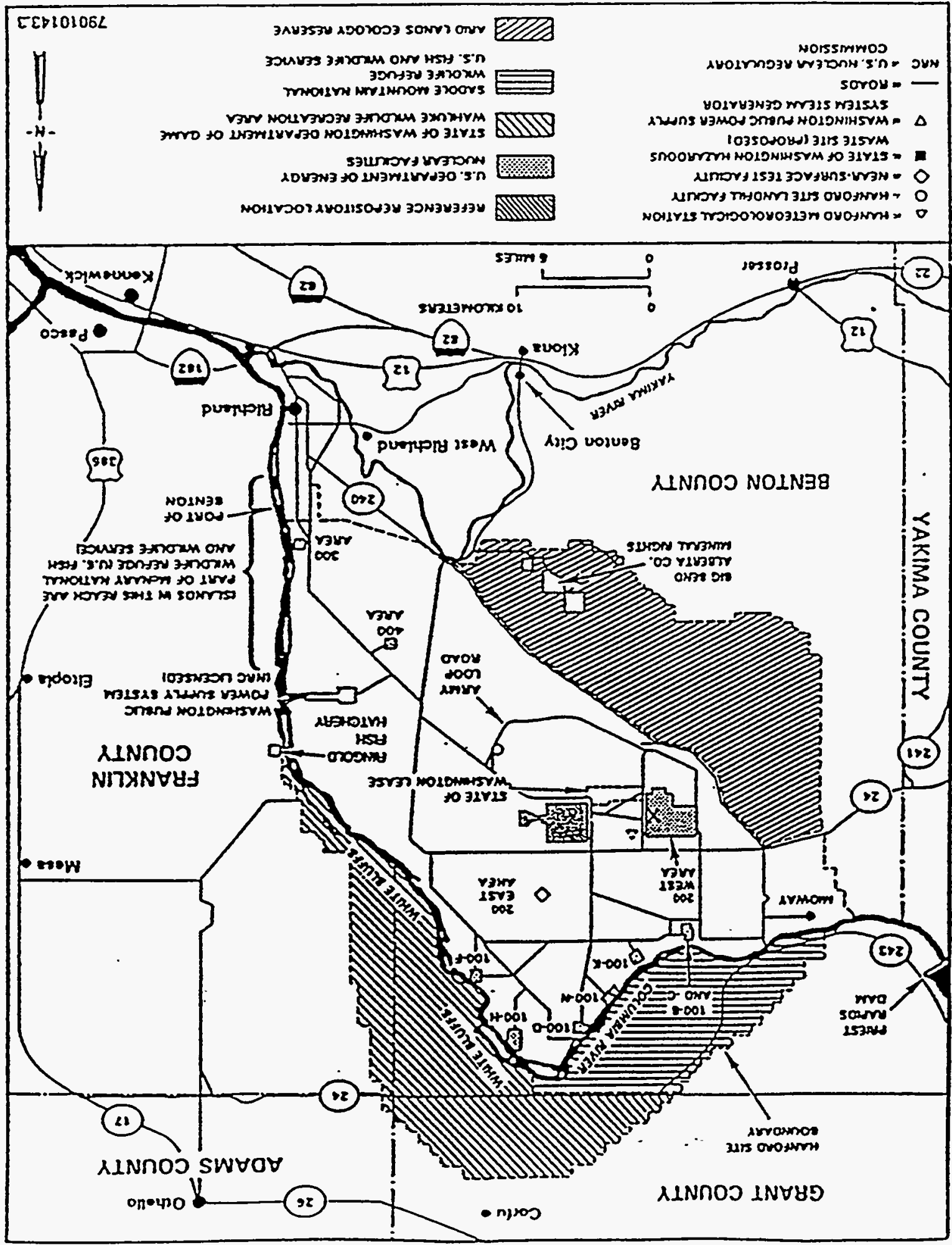




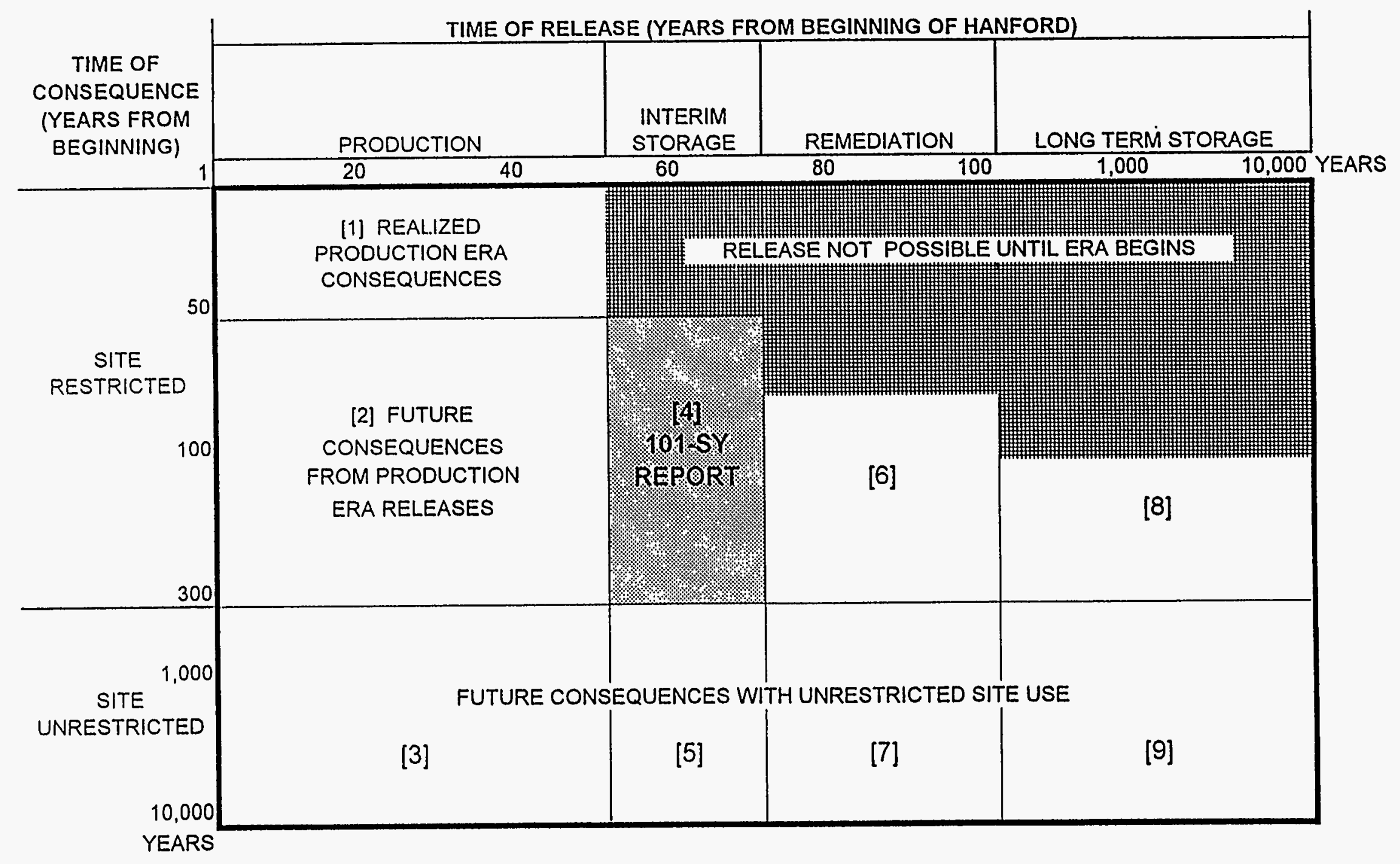

FIGURE 2-2

HANFORD TANK FARM LIFE CYCLE AND SCOPE OF THE PRA 


\begin{tabular}{|c|c|c|c|c|c|c|}
\hline \multirow[b]{3}{*}{$\begin{array}{l}\text { HTF PSA } \\
\text { PHASE }\end{array}$} & \multirow[b]{3}{*}{ HTF LIFE CYCLE ERA } & \multicolumn{5}{|c|}{ CONSEQUENCE MEASURES INCLUDED } \\
\hline & & \multicolumn{3}{|c|}{ HEALTH RISKS } & \multicolumn{2}{|c|}{ ECONOMIC RISKS } \\
\hline & & $\begin{array}{l}\text { Worker } \\
\text { Accident } \\
\text { Exposure }\end{array}$ & $\begin{array}{l}\text { Off Site } \\
\text { Public } \\
\text { Accident } \\
\text { Exposure }\end{array}$ & $\begin{array}{l}\text { Delayed } \\
\text { Exposure } \\
\text { to Leaks }\end{array}$ & $\begin{array}{c}\text { Technological } \\
\text { Failure }\end{array}$ & $\begin{array}{c}\text { Accident } \\
\text { On Site } \\
\text { Clean-Up } \\
\text { Costs } \\
\end{array}$ \\
\hline 1 & Interim Storage [4], Tank 101-SY & $\underline{x}$ & $x$ & $x$ & & $\underline{x}$ \\
\hline 2 & All Tanks & $x$ & $x$ & $x$ & & $x$ \\
\hline 3 & Remediation [6] & $x$ & $x$ & $x$ & $\mathbf{x}$ & $\mathrm{x}$ \\
\hline
\end{tabular}

FIGURE 2-3

INTEGRATED PRA SCOPE DEFINITION MATRIX 




FIGURE $2-4$

RISK CURVES WITH UNCERTAINTY 


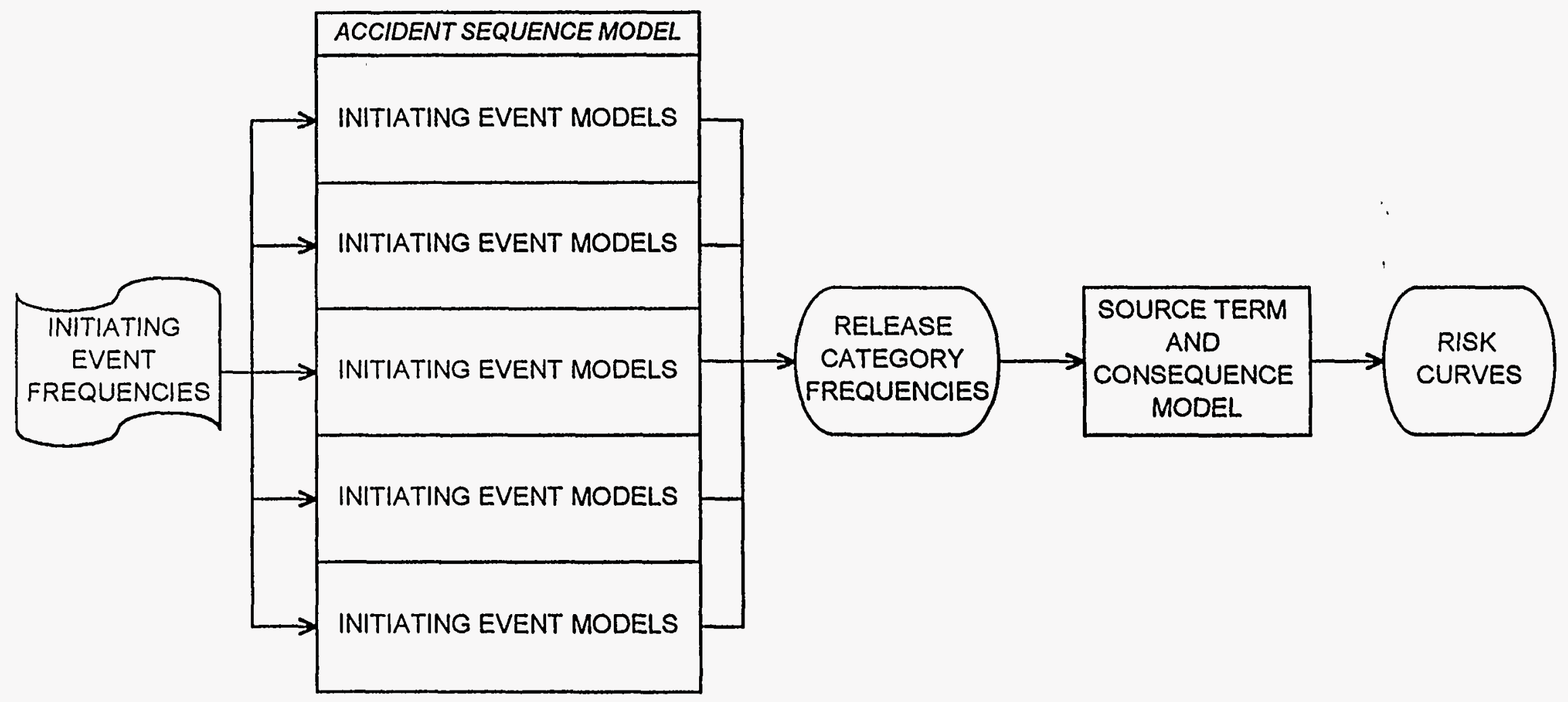

FIGURE 2-5

HTF PRA RISK MODEL STRUCTURE 
HF $\cdots P S A$

Sections 3,4 and 5

$8 / 7 / 94$ 


\section{IDENTIEICATION OF INITIATING EVENTS}

The first step in developing the risk model is to define a set of initiating events. For an accident sequence to occur, an event must first perturb the steady state condition of a waste tank or its contents. Subsequent events may (or may not) result in a release of radionuclides or toxic gas.

The main objectives of this section are as follows:

- To provide adequate assurance that all possible events are accounted for.

- To account for unique tank design and operational features.

- To provide a way to categorize events in all of the unique ways that the event may impact the entire tank population.

- To group together events that present similar threats to safety functions for quantification.

Candidate initiating events were identified for the HTF PRA through the use of several different analytic approaches employed in this and other studies. These include:

- $\quad$ Master Logic Diagram (MLD) Development

- $\quad$ Hazard and Operability (HAZOP) Study Analysis

- External Events Analysis

Applications of the MLD and HAZOP techniques to the HTF are described later in this section. External events analyses are presented in Appendix C. In addition to the above analyses, new insights are often obtained from other PRA tasks that lead to identification of new initiating events or that alter the judgments made in finalizing the list. This is a highly iterative process and is difficult to predict. For example, the results of event sequence quantification for one initiating event may be used to eliminate some others from the list. Also, review of operating experience often reveals new initiating events.

\subsection{MASTER LOGIC DIAGRAM}

The master logic diagram is similar to a fault tree and provides a deductive approach for directly answering the question, How can a significant release of radioactivity (or toxic gas) into the environment occur? The HTF MLD is shown as Figure 3-1.

A key objective of the MLD is to identify all possible types and sources of the hazardous materials and the pathways by which the top event can be satisfied down to a level of detail at which all important safety functions and barriers have been accounted for. Once this is 
accomplished, then specific causal events that can threaten a safety barrier or function can be listed. The question of completeness is then reduced to an assessment of the total frequency of all causal events that could produce any of the conditions shown on the MLD. It should be noted that it is not the objective of the MLD to delineate all possible accident scenarios that could result from the initiating event. For example, safety function failures could result in the failure of one or more fission product barriers. Such scenarios are not illustrated by the MLD but are addressed later in the accident sequence model.

Many of the initiator events shown at the bottom of the MLD may be subdivided to reveal more specific causal events. A listing of such events that could threaten the safety barriers or functions shown at the bottom of the MLD is shown in Table 3-1. The events listed are also matrixed against the MLD initiator events to help identify common cause initiators that can threaten multiple safety barriers or functions, simultaneously. Not all of the basic events shown on the HTF MLD qualify as initiators, however. For example, events such as "Secondary Tank Shell Breach" and "Annulus Vent Line Breach" are not true initiators but events that occur subsequent to an initiator in an accident sequence. These subsequent events are typically found under an "AND" gate in the MLD logic and are shown for completeness in rounded rectangles but are not included in Table 3-1.

\subsection{IDENTIFICATION OF INITIATING EVENT GROUPS}

The process of grouping initiating events by similarity of response is common to all PRA models, and helps to limit the number of plant event sequence models to be developed. It is necessary and practical to analyze only those initiating events that make appreciable contributions to risk. Given knowledge of the approximate frequency of the initiating events and the relative impact of these events on the tanks, it is possible and desirable to group and screen initiating events to simplify the quantification of risk, without introducing significant errors into the risk estimate.

Grouping of the events listed in Table 3-1 is shown in Table 3-2. Different causal events that impact the tanks in a similar way are grouped together. Where a causal event could be applied to multiple groups, the event was assigned to the more severe initiator group.

Care has been taken, however, to keep common cause initiators and initiators with special dependencies separate.

The initiating event groups listed in Table 3-2 are generally applicable to all storage tanks. However, because of differences in tank design, tank status, and waste characteristics, these general initiating event groups may need to be subdivided to account for these differences between tanks in constructing the integrated model of the entire HTF. Evaluations of the susceptibility of individual tanks to each initiating event group are presented in Section 4.2 . 


\subsection{REVIEW OF PREVIOUS STUDIES}

In addition to the development of the initiating event list described in previous sections, initiating events identified for Hanford waste storage tanks in another study was examined to ensure that all important initiators were included in this analysis. This study was the Tank Farm Risk Assessment - Plant Familiarization and Hazard Identification Report performed by WHC (Reference 3-1). The WHC study employed both the MLD approach and also included a hazard analysis. Comparisons of the initiators identified by WHC with the initiating event groups from Table 3-2 are presented in Tables 3-3 and 3-4. 




Figure 3-1. HANFORD TANK FARM HAZARDOUS MATERIAL RELEAS 


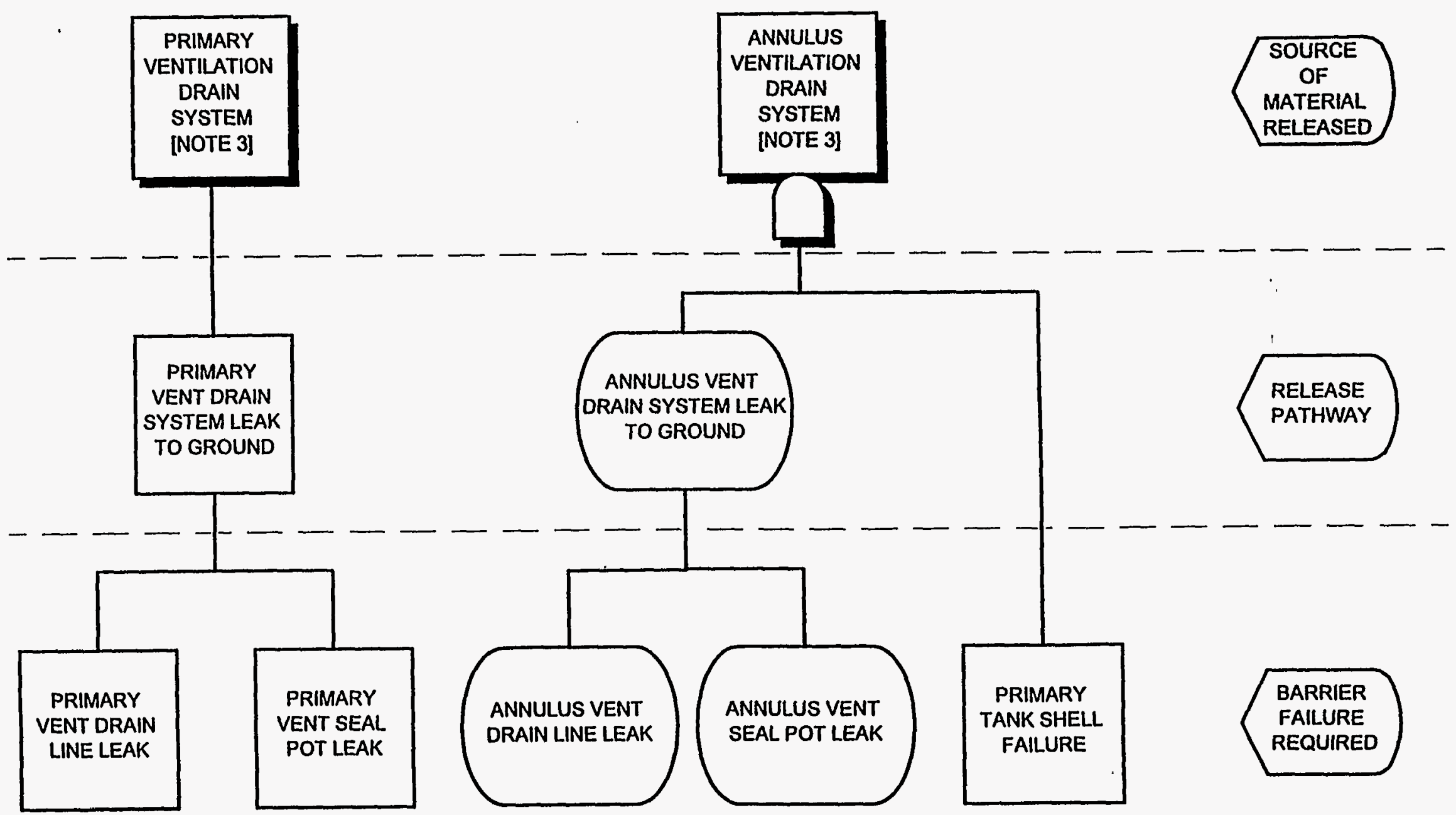

Note: Failure events denoted by $\square$ do not represent initiating events.

Figure 3-1. HANFORD TANK FARM HAZARDOUS MATERIAL RELEAS 


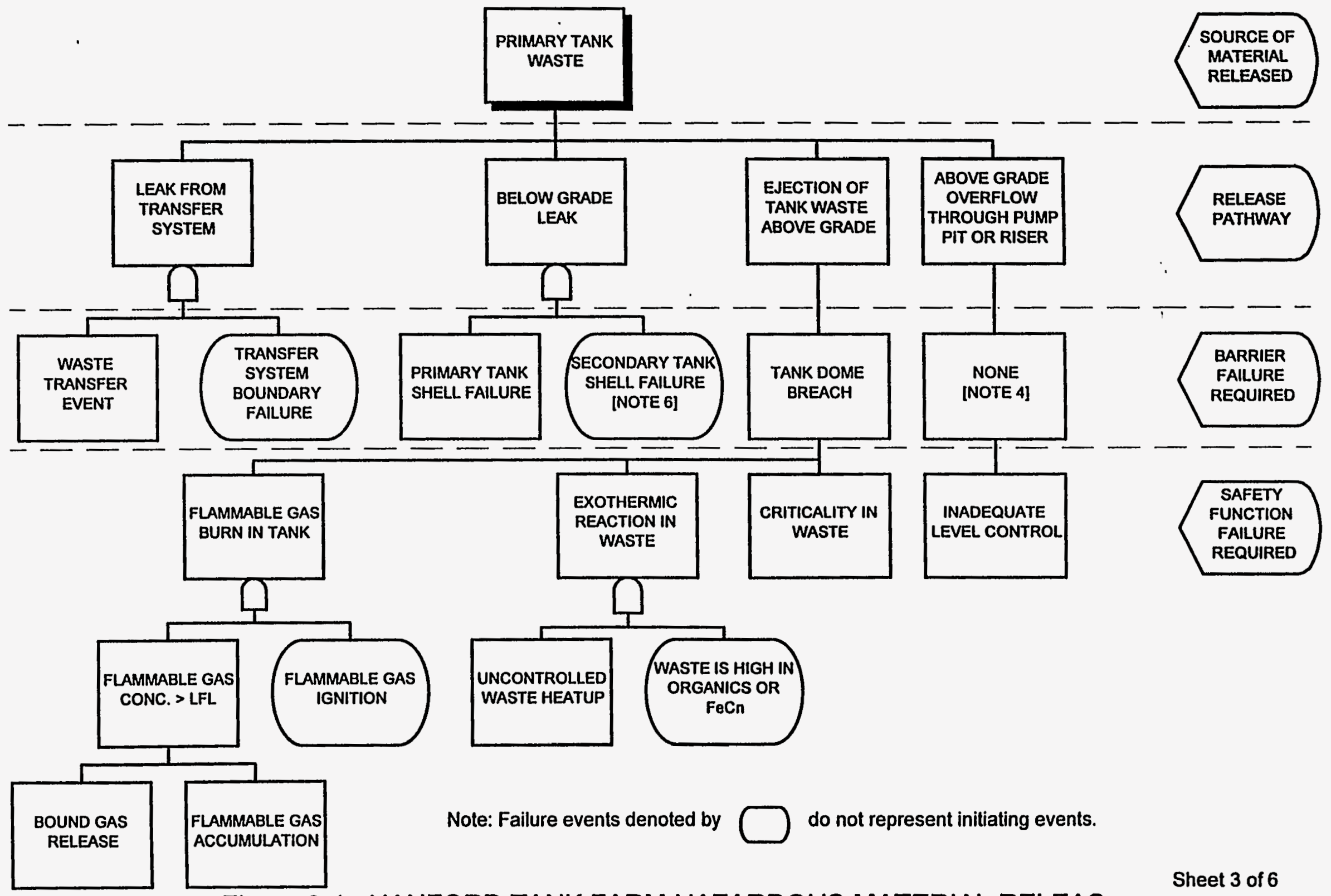

Figure 3-1. HANFORD TANK FARM HAZARDOUS MATERIAL RELEAS 


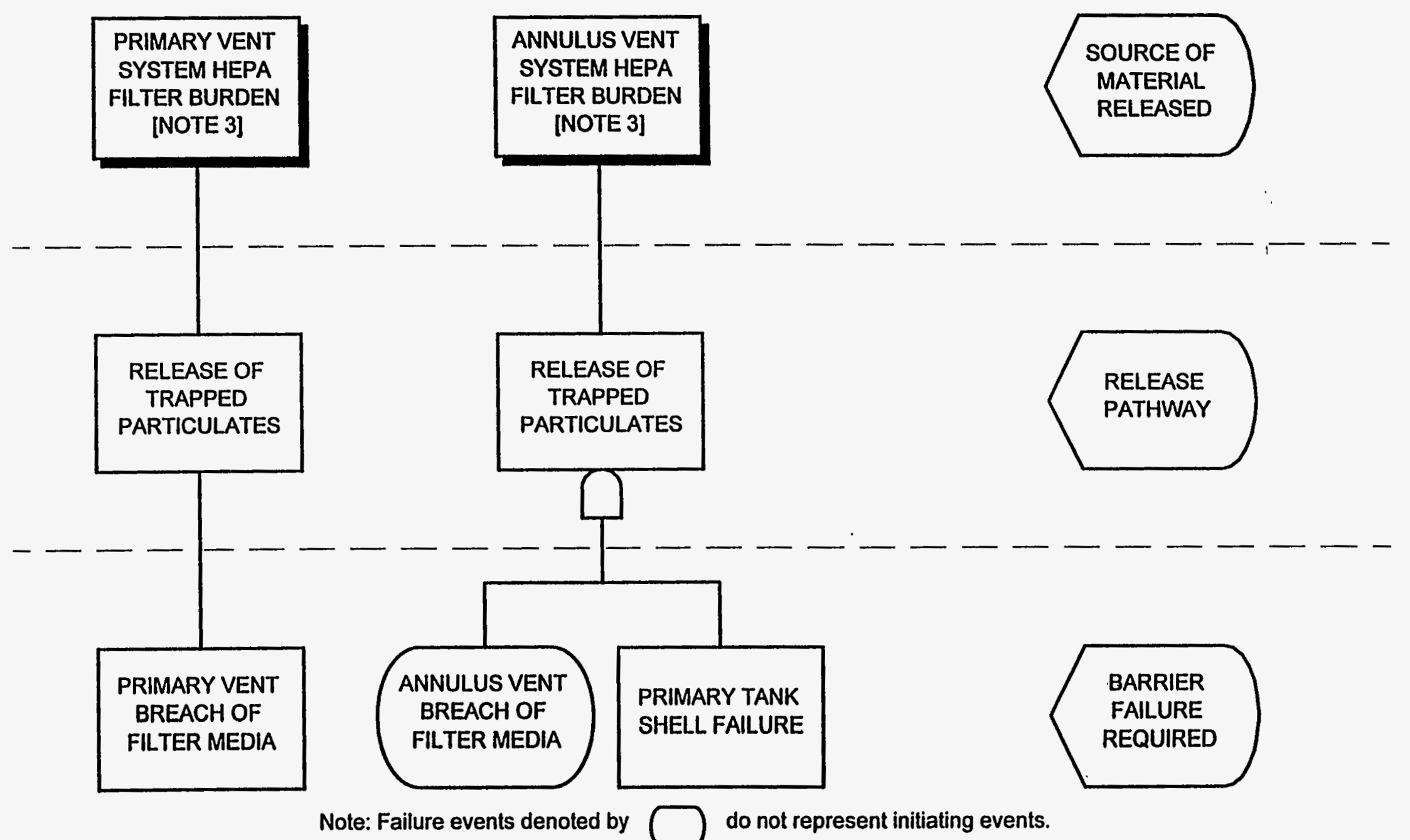

Figure 3-1. HANFORD TANK FARM HAZARDOUS MATERIAL RELEAS Sheet 4 of 6 


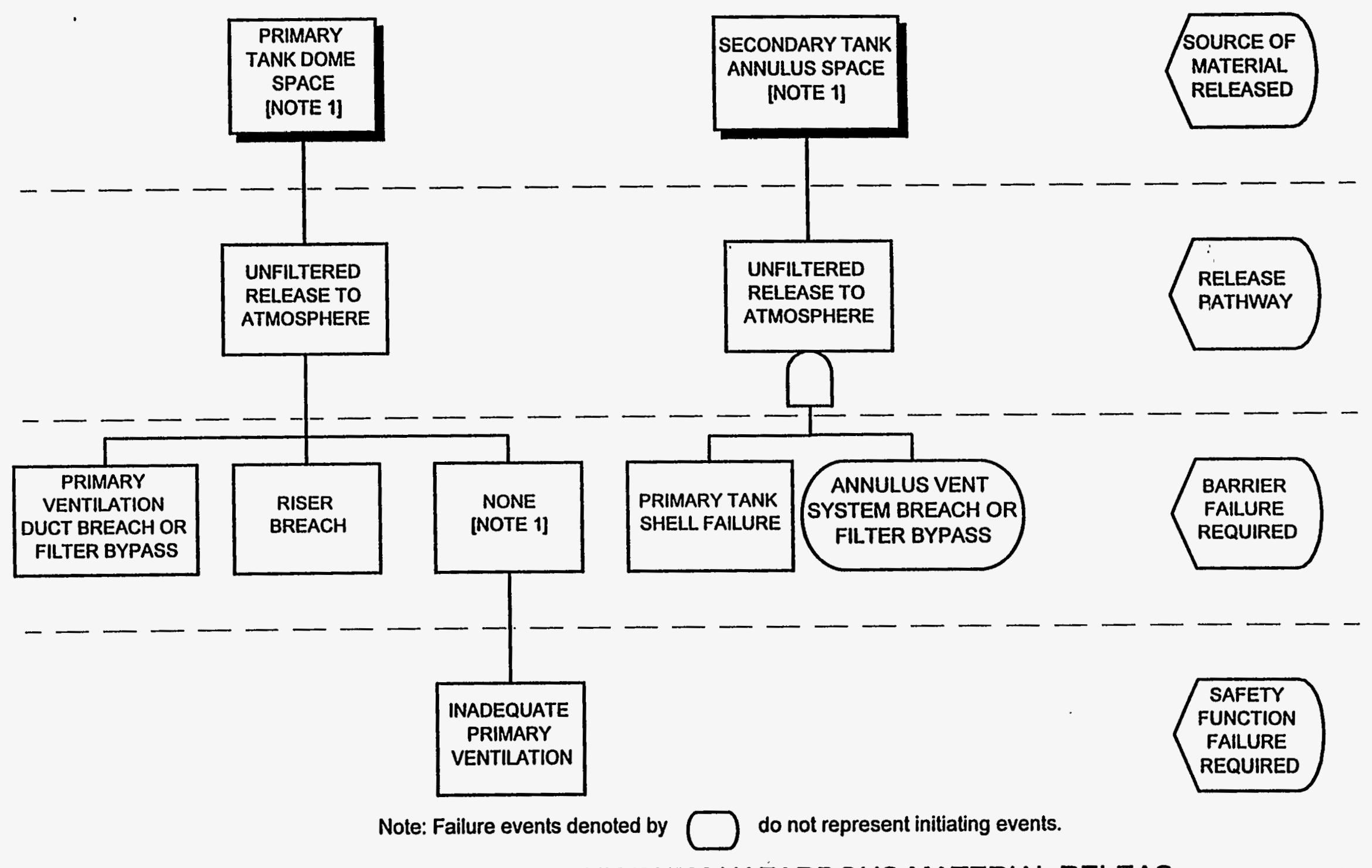

Figure 3-1. HANFORD TANK FARM HAZARDOUS MATERIAL RELEAS Sheet 5 of 6 


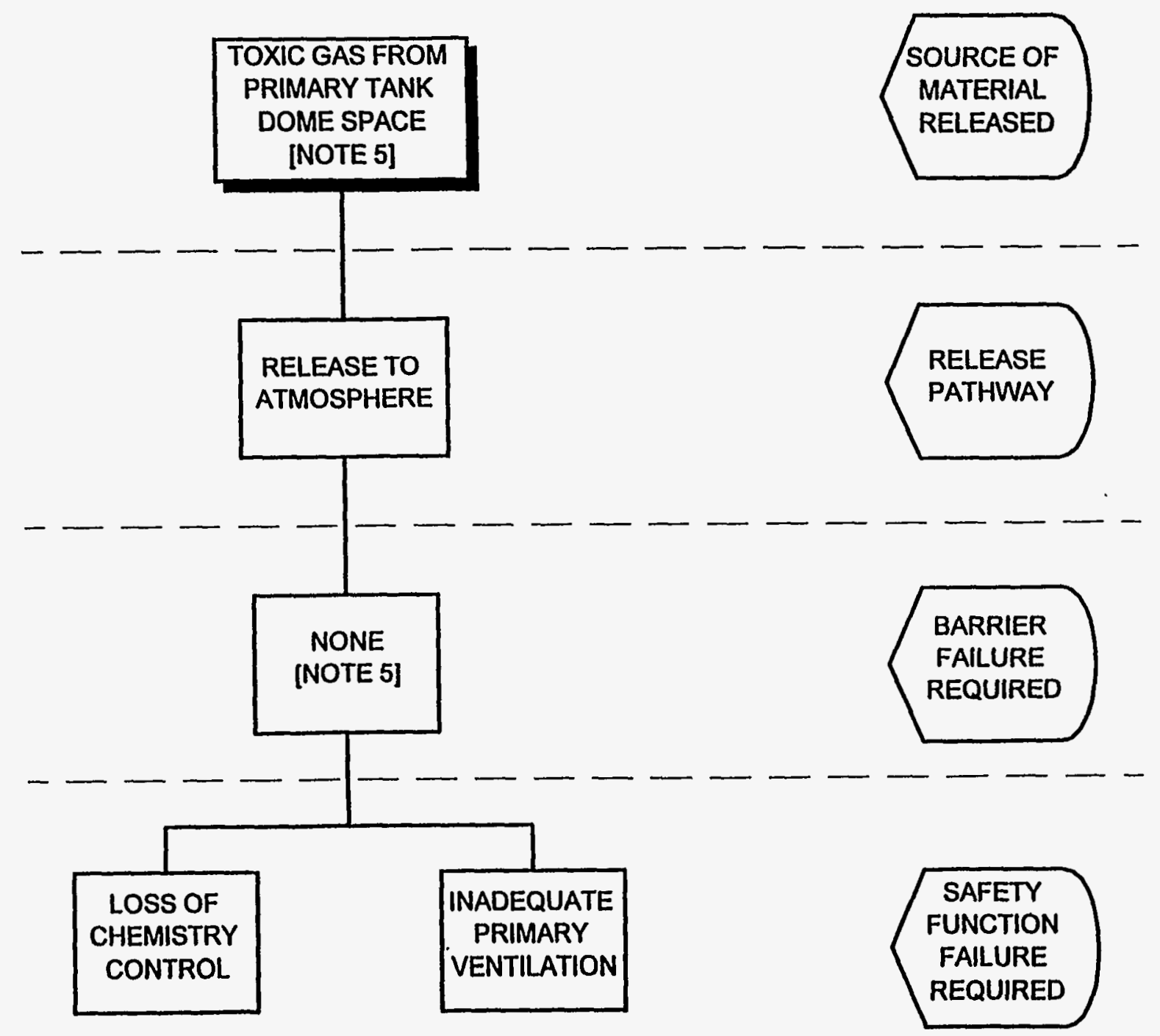

Figure 3-1. HANFORD TANK FARM HAZARDOUS MATERIAL RELEAS 


\section{MLD NOTES:}

1. Radioactive particulates are assumed to be present in the tank vapor space at all times. Active ventilation maintains a negative pressure in non-isolated tanks to retain particulates. Isolated tanks are sealed and allowed to breath through filtered passive vents.

2. Retention of aerosols by the soil is assumed for releases occurring below grade level.

3. Primary tank ventilation filters and drains are assumed to be contaminated and a release will result from their failure. Secondary tank ventilation filters and drains are assumed to be clean, unless a primary tank leak has occurred.

4. Overflow paths to grade level are assumed to exist through the tank central pump pit or other riser.

5. Toxic gases are assumed to be generated at low levels in the tanks at all times. Tank vapor space concentrations are controlled by normal ventilation systems. If not removed through ventilation, toxic gas concentrations are assumed to build to levels of concern. Tank exhaust filters are assumed to be ineffective in retaining toxic gases.

6. For single shell tanks (SST's), there are no secondary shells and primary shell failure leads directly to a release.

7. No active control actions are normally required except for certain specific tanks. In general, some other initiator must occur that changes the current (stable) condition of the tank to challenge safety function control. 


\begin{tabular}{|c|c|c|c|c|c|c|c|c|c|c|c|c|c|c|c|c|c|}
\hline EXAMPLE CAUSAL EVENTS & \begin{tabular}{c|} 
Primey \\
Tenk Shell \\
Broach
\end{tabular} & \begin{tabular}{c|} 
Socondiary \\
Tank Shell \\
Breach
\end{tabular} & \begin{tabular}{|c|} 
Tank Domo \\
Falkre
\end{tabular} & \begin{tabular}{c|} 
Arruchus \\
Vont Lino \\
Brosch
\end{tabular} & Riser Bragct & $\begin{array}{c}\text { Primary } \\
\text { Exhaust } \\
\text { Ventline } \\
\text { Breach }\end{array}$ & \begin{tabular}{|c|} 
Exhausi \\
HEPA Filor \\
Breach
\end{tabular} & \begin{tabular}{|c|}
\multicolumn{2}{c}{ MLD B } \\
Vent. Drain \\
Lhoo Leak
\end{tabular} & $\begin{array}{l}\text { BASIC EVES } \\
\begin{array}{c}\text { Vent. Soal } \\
\text { Pot Loak }\end{array}\end{array}$ & $\begin{array}{l}\text { TS } \\
\text { Wasto } \\
\text { Transter } \\
\text { Event }\end{array}$ & \begin{tabular}{c|} 
Wasto \\
Transfor \\
Syrlem Loak
\end{tabular} & $\begin{array}{c}\text { Insodequale } \\
\text { Primary } \\
\text { Vontiation } \\
\text { Fiow }\end{array}$ & \begin{tabular}{|c|} 
Lradoqusto \\
Level \\
Control
\end{tabular} & $\begin{array}{l}\text { Grikeality } \\
\text { Event in } \\
\text { Wasto }\end{array}$ & \begin{tabular}{|c|} 
Bound \\
Flanmeblo \\
Ges Raloseso
\end{tabular} & $\begin{array}{c}\text { Fleminablo } \\
\text { Ges } \\
\text { Acamulato } \\
n\end{array}$ & $\begin{array}{c}\text { Uncontrolived } \\
\text { Whalle } \\
\text { Hoatup }\end{array}$ \\
\hline Drilling Conlact with Tank & $\underline{x}$ & $x$ & & & & & & & & & & & & & & & \\
\hline Excavalion Contact with Tank & $x$ & $\underline{x}$ & $\underline{x}$ & & $x$ & & & & & & & & & & & & \\
\hline Tank Thermal Stress & $x$ & & & & & & & & & & & & & & & & \\
\hline Tank Liner Corrosion & $x$ & & & & & & & & & & & & & & & & \\
\hline Vehicle Overioads Dome & & & $x$ & & & & & & & & & & & & & & \\
\hline Load Dropped Over Tank & & & $\mathrm{x}$ & $\underline{x}$ & $x$ & $x$ & & & & & & & & & & & \\
\hline Vehicle Impact w Above Ground Equip. & & & & $x$ & $\underline{x}$ & $\underline{x}$ & $\underline{x}$ & $x$ & $x$ & & & & & & & & \\
\hline Vent. Duct Corrosion & & & & $x$ & & & $\theta$ & & & & & & & & & & \\
\hline Human Error, Equip. not restored anter maint. & & & & $x$ & $\underline{x}$ & $x$ & $\underline{x}$ & $x$ & $x$ & & $x$ & $x$ & & & & & \\
\hline Vont. Drain Lino Corrosion & & & & & & & & $x$ & $x$ & & & & & & & & \\
\hline Vent. Drain Line Freozing & & & & & & & & $x$ & & & & & & & & & \\
\hline Excossivo Moisture in Vonl Sysism & & & & & & & $x$ & & & & & & & & & & \\
\hline Ventluation Exhaust Fillor Blockago & & & & & & & & & & & & $\underline{x}$ & & & & & \\
\hline Ventilation Inlat Blockago & & & & & & & & & & & & $x$ & & & & & \\
\hline Vent Fen Failure & & & & & & & & & & & & $x$ & & & & & \\
\hline Loss of Power lo Venl Fan & & & & & & & & & & & & $x$ & & & & & \\
\hline Loss ol Air Supply lo ALC': & & & & & & & & & & & & & & & & & $x$ \\
\hline Drout or Wasie & & & & & & & & & & & & & & & & & $\underline{x}$ \\
\hline Tenk Inundalod by Transifer Spill & & & $x$ & & & & & & & & & & $x$ & & & & \\
\hline Tank Inundalad by Row Waler Loak & & & $\underline{x}$ & & & & & & & & & & $x$ & & & & \\
\hline Tank Imundalod by Heavy Procipitation & & & $x$ & & & & & & & & & & $x$ & & & & \\
\hline New Waste Transters From Oiher Facillios & & & & & & & & & & $x$ & & & $x$ & $x$ & $x$ & $\underline{x}$ & $\underline{x}$ \\
\hline San Well Transfors to Collector Tank & & & & & & & & & & $x$ & & & & $x$ & $\mathbf{x}$ & & \\
\hline Liquid Transiors to 242-A Evaporalor & & & & & & & & & & $\underline{x}$ & & & $x$ & $x$ & $x$ & $x$ & \\
\hline Shury Transfors from 242-A to DST Slorego & & & & & & & & & & $x$ & & & $\underline{x}$ & $x$ & $x$ & $x$ & $\Lambda$ \\
\hline Rodiolosis of Wator h W Wasto & & & & & & & & & & & & & & & & $x$ & \\
\hline Bound Gas Roleaso & $x$ & $x$ & $x$ & $\underline{x}$ & $x$ & $x$ & $x$ & $x$ & $x$ & & & $\underline{x}$ & & & & $x$ & \\
\hline Lhohloning Strike on Tank & & & & & & & & & & & & $\underline{x}$ & & & & & \\
\hline Selsmic Event & $x$ & $x$ & $\mathbf{x}$ & $x$ & $x$ & $x$ & $x$ & $\mathbf{x}$ & $x$ & & $\underline{x}$ & $\underline{x}$ & & & & & \\
\hline Aroran Crash & $\underline{x}$ & $x$ & $\underline{x}$ & $\mathbf{x}$ & $x$ & $x$ & $x$ & $x$ & $x$ & & $x$ & $\underline{x}$ & & & & & \\
\hline Rango Fire" & & & & & & & & & & & & $\mathbf{x}$ & & & & & \\
\hline Hight Wind \& Dust Storm* & & & & $\underline{x}$ & & $x$ & & & & & & $x$ & & & & & \\
\hline Volcanism & & & & & & & & & & & & $\mathbf{x}$ & & & & & \\
\hline Dem Break" & & & $\mathbf{x}$ & & & & & & & & & & $x$ & & & & \\
\hline & & & & & & & & & & & & & & & & & \\
\hline
\end{tabular}

TABLE 3-1 MLD BASIC EVENTS AND CAUSES 


\begin{tabular}{|c|c|c|c|c|c|c|c|c|c|c|c|c|c|}
\hline \multirow{3}{*}{ EXAMPLE CAUSAL EVENTS } & \multicolumn{13}{|c|}{ HTF INITIATING EVENT GROUPS (see Footnotes) } \\
\hline & $\begin{array}{l}\text { Tank Sholl } \\
\text { Bresch }\end{array}$ & $\begin{array}{l}\text { Tank Domo } \\
\text { Failuxe }\end{array}$ & $\begin{array}{l}\text { Riser or } \\
\text { Vont Lho } \\
\text { Bresch }\end{array}$ & $\begin{array}{l}\text { Exhoust } \\
\text { HEPA Filitor } \\
\text { Bresch }\end{array}$ & $\begin{array}{l}\text { Vont. Drah } \\
\text { Systom } \\
\text { Loak }\end{array}$ & $\begin{array}{l}\text { Wasto } \\
\text { Transtor } \\
\text { Event }\end{array}$ & $\begin{array}{l}\text { hradequalo } \\
\text { Primary } \\
\text { Ventilation } \\
\text { Flow }\end{array}$ & $\begin{array}{l}\text { Unconl. } \\
\text { Wasto } \\
\text { Hoalup }\end{array}$ & $\begin{array}{c}\text { Flammablo } \\
\text { Gas } \\
\text { Accomulatio } \\
n\end{array}$ & $\begin{array}{l}\text { Bound Gas } \\
\text { Roleaso }\end{array}$ & \begin{tabular}{|c|} 
Waler \\
Intrusion lo \\
Tank
\end{tabular} & $\begin{array}{l}\text { Soletenic } \\
\text { Everts }\end{array}$ & $\begin{array}{l}\text { Arcten } \\
\text { Creasi }\end{array}$ \\
\hline & TSB & DOMEF & RVB & $\mathbf{F B}$ & VDL & wT & LOTV & HEATUP & FGA & BURP & $\mathbf{m}$ & SEIS & $A C$ \\
\hline Drilling Contact with Tank & & $\mathbf{F}$ & & & & & & & & & & & \\
\hline Excavation Contact wilh Tank & & $\mathbf{F}$ & & & & & & & & & & & \\
\hline Tenk Thermal Stross & $\mathbf{F}$ & & & & & & & & & & & & $:$ \\
\hline Tank Liner Corrosion & $\mathbf{F}$ & & & & & & & & & & & & \\
\hline Vehiclo Overkads Dome & & $\mathbf{F}$ & & & & & & & & & & & \\
\hline Losd Dropped Over Tank & & $\mathbf{F}$ & & & & & & & & & & & \\
\hline Vehiclo impact w Above Ground Equip. & & & $\mathbf{F}$ & & & & & & & & & & \\
\hline Vent. Duct Corrosion & & & $\mathbf{F}$ & & & & & & & & & & \\
\hline Human Error, Equip. not restored affor maint. & & & $\mathbf{F}$ & & & & & & & & & & \\
\hline Vent. Orain Lho Corrosion & & & & & $\mathbf{F}$ & & & & & & & & \\
\hline Vont. Drain Line Froezing & & & & & $\mathbf{F}$ & & & & & & & & \\
\hline Excessive Moisture hn Vent Systsm & & & & $\mathbf{F}$ & & & & & & & & & \\
\hline Ventilation Exhaust Finer Blockago & & & & & & & $\boldsymbol{F}$ & & & & & & \\
\hline Ventitation Infet Blockage & & & & & & & $\boldsymbol{F}$ & & & & & & \\
\hline Vont Fan Failure & & & & & & & $\boldsymbol{F}$ & & & & & & \\
\hline Loss of Power to Vont Fan & & & & & & & $\boldsymbol{F}$ & & & & & & \\
\hline Loss of Atr Supply to ALC's & & & & & & & & $\mathbf{F}$ & & & & & \\
\hline Dryout of Wasto & & & & & & & & $\mathbf{F}$ & & & & & \\
\hline Tank Inundatod by Transfor Spill & & & & & & & & & & & $\mathbf{F}$ & & \\
\hline Tenk Inundaled by Rew Water Loak & & & & & & & & & & & $\mathbf{F}$ & & \\
\hline Tank Inundated by Maay Procipitalion & & & & & & & & & & & $\mathbf{F}$ & & \\
\hline Now Wasto Transters From Other Facilititas & & & & & & $\boldsymbol{F}$ & & & & & & & \\
\hline Sall Wou Transfers to Collector Tank & & & & & & $\boldsymbol{F}$ & & & & & & & \\
\hline Liquid Transfors to 242-A Evaporalor & & & & & & $\boldsymbol{F}$ & & & & & & & \\
\hline Shurry Translers from 242-A lo DST Storago & & & & & & $\boldsymbol{F}$ & & & & & & & \\
\hline Radiolosis of Wator h Waste & & & & & & & & & $\mathbf{F}$ & & & & \\
\hline Bound Gas Reloase & & & & & & & & & & $\boldsymbol{F}$ & & & \\
\hline Lightening Striko on Tank & & & $\boldsymbol{F}$ & & & & & & & & & & \\
\hline Selsmic Event & & & & & & & & & & & & $\mathbf{F}$ & \\
\hline Aircran Crash & & & & & & & & & & & & & $F$ \\
\hline
\end{tabular}

$F=$ Inlitator Family Event

TABLE 3-2 HTF INITIATING EVENT GROUPS

TBL_3_2.XLS 


\begin{tabular}{|c|c|c|}
\hline No. & PHA Initiating Event Description & $\begin{array}{c}\text { Corresponding HTF PRA } \\
\text { Initiating Event Group }\end{array}$ \\
\hline 1 & Lightning strike causes loss of facility electrical power to powered ventilation systems. & LOSP \\
\hline 2 & Accumulation of fissile material and criticality. & Subsequent Event to WT \\
\hline 3 & Air compressors [for DST air lift circulators (ALC) in aging waste tanks] fail and cause waste to heat up. & LOTM \\
\hline 4 & Plugged air line causes ALCs to fail and waste to heat up. & LOTV \\
\hline 5 & Aircraft crash causes structural failure of tank or ignition source from fire. & $\mathbf{A C}$ \\
\hline 6 & Earthquake or large vibration induces shock-sensitive chemical reactions. & SEIS \\
\hline 7 & Seismic event causes structural failure of tank. & SEIS \\
\hline 8 & Tornado causes excessive vacuum in tank. & HW/Tornado \\
\hline 9 & Corrosive materials in pipes cause pipe integrity failure. & Subsequent Event to WT \\
\hline 10 & Line plugs and the pipe ruptures during attempts to free the blockage. & Subsequent Event to WT \\
\hline 11 & Thermal stresses on piping causes pipe failures. & Subsequent Event to WT \\
\hline 12 & Freezing weather causes pipes to burst, possibly flooding a tank farm area with liquids that may get into tanks. & WI \\
\hline 13 & $\begin{array}{l}\text { Earthquake fails ventilation instrumentation, causing a spark source and release of a flammable mixture of } \\
\text { gases. }\end{array}$ & SEIS \\
\hline 14 & Noise from equipment either harms personnel hearing or causes personnel errors due to miscommunication. & Not Applicable \\
\hline 15 & Cranes lifting heavy objects over tank farm areas with potential for dropping. & DOMEF \\
\hline 16 & Radiation field in the tank waste that initiates chemical reactions. & BURP \\
\hline 17 & \begin{tabular}{|l} 
Degradation of chemicals to a more reactive form. \\
\end{tabular} & BURP \\
\hline 18 & Suitable catalysts put into tank wastes that promote chemical reactions. & WT \\
\hline 19 & Corrosion causes leaks in tank wall. & PSB \\
\hline 20 & Radionuclide content sufficient to cause high enough temperature for chemical reactions. & HEATUP \\
\hline 21 & Low humidity in outside air increases probability of static charges in or near flammable gas tanks. & Subsequent Event to BURP \\
\hline 22 & Lightning strike provides a possible ignition source in or near a flammable gas tank. & Subsequent Event to BURP \\
\hline
\end{tabular}




\begin{tabular}{|c|c|c|}
\hline No. & PHA Initiating Event Description & $\begin{array}{l}\text { Corresponding HTF PRA } \\
\text { Initiating Event Group }\end{array}$ \\
\hline 23 & In-tank instrumentation failure causes an electrical spark source in a flammable gas tank. & Subsequent Event to BURP \\
\hline 24 & $\begin{array}{l}\text { Electrical spark created upon re-energizing ventilation system following shutdown of fans in flammable gas } \\
\text { tanks. }\end{array}$ & Subsequent Event to BURP \\
\hline 25 & $\begin{array}{l}\text { Water runoff drains to stabilized tanks and may result in more hydrogen production than when waste was } \\
\text { drier. }\end{array}$ & WI \\
\hline 26 & Range fires may provide ignition sources near flammable gas tanks. & RF \\
\hline 27 & Blowing sand plugs filters or loop seals. & HW \\
\hline 28 & Corrosion of de-entrainers on DST ventilation systems causes filters to fail from moisture plugging. & FB \\
\hline 29 & Corrosion of ventilation ductwork causes releases to either the atmosphere or the ground. & RVB \\
\hline 30 & Personnel discharge static charge buildup near flammable gas tanks. & Subsequent Event to BURP \\
\hline 31 & Steam supply loss to SX exhaust heater fails filters due to moisture plugging. & FB \\
\hline 32 & Higher than expected moisture in tank atmosphere causes plugging of filters and resultant filter failure. & $\overline{\text { FB }}$ \\
\hline 33 & Release of gases that pressurize the tank. & BURP \\
\hline 34 & Heavy equipment placed over top of tanks causes structural failure of tank. & DOMEF \\
\hline 35 & Loss of electrical heaters on ventilation systems causes filters to fail from moisture plugging. & FB \\
\hline 36 & $\begin{array}{l}\text { Steam heater coil leak on SX tank farm ventilation system results in condensing steam to drain to SX tank that } \\
\text { is leaker. }\end{array}$ & WI \\
\hline 37 & Water runoff from heavy rains or snow melt drains into tanks that are already leakers. & WI \\
\hline 38 & $\begin{array}{l}\text { Corrosion failure of condensers on DST ventilation condensers causes contamination to be drained to } \\
\text { condensate storage ponds. }\end{array}$ & VDL \\
\hline 39 & Release of toxic gases. & BURP \\
\hline 40 & Overexposure of personnel to radiation from tank wastes when opening risers, transferring wastes, etc. & Not Applicable \\
\hline
\end{tabular}




\begin{tabular}{|c|c|c|}
\hline Event & Description & $\begin{array}{l}\text { Corresponding HTF PRA } \\
\text { Initiating Event Group }\end{array}$ \\
\hline \multicolumn{3}{|c|}{ I. Release to Ground } \\
\hline$\overline{\mathrm{A}}$ & Release where no barrier exists - tank declared as a leaker. & TSB \\
\hline$\overline{\mathbf{B}}$ & Failure of barrier due to chemical means - corrosion. & TSB \\
\hline $\bar{C}$ & $\begin{array}{l}\text { Failure of barrier due to external mechanical forces on barrier: } \\
\text { - Force exerted by falling object. } \\
\text { - Force exerted by seismic event. } \\
\text { - Force exerted by flooding. } \\
\text { - Force exerted by earth when vacuum exists in tank. }\end{array}$ & $\begin{array}{l}\text { DOMEF, RVB } \\
\text { PSB, DOMEF, RVB } \\
\text { DOMEF } \\
\text { DOMEF, RVB }\end{array}$ \\
\hline $\bar{D}$ & $\begin{array}{l}\text { Failure of barrier due to internal mechanical forces on barrier: } \\
\text { - Force exerted by energetic chemical reaction. } \\
\text { - Force exerted by internal tank fire. } \\
\text { - Force exerted by pressurization of tank. }\end{array}$ & $\begin{array}{l}\text { Consequence of HEATUP, WT } \\
\text { Consequence of HEATUP, WT, } \\
\text { BURP, SEIS, WI } \\
\text { Consequence of HEATUP, WT, } \\
\text { BURP, SEIS, WI }\end{array}$ \\
\hline $\mathrm{E}$ & Failure of barrier by operational failures. & RVB \\
\hline \multicolumn{3}{|c|}{ II. Release to Air } \\
\hline A & Release where no barrier exists - toxic gas release. & ALL \\
\hline B & $\begin{array}{l}\text { Failure of barriers due to chemical means: } \\
\text { - Failure of filters by short-term degradation (includes filter fires). } \\
\text { - Failure of filters by long-term degradation (aging). }\end{array}$ & $\begin{array}{l}\text { FB } \\
\text { FB }\end{array}$ \\
\hline $\bar{C}$ & $\begin{array}{l}\text { Failure of barrier due to mechanical forces: } \\
\text { - Force exerted by falling object. } \\
\text { - Force exerted by explosion. } \\
\text { - Force exerted by high pressure from fire or gas release or high delta pressure from } \\
\text { plugged filters. } \\
\text { - Failure due to cycling filters from moist to dry to moist to dry, etc. }\end{array}$ & $\begin{array}{l}\text { DOMEF, RVB } \\
\text { Consequence of HEATUP, WT, } \\
\text { BURP, SEIS, WI } \\
\text { Consequence of HEATUP, WT, } \\
\text { BURP, SEIS, WI } \\
\text { FB }\end{array}$ \\
\hline $\bar{D}$ & Failure of barrier by operational failures. & RVB \\
\hline
\end{tabular}


m 


\section{ACCIDENT SEOUENCE MODELING AND QUANTIFICATION}

\subsection{TECHNICAL APPROACH}

The Hanford Tank Farm (HTF) accident sequence model serves two primary purposes. The first is to document the probabilistic safety assessment (PSA) team's understanding of how radionuclide and/or toxic gas releases could potentially occur from the HTF facility. The second purpose is to create a logic model describing the potential release scenarios that can be used to quantify the likelihood of releases.

The general approach used for accident sequence model development is depicted in Figure 4-1 and is described in detail in the Tank 101-SY PSA report (Reference 4-1). For this analysis, the modeling approach from the Tank 101-SY analysis is expanded to address all 177 tanks.

In Chapter 3, generic initiating event groups were identified that had the potential to lead to a hazardous material release from one or more tanks. The accident sequence modeling process begins by examining each generic initiator from Chapter 3 to identify any characteristics of the tanks or waste materials that could influence the assessment of the frequency of occurrence of the generic initiator for a particular tank or group of tanks. If segregation of the 177 tanks in to subgroups or families is justified, then initiator frequencies are calculated for each of the initiator families. This calculated frequency represents the total per year for the initiator occurring over all of the tanks belonging to the initiator family. For example, if the frequency of a generic initiator was determined to be 1E-04 per tank per year and the event is equally applicable to all tanks, then the total initiator frequency for this analysis is $177 \mathrm{E}-04$ or $1.8 \mathrm{E}-02$.

These segregated initiating event families are then used for the development of accident sequences and the quantification of sequence likelihood. Event sequence diagrams (ESD) and event trees are developed for each initiator family. The ESDs document the subsequent system responses, phenomenological events, and mitigating actions that can occur in response to the initiator. The ESDs also specify the most appropriate release category describing the end state of each sequence. To quantify the accident sequence frequencies for each initiator, event trees corresponding to the ESDs are developed and quantified. The results produced represent the total frequency per year of each release category for each initiator. Results from each initiator are summed to obtain the total release category frequencies over the entire tank farm.

Section 4.2 examines each generic initiating event group and evaluates the susceptibility of the 177 tanks to the generic initiator, discusses the calculation of initiator frequencies, and presents the development of accident sequence models for each initiator group. Results of the accident sequence quantification process are detailed in Section 4.3.

\subsection{HANFORD TANK FARM ACCIDENT SEOUENCE ANALYSIS AND MODELING}

\subsubsection{FLAMMABLE GAS ACCUMULATION}


The major concerns associated with a burn in the tank and/or ventilation system are the damage to the components and the concurrent release of radioactive materials to the environment. In addition to the burn-induced aerosol release from the dome space (including material entrained from the crust liquid waste), a fraction of the radioactivity trapped within the exhaust system can also be released. Leaks can also develop as a result of tank failure resulting in a liquid pathway for the release of radioactive materials to the environment.

The accident sequences of concern can be tersely characterized as follows:

1. Concentrations of combustible gases exceed the limits of flammability in the tank dome space and ventilation system.

2. An ignition source within the tank or ventilation system ignites the flammable gas.

3. Combustion of the gases produces a pressure and temperature transient that results in a pressurized release of gases and entrained material into the environment. These transients could result in pressures sufficiently high to fail the HEPA filters, ventilation system, and even the tank.

At the present time, 24 tanks are included on the so-called Flammable Gas Watch List. Six of these tanks are double shelled tanks (DSTs) such as Tank 241-SY-101, and the remaining eighteen are single shelled tanks (SSTs). Table 4-1 identifies the tanks currently on the Flammable Gas Watch List. All of the DSTs on this watch list are actively ventilated. The SSTs on the watch list were placed there primarily because they exhibited increases in waste level without the addition of liquids. 1

The Flammable Gas Watch List was used as the initial screening criteria for tanks which might be subject to burns. However, double-contained receiver tanks (DCRTs) have also been identified as having the potential for the accumulation of hydrogen generated while the waste was temporarily held in these tanks. As noted in Reference 4-2, "DCRTs are small holding tanks used for routing, sampling, and other operations in the course of onsite waste transfers." Three of the five DCRTs (244-S, 244-TX, and 244-U) were discussed specifically in Reference 4-2.

Due to the potential presence of flammable organic compounds in the waste material and organic vapors in the dome space, the nine tanks on the High Organic Watch List were also included in Table 4-1 and considered in this evaluation. Two of the tanks 1102-S and 106SX) on the High Organic Watch List are also on the Flammable Gas Watch List. Eight of the nine tanks on the High Organic Watch List are there because they contain more than the equivalent of $10 \%$ by weight of sodium acetate [ $3 \mathrm{wt} \%$ total organic content (TOC)]. The total organic content (TOC) of a tank has been identified (Ref. 4-3) as an important parameter controlling the magnitude of flammable gas generation due to thermolysis. According to Reference 4-2, Tank 103-C is on the High Organic Content Watch List because it "contains a floating layer of organic liquid whose potential flammability is an unreviewed safety question." Relative to the combustion of flammable gases, the

1 As-noted in Reference 4-2, "slurry growth was the basic criterion for watch list designation." 
following two safety issues appear to be of concern for the tanks on High Organic Content Watch List:

1. Uncontrolled reactions (deflagrations) between air and flammable gases in the tank headspace.

2. Uncontrolled reactions between a flammable liquid and air (a pool fire) in tanks that have a layer of floating liquid (i.e., Tank $\mathrm{C}$-103) or solid waste saturated with liquid at the air/waste interface.

In summary, the tanks for which combustion is of concern are listed in:Table 4-1 and represent those on the Flammable Gas Watch List, the DCRTs, and those on the High Organic Watch List. Each of these tanks was evaluated relative to its potential for burns and consequent damage and release of radioactivity to the environment.

flammable species. Hydrogen has a broad flammability range $(4 \%$ to $75 \%)$ and requires only a very low energy source $(0.01 \mathrm{Mj})$ for ignition.

The hazard associated with hydrogen is increased somewhat if nitrous oxide is also generated and released to the dome space, as is the case with Tank 241-SY-101. Nitrous oxide is a strong oxidant and its presence in the gas mixture extends the limits of flammability ( $3 \%$ to $84 \%$ ) somewhat. In addition, the heat of combustion for hydrogen when reacted with nitrous oxide is approximately $34 \%$ greater than that associated with reaction in air (i.e., $\mathrm{O}_{2}$ ) alone. The possible presence of nitrous oxide has not been considered for tanks other than SY-101. However, as will be shown later, ignoring the possible presence of nitrous oxide has virtually no impact on the determination of the frequency of releases due to burns in the tanks.

In the waste tank environment, hydrogen is believed to be produced by three general mechanisms: (1) radiolysis; (2) thermolysis; and (3) corrosion. As shown in Table 4-1, radiolysis and thermolysis are estimated to produce approximately equal amounts of hydrogen in Tank 241-SY-101, and the contribution of corrosion is not negligible. Radiolysis and thermoysis occur in the liquid components of the tank waste. However, since gamma and beta radiation dominate the radiolysis component, the amount of hydrogen produced by radiolysis is assumed to depend on the total radiolytic power of the tank.

In Table 4-1, the production by radiolysis is determined from a tank's radiolytic power and a value for $G$ (molecules produced $/ 100 \mathrm{ev}$ ) which is linearly related to a tank's organic content and that of Tank $241-S Y-101$ by

$$
0.07+0.0376 *(\% \text { TOC in Tank X) /(\% TOC in Tank SY-101). }
$$

The previous relationship is based on values inferred from the report by Ashby, et al (Ref. 4-4) for Tank SY-101.

Hopkins (Ref.4-3) suggests that the thermolysis component of hydrogen production for Tank $X$ can be scaled from that of Tank 241-SY-101 by

Thermolysis Production Rate in Tank $X\left(\mathrm{ft}^{3} /\right.$ day $)=$ Liquid Volume of Tank $X$ (gal) * 
Thermolysis Production Rate in Tank 241-SY-101 (ft3/day/gal) • Adjustment for

TOC Content * Adjustment for Aluminum Content • Adjustment for Waste

Temperature (i.e., its effect on the rate of production)

and

Adjustment for TOC Content $=($ TOC \% in Tank X/TOC \% in Tank SY$101)^{a}$

$$
\begin{aligned}
& a=0.5 \text { if TOC } \%<1.07 \\
& a=1.5 \text { if TOC } \%>1.07
\end{aligned}
$$

Adjustment for Al content $=(A l \% \text { in Tank } X / A l \% \text { in Tank SY-101 })^{b}$

$$
\begin{aligned}
& b=0.5 \text { if } \mathrm{Al} \%<3.0 \\
& \mathrm{~b}=1.5 \text { if } \mathrm{Al} \%>3.0 \\
& \text { Adjustment for Waste Temp }=\operatorname{Exp}\left(-E_{a} / R T X\right) / \operatorname{Exp}\left(-E_{a} / R T S Y-101\right) \\
& \mathrm{Ea}=26,000 \mathrm{~J} / \mathrm{gr} \text {-mole } \\
& R=8.31 \mathrm{~J} / 0 \mathrm{~K} / \mathrm{gr}-\mathrm{mole} \\
& T=\text { Waste Temperature in }{ }^{\circ} \mathrm{K}
\end{aligned}
$$

The production of hydrogen by corrosion for Tank $X$ is scaled from that of Tank SY-101 by the ratio of their respective surface areas (tank bottom and wall) exposed to the waste. For Tank 241-SY-101, the exposed surface area is approximately $12,400 \mathrm{ft}^{2}$ and the "reference production rate" is $5.5 \mathrm{ft}^{3} /$ day.

The above relationships were used to calculate the hydrogen production rates and "equilibrium" concentrations shown in Table 4-1.

For tanks with active ventilation, flammable concentrations can be achieved only by sudden releases ( or "burps") of flammable gases previously trapped within the slurry. In tanks without active ventilation, the flammable gas concentration in the dome space increases gradually, asymptotically approaching an "equilibrium" concentration.

Reference 4-1 discusses the burp-burn scenario associated with Tank 241-SY-101 in considerable detail. The approach used for Tank-241-SY-101 is applicable to all tanks with active ventilation and exhibiting episodic releases to the dome space. 
As indicated above, for those tanks without active ventilation, flammable gas concentrations in the dome space can gradually build up to "equilibrium levels" controlled by the generation and release of hydrogen from the waste material and tank space leakage (in or out) due to infiltration, exfiltration, breathing (fluctuations in atmospheric pressure), and possibly temperature-induced natural circulation. From Reference 4-2 (p. 5.2-16), the following expression can be used to determine the time-dependent concentration of hydrogen in the dome space of a tank:

$$
C=(S / Q) *[1-e-(Q / N) t]
$$

where

$$
\begin{aligned}
& \mathrm{C}=\text { hydrogen concentration (moles/ft } 3 \text { ) } \\
& \mathrm{S}=\text { hydrogen generated (moles/day) } \\
& \mathrm{Q}=\text { ventilation rate }\left(\mathrm{ft}^{3} /\right. \text { day) } \\
& \mathrm{V}=\mathrm{V}_{\mathrm{g}}+\mathrm{H}^{*} \mathrm{~V}_{\mathrm{l}} \\
& \mathrm{V}_{\mathrm{g}}=\text { volume of gas phase }\left(\mathrm{ft}^{3}\right) \\
& \mathrm{H}=\text { Henry's Law coefficient (dimensionless) } \\
& \mathrm{V}_{\mathrm{f}}=\text { volume of liquid in equilibrium with gas }\left(\mathrm{ft}^{3}\right) \\
& \mathrm{t}=\text { time from when } \mathrm{C}=0.0 \text { (days) }
\end{aligned}
$$

For long times, $C$ approaches $S / Q$, which is the hydrogen generation rate divided by the ventilation flow rate. Based on atmospheric pressure fluctuations only, an average value of $\mathrm{Q} / \mathrm{N}_{\mathrm{g}}$ equal to $0.0045 /$ day has been calculated for conditions at the Hanford site (Reference 4-5). Reference 4-3 suggests that $\mathrm{Q} N \mathrm{~N}$ is of the order of $0.0067 /$ day for "breathing" only. This latter value was used to conservatively estimate the equilibrium concentrations given in Table 4-1. Since measured dome gas volume concentrations appear to be significantly lower than those predicted using breathing only estimates for the effective ventilation rate (Ref. 4-3 p. E-16), it is apparent that realistic ventilation rates are much higher than the value reported above. Reference 4-5 notes that some tanks have instrument purge rates that are comparable to the rates caused by atmospheric pressure fluctuations. Studies reported in References 4-6 and 4-7 indicate that natural convection through leak paths could be dominant. Reference 4-4 concluded that Tank $C-103$ was ventilated at a flow rate that was a factor of 21 higher than that which would occur if the tank breathed to the atmosphere through a single vent.

It should also be noted that the equilibrium concentrations calculated for Table 4-1 assume that all of the hydrogen which is generated is instantaneously released to the dome space (i.e., there is no build-up in the waste). This assumption tends to overestimate the hydrogen concentration in the dome when waste levels are occurring in the absence of additions to the tanks. It is not clear as to whether "burps" would eventually occur in such cases.

\subsubsection{TANK SUSCEPTIBILITY EVALUATION}

Tank 241-SY-101 is used as a benchmark for DST hydrogen burn analysis since it is the only tank that has exhibited large episodic releases of flammable gas, and the associated phenomenon have been analyzed extensively (e.g., Ref. 4-1). 
The following attributes were found to be important in the quantification of the Tank 241-SY-101 burp-burn event tree:

1. Probability of ignition in the dome space.

2. Ignition probability in the ventilation lines.

3. Probability of flame propagation from the ventilation line back to the tank.

4. Quantity of slurry gas released into dome space during an episode.

5. Gas concentrations in dome space and ventilation lines during an episode.

6. Pressure rise, given a burn.

7. Tank pressure capacity.

Each of these attributes, where appropriate, are addressed in the susceptibility evaluation for the tanks listed in Table 4-1.

A brief synopsis of each of these attributes is given below.

Probability of Ignition in the Dome Space. Other than static electricity and the potential for sparks caused by metal-to-metal contact, only a few ignition sources within the vapor or waste spaces of Tank 241-SY-101 were identified. The more likely source of ignition of the episodic hydrogen releases is from sources associated with the ventilation system.

The probability of ignition in the dome space due to equipment within the tank per se was addressed in Reference 4-8. Given that a flammable gas mixture exists in the dome, the conditional probability of ignition was assigned a value of 0.0013 for the Tank 241-SY-101 PSA (Ref. 4-1). Despite the fact that the probability of ignition is dependent on the hydrogen concentration level, this value was used for all hydrogen concentration levels. The contributions due to sparks from static electricity and metal-to-metal contact are negligible in comparison to the other ignition sources.

Of the in-tank sources considered for Tank 241-SY-101, only sparks from the FIC level probe are believed to be applicable to passively vented tanks. Sparks were estimated to occur at a rate of $5 \mathrm{E}-08$ per hour (or $4.38 \mathrm{E}-04$ per year). For the passively vented tanks, this spark rate was assumed to be the mean of a lognormal distribution with a range factor of 10 ; i.e., $X_{95} / X_{50}=10$.

Ventilation Line Ignition Probability. This attribute is believed to be important only for tanks such as SY-101 which contain extensive instrumentation in the ventilation system. Reference 4-9 examined the probability of ignition in the ventilation exhaust header for Tank 241-SY-101 in considerable detail. In the analysis reported in Reference 4-9, it was assumed "that the concentration in the ventilation ducting is identical to that in the dome out to the intakes for the Continuous Air Monitor (CAM) in the exhaust stack." Reference 4-10 indicates that three cutsets dominate the probability of ignition in the ventilation system: sample line cabinet leaks and vacuum pump seal leaks into the CAM. Reference 4-9 also considered leaks in the Ammonia Bubbler and Teledyne Hydrogen Analyzer cabinets. According to Reference 4-9, "in each cabinet, the vacuum pump that draws air into the instruments is run by a single phase electrical motor [which] is assumed capable of hydrogen ignition at the lower flammable limit under normal motor operating conditions." 
The ignition model described in Reference 4-9 addressed the following sequence of events and/or assumptions:

1. A leak in the sample tubing results in hydrogen laden air escaping from the tubing into the cabinet.

2. A flammable mixture is produced in the cabinet at a position where an ignition source may occur.

3. An ignition source of sufficient energy to ignite the mixture and produce a sustainable flame front occurs during the mixture residence time.

4. The flame front propagates through an opening back into the sample line.

5. The flame front propagates through the sample line either forward through the return line or backwards through the supply line into the ventilation duct.

6. A flammable mixture is present in the duct at the point of the sample line entry.

7. The flame jets into the duct.

8. A flammable mixture exists in the ventilation duct at the location of the flame jet, and the jet ignites the vent duct mixture to produce a sustainable flame front that could potentially propagate back to the tank dome space.

Based on an application of this model to the six dominant cutsets identified in Reference 4-10, the analysis reported in Reference 4-9 resulted in a point estimate of 6.6E-03 for the conditional probability of ignition in the ventilation duct given a flammable mixture of hydrogen. This ventilation line ignition probability is appropriate for actively ventilated tanks but not for passively vented tanks.

For passively vented tanks, only ignition sources in the dome space of the tank are deemed important.

Probability of Flame Propagation Back to the Tank Dome Space. Once a flammable gas is ignited, the flame spreads outward from the source of ignition. The movement of this flame is measured in terms of "burning velocity" or "flame speed." Burning velocity is defined (Ref.4-11) as "the velocity of propagation of the flame with respect to the unburned gases." Flame speed is defined as "the movement of the flame front relative to a stationary point of reference." Thus, if ignition occurs in a duct with flowing gas, the flame will not be able to propagate upstream from the source of ignition unless the flame speed exceeds the gas velocity.

Minimum velocities in the Tank 241-SY-101 ventilation ducting when the fans are operating are expected to be greater than $2.8 \mathrm{~m} / \mathrm{sec}$. In Reference $4-1$, it was shown that propagation back to the Tank 241-SY-101 is not expected for burns that occur at less than approximately $11 \%$ hydrogen concentration, as the flame speed in the upstream direction would be less than or equal to the minimum flow velocity (corresponding to fan-induced flow only) in the ducting adjacent to the tank. 
Based on probability distributions for hydrogen concentration as a function of the magnitude of the gas release, the amount of gas released, and flame speeds, a probabilistic algorithm (discussed in Ref. 4-1 and quantified with the STADIC program [Ref. 4-12) for determining the conditional frequency of propagation back to Tank 241-SY-101 resulted in a conditional frequency of a burn propagating back to the tank of 0.083 for the case with ventilation operating is 0.083 . A value of 1.0 for propagation was used in the Tank 241-SY-101 analysis for the "Ventilation OFF" case.

Quantities of Slurry Gas Involved With Episodic Releases. The cumulative probability distribution shown in Figure 4-2 was developed in Reference 4-1 for the quantity of gas released during episodic releases in Tank 241-SY-101. This distribution was based on actual release data after March 1989 (when the practice of "air lancing" was terminated) through September 1992 and projected releases for the next 3 years. These projections ignore the installation of the mixing pump and its operation.

Gas Concentrations in Dome Space and Ventilation Lines. Except for burps (spontaneous release of gas from the slurry), flammable gas concentrations in the dome space and ventilation lines of actively ventilated tanks are negligible. Only Tank SY-101 has exhibited a gas release that resulted in a flammable mixture.

Estimates of the so-called "equilibrium concentrations" in passively vented tanks" are provided in Table 4-1. Based on point estimates of these concentrations assuming tank breathing only, a number of these tanks appear to achieve the LFL. In reality, however, measured dome space concentrations of hydrogen have been well below the LFL, indicating substantially higher vent flows from these tanks.

Pressure Rise Given a Burn. Only Tank 241-SY-101 has been evaluated for pressure loads resulting from postulated burns (see Ref. 4-1). The predicted pressure loads for various gas releases were made with the HMS-TRAC computer program.

Tank Pressure Capacity. To fit into the PSA context, a probabilistic description of the pressure capacity of the tank is required. Since pressure capacity is treated as a random variable, it is possible for more than one failure mode to significantly contribute to the risk, and each such failure mode must be evaluated. For probabilistic analysis, stresses are not categorized as primary membrane, primary bending, etc., which are then compared with different allowables, depending on the load condition as is required in a code or design calculation. Rather, failure is based on expected ultimate strengths and elongations using median material properties and associated variabilities.

A probability characterization of the pressure capacity of Tank 241-SY-101 was performed by EQE Engineering Consultants and discussed in Reference 4-1.

The controlling failure mode for Tank 241-SY-101 was determined to be failure of the dome and the median dynamic failure pressure in the dome was estimated to be 46 psig with a lognormal standard deviation of 0.27 . This failure pressure includes consideration of the dynamic response characteristics of the tank including the fact that, of the overburden above the dome is likely to be thrown into the air at pressures approaching failure. Impact of the soil on the dome after being thrown in the air above is unlikely to cause failure 
unless internal tank pressure has resulted in tearing the primary dome liner. However, aboveground components immediately above the tank will likely be failed, and assuming failure of the dome due to internal pressure, impact of the falling soil will likely result in collapse of the dome and soil into the tank with sloshing of liquids out of the tank as well as airborne release.

The SSTs are reported to have a pressure capacity of only approximately 11 psig (Ref. 413). This rather low capacity results from the fact that concrete provides the tanks' strength. A probabilistic characterization of the capacity of SSTs has not been performed.

Probabilistic Model for Estimating the Frequency of Tank Failure Resulting from Induced Hydrogen Burns. For "burps," the frequency of tank failure resulting from hydrogen burns is determined by a probabilistic model that combines the frequency and magnitude of episodic hydrogen releases from the waste to the vapor space of the tank, the likelihood of ignition of this hydrogen, the overpressure resulting from ignition, and the ability of the tank to withstand this overpressure. This model is discussed in detail in Ref. 4-1.

For burns in the SSTs, it is assumed that any burn will fail the tank since its capacity is relatively low. Probabilistic models of the SST pressure capacity are not available.

\subsubsection{Initiating Event Frequency}

\subsection{Double-Shell Tanks}

The DSTs on the Flammable Gas Watch List are all actively ventilated. Continuous operation of the ventilation system maintains flammable gas concentrations at extremely low levels. It is assumed that ventilation system failures are repaired promptly, long before appreciable concentrations can build-up. Therefore, only episodic releases are of concern for DSTs which are all actively ventilated. 2 The magnitude of burps in DSTs other than Tank 241-SY-101 clearly indicates that the events associated with this latter tank dominate the flammability concern with DSTs.

Prior to the installation of the mixing pump, Tank 241-SY-101 experienced a spontaneous release (also referred to as a "burp") of slurry gas approximately every 100 days. In developing the initiating event frequency for burps in Tank 241-SY-101, only events occurring after March 1989 were considered because, at this time, the practice of air lancing in this tank was terminated. Based on these considerations, the mean frequency of Tank 241-SY-101 burps was estimated to be approximately 3.5 per year. A more detailed analysis of the release history (see Appendix D of Ref. 4-1) yields the following attributes for a probability distribution for the frequency of burps in Tank 241-SY-101:
5th Percentile:
2.64 events per year
50th Percentile (Median):
3.44 events per year
Mean:
3.51 events per year

2 Operability of the ventilation system is addressed in the burp-burn event tree (see Section 4.2.1.3) but only to address the issue of burn propagation from the ventilation system back to the tank. 


\section{5th Percentile: $\quad 4.74$ events per year}

A review of the level drop information for the other DSTs indicates mean frequencies of release events from approximately 2.0 events/year to approximately 3.2 events per year (Tank SY-103). 3 However, because the magnitudes of the episodic gas releases in tanks other than Tank SY-101 have been relatively small and flammable gas concentrations in the dome and ventilation system have been only fractions of the LFL, only Tank SY-101 was considered in this evaluation. In other words, the frequency of burns due to episodic releases in other DST's is negligible compared Tank SY-101.

\subsection{Single-Shell Tanks on the Flammability Watch List}

The frequency of passively vented SST failure due to burns has been estimated probabilistically but with the following conservative assumptions:

1. Each electrical spark from the level probe is capable of igniting the gas mixture when the lower limit of flammability (LFL) is exceeded.

2. Each ignition/burn is capable of catastrophic failure (dome collapse and shell failure) of the tank.

The level probe is the only component inside the tank dome space that is deemed important as an ignition source in passively vented tanks.

As shown in Figure 4-3, adiabatic burns (but not complete combustion) at relatively low hydrogen concentrations produce a significant pressure rise in the tank. The presence of nitrous oxide $\left(\mathrm{N}_{2} \mathrm{O}\right)$ as one of the oxidizers increases the magnitude of the pressure rise for the hydrogen concentrations of interest. The failure pressure of single shell tanks (SSTs) 4 has been estimated to be only 11 psig (Ref, 4-13). Thus, there is a high probability that burns at low concentrations will fail an SST. Since there are no probability distributions for either the tank pressure loads induced by burns or the load capacities of the tank lexcept for Tank 241-SY-101 which is a double shelled tank), it was conservatively assumed that each ignition/burn would cause a tank failure. This assumption does not appear to have a dramatic impact on tank failure frequency since sensitivity calculations performed for several of the tanks indicate that the frequencies of ignition/burns at an assumed LFL of 5 $\%$ is not significantly different than that for an assumed LFL of $4 \%$. The failure pressure for SSTs is relatively low compared to the failure pressure calculated for Tank 241-SY-101 and the other DSTs.

The determination of ignition/burn frequency for a passively vented tank can be portrayed by the simple fault tree displayed in Figure 4-4.

The "steady state" concentration of flammable gas (primarily hydrogen) in the dome space of a tank can be expressed by Equation 4.2.1-1. Each of the parameters included in Equation 4.2.1-1 have uncertainties associated with the "state-of-knowledge" of the

3The difference between the average interval (days between events) and the high and low intervals for Tank SY-103 appears to be somewhat greater than that for Tank 241-SY-101. 4 all of the passively vented tanks of interest are SSTs 
parameter. 5 The current state of knowledge is based on limited measurements of parameters such as waste level and temperature, inference, and limited calculations. Thus, the parameters appearing in Equation 4.2.1-1 must be represented by probability distributions expressing the state of knowledge uncertainties in the values of these parameters.

In addition to the state-of-knowledge uncertainties discussed above, there are random variations in some of the parameters, in particular, the effective tank ventilation rate which is controlled by temporal fluctuations in atmospheric pressure and wind speed. Thus, even though the state-of-knowledge uncertainties predict that the flammable gas concentration is below the LFL, there could be times at which the temporal variation causes the LFL to be exceeded. This consideration is illustrated in Figure 4-5. For this evaluation, the impact of the temporal effect is evaluated using a multiplier on the point estimate concentration. This multiplier is assumed to range from 0.93 to 1.07 li.e., although the point estimate concentration is predicted to be $C_{\text {base }}$, the actual value could range from $0.93 \times C_{\text {base }}$ to $\left.1.07 \times \mathrm{C}_{\text {base }}\right)$. Figure 4-6 shows the fraction of a year that the multiplier is assumed to be exceeded. As indicated, the multiplier on the point estimate concentration never exceeds 1.07 and is never less than 0.93. A linear relationship between these points is assumed.

The determination of ignition/burn frequency for each of the tanks is determined with the Monte-Carlo program STADIC (Ref. 4-12) and proceeds as follows:

1. A value of $C_{\text {base }}$ is determined for each trial based on samples from pertinent input distributions.

2. A value for the LFL is determined by sampling the input distribution for LFL.

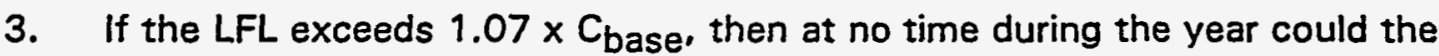
flammable gas concentration exceed the LFL and ignition/burn is impossible. In this case, the sampled spark frequency is multiplied by 0.0 to determine the ignition/burn frequency.

4. If the $L F L$ is less than $0.93 \times C_{\text {base, }}$ then the flammable gas concentration exceeded the LFL at all times and the sampled spark frequency is multiplied by 1.0 to obtain the ignition/burn frequency.

5. If the ratio of $L F L$ to $C_{\text {base }}$ is between values of 0.93 to 1.07 , the fraction of time that LFL is exceed during the year is determined from Figure 4-5 and the ignition/burn frequency is determined by multiplying the spark frequency by that fraction.

The calculated values given in Table 4-1 for hydrogen gas generation by each of the three mechanisms (radiolysis, thermolysis, and corrosion) were assigned a probability of 0.4 in discrete distributions for hydrogen gas released to the dome space, each consisting of three points. In recognition of the perceived conservative assumption that all of the gas generated is continuously released to the dome space, a gas release value equal to $50 \%$ of the Table 4-1 value was assigned an equal probability (i.e., 0.4 ). The final point in the 3

5 In many cases state-of-knowledge can be equated to lack-of-knowledge. 
point distribution accounted for the fact that there is some probability that the hydrogen release rate could be greater than the point estimates are greater than those given in Table 4-1. This final point was assigned a value equal to $150 \%$ of the Table 4-1 value and was assigned a probability of 0.2 .

Based on evidence that flammable gas concentrations are substantially lower than those which would be predicted assuming tank "breathing" only (see Ref. 4-3, p. E-16), a lognormal distribution was assumed for the effective ventilation rate of the dome space. The 10th percentile of this distribution was assigned the breathing rate value 10.0045 dome space volumes per day) cited by Crippen, et al in Ref. 4-5. The 80th percentile of this distribution was assigned a value of 20 times the breathing rate value, based on data discussed in Refs. 4-6 and 4-7.

The dome space volume listed in Table 4-1 was taken as the mean/median of a normal distribution and the 95th percentile of this distribution was assumed to be $10 \%$ greater than the mean.

The LFL was represented by a normal distribution with a mean/median value of $4 \%$ and a 95 th percentile value of $4.5 \%$. The sampled LFL was arbitrarily lowered by $0.5 \%$ for Tank 103-C to account for the possibility of organic vapor contributions to the flammable gas concentrations in the dome space.

The frequency of sparks associated with the FIC level probe was also represented by a lognormal distribution with a value of $5.0 \times 10^{-08} / \mathrm{hr}$ representing the mean of that distribution and a 95 th percentile value of $1.87 \times 10^{-08} / \mathrm{hr}$.

The mean value for the ignition/burn frequency determined in the above manner is given in Table 4-2 for each of the passively vented SSTs (including those on the High Organic Content Watch List) on the Flammability Gas Watch List.

A point estimate for the frequency of burns in Tank 241-SY-101 can be deduced from the branch point probabilities shown on Figure 4-7. Based on these values, the predicted annual frequency of burns for Tank $241-\mathrm{SY}-101$ is approximately $4.8 \mathrm{E}-03$ per year. As indicated in Table 4-2, the combined burn frequency for all of the passively vented tanks considered in this evaluation is 8.1E-04 per year. Thus, the frequency of burns in Tank 241-SY-101 alone is 6 times that of the sum of all of the passively vented tanks. The frequency of burns for the entire tank farm is $5.6 \mathrm{E}-03$ per year, or approximately one burn in 178 years.

4.2.1.2.3 Double Contained Receiver Tanks. Table 4-1 lists eight DCRTs that could contain waste materials that produce and release flammable gas. The DCRTs serve as receiver tanks for process waste, as lift stations, and as vent stations. Four of the tanks (Tanks 244-TX, 244-S, 244-A, and 241-EW-151) are used for storage and treatment. Tanks 244-SX, 244-S, and 244-A have primary tanks made of carbon or stainless steel, which are contained in below-ground concrete vaults. The vaults and liquid collection sumps are lined with steel plate. Three of the DCRTs 1244-CR Vault, 244-BX Catch Station, and the 244-U Catch Station) are used only for managing saltwell wastes removed from the SSTs. 
Six of the DCRTs (Tanks 244-A, 244-BX, 244-CR, 244-S, 244-TX, and 244- U) were determined to have active ventilation systems, and therefore long-term increases in the concentrations of flammable gases in these tanks are very unlikely. The 244-CR Vault is the primary facility used to transfer saltwell waste to the DSTs and is currently in a standby condition.

The DCRT 241-EW-151 Vent Station is used for the containment of possible leaks from the cross-site transfer line encasement. The stainless steel primary tank is contained in a below-ground vault. The vault has both leak detection probes and radiation monitors with alarms connected to the CASS. This DCRT, as well as A-350, did not appear to have active ventilation. The A-350 Lift Station receives drainage from farm complex $A$.

Because of their relatively small size and the sporadic use of the DCRTs, they were judged to be unimportant to risk in comparison with Tank 241-SY and the SSTs, which were analyzed for this study.

\subsection{High Organic Content Tanks.}

Because of the strong dependency of the thermolysis component of hydrogen generation on TOC, all of the tanks with high organic content were considered in the flammability analysis. Tank 103-C is believed to contain a layer of organic liquid floating on top of the aqueous supernatant liquid.

The hazards associated with pool fires have not been quantified deterministically. According to Reference 4-2, simple conservative analyses indicate that a pool fire could overpressurize a tank. However, other evidence suggests that the organic liquid in Tank 103-C might be inerted due to dissolved water. According to Reference 4-2, organic aerosol concentrations are much too low (1 to $2 \%$ of the LFL) to be of concern. Therefore, the approach used for determining the frequency of burns for Tanks 103 is similar to that for the other passively vented SSTs. However, given that a burn occurs in Tank 103-C, it is assumed that the organic layer is ignited and burns in a manner similar to that of aircraft fuel following an aircraft crash.

\subsubsection{ACCIDENT SEOUENCE MODEL}

\subsection{Double-Shell Tanks.}

The accident sequence model for slurry gas release in Tank 241-SY-101 is composed of the event sequence diagram shown in Figure 4-8 and the corresponding event tree shown in Figure 4-7. As indicated in Figure 4-7, each event tree sequence terminates in a release category characterizing the release of hazardous materials into the environment. This burpburn event tree has been quantified only for Tank 241-SY-101 since the burn frequency for the other DSTs on the Flammable Gas Watch List is judged to be negligible in comparison.

The following paragraphs describe each top event in the burp-burn event tree, the split fractions required, and the approach used in the quantifying the split fractions. The split fraction values for each top event and the results of the burp-burn event tree quantification for SY-101 are summarized in Section 4.3. 
-Top Event $\mathrm{H} 2 \mathrm{HI}$ - Hydrogen Concentration Less Than the Lower Limit of Flammability?

-Success Criteria. If the tank dome/ventilation inlet concentration remains below approximately $4 \%$, the lower limit of flammability for a typical Tank 241-SY-101 gas mixture (hydrogen-nitrous oxide-air), then burns are precluded. Although slight tank-to-tank variations in the flammability limit will exist, the same limit is applied to each tank.

-Split Fraction Definition. For Tank 241-SY-101, the value of the split fraction for this top event is based on (1) a combination of actuarial date up to and including the gas release episode that occurred during September 1992 and 3-year projections for the volume of gas released during an episode, ignoring the impact of the mixer pump; and (2) computer code (HMS) calculations of the hydrogen concentrations in the dome space and ventilation line, given a release of a certain magnitude. Projections were based on the observation that the actuarial data exhibited an upward trend in the volume of slurry gas released. This trending was extrapolated for a period of 3 years. Thus, the probability distribution used for Tank 241-SY-101 gas release volume would be appropriate (assuming no perturbations in the existing trend) for a time 3 years in the future but possibly conservative for any time in the interim. $* 6$

-Top Event VOP - Tank Ventilation Available?

-Success Criteria. For actively ventilated tanks, the split fraction for this top event addresses ventilation system operability. For passively ventilated tanks, this top event addresses whether the tank vent pipe or HEPA filter is plugged.

-Split Fraction Definition. Only one split fraction (VOP1) is needed for burp events. The electric power system components required for operation of the ventilation system are included in the fault tree model for the ventilation system.

- Quantification Modeling. The availability of the SY tank farm ventilation system was developed in Appendix D of Reference 4-1.

-Modeling Assumptions. None.

\section{-Top Event TBRN - No Burn Occurs in the Tank?}

Given that a flammable mixture exists in the tank dome space, this top event asks whether the mixture is ignited within the tank.

-Success Criteria. No ignition of the flammable mixture in the tank dome space occurs.

\footnotetext{
$6 *$ It could be argued that because of the observed trends, earlier actuarial data should not be weighted equally with projected data points. Equal weight was given to both actuarial data and projections in the calculation of the split fraction for this top event.
} 
-Split Fraction Definition. For Tank 241-SY-101, the likelihood of ignition within the tank (conditional split fraction TBURN1) was assigned a value of 1.28E-03, which was taken from Reference 4-8.

-Quantification Modeling. The likelihood of ignition in the dome space was addressed in Reférence 4-10.

- Modeling Assumptions. A burn in the tank or ventilation system is assumed to have the following impacts:

1. The tank ventilation systems are assumed to be intact prior to a burn. If no burn occurs, the ventilation systems are assumed to remain intact. If a burn occurs in either the tank dome space or the ventilation system, the ventilation system is assumed to fail.

2. Ventilation system HEPA filters are assumed to be intact prior to a hydrogen burn. If no burn occurs, they are assumed to remain intact. If a burn occurs in either the tank or the ventilation system, the HEPA filters are assumed to fail. Failure of these filters will allow radioactive material to be released to the environment without the benefit of filtration.

3. For double-shelled tanks, the annulus ventilation system is assumed to be intact prior to a burn. If no burn occurs, or a burn occurs and the primary tank remains intact, the annulus ventilation system is assumed to remain intact. If a burn occurs and the primary tank fails, the annulus ventilation system is assumed to fail.

-Top Event VBRN - No Significant Burn in the Ventilation System?

-Success Criteria. No ignition of a flammable mixture occurs in the ventilation system.

Note: All burns are assumed to be capable of damaging ductwork and/or equipment in the ventilation system.

-Split Fraction Definition. For actively ventilated and instrumented tanks such as Tank 241-SY-101, the probability of ignition has been determined to be 0.0066 (conditional split fraction VBRN1).

- Quantification Modeling. The basis for VBRN1 is provided in Reference 4-9.

- Modeling Assumptions. None

-Top Event PROP - No Propagation of a Burn from the Vent Line to the Tank?

-Success Criteria. No propagation of a hydrogen burn that originates in the ventilation system back to the tank dome space. 
-Split Fraction Definition. For tanks with active ventilation systems, the likelihood of propagation of a burn back to the tank is dependent on ventilation flow rates and flame speed. For the case in which an active ventilation system has failed or for the case in which ignition occurs in a passive ventilation system, it is assumed that propagation back to the tank is guaranteed; i.e., the split fraction (PROP2) is assigned a value of 1.0. For Tank 241-SY-101, the likelihood of propagation back to the tank, given ignition in operational ventilation system, was calculated (Reference $4-1$ ) to be 0.083 .

- Quantification Modeling. An analysis of hydrogen burn propagation for Tank 241-SY-101 was given in Reference 4-1.

-Modeling Assumptions. If a burn propagates back into the tank from the ventilation system, the effects of the burn in the tank are assumed to be the same as if the burn had originated in the tank.

\section{-Top Event Dome - Dome Integrity Maintained?}

This top event addresses the integrity of the tank dome following a burn.

-Success Criteria. No direct pathways for the release of tank gases and aerosols to the environment, except through the risers.

-Split Fraction Definition. The question regarding dome integrity is only asked if hydrogen burns occur in the tank (including those that originated in the ventilation system). The analysis discussed in Appendix $E$ to Reference 4-1 indicated that the dominant failure mode for burns was the collapse of the dome as opposed to failure of the shell. Based on a Monte Carlo simulation performed with the STADIC program (Ref. 4-12), a single split fraction (DOME1) with a mean value of 0.12 was determined.

-Quantification Modeling. The susceptibility of the tank dome to failure was assessed in Appendix E of Reference 4-1.

-Modeling Assumptions. The assumptions regarding modeling are discussed in Appendix E to Reference 4-1.

4.2.1.3.2 Passively Vented Single Shell Tanks. Because of the relatively low strength of the SSTs, tank failure is assumed for each burn. As shown in Figure 4-3, burns at hydrogen concentrations of only $5 \%$ will produce pressures in the tanks that exceed the reported 11.0 psig capacity of the tanks. Analyses for selected tanks indicate that a substantial fraction of the burns would occur at concentrations greater than $5 \%$ hydrogen concentration. Therefore, the assumption of failure given a burn is not unduly conservative. 
Because Tank 112-S contains a substantial quantity of Cs-137, the frequency of burns will be assigned to a unique release category (DCLLK2). This release category reflects both airborne and liquid pathways (similar to DCLLK for Tank 101-SY) but with increased source terms.

\subsection{High Organic Tanks.}

As was the case for the passively vented single-shell tanks, all of the frequency associated with burns in the high organic tanks is assumed to result in tank failures. In addition, both airborne and liquid pathways are assumed to be created. A special release category, DCHORG, was created for Tank 103-C to account for an increase in the airborne release due to the potential for pool fires in that tank.

\subsubsection{TANK SHELL LEAKS}

\subsubsection{Susceptibility}

This initiating event group includes spontaneous leaks from the side or bottom of both single-shell and double-shell HTF waste tanks. Tank leaks resulting directly from other initiators are included in the analyses of those events.

The objective of this analysis is to estimate the likelihood of tank leaks for the remainder of the interim storage era at Hanford. This time period extends generally from now to the retrieval of tank waste for treatment and long-term storage (10 to 20 years). It is believed that the operation practices and the general environment of the tank farm will not change significantly over this time frame. Furthermore, it is expected that natural tank aging processes would be likely to remain at the current level. Therefore, predictions based on the current information and operating experience would be most relevant and applicable.

Of the 177 HTF storage tanks, 68 are officially reported to have already failed as recorded in the tank database in Appendix C. More detailed investigations by S. Agnew of Los Alamos National Laboratory (Reference 4-14) have revealed that 12 of the reported 68 events were actually transfer line leaks or tank overflows and not tank shell leaks. Therefore, this analysis will consider only 56 tanks to be already failed, and the remaining 121 will be evaluated as potential leak sources. Table 4-3 lists the tanks categorized as leakers for this analysis. Future leakage events are also possible from already failed tanks as a result of water intrusions or misrouted transfers, and these scenarios are addressed under those initiators.

The HTF waste tanks are divided into two subgroups for analysis: SSTs and DSTs. Although two general types of single-shell tanks were constructed (128 - "100" series and 16 - "200" series), all SSTs are modeled as one family due to the sparsity of data for the "200" series. All 56 confirmed failures have been in SSTs.

\subsubsection{Initiating Event Frequency}

\subsection{SST Leak Frequency}


4.2.2.2.1.1 Analysis of Historical SST Leak Data. Initially, all tanks constructed at Hanford were SST structures. A total of 149 SSTs were built in groups (called farms) from 1944 to around 1964. A total of 68 SST tanks are reported to be leakers in official Hanford records. Except for four tanks built in 1964, every group has tanks that developed leaks of various sizes, from a few hundred gallons to hundreds of thousands of gallons. Once a leak is detected in any tank, efforts are made to minimize the continuing leak over the future years by removing the drainable liquid out of the tank. The time of detection of these leaks may not be precisely known because of the sparsity of leak detectors around the tanks and the difficulty in detecting leaks by observing changes in tank liquid level ( 1 inch $=2,750$ gallons). Historically, both methods have detected leaks.

The Tank Farm Surveillance Report (Reference 4-15) provides tank data on the year these tanks were built, the year they began to leak, the quantity of various liquid and solid wastes they contain, and other relevant information. Appendix $C$ presents these data from the June 1993 report for all tanks.

Recent research performed by scientists at LANL (Reference 4-14) revealed that at least 12 of the 68 reported tank leaks were attributable to overfilling and/or transfer line leaks. Also, reported leak dates were revised to reflect the actual time of the leak rather than the declared dates. Therefore, the leak data included in the Surveillance Report were modified in light of this new information. Table 4-3 contains information on all confirmed leakers by combining the Surveillance Report with the new information.

- SST Leaks versus Time. The leak history listed in Table 4-3 is plotted according to the calendar year in which the leaks occurred in Figure 4-9. It is clear from this plot that the number of tank leaks increased steadily with time throughout the period in which new, high heat generating waste was routed to the SSTs. After the SSTs were removed from active service in 1980, the number of detected leakers dropped precipitously and has remained very low for the past 15 years. This behavior pattern is confirmed by Figure 4-10, which shows the total SST population, the number of leakers, and the leakage rate all plotted as a function of tank age. Since 1979 , only three tanks have been detected as leaking, and these three leaking were distributed evenly, about every 5 years. On average, tanks experienced about 0.2 leaks per year in the last 15 years as against historical about 1.5 leaks per year (ended in 1979). Table 4-4 lists these three tanks and their leaking data.

- Multiple Failures. Considering the total number of failures over a lifetime of about 50 years and the resulting average tank leak rate of about 1.1 per calendar year, it would be expected that the likelihood of multiple leaks in any given year would be small. Since the whole tank population is divided into 12 farms and the largest farm ( $T$ farm) contains 18 tanks, the likelihood of multiple leaks in any given year for any 1 farm would be even smaller. However, the raw data show that the number of tank leaks from certain farms for some years were four and five!

For the $T$ farm of 100 series tanks, there are 12 tanks and 4 are leakers. These four leakers all happened in 1974 in its 50 years of life. For the $\mathrm{C}$ farm of 200 series tanks, there are only four tanks, and all of them failed in 1976. For the TX farm, there are 18 tanks, and 8 are leakers and 5 failed in 1977. For the $B$ farm of 100 series, there are 12 tanks, and 7 are leakers in which 4 failed in 1978 . Viewed 
from an individual tank farm basis, it is very unlikely that these were results of random processes. In fact, the likelihood of 4 tanks out of 18 failing in a single year due to random causes, using the overall tank farm average failure rate, is about 1E-05. Thus, these multiple failures were more likely the results of some kind of common cause failure mechanism. Table 4-5 shows this phenomenon.

- Possible Root Causes of Leaks. Two primary conclusions appear to be supportable from the above analysis of historical SST leak data. First, a dramatic change in SST leak frequency occurred when these tanks were removed from active service and has continued to the present. Second, the patterns and timing of the recorded failures indicate that common cause mechanisms are the primary causes of tank leaks. Physical evidence of failure causes is not readily available; however, several hypotheses have been suggested during our investigations that may help explain the observed data. These are discussed in the following paragraphs.

- Many of the recorded tank leaks may have been overflows or transfer line leaks. As discussed in Section 4.2.2.2.1.2, LANL researchers were able to determine from transfer records that 12 of the officially reported 68 tank leaks were really transfer accidents. The leaks occurred from transfer lines and from unsealed cascade line penetrations. Since transfers into the SSTs and, presumably, cascade operations were terminated in 1980, this hypothesis fits very nicely with the observed precipitous drop in reported leaks since 1980.

- High heat waste may be responsible for multiple tank failures in many farms. As indicated in Table 4-3, LANL researchers were able to attribute 9 of the 56 tank failures to buckling of the liner bottom. This buckling is believed to result from excessive thermal expansion of the liner bottom. Since individual tank farms were often dedicated to one particular process at any one time, it is possible that multiple tanks in a single farm would be the recipients of similar wastes at about the same time. If these wastes were capable of overheating the liner, multiple tank failures over a short time period could result. The concentration of the nine documented overheating failures in only four tank farms also supports this hypothesis. Thus, other multiple tank failures grouped closely in time may be the result of overheating.

4.2.2.2.1.2 Future SST Leak Frequencies. From the data and conclusions presented above, we conclude that tank leak frequency, thus far, does not correlate with age. Therefore, a predictive model of leak frequency for the near-term future (10 to 20 years) can be linear over this period.

The analysis of the SST leak data presented above leads us to conclude that the entire SST leak history should not be equally weighted to estimate future tank leak frequencies. More specifically, we believe that the experience over the last 15 years is the best indicator of future performance. However, since the earlier higher leak frequency experience cannot be entirely dismissed, it seems reasonable to use a combination of past and recent experience to predict future leak frequencies and properly account for uncertainty in the projections. 
To form this combination, the historical SST leak history is divided at 1980 into two periods representing active operation (before 1980) and inactive operation (after 1980). Average leak rates over the two periods are computed as shown in Table 4-6.

To avoid excessive conservatism, leak events that are believed to emanate from causes not applicable during the future interim storage era are deleted from the calculations. These include overheating failures (9) and simultaneous multiple leaks in a single tank farm (17).

The final distribution for future SST leak frequency is then constructed by assuming that the leak frequency is represented by a lognormal distribution. The average leak frequency for the inactive periods since 1980 from Table 4-6 is designated as the 20th percentile of the distribution and the average leak frequency for the active era is designated as the 80th percentile. The resulting parameters of the complete distribution are shown in Table 4-6. This treatment of the historical data for estimating the future provides a very broad distribution with a high likelihood that future SST leak frequencies will be near the recent experience but with the possibility that the higher leak rates of the earlier active operating era could be seen again.

4.2.2.2 DST Leak Frequency. Since 1970, DST tanks, a total of 28 , were built and entered into the service. To date, the DSTs have accumulated 379 tank-years of experience with no recorded leaks. Table 4-7 shows the years that the DST tanks were built and other relevant information. The outer or secondary tanks are physically similar to the 100 series SSTs. The inner or primary tanks are a freestanding carbon steel shell separated from the secondary by an annular space of approximately 18 inches. There are monitoring devices between the two shells, which will detect leaks from the primary shell to the secondary shell. The detectors monitor conductivity and radiation.

The model developed for the leaks in DST tanks considers the failure of each shell independently. The likelihood of common cause failures of both shells due to internal events is considered to be very small, and the likelihood of common cause failures of both shells due to external events is treated elsewhere.

4.2.2.2.2.1 Primary Shell Leak Frequency. Application of the mean SST leak frequency to the binomial distribution for the recorded 379 tank-years of DST experience produces a probability of $36 \%$ that no failures would have been observed in this period. Thus, application of the SST leak frequency directly to the DSTs would not be completely unreasonable. A lower estimate of future DST leak frequency could be obtained through Bayesian updating of the SST leak projections with DST experience. However, this was not done because it was judged that this could produce unconservative results for future performance. Although no leak has been detected for a total of 379 tank-service years, it is likely that some wearout has occurred and that the DSTs are operating in a somewhat degradated status. Also, independent of issue of tank aging, it is believed that most mechanisms leading to leaks are cumulative. Therefore, with continued operation, the likelihood of primary shell leakage is expected to increase. Furthermore, the bulk of SST tanks developed leaks after they were 20 years old, and only three DST tanks are older than 20.

Therefore, the future leak frequency distribution developed for SSTs is also applied to the primary shell of the DST's. 
4.2.2.2.2.2 Secondary Shell Leak Frequency. Because the outer or secondary shell of a DST closely resembles a 100 series SST, the predicted SST leak frequency is direct applied to DST secondary tank failure. It could be argued that the SST leak frequency should be reduced before application to DST secondaries because the DST shells are not normally wetted and therefore are not exposed to the cumulative effects of waste storage that are believed to cause most leaks. However, it could also be argued that the DST shells have never been wetted and because their integrity is not known, could have preexsisting flaws. We believe that use of the projected SST leak frequency for DST secondary shells adequately balances these concerns.

\subsubsection{Accident Sequence Model}

4.2.2.3.1 SST Leak Model. For an SST, this initiator is defined to mean that a leak has occurred in the tank. The accident frequency analysis is completed by assessing the size of the resulting leak. Additional questions could be included in the accident sequence model to examine the probability of leak detection and subsequent operator intervention to minimize the consequences of the leak. Since no formal plans are known to exist for the possible mitigation of a leak from a tank, no recovery actions were included in the model.

Because of the simplicity of this event model, an event sequence diagram has not been developed. The event tree for leaks from an SST is presented as Figure 4-11. This model is used to quantify the frequency of radionuclide releases from all 93 sound SSTs. The following paragraphs describe each top event, the split fractions required, and the approach used in quantification of the split fractions. Split fraction definitions and values for each top event and the results of the event tree quantification are detailed in Section 4.3.

Top Event SIZE - Tank Leak is Small?

- Success Criteria. The volume of a leak from an SST is less than 10,000 gallons.

- Split Fraction Definition. Only one split fraction (SIZE1) is needed for all SST events.

- Quantification Modeling. The volume of liquid waste escaping from a tank leak is dependent on many variables including the available tank liquid inventory and the location of the leak. In addition, leaks may be resealed by the movement of sludge and solids to the leak point. Because of these complexities, past leak experience is judged to be the best indicator of future experience. Figure 4-12 presents the distribution of reported leak volumes for the 56 confirmed leak events from SSTs. This distribution shows the clear dominance of small leaks of less than 10,000 gallons. Note that the largest reported leak of 144,000 gallons is nowhere near the maximum liquid inventory of many tanks. Also, this event has been attributed to tank overheating, causing the buckling of the bottom shell. Since new, high heat wastes are no longer being produced at Hanford, this event may not be good evidence of future performance. 
Using the data from Figure 4-12, only 12 of the 56 leak events, or $21.4 \%$, were greater than 10,000 gallons. In addition, a review of the tank liquid inventories listed in Appendix $C$ reveals that stabilization activities have reduced the liquid inventories of 36 of the 93 sound SSTs to less than 10,000 gallons. Thus, only about $61 \%$ of the SSTs are capable of producing a large leak, even if all of their contents are lost. Combining these two factors $\left(.214^{*} .613\right)$, a probability of 0.131 is calculated for the likelihood of a large leak from an SST. This fraction is used for split fraction SIZE1.

- Modeling Assumptions. Although no uncertainty is assigned to the frequency of large versus small leaks, uncertainty in the actual volume released is accounted for in defining the resulting source terms for these sequences (see Section 5 more information).

4.2.2.3.1 DST Leak Model. For a DST, this initiator is defined to mean that a leak has occurred in the primary or inner tank. The accident frequency analysis is completed by assessing the likelihood that the primary leak is not contained by the secondary tank and what the size of the resulting leak is. The same analysis approach described above that was used to calculate the frequency of primary tank failure was employed for the secondary tank. Additional questions could be included in the accident sequence model to examine the probability of leak detection and subsequent operator intervention to minimize the consequences of the leak. Since no formal plans are known to exist for the possible mitigation of a leak from a tank, no recovery actions were included in the model.

The event sequence diagram and corresponding event tree for primary leaks from a DST are presented as Figures 4-11 and 4-13. These models are used to quantify the frequency of radionuclide releases from all 28 DSTs. The following paragraphs describe each top event, the split fractions required, and the approach used in quantification of the split fractions. Split fraction definitions and values for each top event and the results of the event tree quantification are detailed in Section 4.3.

- Top Event SSI - Secondary Shell Integrity Maintained?

This block is questioned following failure of the primary shell for double-shell tanks. Failure of this block leads directly to a subterranean ground release.

- Success Criteria. No detectable quantities of liquids can leak from a tank.

- Split Fraction Definition. Only one split fraction (SSI1) is needed for both large and small primary shell breach initiating events.

- Quantification Modeling. As discussed in Section 4.2.2.2.2.2, the annual leak frequency for the 100 series SSTs is also used for the secondary shell of the DSTs. Top Event SSI questions the integrity of the sceondary shell following failure of the primary tank. A leak in the secondary could have occurred at any time since the tank was built, and gone undetected until the leak in the primary tank occurred. The average age of the DSTs is 14 years. Therefore the exposure time used for the quantification of Split Fraction SSI1 is 20 years, which is the approximately the average DST age over the 
next ten years. Assuming the the occurrence of leaks in the single shell tanks can be represented as a Poisson process, the following equation is used to calculate Split Fraction SSI1:

where

$$
\text { SSI }=-1-e^{-\lambda t}
$$

$$
\begin{array}{ll}
t & =\text { exposure time (years) } \\
\lambda & =\text { SST leak frequency (per year) }
\end{array}
$$

- Modeling Assumptions. See Section 4.2.2.2.2.2.

- $\quad$ Top Event AVI - Annulus System Integrity Maintained?

- Success Criteria. The annulus ventilation piping must contain secondary tank aerosols and direct annulus ventilation flow to the annulus exhaust HEPA filter.

- Split Fraction Definition. Only one split fraction (AVI1) is required for the quantification of the large and small primary tank leak events.

- Split Fraction Quantification. The likelihood of breaching the annulus ventilation system is assumed to be the same as the likelihood of breaching the primary tank ventilation system.

- Modeling Assumptions. DST tank farm ventilation systems, including the annulus system, are assumed to be intact at the time of the primary tank leak initiating event. It is assumed that the material leaked into the annulus would remain there for 1 year. Failure of the annulus vent system integrity within that time would cause a radionuclide release.

- Top Event SIZE - Tank Leak is Small?

- Success Criteria. The volume of a leak from a DST is less than 10,000 gallons.

- Split Fraction Definition. Only one split fraction (SIZE2) is needed for all DST events.

- Quantification Modeling. For DSTs, this top event is conservatively assigned as a guaranteed failure (1.0) because all DSTs contain significantly more liquid volume than the 10,000 gallons required to produce a large leak.

- Modeling Assumptions. Small leaks of less than the 10,000-gallon limit could result from DST leaks. However, since no plans are known to exist for the prompt mitigation of a leak and the volumes available to leak are much greater than the 10,000-gallon threshold, it is conservatively assumed that all leaks from DSTs would fall into the "LARGE" category. 


\subsubsection{TANK DOME FAILURE}

A tank dome failure is a leak or crack in the dome structure due to nonexternal events, excluding aircraft crashes. The initiating event is called DOMEF. Two failure modes are considered: breach and collapse. If the dome is breached but does not collapse, only airborne aerosol releases are possible. If collapse of the dome occurs, a significant pathway would be open to the environment, and soil or other material falling into the tank could cause the displacement of waste material above-grade.

\subsubsection{Tank Susceptibility Evaluation}

The contributors to the dome failure initiating event are dome breaches due to drilling or excavation contact, or a pump or pit cover dropped into the pump pit, and dome collapses due to to overloading the dome. With the exception of the dome breach caused by dropping a pump pit cover, all 177 tanks are assumed to be equally susceptible to each of these contributors. Intrusion-prevented tanks (i.e., tanks that have had pump pits sealed) are not susceptible to dome breaches due to dropping of pump pit covers. Tank dome failure due to vacuum is also considered (see Initiator Loss of Active Ventilation Flow, Section 4.2.7).

\subsubsection{Initiating Event Frequency Quantification}

Where applicable, the frequencies of HTF PSA initiating events are based on empirical data developed from unusual occurrence reports (UOR) at the site. A summary of event frequencies generated from the UORs can be found in Appendix D of Reference 4-1.

The frequencies of drilling and excavation activities impacting a tank dome are represented by UOR events 46 and 47 , respectively. These events represent contact being made with the dome. It is assumed that 5 percent of these events would cause a breach in the dome. All 177 tanks are susceptible to this failure mode. Another event that could cause a dome breach is the dropping of a pump pit cover into a pump pit. The frequency of dropping a pump pit cover (see Table F-1 of Reference 4-16) is 3.OE-4 per tank year. Only those tanks that have not been intrusion prevented are susceptible to pump pit cover dropping. Of the 177 tanks at the site, 79 have not been intrusion prevented. Saltwell pumping no longer takes place on tanks that have been intrusion prevented.

A dome collapse could be caused by placing a heavy load above a tank. The weight load above the tank could be increased by flooding or extreme precipitation. An analysis of the frequency of flooding events at the Hanford Tank Farm site can be found in Appendix $C$ of Ref. 4-1. The results of the reference study showed that flooding (e.g., high Columbia river flow, Grand Coulee Dam failure, or extreme precipitation) of the tank farms is not a credible event. There have been a number of raw water surface spills/leaks documented at the site (see UOR database event UOR25); however, due to small spill rates and the localized area of impact, these events are not considered to be a threat to the dome integrity. The frequency of dome collapse due to a very heavy point load (e.g., vehicle or equipment) above a tank is judged to be insignificant. Dome collapse as a result of hydrogen generation, seismic or aircraft crash events is discussed in Sections 4.2.1, 4.2.13 and 4.2.14 respectively. 
Based on the failure modes discused above, the mean DOMEF initiating event frequency can be calculated using the equation shown below:

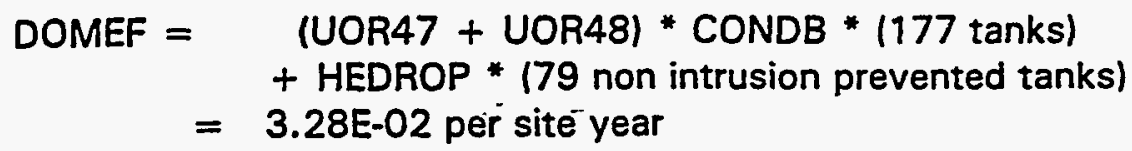

where;

UOR47 = drilling contacts tank (per tank year)

UOR48 = excavation contacts tank (per tank year)

CONDB $=$ probability of tank breach given drilling or excavation contacts tank

HEDROP $=$ pump or pump pit cover dropped in pump pit causing dome breach (per tank year)

\subsubsection{Accident Sequence Model}

The frequency of the DOMEF initiating event is comprized $(100 \%)$ of dome breach events, no credible dome collapse events were identified. A dome breach event is defined as an event that allows the dome space aerosols to escape the tank, resulting in an unfiltered release; i.e., release category BPL. Therefore, the frequency of the dome failure initiating event is mapped directly to release category $B P L$.

\subsubsection{VENTILATION LINE BREACH}

The Ventilation Line Breach initiating event is defined as an event that allows the dome space aerosols to escape the tank, bypassing the ventilation system and HEPA filter. A ventilation line breach can occur when a tank riser or ventilation piping is breached.

\subsubsection{Iank Susceptibility Evaluation}

Failure of risers or ventilation piping results in a direct release path to the environment for tank aerosols. All of the tanks at the Hanford Tank Farm have either passive or active ventilation as well as tank risers. All of the tanks at Hanford are susceptible to a ventilation line breach but not at the same frequency. Actively ventilated tanks have a much more complex ventilation system. Consequently, the number of potential failures that can lead to a breach of the ventilation system is greater than for a passively ventilated tank. Table 4-8 provides a list of the actively ventilated tanks.

There are a total of 47 actively ventilated tanks serviced by 8 ventilation systems. All 28 double-shell tanks and 19 single-shell tanks are actively ventilated. The remaining 130 single-shell tanks are passively ventilated.

For passively ventilated tanks, there are two ventilation breach failure modes that can lead to an unfiltered release. A tank riser can be damaged by a vehicle, or the loop seal pressure relief line can lose its liquid. In both of these instances, tank gases are directly released into the environment.

\subsubsection{Initiating Event Quantification}


Initiating event RVBA models ventilation line breaches for actively ventilated tanks, and initiating event RVBP models ventilation line breach for passively ventilated tanks. Ventilation line breach can be caused by a leak or crack in ventilation ductwork or riser piping.

The UOR database categories applied to the ventilation line breach initiating event frequency for actively ventilated tanks (RVBA) include "Failure to restore" (UOR39), "Riser leaks" (UOR41), and "Tank riser damaged by a vehicle" (UOR46). Frequency contributions from these UOR categories were summed to derive the RVBA initiating event frequency (see Appendix D of Ref. 4-1). The "Failure to restore" UOR category has units of per ventilation system per year. The latter two UOR categories have units of per tank per year. The calculation of initiating event RVBA multiplies the "Failure to restore" category frequency by the number of active ventilation systems $(8)$ and adds this to the sum of the latter two UOR categories, which are multiplied by the number of actively ventilated tanks (47). This equation is shown below:

$$
\begin{aligned}
\text { RVBA }= & \text { (Failure to restore }) *(8 \text { active ventilation systems }) \\
& + \text { (Riser leaks }+ \text { Tank riser damaged by vehicle }) *(47 \text { actively ventilated } \\
& \text { tanks }) \\
= & \text { UOR39*8+(UOR41+UOR46)*47 } \\
= & 6.43 E-01 \text { per year for the Hanford Tank Farm site }
\end{aligned}
$$

Three failure modes are considered for the quantification of the ventilation line breach initiating event frequency for the 130 passively ventilated tanks (RVBP). Two of these, "Riser leaks" (UOR41) and "Tank riser damaged by a vehicle" (UOR46), are taken from the UOR database. The units for these events is per tank per year.

The third ventilation line failure mode considered for the passive tanks is a loss of the fluid in the loop seal. This would provide an unfiltered release path to the atmosphere for the tank aerosols. The oil-filled loop seals provide pressure relief, should the breather HEPA filter become plugged. The loop seals are equipped with a sight glass and are inspected weekly. No UOR database event is provided for this failure mode; therefore, the frequency of failure of the loop seal piping is based on the W-1400 Reactor Safety Study (Reference 4-17) failure rate for pipe failure per hour. The RVBP initiating event mean frequency can then be calculated as follows:

RVBP $=$ (Riser leaks + Tank riser damaged by vehicle)

$$
\begin{aligned}
& *(130 \text { passive ventilated tanks) + (Loop Seal Leak) *130 } \\
= & (\text { UOR4 } 1+\text { UOR46 + PIPERP* } 8760) * 130 \\
= & 1.35 \text { per year for the Hanford Tank Farm site }
\end{aligned}
$$


The total frequency for the ventilation line breach initiating event (RVB) is equal to the sum of the frequencies calulated for the actively and passively ventilated tanks. Therefore, the RVB frequency per year for the entire tank farm is 1.98 per year.

\subsubsection{Accident Sequence Model}

A breach in a ventilation line leads directly to an unfiltered release of aerosols to the atmosphere. No subsequent events to produce a release. Therefore, the frequency of ventilation line breach initiating event (RVB) is mapped directly to release category BPL.

\subsubsection{VENTILATION EXHAUST HEPA FILTER FAILURE}

Failure of the ventilation exhaust HEPA filter will result in an unmitigated release path (bypass) to the environment of tank aerosols and the release of radionuclides formerly trapped by the filter material. Some of the causes of HEPA filter failure include the clogging and subsequent blow-through of the filter media, and damage to the filter frame.

\subsubsection{Iank_Susceptibility Evaluation}

All tanks have ventilation systems, either passive or powered, that use HEPA filters. However, actively powered ventilation systems are mechanically more complex than passive ventilation systems, and are therefore susceptible to HEPA filter failures. The UOR database supports this conclusion. There have been no reported HEPA filter failures associated with the passive ventilation systems, while there have been several associated with the active ventilation systems.

There are several reasons for the lack of failures associated with the passive ventilation systems. First, as compared to the active ventilation systems, the pressure drop across the HEPA filter is far less because of the lack of forced air flow. Second, if the HEPA filter should plug, the passive ventilation systems have a loop seal pressure relief system that will permit air flow (see initiator RVB, ventilation line breach, for a discussion and quantification of loss of the loop seall. The loop seal pressure relief system is oil filled and resists evaporation and clogging. Consequently, HEPA filter failures for passively ventilated tanks are not modeled because of the expected very low annual frequency rate.

\subsubsection{Initiating Event Frequency Quantification}

Initiating event FB represents Hanford Tank Farm exhaust HEPA filter failure. The causes for $F B$ are the plugging of ventilation lines and the events categorized in the UOR database (Appendix D) as a "Filter blowthrough," (UOR36) or "Damage to the filter frame," (UOR37). The frequencies of these UOR categories were summed together to derive the initiating event frequency for a single exhaust HEPA filter failure. To arrive at the initiating event frequency for the active ventilation systems, the sum of the UOR database events frequencies must be multiplied by the number of active ventilation systems ( 8 ). The mean frequency per year for initiating event FB1 is calculated with the following equation:

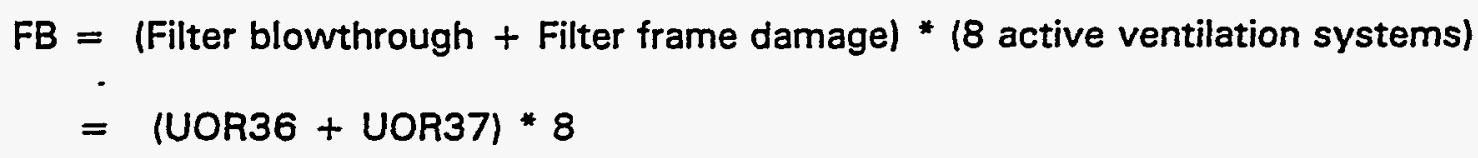




\section{$=$ 7.73E-01 per year for the Hanford Tank Farm site.}

\subsubsection{Accident Sequence Model}

Failure of the exhaust HEPA filter will result in a direct release path to the environment for tank aerosols and the release of any radionuclides trapped by the filter material. No subsequent events are required to produce a release. Therefore, the frequency of HEPA breach initiating event is mapped directly to release category HEPAL. HEPA failure could also result from other initiators such as BURP and is included in the models for those initiators.

\subsubsection{VENTILATION DRAINAGE SYSTEM LEAK}

Ventilation system drainage leak, VDL, is an initiating event where an active ventilation system's condensation drains are not returned to a tank but are released into the environment through a breach of piping.

\subsubsection{Tank Susceptibility Evaluation}

All tanks with active ventilation systems have a means to direct ventilation drains back to.a specified tank. Passive ventilation systems do not need to have a means to collect condensation because any condensation in the passive breather filter will naturally flow back into the tank from the exhaust duct. Furthermore, because there is no forced air flow, condensation does not build up in passively ventilated tanks. Only active ventilation systems are susceptible to drainage system leaks (see Table 4-8).

\subsubsection{Initiating Event Frequency Quantification}

The UOR database categories that apply to ventilation drainage leaks, VDL, include "Duct condensate leakage" (UOR38) and "Loop seal pot loss" (UOR40). These two event categories are summed together and multiplied by the number of active ventilation systems to arrive at the frequency per year of initiating event VDL. The equation used to calculate the initiating event frequency for the tank farm and the resultant mean frequency are shown below:

$$
\begin{aligned}
\mathrm{VDL} & =\quad \text { (Duct condensate leakage }+ \text { Loop seal pot loss }) *(8 \text { active vent systems }) \\
& =(\mathrm{UOR} 38+\text { UOR40 }) * 8 \\
& =2.24 \mathrm{E}-01 \text { per year for the Hanford Tank Farm site. }
\end{aligned}
$$

\subsubsection{Accident Sequence Model}

A ventilation drainage leak results in the spill of a small amount of contaminated liquid and aboveground. No subsequent events to produce a release. Therefore, the frequency of the ventilation drainage leak initiating event is mapped directly to release category SSP.

\subsubsection{LOSS OF ACTIVE VENTILATION FLOW}


The loss of active tank ventilation flow is defined as the interruption of tank ventilation due to a variety of causes. These causes range from the failure of exhauster fans, for actively ventilated tanks, to the clogging of HEPA filters.

\subsubsection{Iank Susceptibility Evaluation}

All tanks and tank farms with ventilation systems are susceptible to ventilation failures. Tanks or tank farms that have active ventilation systems require a motive force as well as considerable piping to ventilate the tank or tanks. Because of the added complexity of an active ventilation system, the annual failure rate for actively ventilated tanks is greater than for passively ventilated tanks (see quantification section below). Active ventilation is required for these tanks because the tanks either produce flammable gases or excess heat. Table 4-8 lists the actively ventilated tanks. All of the other tanks are passively ventilated, employing a simple filter and duct system.

\subsubsection{Initiating Event Quantification}

Three separate loss of tank ventilation initiators are quantified in this section: (1) LOTVA, loss of ventilation for actively ventilated tanks, excluding the aging waste tanks,

(2) LOTVAW, loss of ventilation for aging waste tanks, and (3) LOTVP, loss of ventilation for passively ventilated tanks.

Initiating event LOTVA models the plugging of ventilation lines and/or the failure of the exhaust fans (except for the aging waste tanks). Potential consequences of such an event are the heatup of waste that could cause unwanted chemical reactions or the accumulation of flammable or toxic gases in the dome space. The causes for LOTVA are categorized in the UOR database, (see Appendix D of Ref. 4-1), as "Loss of ventilation fan" (UOR30), "Inadequate ventilation" (UOR32), "Filter plugging" (UOR34), or "Deentrainer plugging" (UOR36). The frequency contributions from these UOR categories were summed together to arrive at the yearly initiating event frequency for a loss of ventilation in an actively ventilated tank. The following equation was used to calculate the LOTVA initiating event frequency:

$$
\begin{aligned}
\text { LOTVA }= & \text { (Loss of ventilation fan }+ \text { Filter plugging } \\
& + \text { Deentrainer plugging } *(7 \text { active ventilation systems }) \\
& +(\text { Inadequate ventilation }) *(43 \text { active ventilation tanks }) \\
= & (\text { UOR } 30+\text { UOR34+UOR35)*7+UOR32*43 } \\
= & 4.11 \text { per year for the Hanford Tank Farm site }
\end{aligned}
$$

The causes for loss of ventilation in the aging waste tanks (LOTVAW) are the same as listed above for LOTVA with the addition of UOR category "Accidental loop seal filling" (UOR28). The following equation is used to calculate the annual initiating event frequency for LOTVAW: 
LOTVAW $=$ (Loss of ventilation fan + Filter plugging

+ Deentrainer plugging) * (1 active ventilation systems)

+ (Inadequate ventilation + Accidental loop seal filling $) \cdot(4$ tanks $)$

$=($ UOR3O + UOR34 + UOR35) $* 1+($ UOR32 + UOR28)* 4

$=6.54 \mathrm{E}-01$ per year for the Hanford Tank Farm site.

Initiating event LOTVP models the plugging of the passive ventilation line. Passive ventilation is found on most of the single-shell tanks; 130 of the 177 tanks have passive ventilation. Due to the lack of failures experienced at the Hanford site given the number of years of experience with the passive ventilation system, initiating event LOTVP was quantified in the following way. Because the passive ventilation system is significantly less complex than an active ventilation system, the per-tank failure rate for the passive ventilation system was judgmentally assigned a failure rate 1000 times less than that of an active ventilation system. The initiating event frequency for LOTVP is therefore:

LOTVP $=((U O R 30+$ UOR34 + UOR35 + UOR32)/1000) *130 tanks

$=7.09 E-02$ per year for the Hanford Tank Farm site

\subsubsection{Accident Sequence Model}

For active ventilation tanks, a loss of ventilation flow would result in an equilibrium of internal tank pressure with the environment and the reduction of heat and flammable gas removal from the wastes. Loss of the normal negative tank pressure could allow dome space aerosols to escape into the atmosphere through the normal inlet leakage paths. The accident sequence model for initiating events LOTVA, LOTVAW, and LOTVP is discussed below.

4.2.7.3.1 LOTVA Accident Sequence Model. Loss of heat removal for those tanks with a high heat load would result in rising waste temperature. The peak temperature in Tank $101-\mathrm{SY}$, for example, is normally about $130^{\circ} \mathrm{F}$. If the temperature were to increase significantly, increased hydrogen production and enhanced aerosolization of wastes could result. A scoping level analysis of tank heatup for Tank 101-SY is presented in Appendix E.6 of Ref. 4-1. This analysis shows that several years without evaporative heat removal would be required for waste temperatures to reach levels of concern. Based on this finding and the knowledge that tank temperatures are regularly monitored, it can be concluded that loss of ventilation flow in Tank 101-SY is not of significant importance with respect to water heatup. As discussed under the BURP initiator, ventilation system availability following a bound gas release is important and is evaluated under that initiator.

Tank 106-C is the only single-shell tank that is on the Watch List for High Heat Production. For a 5-month period in 1992, ventilation was unavailable to this tank. Water additions that normally cause evaporative cooling in the tank were also not made during this period. At the end of the 5-month period, the tank temperature was still within acceptable limits. 
Therefore, it can be concluded that the lack of ventilation for single-shell tanks with a high heat load is not an important scenario and is not developed.

The potential for developing a vacuum in an actively ventilated tank that could threaten the structural integrity of the tank has been considered. Total loss of ventilation combined with the clogging of the ventilation paths is a potential scenario; however, the likelihood is very low. The ventilation inlet paths must all become sealed in order for the ventilation system to have an opportunity to draw a vacuum. Then, the exhauster fan must not trip due to high amperes. This combination of failures is too low to be considered.

Furthermore, if both inlet and outlet ventilation paths were to become blocked, and the ventilation system were to trip, a tank could become sealed. This scenario presents an opportunity for the tank to experience a vacuum if the outside air pressure were to rise. Again, this scenario will not be considered due to the multiple failures that must take place. For all of the double-shell tanks, the minimum design pressure is $-6-i n$ w.g.

(Reference 4-18, p. 3-15). The minimum design pressure applies to the tank when it is empty. Under this condition, the bottom of the tank is the weakest location. Given that all tanks have some liquid/sludge volume in them, it can be judged that the tanks can safely withstand negative pressures in excess of the design limit.

A loss of ventilation flow to an actively ventilated tank leads to loss of normal negative tank pressure and would allow dome space aerosols to escape into the atmosphere through the normal unfiltered inlet leakage paths. Therefore, initiating event LOTVA frequency is mapped directly to release category BPL.

\subsection{LOTVAW Accident Sequence Model. The aging waste tanks that are} double-shell tanks can produce more heat than tank 106-C, which is on the Watch List for High Heat production. Tank $106-\mathrm{C}$ is estimated to produce $150,000 \mathrm{Btu} / \mathrm{hr}$ (Reference 4-16), while $302,000 \mathrm{Btu} / \mathrm{hr}$ is estimated to be produced in the highest heat generating aging waste tank (Reference 4-15). If left unventilated, the aging waste tanks could heat up to temperatures high enough to cause boiling of the tank contents and cause increased generation of hydrogen. It is estimated that the steam generation rate could be as much as $460 \mathrm{ft}^{3}$ per minute, which is a high enough rate to sweep the generated hydrogen from the tanks vapor space (Reference 4-18) and prevent dome space hydrogen levels from reaching flammable levels. The boiling action would cause tank waste to become entrained with the vapors escaping into the atmosphere through the normal unfiltered inlet leakage paths. The analysis in Reference 4-18 estimated a release quantity of about $1.4 \mathrm{~kg}$ for this scenario. This analysis included several conservative assumptions, such as a heat generation rate $(700,000 \mathrm{Btu} / \mathrm{hr})$ of over twice the current maximum for the aging waste tanks, and that the air lift circulators were assumed to be unavailable as well as the ventilation flow. Even under these conservative assumptions, boiling is not expected to occur in the tank for 72 hours following the loss of ventilation, provided that operators had an opportunity to recover ventilation flow prior to boiling.

The event sequence model for LOTVAW takes credit for operator recovery of ventilation flow prior to the occurrence of boiling in the tank. If the recovery action is successful, the release is mapped to release category BPL. Scenarios with failure to recover ventilation are mapped to release category BPH. Note that the mean release quantity assumed for release category BPH is $1.8 \mathrm{~kg}$. The event tree used to quantify initiating event LOTVAW is presented as Figure 4-14. The following paragraph describes the single top event that 
appears in this event tree and the basis for the split fraction value used in the quantification.

\section{- Top Event ORV - Operator Recovers Primary Tank Ventilation}

This event assesses the successful recovery of ventilation flow to the aging waste tanks prior to boiling of the tank waste.

- Success Criteria. The operator must diagnose ventilation flow loss and successfully recover ventilation within 72 hours.

- Split Fraction Definition. Split fraction ORV1 represents failure of the operator to recover ventilation prior to boiling of tank waste.

- Quantification Modeling. The analysis of operator actions is presented in Appendix F of Ref. 4-1.

- Modeling Assumptions. None.

4.2.7.3.3 LOTVP Accident Sequence Model. Passively ventilated tanks breathe in and out through a single HEPA filter unit at a rate dictated by changes in barometric pressure. In the unlikely event that the HEPA filter became plugged to the point where these changes in pressure could not be accommodated, the tank could still breathe through the pressure relief loop seal. The loop seal provides a path for a small unfiltered release but protects the tank from implosion events caused by the development of a vacuum in the tank. The event sequence model maps the loss of ventilation in a passively ventilated tank initiating event directly to release category BPL.

\subsubsection{LOSS OF TANK MIXING}

The Loss of Tank Mixing Initiating Event (LOTM) models failure of the airlift circulators in the waste tanks. The airlift circulators are operated to mildly agitate the supernate, providing heat transfer from the waste solids that contain many of the fission products. In this manner, fission product decay heat is conducted into the liquid and carried off by evaporation. Failure of the air lift circulators can lead to localized heating and a subsequent tank bump; i.e., release of bound gas.

\subsubsection{Tank Susceptibility Evaluation}

Initiating event LOTM is applicable to the aging waste tanks only, where airlift circulators are operated to enhance heat removal.

\subsubsection{Initiating Event Frequency Quantification}

The "Aging Waste Facility Safety Analysis Report" (Reference 4-20) developed a detailed fault tree for failure of the aging waste tank airlift circulators. The result of this quantification was a frequency of 8.23E-02 per year. The dominant cutsets involved failure of an air supply valve on a process air supply header common to both tank farms AY and $A Z$, and human failures associated with the loss of the process air system or loss of air 
to an individual tank. Reference 4-20 suggests that some recovery actions could be modeled to reduce the frequency of some of the dominant cutsets, but the potential frequency reduction would be a factor of 2 of 3 only. For this analysis, a frequency of 8.23E-02 per year will be used for the LOTM initiator.

\subsubsection{Accident Sequence Módel}

Loss of tank mixing can lead to localized heating and a subsequent tank bump; i.e., release of bound gas. The frequency of Initiating event LOTM is negligible with respect to bound gas release events modeled for Tank SY-101; therefore, the bump phenomenon is not modeled for the LOTM event. The bump event could cause a temporary loss of negative tank pressure and allow dome space aerosols to escape into the atmosphere through the normal unfiltered inlet leakage paths; however, with the ventilation system operating, the release would be very small. Therefore, the frequency of initiating event LOTM is mapped directly to release category BPL.

\subsubsection{UNCONTROLLED HEATUP OF TANK WASTE}

Tank heatup was discussed in detail in Appendix E of Reference 4-1. Detailed tank heatup calculations revealed that the tank heatup process will not occur as long as the tanks have adequate water content or moisture level. This conclusion is also reached in Section 5.1 of Reference 4-18. In the presence of adequate water level or moisture content, water evaporation will not allow the temperature to exceed $100^{\circ} \mathrm{C}$. More than 89 of the 177 Hanford tanks have more than adequate moisture levels.

Further tank heatup calculations also revealed that for the remaining 88 tanks with no or possible inadequate moisture levels (indicating complete dryout), the temperature rise, if any, would be a very slow process. In the event of this slow temperature rise, uncontrolled heatup can only be expected if certain organic or ferrocyanides compounds are present and the ignition temperatures for these select organic reactions or ferrocyanide reactions are achieved. Ignition temperatures for organic and ferrocyanide reactions are $200^{\circ} \mathrm{C}$ and $285^{\circ} \mathrm{C}$, respectively. Currently, all tank temperatures are below $100^{\circ} \mathrm{C}$. Calculations reported in Appendix E of Ref. 4-1 for 241-SY-101 indicate that the time periods required for the slow temperature rise to reach ignition temperatures are in order of multiple months (and even years).

Current technical specifications for the Hanford waste tanks indicate that the temperatures for all tanks are routinely monitored. Tank temperatures are not allowed to exceed the specification limits prescribed for each tank. If tank temperatures are seen to increase (even a few degrees over these limits), then actions (as defined in the technical specifications) will be taken to reduce the temperature levels. One such prescribed action is to add water to the tank.

Scenarios involving lack of monitoring of tank temperatures for extended periods were judged to be improbable. It is highly unlikely that tanks with high organic or ferrocyanide content and/or high heat content will not be monitored for extended periods.

In light of the above discussion, accident scenarios involving uncontrolled heatup of tank waste are dismissed as improbable and not further quantified. 


\subsubsection{WATER INTRUSION}

Water intrusion is an initiating event during which water from precipitation, raw water system spills, or other sources, excluding waste transfers, inadvertently enters a waste tank.

\subsubsection{Tank Susceptibility Evaluation}

The susceptibility of a tank to water intrusion is a function of the degree of isolation of the tank, which is bounded by the following:

- If the tank is in service.

- If the tank is partially isolated.

- If the tank has undergone intrusion prevention.

If a tank is in service, all of the sources of water intrusion are available. Raw water is available; liquid from interfacing systems is available; and ventilation inlets or unsealed hatch covers are an intrusion pathway for precipitation, given enough rainfall. For this subset of tanks, no special mitigating features have been put in place. All 28 of the double-shell tanks are categorized as "in service"; however, because several are on the high hydrogen watch list, they are not allowed to receive waste. The capability to receive waste still exists, however. Initiating event WIA models this set of 28 in-service or active tanks.

If a tank has been partially interim isolated, all of the special precautions that are associated with intrusion prevention (see below) have been installed except for the following. These tanks are undergoing or are expected to undergo further interim stabilization efforts; i.e., pumping of liquids. Because of this intention, risers, pump pits, and piping that may be needed for pumping are still in place and are functional. This status applies to 51 tanks. Initiating event WIPI models this set of tanks.

For those tanks that are designated intrusion prevented, all transfer lines to and from the tank have been blanked off, and hatch covers have been sealed. This prevents any unplanned introduction of liquids into the tank. There are 98 intrusion-prevented tanks. Initiating event WIIP models water intrusion for this set of tanks.

\subsubsection{Initiatino Event Frequency Quantification}

WIA is a water intrusion event into a tank that is still in service. The UOR database categories that apply to this event and that were used to quantify WIA are "Surface water intrusion" (UOR18), "Raw water leak intrusions" (UOR19), or "Intrusions from interfacing systems" (UOR21). The frequencies of these UOR events were summed together and then multiplied by the number of active tanks $(28)$ to derive the initiating event frequency for a water intrusion event into an in-service tank at the Hanford Tank Farm. The equation used for this calculation and the WIA initiating event mean frequency is shown below:

$W I A^{-}=\quad$ Surface water intrusion + Raw water leak intrusions 


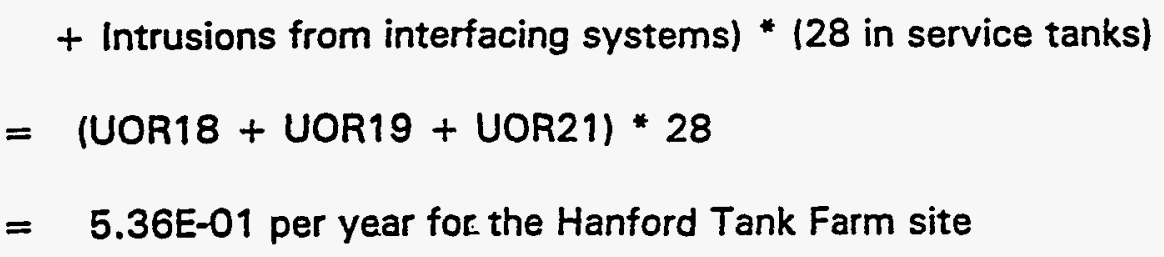

WIPI is a water intrusion event into a tank that has been partially interim isolated. The UOR database categories that were used to quantify WIPI are "Surface water intrusion" and "Raw water leak intrusions." The frequencies of these UOR events were summed together and then multiplied by the number of partially interim isolated tanks (51) to derive the initiating event frequency for a water intrusion event into a partialiy interim isolated tank at the Hanford Tank Farm. The equation used for this calculation and the WIPI initiating event mean frequency is shown below:

$$
\begin{aligned}
W I P I & =\text { (Surface water intrusion }+ \text { Raw water leak intrusions) * (51 P.I. tanks) } \\
& =(\text { UOR18 }+ \text { UOR19) } * 51 \\
& =4.95 E-01 \text { per year for the Hanford Tank Farm site }
\end{aligned}
$$

WIIP is a water intrusion event into a tank that has been water intrusion prevented (formerly interim isolated). The UOR database category that was used to quantify WIIP is "Intrusion into an interim isolated tank" (UOR22). The frequency of this UOR event was then multiplied by the number of intrusion-prevented tanks (98) to derive the initiating event frequency for a water intrusion event into an intrusion-prevented tank at the Hanford Tank Farm. The equation used for this calculation and the WIIP initiating event mean frequency is shown below:

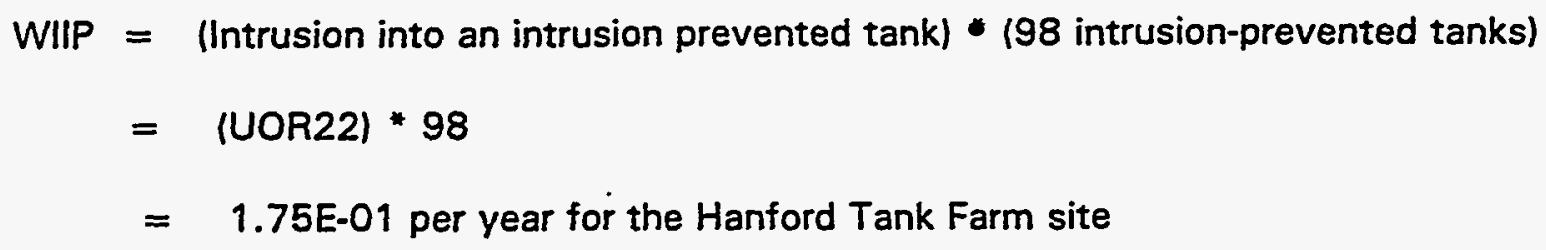

\subsubsection{Accident Sequence Model}

The accident sequence model considers three possible outcomes for water intrusion events. If the intrusion is of limited volume, or is detected and mitigated by the operator, no release occurs. If the tank level is high enough such that an overflow is possible, and operators do not detect and mitigate the intrusion, a small surface spill will occur. Water intrusion into a confirmed leaker results in additional subterranean leakage from the tank.

The most-full tanks in the Hanford Tank Farm are the in-service tanks. These are the double-shell tanks. Of those tanks, 101-SY is representative of the in-service tanks in terms of the volume of waste they contain. Water intrusion to Tank 101-SY could result from precipitation runoff or raw water from a broken line or other cause leaking into the tank through the unsealed hatch covers. Even though Tank 101-SY is filled to near its working limit, an intrusion of about 200,000 gallons would be needed to overflow the tank. An intrusion of this volume would take many hours or even days to reach overflow, thus 
providing an opportunity for operator detection and intervention to stop the intrusion before overflow. In addition, many intrusion sources will not be large enough to produce overflow even if unchecked.

Water intrusion into a waste tank that is a confirmed leaker can lead to continued or increased leakage from the tank. With the exception of several of the $55-\mathrm{kgal}$ capacity (200 Series) tanks, all of the confirmed leakers (10 partially interim isolated and 56 intrusion prevented) have over $200-\mathrm{kgal}$ remaining capacity available before an intrusion event could overflow the tank and cause a surface spill. Therefore, the accident sequence model assumes that a water intrusion into a "leaker" leads directly to the small leak (SLK) release category.

Another possible side effect of a water intrusion is a BURP event. A candidate for this event is Tank 101-SY. Sludge dilution caused by the intrusion of water could cause this event. Assuming that all water intrusion events cause a BURP, the frequency of water intrusion BURP events would be about one half of one percent of the frequency of a spontaneous BURP (prior to the mixing operations now being performed on 101-SY). Thus, risks from water intrusion BURPs are judged to be enveloped quantitatively by the BURP initiator.

The event sequence diagram and corresponding event tree for water intrusion and overflow are presented as Figures 4-15 and 4-16. This model is used to quantify the WIA, WIPI, and WIIP initiating events. The following paragraphs describe each top event, the split fractions required for each initiating event, and the approach used in quantification of the split fractions. Split fraction definitions and values for each top event and the event tree quantification results are presented in Section 4.3.

- Top Event LEAK - Tank is a Confirmed Leaker?

- Success Criteria. Tank is not a confirmed leaker.

- Split Fraction Definition. Three split fractions (LEAK1, LEAK2 and LEAK3) are defined for this top event, one split fraction corresponding to each of the three water intrusion initiating events, WIA, WIPI, and WIIP, respectively.

- Quantification Modeling. The split fraction values are calculated as the fraction of tanks in a given category (e.g., active, partially isolated, or intrusion prevented) that are confirmed leakers, divided by the total number of tanks in the category. The equations used to calculate the split fractions are presented below:

LEAK1 (fraction confirmed leakers, active tanks) $=0 / 28$

LEAK2 (fraction of confirmed leakers, PI tanks) $=8 / 51$

LEAK3 (fraction of confirmed leakers, IP tanks) $=48 / 98$

- Top Event LEVEL - Tank Level Remains Within Limits?

- Success Criteria. Tank level must remain below the operating limit at all times. 
- Split Fraction Definition. Three split fractions for Top Event LEVEL are needed for quantification of the water intrusion initiating events. These failure fraction represent the fraction of water intrusion initiating events that would cause a tank overflow. Split fractions LEVEL1, LEVEL2, and LEVEL3 are used for initiators WIA, WIPI, and WIIP, respectively.

- Quantification Modeling. If the tank experiencing a water intrusion is a confirmed leaker, Top Event LEVEL is not questioned in the event tree. Since none of the water intrusion events that have occurred at the site have caused a tank to overflow, a value of 0.1 was conservatively used for all active tanks; i.e., for initiating event WIA. This value is very conservative for tanks that have a large volume of remaining capacity, but these tanks are, by definition, active and may be filled to near capacity in the near future.

For water intrusion event into partially isolated (WIPI) or intrusion-prevented (WIIP) tanks, it can be assumed that the volume of waste in the tanks will remain the same or decreased in the future as stabilization and jet pumping efforts continue. The 0.1 value used for initiating event WIA is overly conservative for initiators WIPI and WIIP. Therefore, the split fractions used to quantify initiators WIPI and WIIP assume that tanks with 300,000 gallons or more of remaining capacity have no chance of going over operating limits due to water intrusion events. Water intrusion events into tanks with less than 300,000 gallons of remaining capacity are given a 0.1 chance of exceeding the tank operation limit. The equations used to calculate split fractions LEVEL1, LEVEL2, and LEVEL3 are presented below.

LEVEL $1=$ PROBL

LEVEL2 $=\left(\right.$ NPIL ${ }^{*}$ PROBL + NPIH*PROBH) $/($ NPIL + NPIH $)$

LEVEL3 $=\left(\right.$ NIPL ${ }^{*}$ PROBL + NIPH*PROBH)/(NIPL + NIPH)

where

NPIL = number (21) of pi tanks (nonleakers) with low remaining capacity

(less than $300 \mathrm{kgal}$ ).

NPIH $=$ number (20) of pi tanks (nonleakers) with high remaining capacity (more than $300 \mathrm{kgal}$ ).

NIPL $\quad=$ number (13) of ip tanks (nonleakers) with low remaining capacity

(less than $300 \mathrm{kgall}$.

NIPH $\quad=\quad$ number (29) of ip tanks (nonleakers) with high remaining

capacity (more than 300 kgal). 


$$
\begin{aligned}
& \text { PROBL }=\quad \begin{array}{c}
\text { probability }(0.1) \text { of exceeding tank Limits given low remaining } \\
\text { capacity (less than } 300 \mathrm{kgal}) .
\end{array} \\
& \text { PROBH }=\ldots \cdot \begin{array}{l}
\text { probability }(0.0) \text { of exceeding tank Limits given high remaining } \\
\text { capacity (more than } 300 \mathrm{kgal}) .
\end{array}
\end{aligned}
$$

- Modeling Assumptions. If overfilled waste liquids exit the tank through the pump pit risers, enter the pump pit, and overflow onto the ground from the pump pit hatch covers.

- $\quad$ Top Event $\mathrm{LI}$ - Tank Level Indication Operates

This event is questioned on scenarios that could lead to a tank overflow to determine if tank level indication is available to the operators. If level indication is operable, operator intervention to prevent the overflow is questioned.

- Success Criteria. Continuous, accurate level indication must be provided to the CASS in building 2750-E.

- Split Fraction Definition. Three split fractions (LI1, LI2 and LI3) are defined : for this top event. One corresponding to each of the three water intrution initiating events, WIA, WIPI and WIIP, respectively.

- Quantification Modeling. Level indication availability is approximated from the WHC short-term equipment condition report (see Table D-2 of Appendix $D$ of Ref. 4-1). All of the double-shell tank farms (i.e., the active tanks) are given a condition code of 3 for level/intrusion instrumentation except for the four aging waste tanks that received a condition code of 2 . Therefore, split fraction LII (used for the WIA initiator) was calculated as the weighted average of the failure rates associated with condition codes 2 and 3. All of the single-shell tank farms are given a condition code of 3 for level/intrusion instrumentation except for tank farms $A$ and $A X$, which received a condition code of 2 . The split fractions used in the quantification of initiators WIPI and WIIP (i.e., LI2 and L13, respectively) were calculated in the same manner as split fraction LI1. The equations used to calculate split fractions LI1, LLI2, and LI3 are shown below:

$$
\begin{aligned}
\mathrm{L} 11 & =(@ N A 2 * @ 02+\text { + } \\
& =0.229 \\
\mathrm{LI} 2 & =\left(@ N P 3^{*}\right. \text { @Q3)/(@NA2 + @NA3) } \\
& =0.166 \\
\mathrm{LI3} & =(\text { @NIP2*@Q2 + @NIP3*@Q3)/(@NIP2 + @NIP3) } \\
& =0.143
\end{aligned}
$$


where

$$
\begin{aligned}
\text { NA2 }= & \text { number (4) of active tanks with level/intrusion instrument } \\
& \text { status code } 2 . \\
\text { NA3 = } & \text { number (24) of active tanks with level/intrusion instrument } \\
& \text { status code } 3 . \\
\text { NPI2 = } & \text { number (3) of partially isolated tanks (nonleakers) with } \\
& \text { level/intrusion instrument status code } 2 . \\
\text { NPI3 = } & \text { number (38) of partially isolated tanks (nonleakers) with } \\
& \text { level/intrusion instrument status code } 3 . \\
\text { NIP2 = } & \text { number (2) of intrusion-prevented tanks (nonleakers) with } \\
& \text { level/intrusion instrument status code } 2 . \\
\text { NIP3 = } & \text { number (40) of intrusion-prevented tanks (nonleakers) with } \\
& \text { level/intrusion instrument status code } 3 . \\
\text { Q2 }= & \text { unavailability (1.0) of systems with condition code } 2 . \\
\text { Q3 = } & \text { unavailability (0.1) of systems with condition code } 3 .
\end{aligned}
$$

- Modeling Assumptions. None.

- Top Event OP - Operator Responds to Increasing Tank Level and Prevents a Release

Given that level indication is available, this top event assesses the success of operator intervention to prevent tank overflow.

- Success Criteria. The operator must diagnose potential tank trouble and initiate the actions required to prevent the tank overflow and release of radionuclides. The potential accident scenario must be proceeding slowly enough to allow operator intervention.

- Split Fraction Definition. Split fraction OP1 represents failure of the operator to intervene given a water intrusion event with level indication available.

- Quantification Modeling. The analysis of this operator action is presented in Appendix F of Ref. 4-1.

- Modeling Assumptions. None.

\subsubsection{WASTE TRANSFER}


During waste transfers, radioactive liquid waste is moved from one location to another along a prescribed route. Waste transfers are performed to mitigate a loss of tank integrity, and accommodate changing processing requirements and storage needs.

\subsubsection{Tank Susceptibility Exaluation}

Events have occurred during waste transfers that directly involved the tanks. As stated in Section 4.2.2.2, 12 of the 68 documented tank leaks were actually transfer leaks at the tanks. These events included tank overfill, leaks through open flanges (i.e., tank construction errorsl, and undesired reactions after transfer. Over the course of tank farm operations, procedures have improved, allowing tank volumes and waste characteristics to be carefully monitored, thus eliminating the root cause of several of these events.

Additionally, new waste generation has ceased, and many of the tanks cannot receive or discharge waste. Therefore, waste transfer leaks are assumed to occur in the transfer lines rather than at the tanks themselves.

The tank susceptibility evaluation is used to determine the tanks that are capable of receiving or discharging waste. All 28 double-shell tanks are "in service" and are considered capable of receiving or discharging waste. Several of the double-shell tanks are on the high hydrogen watch list and are not allowed to receive waste, but the capability to receive waste exists.

Of the 149 single-shell tanks, 98 are "intrusion prevented" with all transfer lines to and from the tanks blanked off. The remaining 51 single-shell tanks are "partially interim isolated" and are capable of having waste pumped from them during stabilization activities.

\subsubsection{Initiating Event Frequency Quantification}

The waste transfer initiating event is designated WT. The frequency of WT was based on the assumed number of waste transfers per year used in the creation of the Hanford Waste Tank Farm Unusual Occurrence (UOR) database shown in Appendix D.1 of Ref. 4-1. The mean frequency of initiating event WT is 1,000 transfers per year.

\subsubsection{Accident Sequence Model}

The accident sequence model considers five possible outcomes for waste transfer events. A successful outcome (SUCCESS) is considered to be a waste transfer that does not release waste into the environment. If a transfer line leak occurs in the waste transfer system, it is assumed to cause at least a small spill (SSP). If an area radiation monitor (ARM) does not detect the increase in radiation due to the leak, the leak is assumed to continue and cause a large spill (LSP). If a spray leak occurs within a confined pump or double-contained receiver tank (DCRT) pit, it is not assumed to release waste into the environment since these pits are equipped with drains. If the spray occurs in a pit in which one or more cover blocks is removed, it is assumed to cause at least a small spray (SSPRY) release. If an area radiation monitor (ARM) does not detect the increase in radiation due to the spray leak, the spray leak is assumed to continue and cause a large spray (LSPRY) release. 
Waste misrouting is also considered in the accident sequence model. The results of misrouting can cause (1) no release or other adverse impact, (2) a direct release of waste to the environment through an open line, or (3) a release through a transfer line leak. Based on the analysis in Reference 4-21, it is not assumed that misrouting will cause criticality, or other waste stability events. As discussed in Section 4.2.11.1, it also assumed that tank overfill events will not occur as the result of waste transfers or misrouting.

The resulting event sequence diagram and event tree for waste transfers are shown in Figures 4-17 and 4-18. This model is used to quantify the WT initiating event. The following paragraphs describe the top event and split fractions required for initiating event WT, and the approach used to quantify the split fractions. Split fraction definition and their values and the results of the event tree quantification are presented in Section 4.3.

- Top Event ROUTE - Was the Waste Transfer Routed Properly?

- Success Criteria. The waste transfer was route correctly.

- Split Fraction Description. One split fraction (ROUTE1) is defined for this top event.

- Quantification Modeling. The split fraction value is calculated as the fraction of waste transfers that resulted in misrouting divided by the total number of waste transfers. The equation used to calculate split fraction ROUTE1 refers to frequencies from the UOR database in Appendix D.1 of Ref. 4-1 and is given below:

$$
\begin{aligned}
\text { ROUTE1 }= & \text { (UOR1*28+UOR2*28+UOR3+UOR4+ UOR5 } \\
& + \text { UOR6*28+UOR7*28)/WT }
\end{aligned}
$$

where

$$
\begin{aligned}
& \text { UOR1 = } \begin{aligned}
& \text { number of tank-to-tank misroutings per double-shell tank } \\
& \text { per year ( } 28 \text { double-shell tanks). }
\end{aligned} \\
& \text { UOR2 = } \\
& \begin{aligned}
\text { number of misroutings to a valve pit of diversion box per } \\
\text { double-shell tank per year ( } 28 \text { double-shell tanks). }
\end{aligned} \\
& \text { UOR3 = number of misroutings to a crib per year. } \\
& \text { UOR4 = number of misroutings to blanked lines per year. } \\
& \text { UOR6 = number of misroutings to the environment per year. } \\
& \text { double shell tank per year ( } 28 \text { double-shell tanks). }
\end{aligned}
$$




$$
\begin{aligned}
& \text { UOR7 }= \text { number of inadvertent tank gravity drain events per } \\
& \text { double-shell tank per year ( } 28 \text { double-shell tank). }
\end{aligned}
$$

WT = number of transfers per year.

- Model Assumptions. None.

- Top Event CRIB - Was the Waste Transfer Misrouted to a Crib?

- Success Criteria. The waste transfer did not result in a leak into the environment in a crib or overflow of a pit.

- Split Fraction Description. One split fraction (CRIB1) is defined for this top event.

- Quantification Modeling. Top Event CRIB is only questioned if Top Event ROUTE has failed. The split fraction value is calculated as the fraction of misrouted waste transfers that resulted in leaks to the environment, cribs, or valve pits divided by the total number of misrouted waste transfers. The equation used to calculate split fraction CRIB1 refers to frequencies from the UOR database in Appendix D. 1 of Ref. $4-1$ and is given below:

$$
\text { CRIB1 }=(\text { UOR2 } * 28+\text { UOR3 }+ \text { UOR5) NTTROUTE1 }
$$

where

$$
\begin{aligned}
& \text { UOR2 = number of misroutings to a valve pit of diversion box per } \\
& \text { double-shell tank per year ( } 28 \text { double-shell tanks). } \\
& \text { UOR3 = number of misroutings to a crib per year. } \\
& \text { UOR5 = number of misroutings to the environment per year. } \\
& \text { WT } \quad=\text { number of transfers per year. } \\
& \text { ROUTE1 = number of misroutes per transfer. }
\end{aligned}
$$

- Modeling Assumptions. Tank-to-tank misroutings, misroutings to blanked lines, inadvertent pumped waste transfers, and the inadvertent gravity drain of waste are not assumed to cause a leak into the environment. A misrouting of waste to a valve pit is conservatively assumed to cause at least a small spill.

- Top Event TLL - Transfer Line Leak?

- Success Criteria. There was no leak in a waste transfer line.

- Split Fraction Description. One split fraction (TLL1) is defined for this top event. 
- Quantification Modeling. The split fraction value is calculated as the fraction of waste transfers line leaks divided by the total number of waste transfers. The equation used to calculate split fraction TTL1 refers to frequencies from the UOR database-in Appendix D.1 of Ref. 4-1 and is given below:

$$
\text { TLL1 }=\text { (UOR56 + UOR57 + UOR58) NT }
$$

where

$$
\begin{aligned}
& \text { UOR56 }=\text { number of stabilization line leaks per year. } \\
& \text { UOR57 }=\text { number of transfer line leaks per year. } \\
& \text { UOR58 }=\text { number of slurry line leaks per year. } \\
& \text { WT } \quad=\text { number of transfers per year. }
\end{aligned}
$$

- Modeling Assumptions. All line leaks used to calculate split fraction TTL1 are assumed to cause at least small spills. Jumper line leaks are included in the model for Top Event SPRAY.

- Top Event SPRAY - Dịd a Spray Leak Occur?

- Success Criteria. There was no spray leak in a DCRT or pump pit.

- Split Fraction Description. One split fraction (SPRAY1) is defined for this top event.

- Quantification Modeling. The split fraction value is calculated as the fraction of waste transfers that resulted in spray leaks divided by the total number of waste transfers. The equation used to calculate split fraction SPRAY1 is given below:

$$
\text { SPRAY1 }=\text { UOR59 } / W T
$$

where

$$
\begin{aligned}
& \text { UOR59 }=\text { number of jumper line leaks per year. } \\
& \text { WT } \quad=\text { number of transfers per year. }
\end{aligned}
$$

- Modeling Assumptions. In many transfer lines, flow rates are not sufficient to cause spray leaks. Flow rates directly downstream of transfer pumps, however, can be high enough to produce a spray if a leak occurred. While the UOR database does not make mention of spray leaks, it does indicate that there was one jumper line leak. Since jumper lines are used primarily in pump and valve pits, and jumper misalignment is assumed to be a significant 
contributor to spray leak occurrence, it was assumed that the event was a spray leak.

Top Event COVER - Were the Cover Blocks in Place?

- Success Criteria. The DCRT or pump pit cover blocks were in place.

- Split Fraction Description. One split fraction (COVER1) is defined for this top event.

- Quantification Modeling. Top Event COVER is only questioned if Top Event SPRAY is failed. The split fraction value is determined through engineering judgment. A conservative point estimate value of 0.1 is used due to the lack of documentation concerning cover block placement procedures during waste transfers. If operating procedures involving the placement of cover blocks during waste transfers exist, this value could be reduced significantly.

- Modeling Assumptions. It is assumed that a spray leak occurring in a confined pit will not cause a spill, due to drains and leak detection equipment.

- Top Event ARM - Did the Area Radiation Monitor Alarm?

- Success Criteria. The ARM alarmed on high radiation due to the leak.

- Split Fraction Description. Two split fractions (ARM1 and ARM2) are defined for this top event. Split fractions ARM1 and ARM2 apply to transfer line leaks and spray leaks, respectively.

- Quantification Modeling. The split fraction values are determined through engineering judgment. A conservative point estimate value of 0.1 is used due to the uncertainty in the placement of the ARM relative to the transfer line leak. If an unconfined spray leak occurs (cover blocks not in place), it is assumed that the probability of ARM detection failure will decrease to a point estimate value of 0.05 .

- Modeling Assumptions. Refer to Quantification Modeling.

\subsubsection{CRITICALITY}

Recently concluded studies (Reference 4-22) indicate that criticality and the associated release of energy and fission products cannot occur in any of the 177 tanks in the Hanford Tank Farm. The question of criticality resulting from concentrations of fissionable materials (primarily plutonium) produced during the defense materials processing era was identified as an Unreviewed Safety Question (USQ) in April 1992.

Although future activities such as pretreatment and retrieval of wastes will require additional analyses to provide nuclear criticality safety, existing operations were found not to contribute to risk. 


\subsubsection{SEISMIC RESPONSE ANALYSIS}

A seismic response assessment was performed on a double-walled waste storage tank, associated equipment pits, tank gas exhaust ductwork system, and support facilities. The assessment consisted of the following:

- Seismic Hazard Analysis. Determination of the frequency of various potential peak ground accelerations at the site.

- Fragility Analysis. Determination of the seismic-initiated peak ground acceleration at which plant structures and components are predicted to fail.

- Accident Sequence Model. Development of a logic model that depicts the potential component failure scenarios, considering possible combinations of associated equipment or structure failures.

- Preliminary Quantification and Results. Assembly of seismic hazard, fragilities, and models, and the quantification of the frequency of causing sufficient damage to release hazardous materials, as well as identification of dominant contributors.

- Final Quantification. Calculation of uncertainty in the damage and release frequency. The seismic uncertainty analysis was not performed in this study because the contribution to total risk owing to seismic events was negligible compared to nonseismic-initiated events.

A summary of the quantification process and the results are presented in the following sections.

\subsubsection{Seismic Hazards}

A seismic hazard analysis was performed by Woodward-Clyde Consultants (WCC) in April 1989 for a number of nonreactor locations at the Hanford Reservation

(Reference 4-23). In addition, a seismic hazard evaluation was performed by Sandia National Laboratories (SNL) in November 1990 as part of an analysis of external events effects at the $N$ Reactor site (Reference 4-24). Rather than initiate new seismic hazard studies for this tank assessment project, it was decided to use both of the earlier studies, being satisfied that within the uncertainty of seismic hazard predictions, the use of the studies should be quite acceptable.

The SY Tank Farm is located in Site 1 at Hanford. The WCC study predicted peak ground acceleration frequencies at six Hanford sites, including Site 1 and Site N, the location of the N Reactor, which is the subject of Reference 4-24. As in other contemporary probabilistic hazard studies, the WCC results were based on: (1) the location and geometry of earthquake sources relative to the site, (2) the recurrence of earthquakes of various magnitudes on the sources up to the maximum magnitudes for each source, and (3) the attenuation of ground motions from the sources to Site 1 . The source models and attenuation relationships that were developed earlier by WCC in the seismic hazard studies for the WNP-2 nuclear power plant, which is located in the region, and for the N Reactor 
studies performed earlier in 1987, were used in the WCC 1989 study. The uncertainty in the source models and attenuation relationships in these studies was embedded in the 1989 study.

Figure 4-19 presents the overall-site plan and indicates the proximity of Sites 1 and $\mathrm{N}$ to each other. Table 4-9 presents the annual mean number of events exceeding the peak accelerations at Site 1 and Site N. Figure 4-20 presents the mean hazard curve for Site 1 in graphical form. These three exhibits were taken directly from Reference 4-23. It can be seen from this information for Site 1 that, although the curve is represented as the mean curve, the uncertainty about the curve is not represented, nor was it included in Reference 4-23 or available elsewhere (Reference 4-25). However, the 1990 SNL study calculated an uncertainty distribution about the mean for the $N$ Reactor site. By comparing in Table 4-9 the results for Site 1 and Site $N$, it can be seen that there is a similarity in the annual probability of exceedance between the two sites. Therefore, it was judged reasonable to apply the uncertainty distribution about the Site $\mathrm{N}$ mean curve to the Site 1 mean curve. This is seen in Figure 4-21, which also shows the extrapolation of the hazard curves to an annual exceedance frequency of $1 \mathrm{E}-07$. The extrapolated curves were used in this analysis.

To develop point estimates of scenario frequencies, it is necessary to divide the mean frequency curve into a number of incremental ranges of acceleration. Five ranges were judged to be ample to reflect the curve shape. Table 4-10 presents the mean frequency for the increments of acceleration ranges. These ranges are each given a designated acceleration for ease of reference, which was used in the analysis along with the mean frequency within the range. The lower bound acceleration is discussed in

Section 4.2.13.2. The upper bound at an acceleration of approximately $1.3 \mathrm{~g}$ is limited by the mean frequency of 1E-07 per year because values lower than this are of little interest in the tank farm risk assessment.

\subsubsection{Eragility Analyses}

Fragility analyses of Tank 101-SY and of associated facilities and of the 241-AX single shell tanks are included as Appendix $B$ to this report. These analyses are applied generically to all double and singe-shell tanks, respectively. A summary of these analyses and the results are presented here.

4.2.13.2.1 Fragility Curve Formulation. Seismic-induced failure data are generally unavailable for specific plant components or structures. Thus, the peak ground acceleration at which the component is expected to fail must be determined primarily from analysis and engineering judgment supported by limited test data. See Appendix $C$ of Ref. 4-1 for a detailed description of the fragility curve formulation.

4.2.13.2.2 Structure and Equipment Fragilities. The approach used to analyze fragilities relied on existing reports, drawings, photographs taken by others in the field, and seismic capacity calculations performed by others. The following components were evaluated as part of the double-shell tank (i.e., Tank 241-SY-101) analysis:

- Primary Tank

- Secondary Tank 


- $\quad$ Exhaust Ductwork
- Exhaust Fan
- $\quad$ Instrical Panels
- Offsite Power
- Piping

Possible failure modes were evaluated for each of the components, recognizing that for a single component, alternative failure modes are not independent; that is, one failure mode will likely influence other failure modes of that component. Therefore, the capacity of a component was determined to be that of the most likely failure mode that would result in the same type of release as other modes.

The fragility analysis of the single-shell tanks (as represented by the 241-AX tanks) evaluated the seismic capacity of the tank itself. No other associated facilities were evaluated since the single-shell tanks are passively operated.

A review of the mean seismic hazard curve in Figure 4-21 indicates that the annual frequency of a $1.0 \mathrm{~g}$ peak ground acceleration is less than 1E-06. Where it could be shown that the median capacity of a component is greater than $1.0 \mathrm{~g}$, and therefore the unconditional failure frequency is approaching 1.0E-07 per year, no further analysis was conducted.

The results of the fragility analyses are presented in Table 4-11. Besides the values of $\$, \beta$ $R$, and $\beta_{U}$ that define the fragility family for each component (as defined in Appendix C), the high confidence, low probability of failure (HCLPF) value is also shown. the HCLPF is the value at which there is a $95 \%$ probability that there is no greater than a $5 \%$ chance of failure, or essentially less than a $1 \%$ chance of failure. By scanning the components for the lowest HCLPF value, it was determined that there is no need to include failure contributions below $0.10 \mathrm{~g}$ because none of the components would fail below that value. Thus, $0.10 \mathrm{~g}$ was established in Table 4-10 as the lower bound acceleration of interest.

\subsubsection{Accident Sequence Model}

It can be seen from the fragility analyses that only offsite power, electrical panels, instrument racks, the primary tank of the DSTs, and the tank of the SSTs can fail within the possible acceleration levels. The unconditional frequency per year of failing these components for each of the seismic acceleration ranges is shown in Table 4-12. The safety assessment performed for double shell tank 241-SY-101 (see Reference 4-1), showed that seismic failures of offsite power, electrical panels, instrument panels, and the primary shell of SY-101 were insignificant contributors to public health or economic risks. This was due to the low frequency of the seismic induced failures and also by the relatively minor consequences associated with these failures. Failure of the primary shell integrity could lead to a large spill of waste material but only if the secondary shell (with a median acceleration greater than 1.0 ) is simultaneously breached which is very unlikely. Therefore, the risks due seismic failures impacting the double shell tanks will not be developed further in this report. 
The comments made above with respect to the seismic risks associated with the double shell tanks, in general apply to the single shell tanks as well. The availability of electric power and instrument controls are even less important with respect to risk for the single shell tanks since nearly all of the 149 SSTs are passively ventilated.

The failure mode that requires a more rigorous evaluation for the SSTs is failure of tank integrity. As described in the fragility analysis of the 241-AX tanks in Appendix B, this failure mode involves structural failure near the rim of the tank wall leading to a collapse of the dome, i.e., Release Category DCL. The collapse of a single tank dome at a frequency of 2.71E-06 is not significant compared to other scenarios included in this report, but the seismic event challenges the integrity of all 149 SSTs at the site simultaneously, increasing the probability that at least one, and possibly many of the SST domes collapse. Therefore, the frequency per year of failing 1,2,3 or more tanks, up to 149, due to seismic events must be calculated. The quantification process can be summarized by the following three steps:

1. Calculate the conditional failure fraction for collapse of the SST dome based on the fragility curve formulation presented in Appendix C. Failure fractions must be calculated for each of the acceleration ranges defined in Table 4-10.

2. Based on the failure fractions calculated in step 1, calculate the probability of failing 1 to 149 of the SSTs for each of the acceleration ranges. The binomial distribution was used to calculate the probability of failing " $n$ " tanks.

3. Using the mean annual frequencies listed in Table 4-12 for the occurrence of seismic events, and the tank failure probabilities calculated in step 2, calculate the annual frequency of collapse of 1 to 149 SST domes. These frequencies can then be summed across all acceleration ranges to calculate the frequency of tank failures ( 1 to 149 ) caused by seismic events.

The binomial model used in step 2 to calculate the probability of " $n$ " tank failures assumes that the failure probability is a constant for each tank, and that the tank failures are independent of each other. The assumption of independence from tank to tank is judged to be valid for a given seismic event, but, as explained in Appendix C of Ref. 4-1, earthquakes causing the same peak ground acceleration at the site can have different energy contents and durations. The magnitude of these factors varies randomly, and therefore, the effects on the SSTs at the same acceleration but from different earthquakes differ. This leads to the formation of a family of curves used to represent the fragility of a component. Therefore, instead of calculating failure fractions for dome collapse based on the mean fragility curve in step 1, failure fractions were calculated using five distinct curves from the family of fragility curves representing SST dome collapse. The 95th, 80th, 50th, 20th and 5 th percentile curves were used in the calculation and are displayed along with the mean curve in Figure 4-22. Failure fractions were conservatively calculated at the upper bound of the acceleration range.

In step 2 above, the binomial distribution was used to calculate the probability of failing 1 to 149 tanks using five values for the failure probability at each acceleration level, one from each of the five percentile curves shown in Figure 4-22. Mean values for the 
conditional probability of failing " $n$ " tanks are then calculated as the weighted average of five resultant probabilities.

\subsubsection{Accident Sequence Quantification}

The dome collapse of a single shell tank leads directly to a release of tank aerosols to the atmosphere and spilling of waste material above ground caused by collapse of the dome into the tank. This corresponds to Release Category DCL. The amount of material released due seismic events leading to SST dome collapses will be proportional to the number of tanks failed. The results of the seismic quantification are presented in Section 4.3.

\subsubsection{AIRCRAFT CRASH}

The frequency of a large aircraft crash 175,000 lbs or greater) crashing into a tank in the Hanford area was quantified for Tank SY-101 in the report "Risk Assessment for Hanford High Level Waste Tank 241-SY-101 (Ref. 4-1)." The aircraft crash was assumed to result in dome collapse of the tank, spill of jet fuel into the tank, and subsequent fire involving jet fuel and tank waste. As such a fire could cause waste material to be dispersed over a wide area, producing a severe release, a separate release category (DCVH) was defined. The frequency of aircraft crash initiating event was directly mapped to this release category DCVH. The frequency distribution was quantified in Table 4-13.

As the aircraft crash frequency distribution developed for Tank SY-101 was based on information generic to the entire Hanford Tank Farm area, this aircraft crash frequency distribution is equally applicable to all 177 Hanford tanks. Thus, each of the 177 Hanford tanks could be expected to have an aircraft crash and fire frequency shown in Table 4-13.

However, as the tank contents in each of the 177 Hanford tanks differ, the response to the fuel fire would be different. While some of these tanks are moist like SY-101 (i.e., with adequate moisture contents or a layer of supernatant liquid), other tanks are dry with little or no moisture content. While one can expect the moist tank contents to have the same response as SY-101 tank contents to the aircraft crash and fire, the response of the dry tanks could be different. Presence of water allows the heat from the fire to be dissipated as latent heat of water, and, thus, most of the heat generated from the ensuing fuel fire is consumed in boiling off the water or moisture content. This boiling mechanism limits the heatup and temperature rise in the tank wastes. For the dry tanks, absence of moisture (and, thus, lack of this boiling mechanism) will lead to a more severe heatup of the dry tank contents. This would lead to potentially more severe dispersion of these dry tank contents.

In addition, if these dry tanks contain appreciable amount of organics or ferrocyanides, they could be even more vulnerable. If the organic tanks are allowed to heat up $200^{\circ} \mathrm{C}$ (the ignition temperature of the organic compounds), the tanks contents may spontaneously participate in the combustion process. This internal combustion or internal fire of the organic tank contents will result in an increased dispersion of the waste into the atmosphere. Similarly, if the ferrocyanide tanks are allowed to heat up $285^{\circ} \mathrm{C}$ (the ignition temperature of the ferrocyanide compounds), the tanks contents may spontaneously participate in the combustion process. This internal combustion or internal fire of the ferrocyanide tank contents will result in an increased dispersion of the waste into the atmosphere. 
In light of the above discussion, four new release categories are defined. The first release category DCVH (similar to the one used for SY-101) would be used for all tanks with adequate moisture levels. Three new release categories (DCVHO, DCVHF, and DCVHI) are defined to address the dry-organic tanks, dry ferrocyanide tanks, and dry inert tanks (without high organic or ferrocyanide content), respectively. The logic model to assign each of the 177 Hanford tanks to a release category is shown in Figure 4-23.

Evaluation of all of the 177 Hanford tanks (as per the logic model shown in Figure 4-23) revealed that 88 tanks have adequate moisture levels, 5 tanks are dry with high organic content, 16 tanks are dry with high ferrocyanide content, and 68 tanks are dry and inert. These tanks were appropriately assigned to release categories defined earlier. The release category assignment results are schematically shown in Figure 4-24. Table 4-14 shows the assignment of each tank to one of the four release categories.

The release frequencies for each of these four release categories are evaluated in accordance with the number of tanks in each release category and the single tank release frequency (as quantified for Tank SY-101). The resultant release frequencies for each category are shown in Table 4-15.

\subsection{ACCIDENT SEOUENCE QUANTIFICATION}

Accident sequence quantification is the calculation of complete accident sequence frequencies. It involves the combination of the frequency of equipment operation and operator actions in response to initiating events with the frequency of those initiating events. The sequences that are of most interest are those that result in radionuclide or toxic gas release, although the quantification process treats all sequences including those resulting in successful event mitigation. This process requires the assembly of many distinct parts of the probabilistic safety assessment (PSA) model; it can be divided into two major tasks: sequence assembly and sequence quantification.

Sequence assembly requires the linking of the initiating events that have been identified for the analysis with the event trees that model the subsequent hardware, human, and phenomenological questions that are needed to respond to the initiating event. The development of initiating event frequencies and corresponding event sequence models was presented in Section 4.2. These models provide the input to the sequence quantification process.

Sequence quantification requires the assignment of a split fraction value to each branch in each event tree. The annual frequency of each accident sequence is simply the initiating event frequency multiplied by the conditional split fraction value of each top event that is appropriate for that sequence. Section 4.3.1 contains a summary of the quantification input; i.e., initiating event frequencies and top event split fraction values. The results of the accident sequence quantification are presented in Section 4.3.2.

The event tree computations outlined above must account for a variety of sources of uncertainty that prevent the development of highly accurate estimates of accident sequence frequencies. These sources of uncertainty include the lack or sparsity of data from which to quantify the risk model input parameters (i.e., component failure rates, 
initiating event frequencies, etc.), modeling uncertainty, equipment behavior in harsh environments, and many other sources. The basic approach to quantifying the effects of uncertainties on the PSA results is to determine the appropriate probability distributions for each uncertain parameter in the analysis.

When the event trees are quantified, the mean values of the initiating events and split fractions are used. The uncertainty of the overall risk can then be expressed for predefined groups of accident sequences, such as:

- All release sequences.

- $\quad$ Each release category or release category group.

- $\quad$ Each initiating event.

- $\quad$ Any other groups of interest.

For each group, the sequence frequencies are requantified using a Monte Carlo sampling algorithm to propagate the initiating event and split fraction uncertainties to obtain the uncertainties in the overall results. An uncertainty propagation accomplished in this manner encompasses the major contributor to risk while permitting efficiency in calculation for large models.

The PC computer code RISKMAN@ (Reference 4-26) was used to perform the event tree quantification and uncertainty propagation for the Hanford Tank Farm (HTF) PSA.

\subsubsection{SUMMARY OF QUANTIFICATION INPUT}

Table 4-16 lists the initiating events used in the accident sequence model for the HTF PSA. Also shown are the key parameters of their frequency distributions and references to the report sections that describe their development.

Table 4-17 lists the event tree top event split fraction values used in the accident sequence models. Also shown are the key parameters of their frequency distributions and references to the report sections that describe their development.

Descriptions of the release categories into which the event tree sequences are binned are provided in Section 5.2.

The calculation of conditional health effect consequences for each important release category is presented in Section 6.

\subsubsection{ACCIDENT SEQUENCE RESULTS}

This section presents the results of the accident sequence models described in Section 4.2. The top-level quantification results are the frequencies of each release category. The release category results are then broken down to reveal the important contributing initiators and scenarios. The release category frequencies are then used, along with the accident sequence descriptions, in the consequence analysis described in Section 6.

The result of sequence assembly and quantification is a set of scenarios and their frequencies, each scenario leading to success or to one of various release categories. The 
sequences include all of the possible combinations of success and failure of the event tree top events. The individual sequence frequencies are summed by release category to determine the annual release category frequencies (and of successful mitigation). The sum total of all of the sequence frequencies is equal to the sum total of all of the release categories frequencies (including-success), which is also equal to the sum total of all of the initiating event frequencies. This is true because the event tree sequences represent a set of exhaustive and mutually exclusive outcomes of the initiating events.

Table 4-18 presents the mean annual frequency for each release category defined for the HTF PSA. The release categories are listed in descending order by frequency. Table 4-18 also describes the highest frequency accident sequences contributing to each release category.

The contributions of each initiating event to each release category are presented in matrix form in Table 4-19. This table shows that most of the initiating events contribute to only one or, at most, four release categories. Many of the release categories were defined to characterize the unique radionuclide releases caused by particular initiating events, such as hydrogen generation in specific tanks or an aircraft crash impacting a tank with high organic or ferro-cyanide waste content.

\subsection{BEFERENCES}

4-1. MacFarlane, D. R., et al., "Risk Assessment for Hanford High-Level Waste Tank 241-SY-101," Draft Los Alamos National Laboratory Report, July 1993.

4-2. Westinghouse Hanford Company, "Hanford Site Tank Farm, Facilities Interim Safety Basis," WHC-SD-WM-ISB-001, Rev. 0, Vol. 1, August 1993.

4-3. Hopkins, J.D., Criteria for Flammable Gas Watch List Tanks," WHC-EP-0702, Final Draft, April 1944.

4-4. Ashby, E.C., et al, "Gas Generation and Retention in Tank 101-SY: A Summary of Laboratory Studies, Tank Data, and Information Needs," PNL-8124, June 1992.

4-5. Crippen, M. D., and J. D. McCormack, "Barometric Pressure Variations," WHC-EP-0651, 1993.

4-6. Claybrook, S. W., and T. M. Burke, "Evaporation Modeling for Tank C-103," WHC-SD-WM-ER-127, Rev. 0, 1991.

4-7. McLaren, J. M., "Single-Shell Tank 104-BY Thermal-Hydraulic Analysis," WHC-EP-0521, 1991.

4-8. Scaief, C. C., "Hydrogen Ignition Capability of Tank Farm instrumentation and Electrical Equipment," Westinghouse Hanford Company Report No. WHC-SD-WM-ES-176, Rev. 0, September 1992.

4-9. Bott, T. F., "Ignition Probability of Hydrogen in the Tank 241-101-SY Vent Header." 
4-10. Powers, T. B., and S. D. Morales, "SY Tank Farm Ventilation Isolation Option Risk Assessment Report," Draft Westinghouse Hanford Division Report, June 1992.

4-11. Stull, D. R., "Fundamentals of Fire and Explosion," AIChE Monograph Series, No. 10, Vol. 73, 1977.

4-12. Wakefield, D. J., and K. N. Fleming, "STADIC Computer Code User Manual," PLG Proprietary Report No. PLG-0689, Rev. O/PC, October 1990.

4-13. "Advent Engineering Corporation Report".

4-14. Investigations by S. Agnew

4-15. Hanlon, B. M., Tank Farm Surveillance and Waste Status Summary Report for June 1993, Westinghouse Hanford Company, WHC-EP-0182-63.

4-16. Los Alamos National Laboratory, "A Safety Assessment for Proposed Pump Mixing Operations to Mitigate Episodic Gas Releases in Tank 241-101-SY: Hanford Site, Richland, Washington," prepared for U.S. Department of Energy, Rev. 4, September 2, 1992.

4-17. U.S. Nuclear Regulatory Commission, "Reactor Safety Study: An Assessment of Acident Risks in U.S. Commercial Nuclear Power Plants," WASH-1400 (NUREG75/0141, October 1975.

4-18 Hanford Site Tank Farm Facilities Interim Safety Basis, Westinghouse Hanford Company, August 1993, WHC-SD-WM-ISB-001, Revision 0.

4-19. Memo to file, "Ongoing Waste Tank Heat Loads," April 25, 1994.

4-20. Westinghouse Hanford Company, "Aging Waste Facility Safety Analysis Report," SD-HS-SAR-010, Rev. 3, February 1990.

4-21. "First Revision to Safety Study Support; Waste Stability Following Mistransfers and Hydrogen Accumulation Within the DCRTs," WHC-SD-WN-RPT-048, Rev. 0, Attachment D, June 1992.

4-22. "High Level Waste Tank Subcriticality Safety Assessment," WHC-SD-WM-SARR-003, March 1994.

4-23. Woodward-Clyde Consultants, "Evaluation of Seismic Hazard for Non-Reactor Facilities, Hanford Reservation," Westinghouse Hanford Company Report WHC-MR-0023, July 1989.

4-24. Sandia National Laboratories, "Analysis of Core Damage Frequency due to External Events at the DOE N-Reactor,"SAND89-1147, UC-610, November 1990. 
4-25. Telephone Communication, A. M. Tallman, Westinghouse Hanford Company, and H. F. Perla, PLG, May 29, 1992.

4-26. PLG, Inc., "RISKMAN-PRA Workstation Software," User Manuals I-IV, Version 5.0, 1994. 


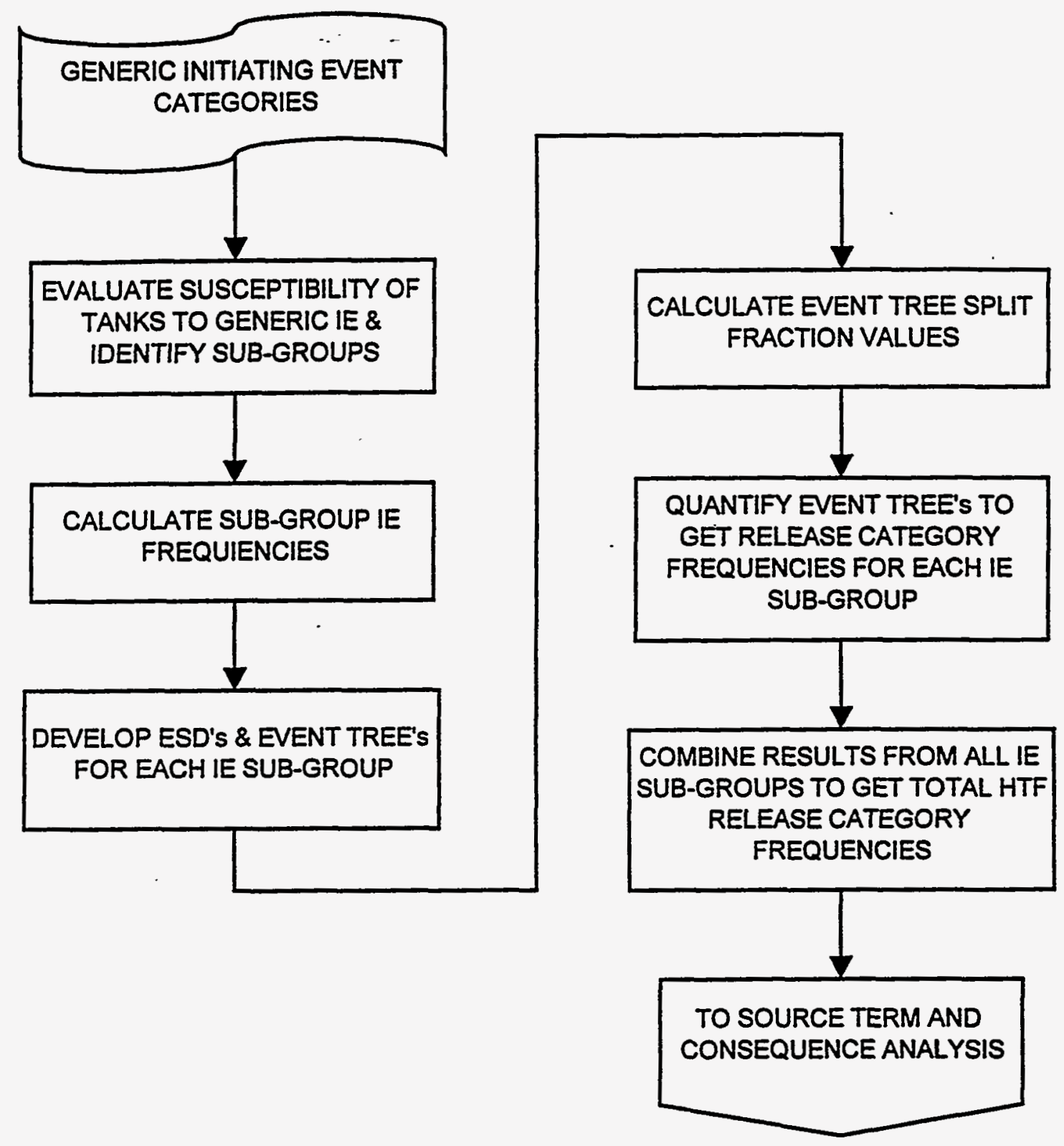

FIGURE 4-1

ACCIDENT SEQUENCE MODELING STEPS FOR THE HTF PSA 


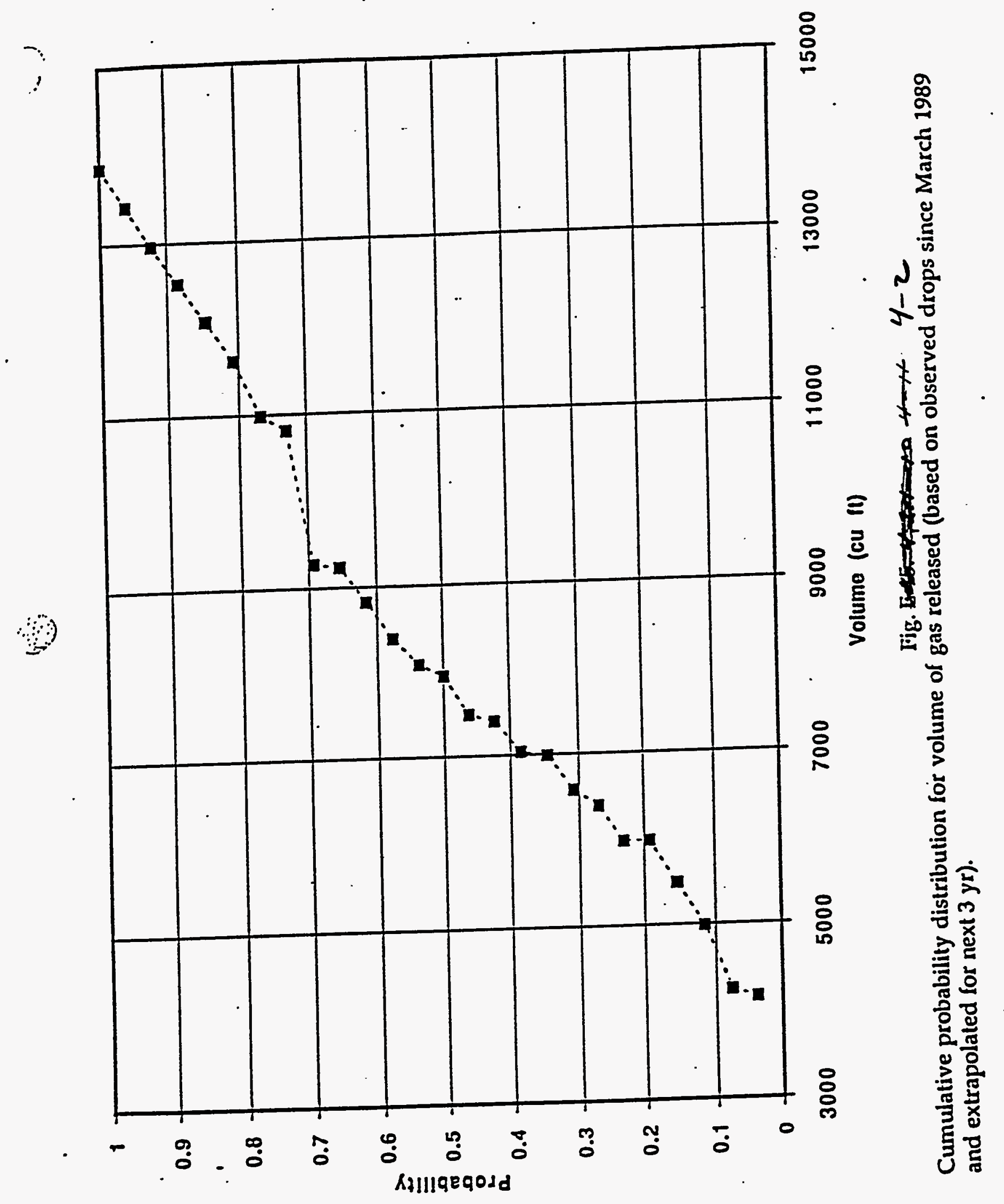


$\frac{\text { ரे }}{\frac{\infty}{\omega}}$
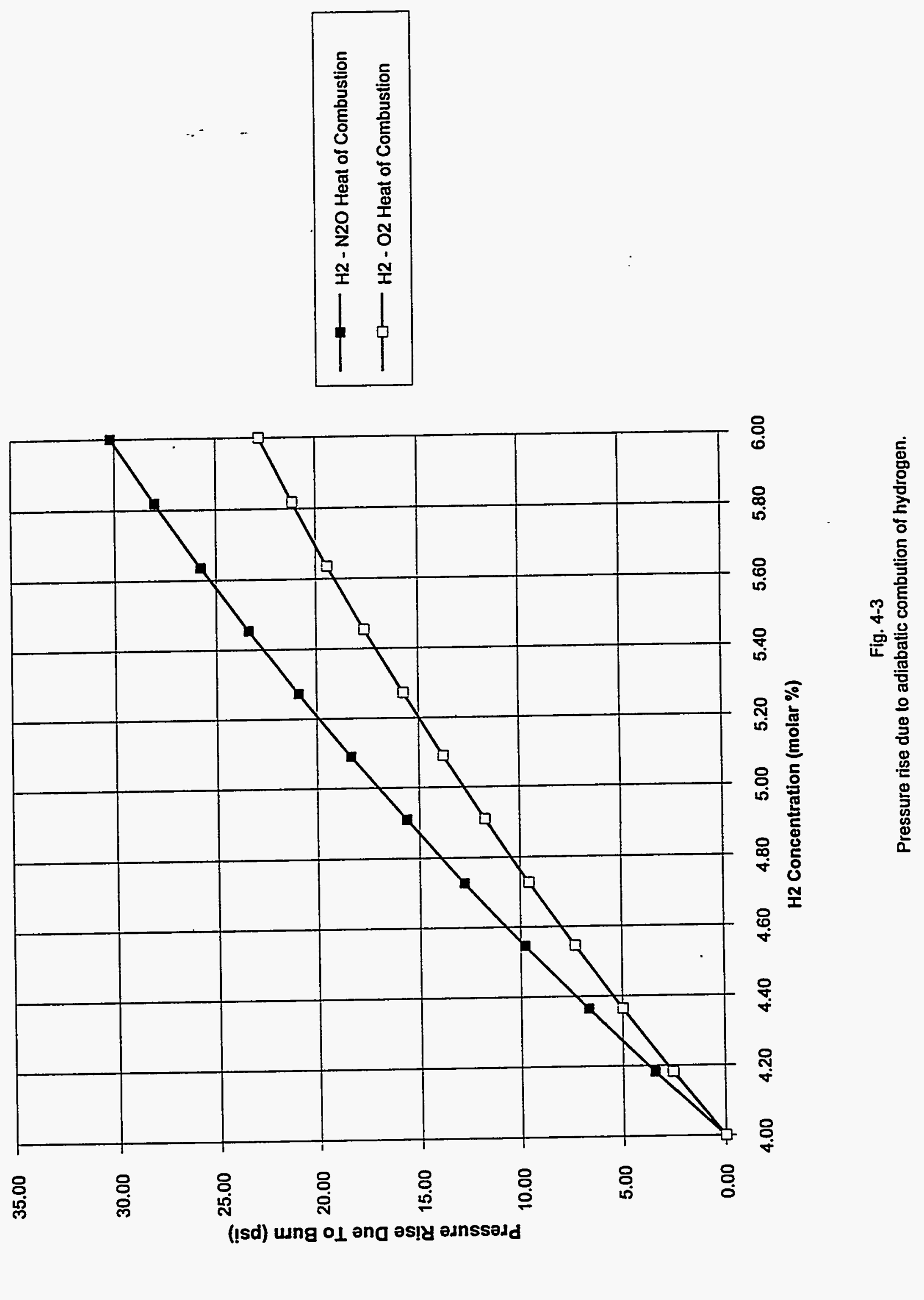

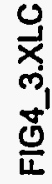


C:ILANL177IREV_7_94ISECT_4IFIG4_4.AF2

$8 / 5 / 94$



Figure 4-4.

Simplified Fault Tree for Burn in Passively Vented Tanks 


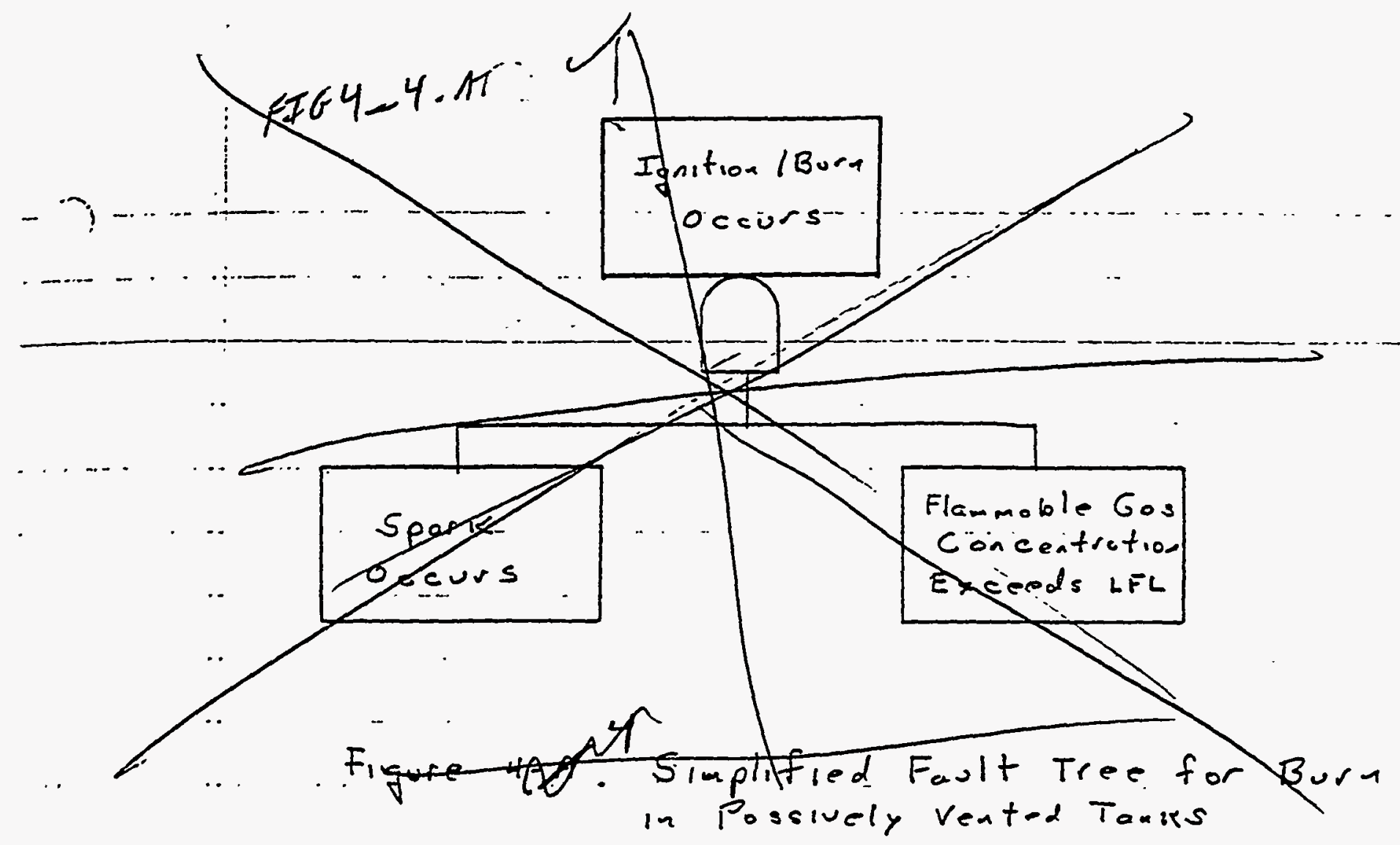

in Possively Vented Tanirs

3

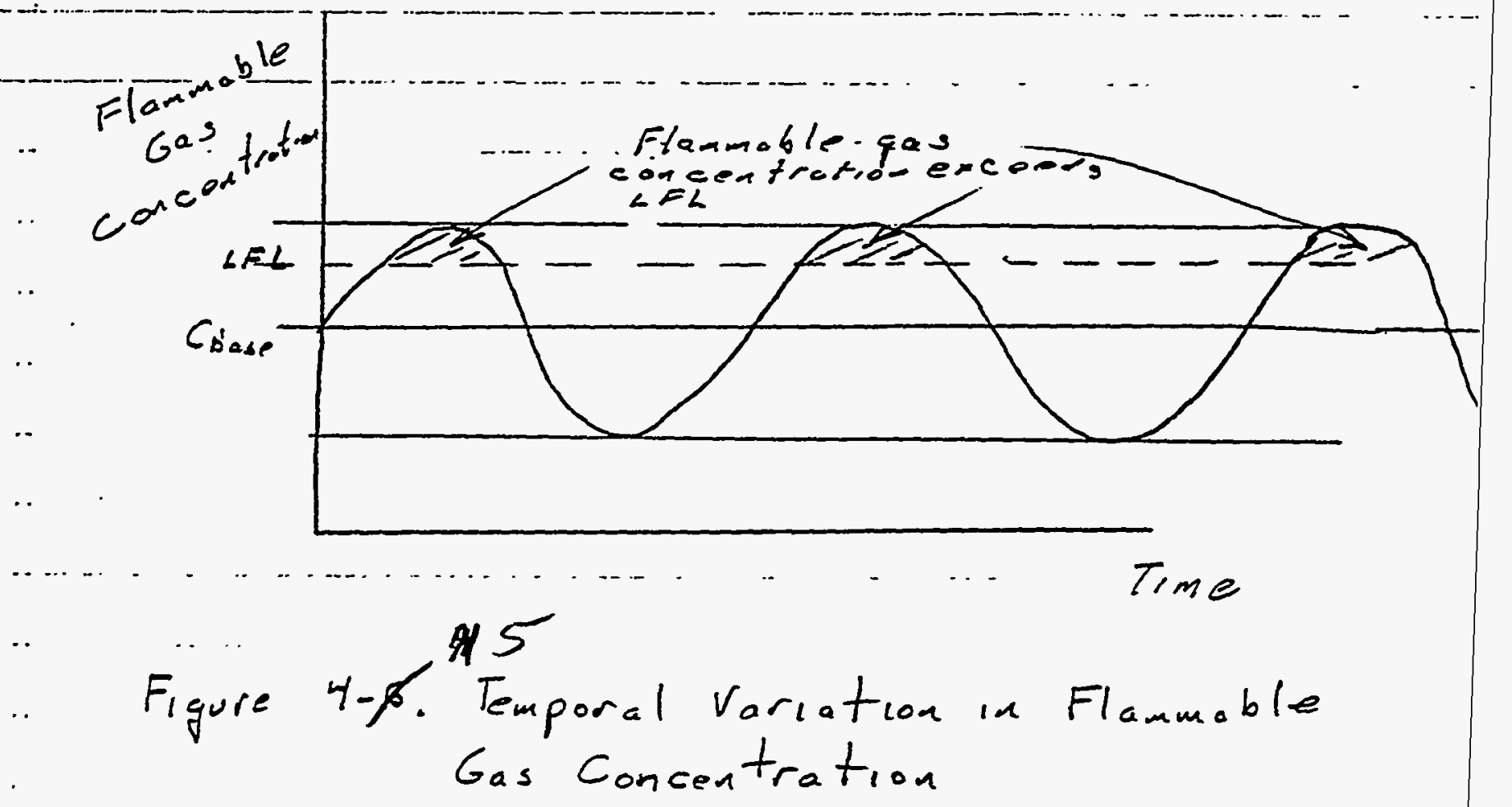




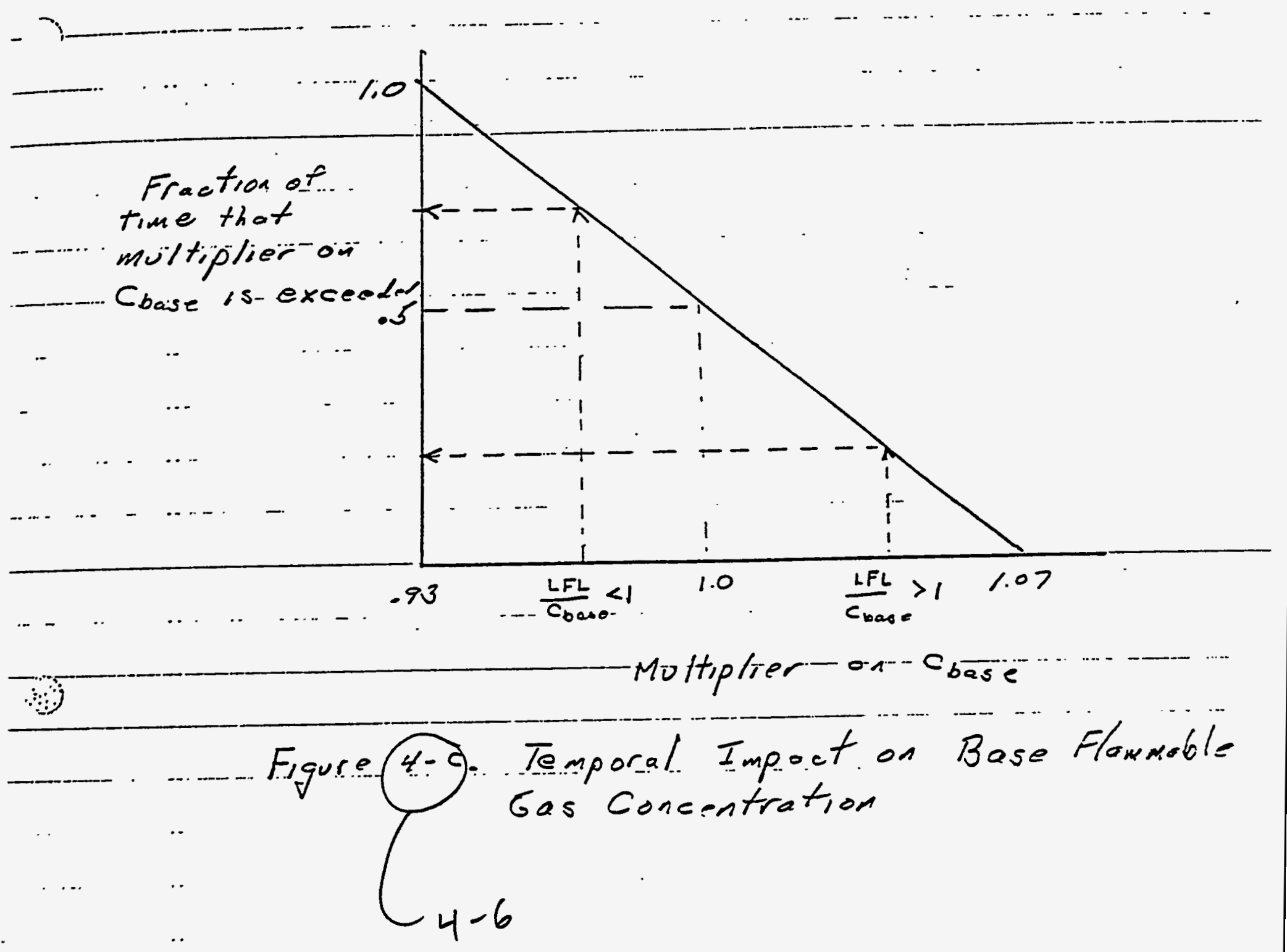




\begin{tabular}{|c|c|c|c|c|c|c|c|c|c|}
\hline $\begin{array}{l}\text { BURP } \\
\text { Initiating } \\
\text { Event }\end{array}$ & $\begin{array}{c}\text { Hydrogen } \\
\text { Concentration } \\
<4 \%\end{array}$ & $\begin{array}{c}\text { Ventilation } \\
\text { System } \\
\text { Operates } \\
\text { Susccessfully }\end{array}$ & $\begin{array}{l}\text { No Hydrogen } \\
\text { Burn in Tank }\end{array}$ & $\begin{array}{c}\text { No Hydrogen } \\
\text { Burn in Vent } \\
\text { System }\end{array}$ & $\begin{array}{c}\text { No } \\
\text { Propagation } \\
\text { from Vent } \\
\text { Line to Tank }\end{array}$ & $\begin{array}{c}\text { Dome } \\
\text { Integrity } \\
\text { OK }\end{array}$ & $\begin{array}{c}\text { Seq. } \\
\#\end{array}$ & $\begin{array}{l}\text { Frequency } \\
\text { per Year }\end{array}$ & $\begin{array}{l}\vdots \\
\text { Release } \\
\text { Category }\end{array}$ \\
\hline \multirow[t]{9}{*}{3.51} & $1.1 \mathrm{E}-1$ & $\mathrm{~N} / \mathrm{I}$ & N/A & N/A & N/A & N/A & 1 & 3.9E-01 & TG * \\
\hline & $8.9 E-1$ & $1.0 \mathrm{E}+0$ & $1.0 E+0$ & $9.9 \mathrm{E}-1$ & N/A & N/A & 2 & $3.1 E+00$ & TG \\
\hline & & & & $6.6 \mathrm{E}-3$ & $9.2 \mathrm{E}-1$ & N/A & 3 & $1.9 \mathrm{E}-02$ & HEPAL \\
\hline & & & & & $8.3 \mathrm{E}-2$ & $8.8 \mathrm{E}-1$ & 4 & $1.5 \mathrm{E}-03$ & HEPAH \\
\hline & & & & & & $1.2 \mathrm{E}-1$ & 5 & 2.0E-04 & $\mathrm{DCH}$ \\
\hline & & & $1.3 \mathrm{E}-3$ & G/F & N/A & $8.8 \mathrm{E}-1$ & 6 & 3.6E-03 & HEPAH \\
\hline & & & & & & $1.2 \mathrm{E}-1$ & 7 & $4.9 E-04$ & $\mathrm{DCH}$ \\
\hline & & $4.5 E-3$ & $1.0 E+0$ & $9.9 \mathrm{E}-1$ & N/A & N/A & 8 & 1.4E-02 & TG \\
\hline & & & & $6.6 \mathrm{E}-3$ & $G / F$ & $8.8 \mathrm{E}-1$ & 9 & 8.2E-05 & HEPAH \\
\hline LEGEND: & & & & & & $1.2 \mathrm{E}-1$ & 10 & 1.1E-05 & $\mathrm{DCH}$ \\
\hline $\mathrm{N} / 1$ & \multicolumn{2}{|l|}{ Not Important } & $1.3 \mathrm{E}-3$ & $G / F$ & N/A & $8.8 \mathrm{E}-1$ & 11 & 1.6E-05 & HEPAH \\
\hline N/A & \multirow{2}{*}{\multicolumn{2}{|c|}{ Not Applicable }} & & & & $1.2 E-1$ & 12 & 2.2E-06 & $\mathrm{DCH}$ \\
\hline G/F & & & & & & & & & \\
\hline
\end{tabular}

- Note: Risks associated with toxic gas (TG) releases are not covered in this PSA.

Fig. 4-7.

BURP Event Tree. 


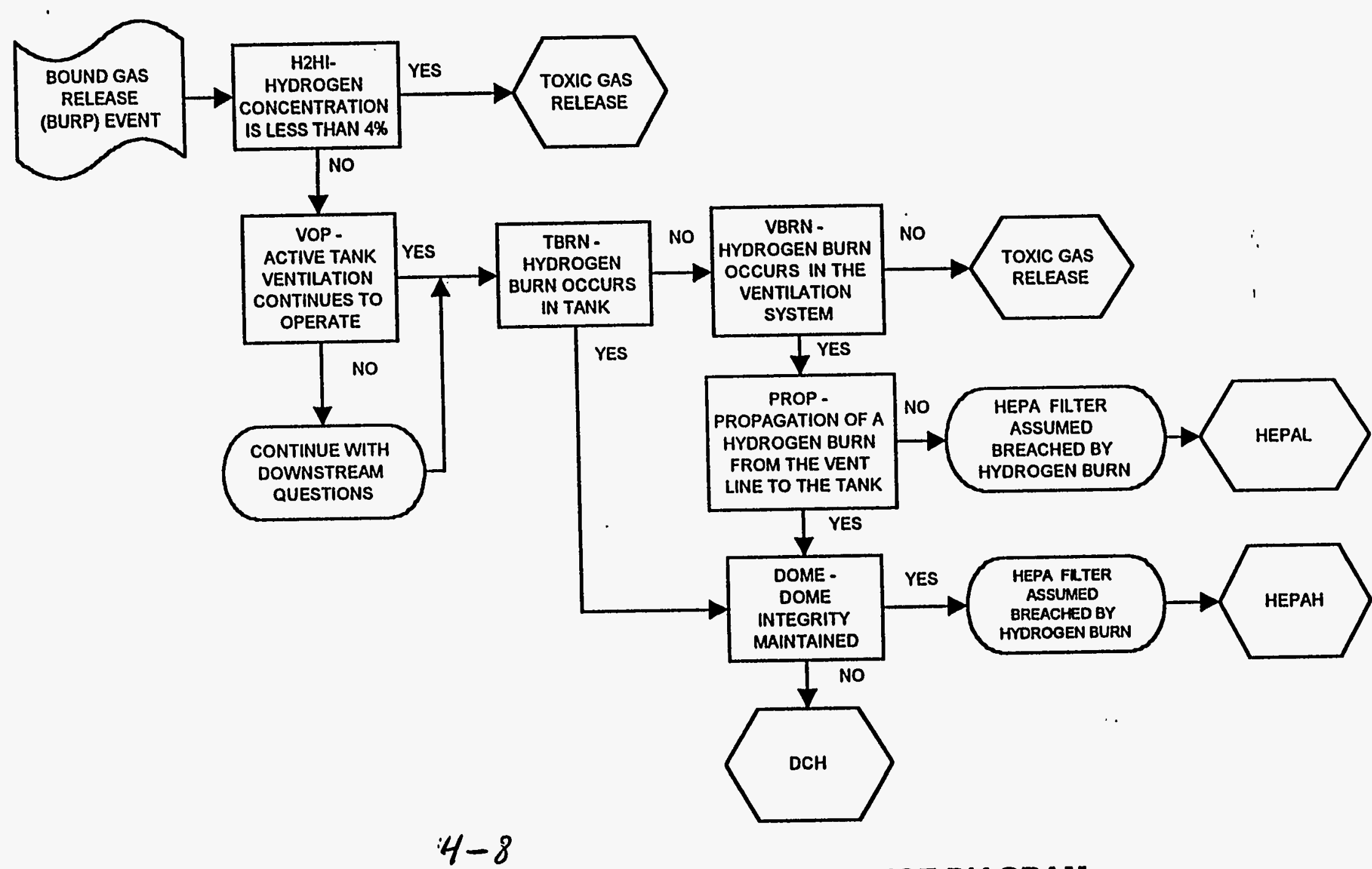

Figure 4.2.T- BURP EVENT SEQUENCE DIAGRAM 


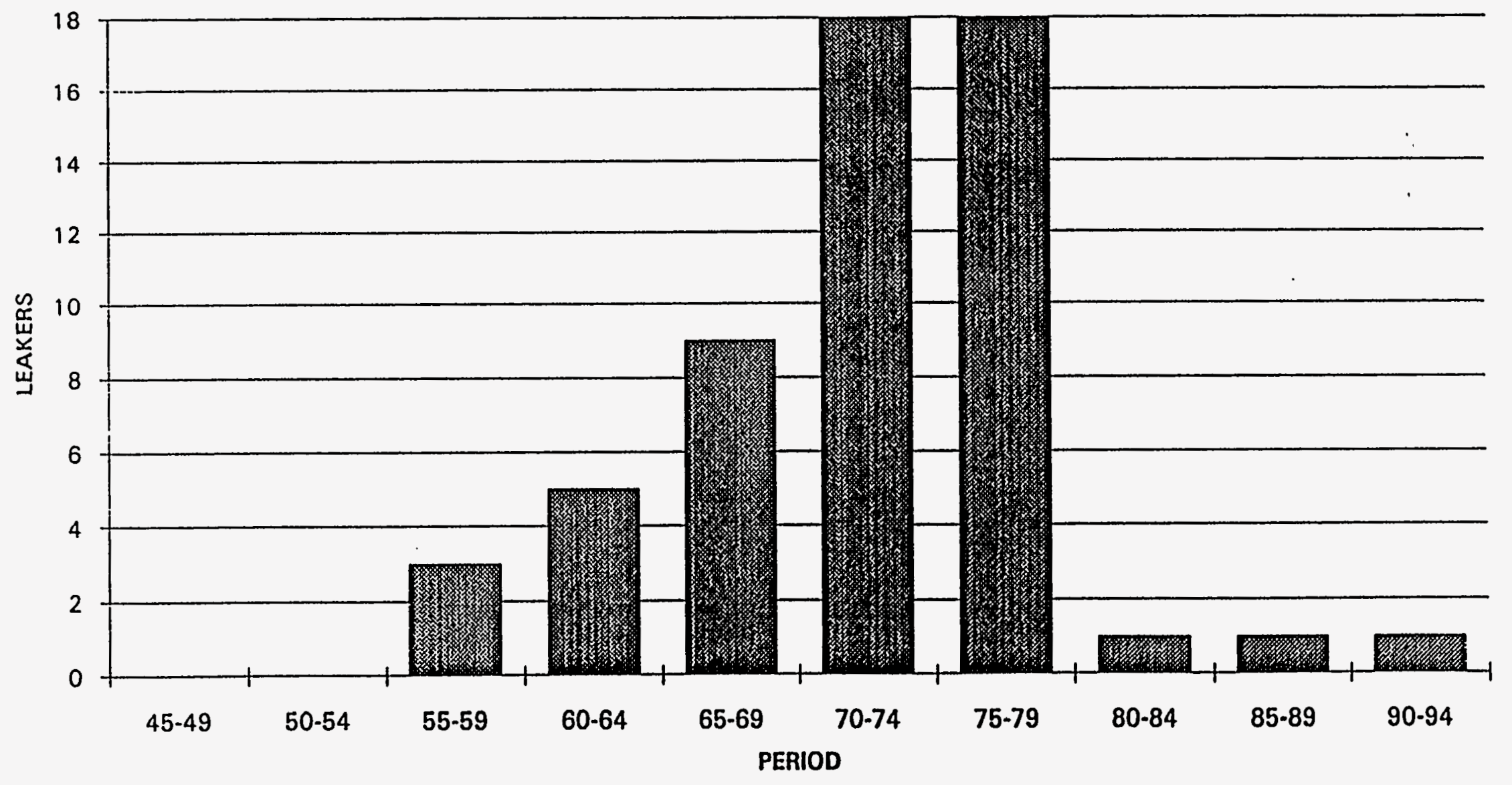

$$
4 \pi^{9}
$$




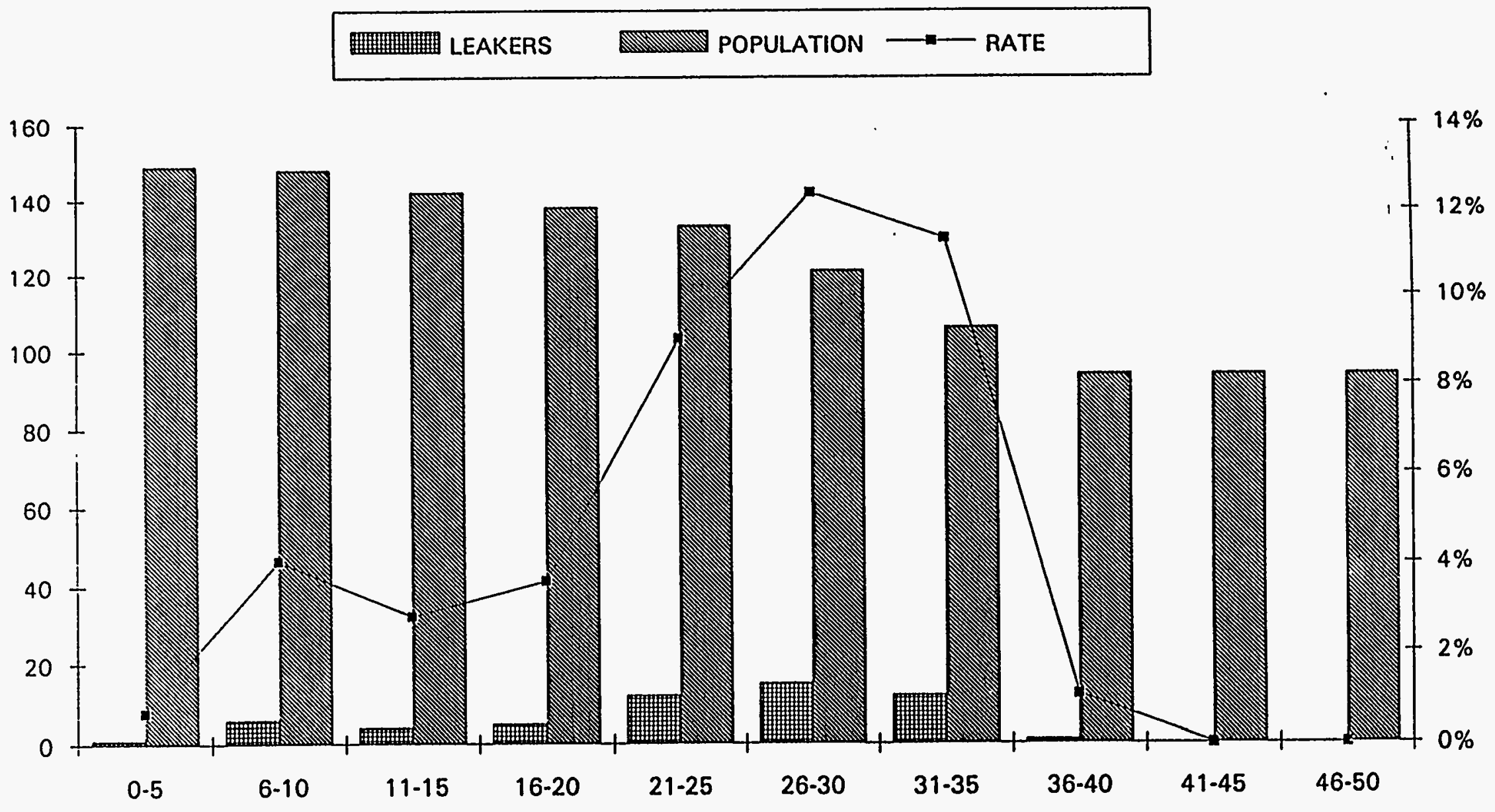

$$
4+188^{10}
$$

FIGURE 4.2-2 LEAK DATA VERSES TANK AGE 


\begin{tabular}{|c|c|c|c|c|}
\hline \multirow{2}{*}{$\begin{array}{c}\text { SST Shell } \\
\text { Breach Initiating } \\
\text { Event } \\
\text { (93 Tanks) }\end{array}$} & \multicolumn{4}{|c|}{ SST LEAK EVENT TREE } \\
\hline & $\begin{array}{c}\text { Leak Size is } \\
\text { Small? }\end{array}$ & $\begin{array}{c}\text { Seq. } \\
\#\end{array}$ & $\begin{array}{c}\text { Frequency } \\
\text { per Year }\end{array}$ & $\begin{array}{l}\text { Release } \\
\text { Category }\end{array}$ \\
\hline SSTSB & SIZE & & & \\
\hline \multirow[t]{2}{*}{ 4.26E-01 } & 0.869 & 1 & 3.7E-01 & SLK \\
\hline & 0.131 & 2 & $5.6 \mathrm{E}-02$ & LLK \\
\hline
\end{tabular}

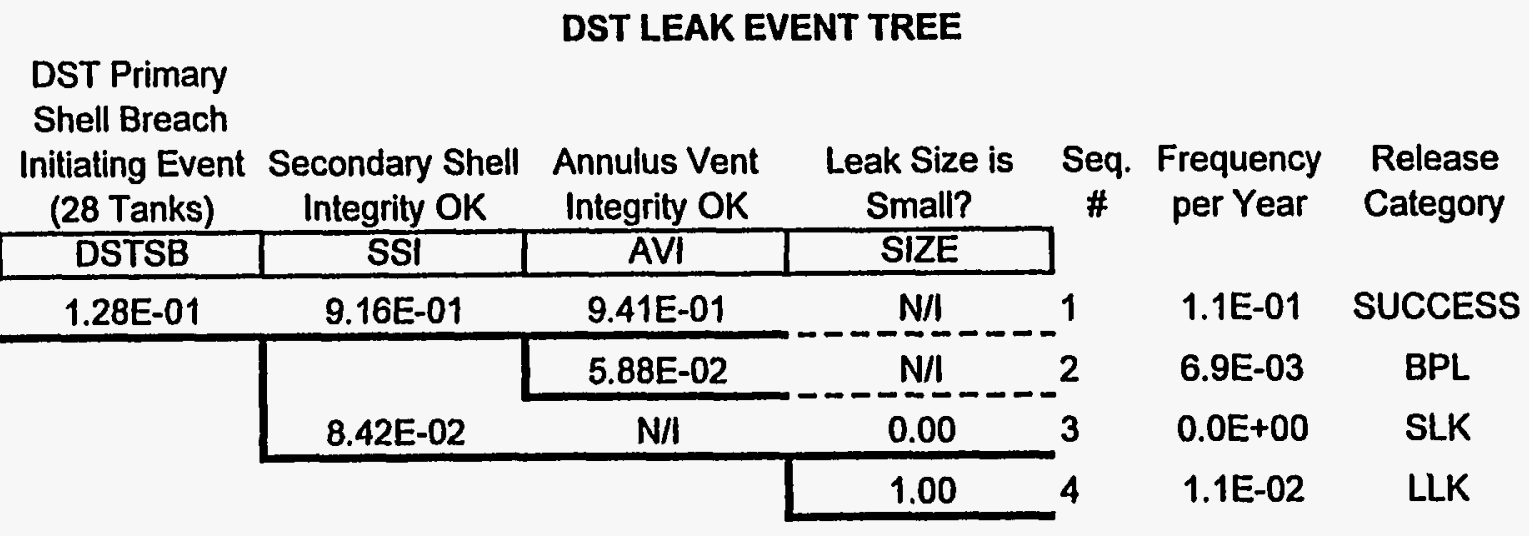

Legend:

$\mathrm{N} / \mathrm{I}=$ Not Important

Figure 4-11. SST and DST Shell Leak Event Trees 


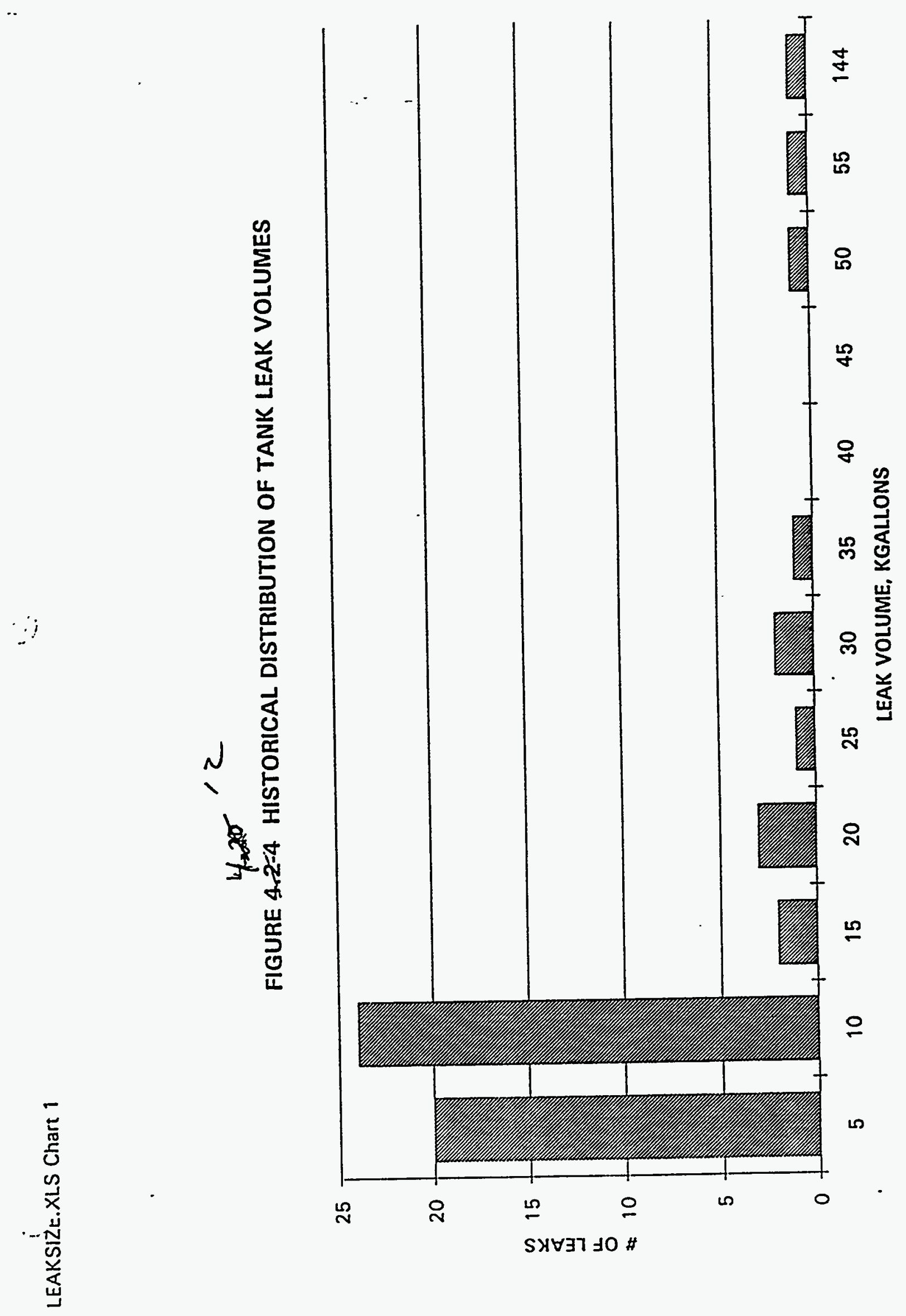






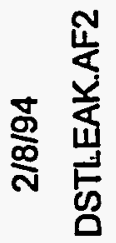


LOTVAW EVENT TREE

\begin{tabular}{|c|c|c|c|c|}
\hline \multirow{3}{*}{$\begin{array}{l}\text { Loss of Tank } \\
\text { Ventilation } \\
\text { Initiating Event } \\
\text { (Aging Waste } \\
\text { Tanks) } \\
\end{array}$} & & & & \\
\hline & $\begin{array}{c}\text { Operator } \\
\text { Recovers } \\
\text { Primary Tank } \\
\text { Ventilation }\end{array}$ & $\begin{array}{c}\text { Seq. } \\
\#\end{array}$ & $\begin{array}{l}\text { Frequency } \\
\text { per Year }\end{array}$ & $\begin{array}{l}\text { Release } \\
\text { Category }\end{array}$ \\
\hline & ORV & & & \\
\hline \multirow[t]{2}{*}{ 6.54E-01 } & 0.987 & 1 & $6.5 E-01$ & BPL \\
\hline & 0.013 & 2 & 8.5E-03 & BPH \\
\hline
\end{tabular}

Figure 4-14.

Loss of Tank Ventilation Event Tree for Aging Waste Tanks 
C:ILANL177IREV_7_94ISECT_4IWI_ESD.AF2



Figure 4-15. Water Intrusion Event Sequence Diagram 


\begin{tabular}{|c|c|c|c|c|c|c|c|c|}
\hline & $\begin{array}{c}\text { Water } \\
\text { Intrusion } \\
\text { Initiating } \\
\text { Event: } \\
\end{array}$ & $\begin{array}{c}\text { Tank is } \\
\text { not a } \\
\text { Leaker }\end{array}$ & $\begin{array}{c}\text { Level } \\
\text { Remains } \\
\text { Within } \\
\text { Limits } \\
\end{array}$ & $\begin{array}{c}\text { Level } \\
\text { Indication }\end{array}$ & $\begin{array}{l}\text { Operator } \\
\text { Prevents } \\
\text { Release }\end{array}$ & $\begin{array}{c}\text { Seq. } \\
\#\end{array}$ & $\begin{array}{c}\text { Frequency } \\
\text { per Year }\end{array}$ & $\begin{array}{l}\text { Release } \\
\text { Category }\end{array}$ \\
\hline \multirow[t]{5}{*}{ WIA } & \multirow[t]{5}{*}{$5.36 \mathrm{E}-01$} & & & $N / I$ & $N / I$ & 1 & 4.8E-01 & SUCCESS \\
\hline & & & $1.00 \mathrm{E}-01$ & & & 2 & 4.1E-02 & SUCCESS \\
\hline & & & & & 1.30E-02 & 3 & $5.4 \mathrm{E}-04$ & SSP \\
\hline & & & & $2.29 \mathrm{E}-01$ & $\mathrm{G} / \mathrm{F}$ & 4 & $1.2 \mathrm{E}-02$ & SSP \\
\hline & & $0.00 E+0$ & & & & 5 & $0.0 \mathrm{E}+00$ & SLK \\
\hline
\end{tabular}

\begin{tabular}{|c|c|c|c|c|c|c|c|c|}
\hline \multirow[t]{5}{*}{ WIPI } & \multirow{2}{*}{$4.95 \mathrm{E}-01$} & & & $N / I$ & $\mathrm{~N} / \mathrm{I}$ & \multirow{2}{*}{$\begin{array}{l}1 \\
2\end{array}$} & \multirow{2}{*}{$\begin{array}{l}4.0 \mathrm{E}-01 \\
1.8 \mathrm{E}-02\end{array}$} & \multirow{2}{*}{$\begin{array}{l}\text { SUCCESS } \\
\text { SUCCESS }\end{array}$} \\
\hline & & & $5.12 E-02$ & & & & & \\
\hline & & & & & $1.30 \mathrm{E}-02$ & 3 & 2.3E-04 & SSP \\
\hline & & & & 1.62E-01 & $\mathrm{G} / \mathrm{F}$ & 4 & $3.5 E-03$ & SSP \\
\hline & & $1.57 \mathrm{E}-01$ & & & & 5 & $7.8 \mathrm{E}-02$ & SLK \\
\hline
\end{tabular}

\begin{tabular}{|c|c|c|c|c|c|c|c|c|}
\hline \multirow[t]{5}{*}{ WIP } & \multirow[t]{5}{*}{$1.75 \mathrm{E}-01$} & & & $\mathrm{~N} / \mathrm{I}$ & $\mathrm{N} / \mathrm{I}$ & 1 & 8.7E-02 & SUCCESS \\
\hline & & & $2.80 \mathrm{E}-02$ & & & 2 & 2.0E-03 & SUCCESS \\
\hline & & & & & $1.30 \mathrm{E}-02$ & 3 & 2.7E-05 & SSP \\
\hline & & & & $1.74 \mathrm{E}-01$ & $\mathrm{G} / \mathrm{F}$ & 4 & 4.3E-04 & SSP \\
\hline & & 4.90E-01 & & & & 5 & $8.6 \mathrm{E}-02$ & SLK \\
\hline
\end{tabular}

LEGEND:

WLA

WIPI

WIIP

N/I

G/F
Water Intrusion into Tanks in Service

Water Intrusion into Partially Interim Isolated Tanks

Water Intrusion into Intrusion Prevented Tanks

Not Important

Guaranteed Failure
Figure 4-16.

Water Intrusion Event Tree 


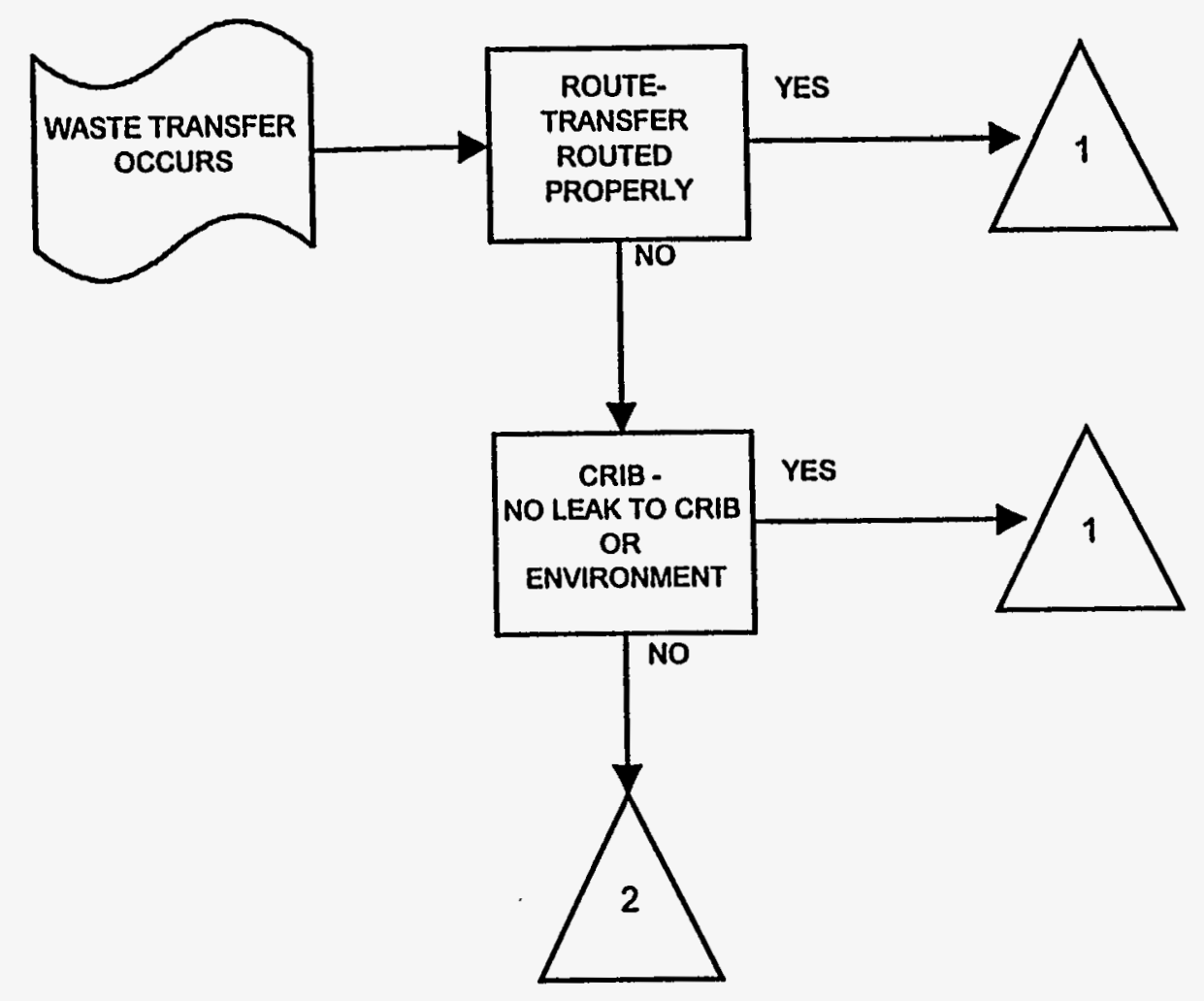

Figure 4-17. WASTE TRANSFER ESD 


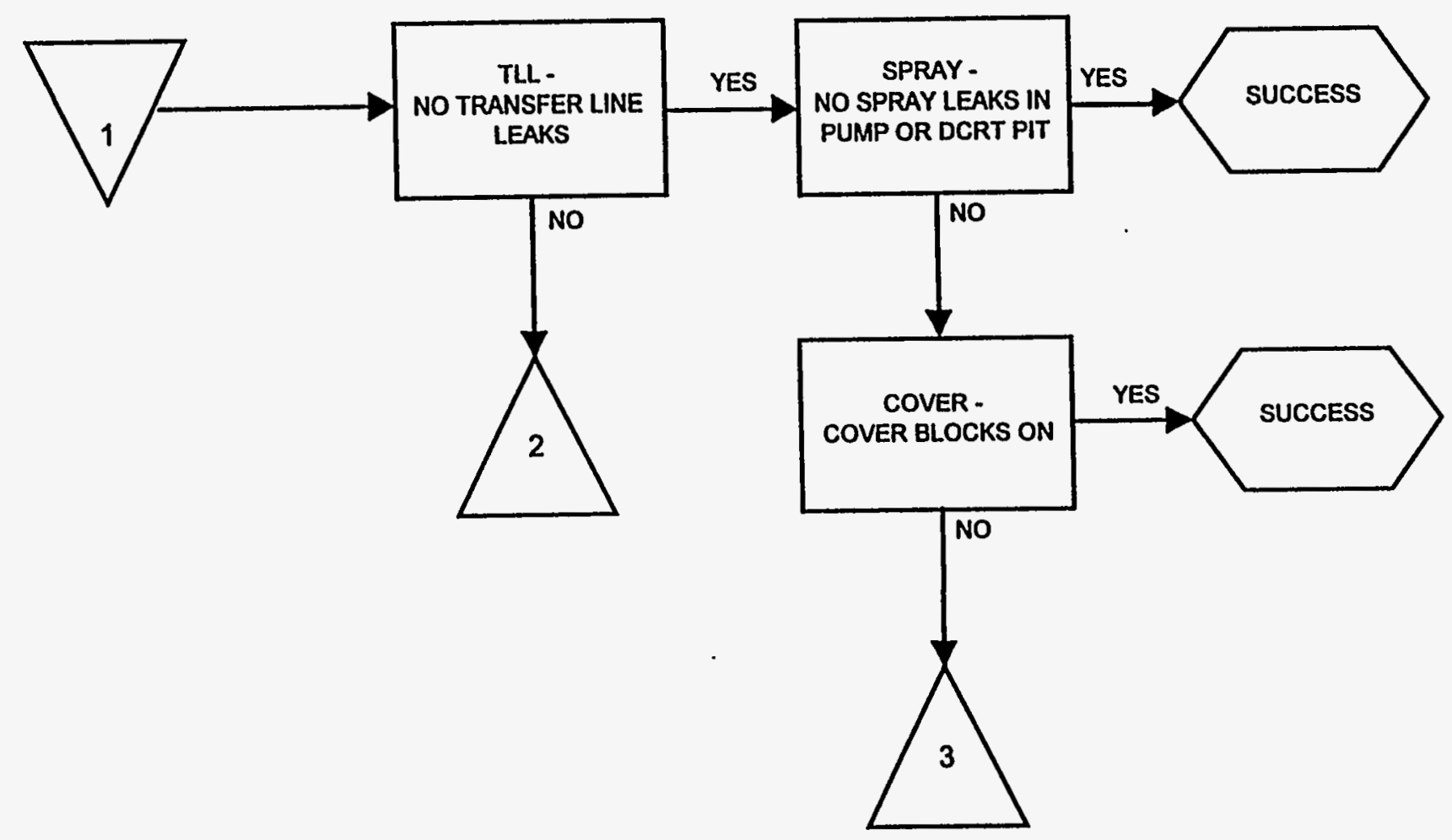

Figure 4-17. (CONTINUED) 


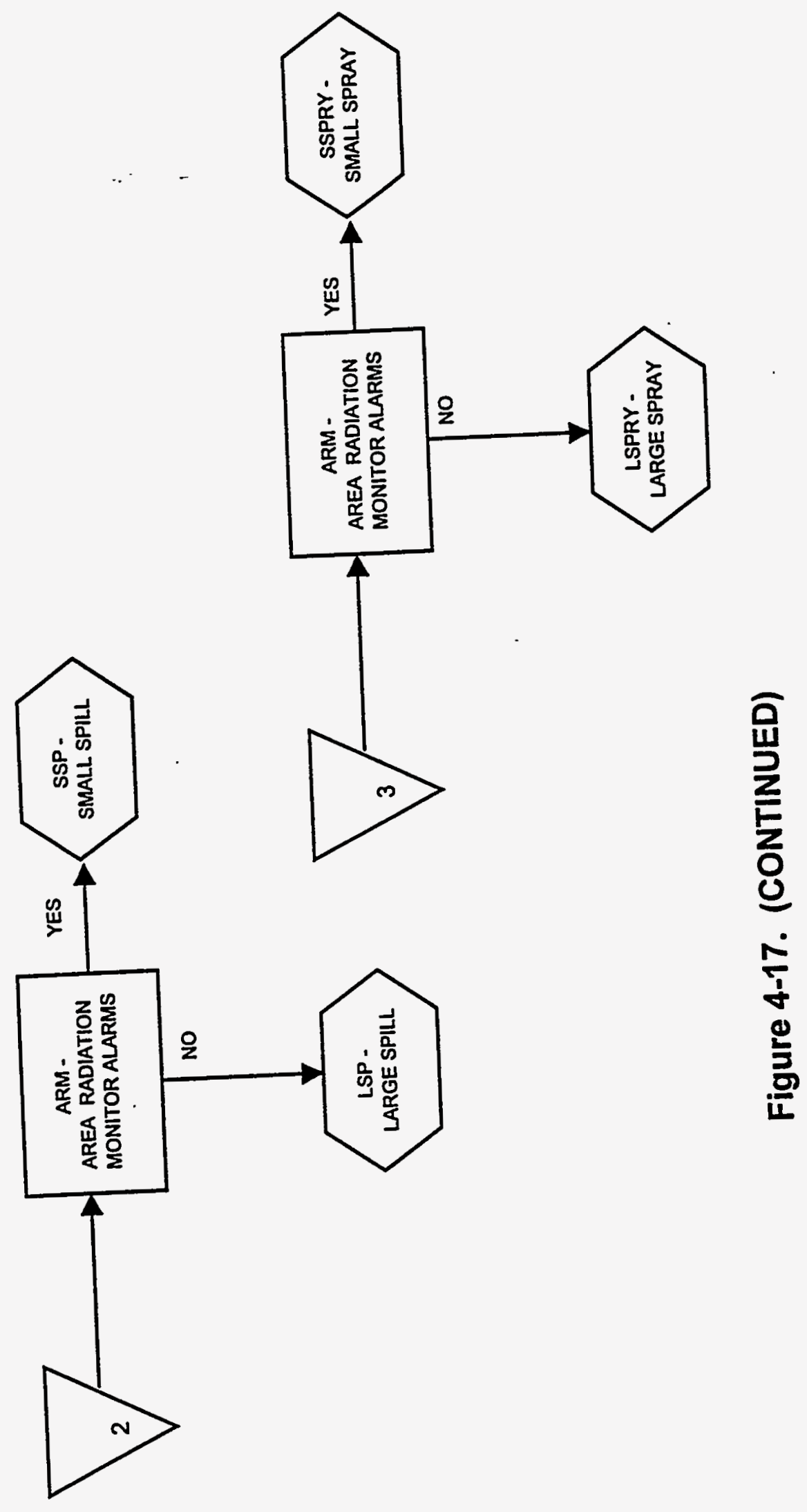




\section{WASTE TRANSFER EVENT TREE}

\begin{tabular}{|c|c|c|c|c|c|c|c|c|c|}
\hline $\begin{array}{c}\text { Waste } \\
\text { Transfer Event }\end{array}$ & $\begin{array}{c}\text { Waste Routed } \\
\text { Properly? }\end{array}$ & $\begin{array}{c}\text { No Leak to } \\
\text { Crib or } \\
\text { Environment }\end{array}$ & $\begin{array}{c}\text { No Transfer } \\
\text { Line Leak }\end{array}$ & No Spray Leak & $\begin{array}{c}\text { Cover Blocks } \\
\text { On? }\end{array}$ & $\begin{array}{l}\text { Area Radiation } \\
\text { Monitor Alarms }\end{array}$ & $\begin{array}{c}\text { Seq. } \\
\#\end{array}$ & $\begin{array}{c}\text { Frequency } \\
\text { per Year }\end{array}$ & $\begin{array}{l}\text { Release } \\
\text { Category }\end{array}$ \\
\hline WT & ROUTE & CRIB & TLL & SPRAY & COVER & ARM & & & \\
\hline \multirow[t]{14}{*}{$1.00 E+03$} & 9.96E-01 & & 9.99E-01 & $1.00 E+00$ & & & 1 & $9.95 E+02$ & SUCCESS \\
\hline & & & & 9.06E-05 & $9.00 \mathrm{E}-01$ & & 2 & 8.11E-02 & SUCCESS \\
\hline & & & & & $1.00 \mathrm{E}-01$ & 9.50E-01 & 3 & 8.57E-03 & SSPRY \\
\hline & & & & & & $5.00 \mathrm{E}-02$ & 4 & 4.51E-04 & LSPRY \\
\hline & & & $9.28 E-04$ & & & 9.00 E-01 & 5 & 8.32E-01 & SSP \\
\hline & & & & & & 1.00E-01 & 6 & $9.24 \mathrm{E}-02$ & LSP \\
\hline & $3.99 \mathrm{E}-03$ & 8.40E-01 & 9.99E-01 & $1.00 E+00$ & & & 7 & $3.35 E+00$ & SUCCESS \\
\hline & & & & $9.06 \mathrm{E}-05$ & $9.00 \mathrm{E}-01$ & & 8 & 2.73E-04 & SUCCESS \\
\hline & & & & & $1.00 \mathrm{E}-01$ & $9.50 \mathrm{E}-01$ & 9 & 2.88E-05 & SSPRY \\
\hline & & & & & & 5.00E-02 & 10 & $1.52 E-06$ & LSPRY \\
\hline & & & $9.28 \mathrm{E}-04$ & & & $9.00 \mathrm{E}-01$ & 11 & $2.80 E-03$ & SSP \\
\hline & & & & & & $1.00 \mathrm{E}-01$ & 12 & $3.11 E-04$ & LSP \\
\hline & & 1.60E-01 & & & & $9.00 \mathrm{E}-01$ & 13 & 5.75E-01 & SSP \\
\hline & & & & & & $1.00 \mathrm{E}-01$ & 14 & $6.38 E-02$ & LSP \\
\hline
\end{tabular}

Figure 4-18.

Waste Transfer Event Tree 



$4-19$

Fig. 4.11.

Location map. 




4-20

Fig. 4.12.

Mean seismic hazard curve, Site 1. 


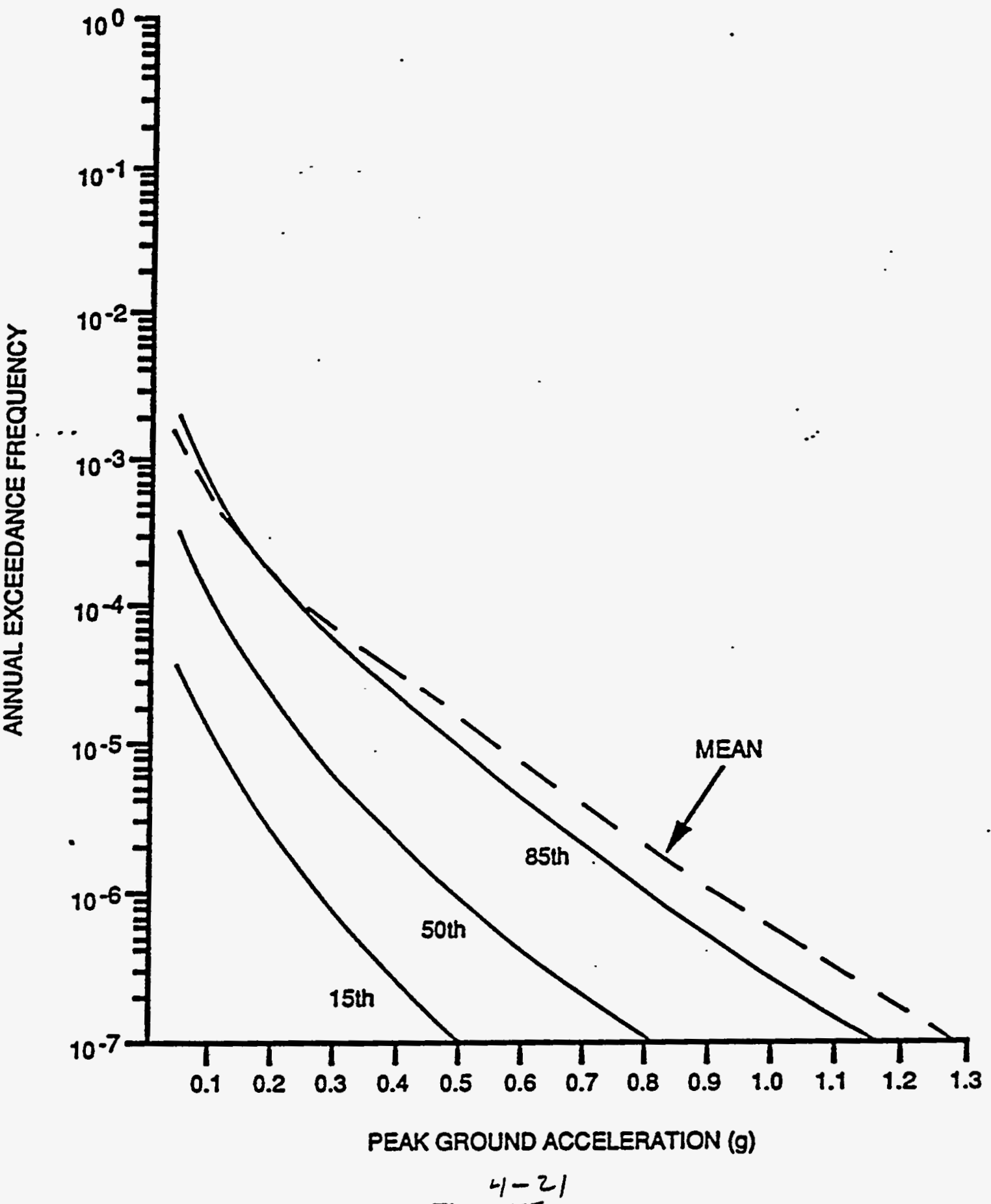

Fig. 413.

Seismic hazard curves, Site 1 , used in analysis. 
Fig. 4-2e.

Fragility Curves for Failure of Single Shell Tank

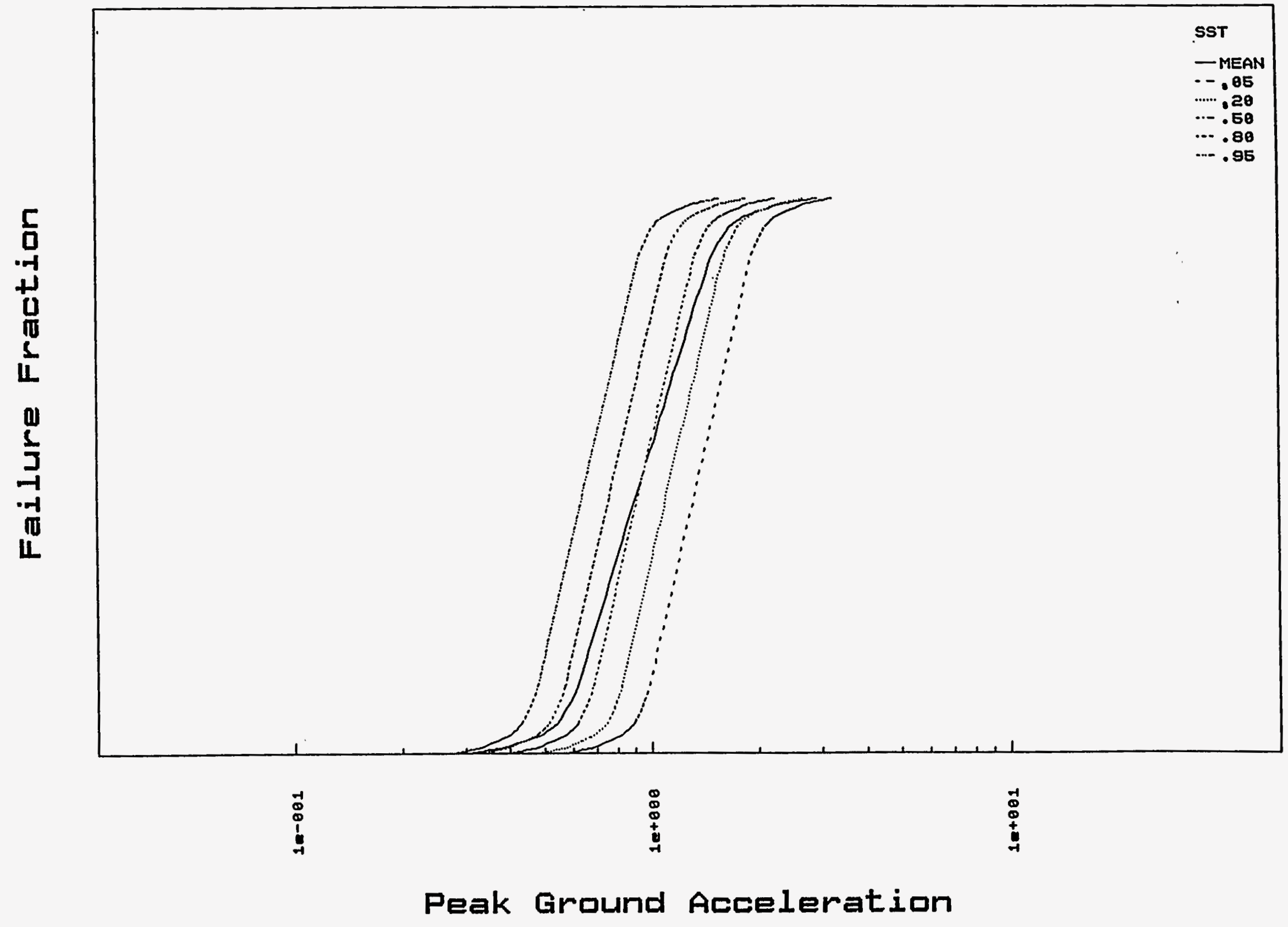






0
0
1
4
4
1
0
5
$\frac{1}{4}$ 


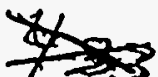

Figure $\times \times .2$ Reloase calegories for alrcrafl crash

$$
4-24
$$

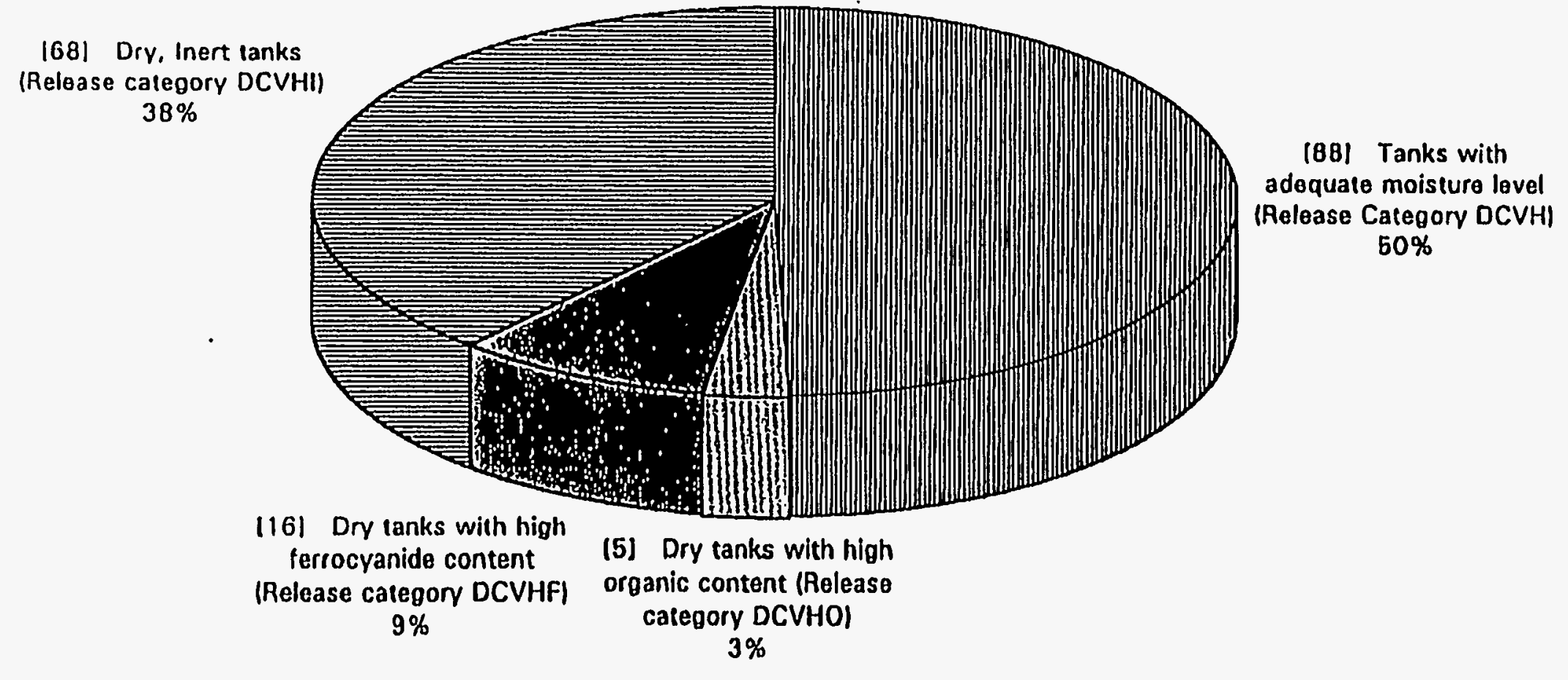




\section{Table 4-2. Burn Frequency for Passively Vented Tanks}

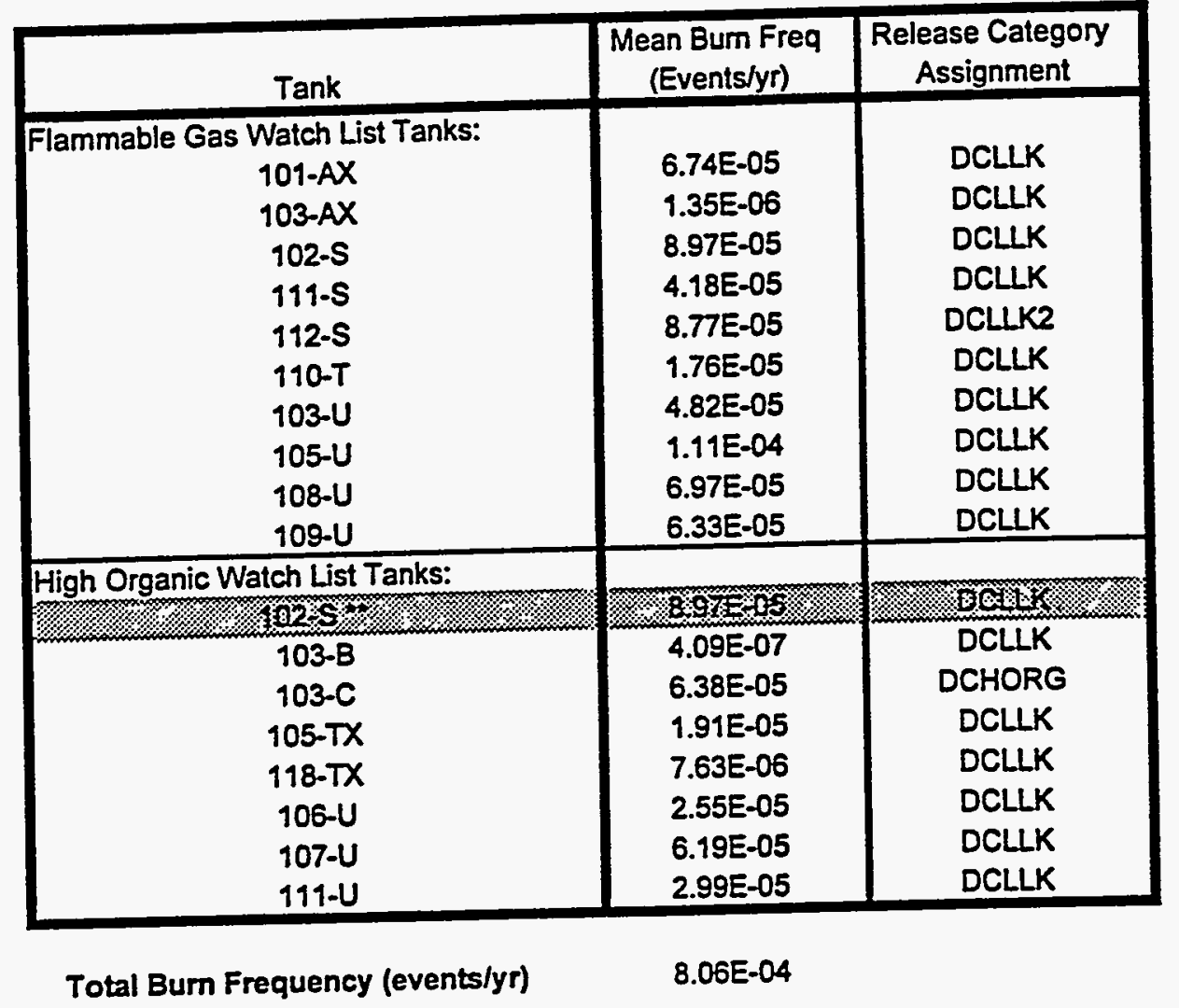

- Also on Flammable Gas Watch List 
Table 4-3. (Page 1 of 2). Updated SST Leak History

\begin{tabular}{|c|c|c|c|c|c|c|c|c|}
\hline No. & Tank & $\begin{array}{c}\text { Actual } \\
\text { Leak Year }\end{array}$ & $\begin{array}{l}\text { Declared } \\
\text { Leak Year }\end{array}$ & $\begin{array}{l}\text { Leak } \\
\text { Volume } \\
\text { (kgal) }\end{array}$ & Cause & $\begin{array}{l}\text { Tank } \\
\text { ISYR }\end{array}$ & $\begin{array}{l}\text { Tank Age } \\
\text { at Leak }\end{array}$ & $\begin{array}{c}\text { Interim } \\
\text { Stabilized Date }\end{array}$ \\
\hline 1 & $\mathrm{~B}-204$ & 1976 & 1984 & 0.4 & Corrosion & 44 & 32 & May-80 \\
\hline 2 & $C-203$ & 1976 & 1984 & 0.4 & Unknown & 44 & 32 & Feb-78 \\
\hline 3 & C-204 & 1976 & 1988 & 0.4 & Unknown & 44 & 32 & Aug-78 \\
\hline 4 & C-202 & 1976 & 1988 & 0.5 & Unknown & 44 & 32 & Jul-77 \\
\hline 5 & C-201 & 1976 & 1988 & 0.6 & Unknown & 44 & 32 & Feb-78 \\
\hline$\overline{6}$ & B-201 & 1971 & 1980 & 1 & Unknown & 44 & 27 & Jul-77 \\
\hline 7 & SX-111 & 1974 & 1974 & 1 & Overheat & 54 & 20 & Jun-75 \\
\hline 8 & $T-108$ & 1974 & 1974 & 1 & Unknown & 44 & 30 & Oct-74 \\
\hline 9 & $T-109$ & 1974 & 1974 & 1 & Unknown & 44 & 30 & Nov-80 \\
\hline 10 & $T-111$ & 1974 & 1984 & 1 & Unknown & 44 & 30 & N/A \\
\hline 11 & $T Y-101$ & 1973 & 1973 & 1 & Unknown & 52 & 21 & Jul-79 \\
\hline 12 & TY-104 & 1974 & 1981 & 1 & Unknown & 52 & 22 & Dec-78 \\
\hline 13 & A-104 & 1975 & 1975 & 2 & Overheat & 55 & 20 & Aug-74 \\
\hline 14 & B-112 & 1978 & 1978 & 2 & Unknown & 44 & 34 & Apr-81 \\
\hline 15 & $T X-107$ & 1977 & 1984 & 3 & Unknown & 48 & 29 & Sep-75 \\
\hline 16 & $T Y-103$ & 1973 & 1973 & 3 & Unknown & 52 & 21 & $\operatorname{Jan}-79$ \\
\hline 17 & $B Y-103$ & 1973 & 1973 & 5 & Unknown & 49 & 24 & N/A \\
\hline 18 & $B Y-108$ & 1971 & 1972 & 5 & Unknown & 49 & 22 & Jan-81 \\
\hline 19 & $5 x-102$ & 1993 & 1993 & 5 & Unknown & 54 & 39 & N/A \\
\hline 20 & $5 x-107$ & 1964 & 1964 & 5 & Unknown & 54 & 10 & Sep-75 \\
\hline 21 & $A-103$ & 1964 & 1987 & 6 & Unknown & 55 & 9 & Jul-84 \\
\hline 22 & $C-111$ & 1968 & 1968 & 6 & Unknown & 44 & 24 & Feb-80 \\
\hline 23 & $5 x-104$ & 1988 & 1988 & 6 & Unknown & 54 & 34 & N/A \\
\hline 24 & $5 x-110$ & 1976 & 1976 & 6 & Overheat & 54 & 22 & Jul-75 \\
\hline 25 & U-110 & 1975 & 1975 & 7 & Unknown & 44 & 31 & Nov-80 \\
\hline 26 & $B-101$ & 1974 & 1974 & 8 & Unknown & 44 & 30 & Feb-77 \\
\hline 27 & $\mathrm{~B}-103$ & 1978 & 1978 & 8 & Unknowri & 44 & 34 & Jan-81 \\
\hline 28 & B-105 & 1978 & 1978 & 8 & Unknown & 44 & 34 & Nov-80 \\
\hline 29 & B-107 & 1969 & 1980 & 8 & Unknown & 44 & 25 & Feb-81 \\
\hline 30 & $\mathrm{~B}-111$ & 1978 & 1978 & 8 & Unknown & 44 & 34 & May-81 \\
\hline 31 & $B X-111$ & 1976 & 1984 & 8 & Unknown & 47 & 29 & N/A \\
\hline 32 & $B Y-105$ & 1984 & 1984 & 8 & Unknown & 49 & 35 & N/A \\
\hline 33 & $5 x-114$ & 1972 & 1972 & 8 & Overheat & 54 & 18 & Jun-75 \\
\hline 34 & $T-107$ & 1974 & 1984 & 8 & Unknown & 44 & 30 & N/A \\
\hline 35 & $T X-105$ & 1977 & 1977 & 8 & Unknown & 48 & 29 & Aug.79 \\
\hline 36 & $T X-110$ & 1977 & 1977 & 8 & Unknown & 48 & 29 & Mar-79 \\
\hline 37 & $T X-113$ & 1971 & 1974 & 8 & Unknown & 48 & 23 & Mar-79 \\
\hline 38 & $T X-114$ & 1974 & 1974 & 8 & Unknown & 48 & 26 & Mar-79 \\
\hline 39 & $T X-115$ & 1977 & 1977 & 8 & Unknown & 48 & 29 & Aug-79 \\
\hline 40 & $T X-116$ & 1977 & 1977 & 8 & Unknown & 48 & 29 & Mar-79 \\
\hline 41 & $T X-117$ & 1969 & 1977 & 8 & Unknown & 48 & 21 & Feb-79 \\
\hline 42 & $\mathrm{U}-112$ & 1970 & 1980 & 9 & Unknown & 44 & 26 & Aug-74 \\
\hline 43 & $B-110$ & 9970 & 1981 & 10 & Unknown & 44 & 26 & Nov-80 \\
\hline 44 & $5 x-109$ & 1965 & 1965 & 10 & Unknown & 54 & 11 & Apr-77 \\
\hline 45 & $B Y-107$ & 1974 & 1984 & 15 & Overheat & 49 & 25 & Jun-75 \\
\hline 46 & $5 x-113$ & 1958 & 1962 & 15 & Overheat & 54 & 4 & Oct-74 \\
\hline 47 & $5 x-108$ & 1962 & 1962 & 18 & Unknown & 54 & 8 & Jul-75 \\
\hline 48 & C-101 & 1969 & 1980 & 20 & Unknown & 44 & 25 & Oct-79 \\
\hline 49 & TY-106 & 1959 & 1959 & 20 & Unknown & 52 & 7 & Oct-74 \\
\hline
\end{tabular}


Table 4-3 (Page 2 of 2). Updated SST Leak History

\begin{tabular}{|c|c|c|c|c|c|c|c|c|}
\hline No. & Tank & $\begin{array}{c}\text { Actual } \\
\text { Leak Year }\end{array}$ & $\begin{array}{c}\text { Declared } \\
\text { Leak Year }\end{array}$ & $\begin{array}{c}\text { Leak } \\
\text { Volume } \\
\text { (kgal) }\end{array}$ & Cause & $\begin{array}{c}\text { Tank } \\
\text { ISYR }\end{array}$ & $\begin{array}{c}\text { Tank Age } \\
\text { at Leak }\end{array}$ & $\begin{array}{c}\text { Interim } \\
\text { Stabilized Date }\end{array}$ \\
\hline 50 & $5-104$ & 1968 & 1968 & 24 & Unknown & 51 & 17 & Nov-80 \\
\hline 51 & $5 X-112$ & 1969 & 1969 & 30 & Overheat & 54 & 15 & Jun-75 \\
\hline 52 & U-101 & 1959 & 1959 & 30 & Unknown & 44 & 15 & Aug-75 \\
\hline 53 & TY-105 & 1960 & 1960 & 35 & Unknown & 52 & 8 & Jan-79 \\
\hline 54 & $5 X-115$ & 1965 & 1965 & 50 & Unknown & 54 & 11 & Aug-74 \\
\hline 55 & U-104 & 1961 & 1961 & 55 & Overheat & 44 & 17 & Sep-74 \\
\hline 56 & A-105 & 1965 & 1963 & 144 & Overheat & 55 & 10 & Jun-75 \\
\hline
\end{tabular}


Table 4-4. Recent Leaking Experience

\begin{tabular}{|c|c|c|c|}
\hline Tank & In-Service Year & Leak Age & Leak Year \\
\hline BY-105 & 1949 & 35 & 1984 \\
\hline SX-104 & 1954 & 34 & 1988 \\
\hline SX-102 & 1954 & 39 & 1993 \\
\hline
\end{tabular}


Table 4-5. Multiple Leaks in Same Tank Farms

\begin{tabular}{|l|c|c|c|l|c|}
\hline $\begin{array}{c}\text { Farm } \\
\text { I.D. }\end{array}$ & $\begin{array}{c}\text { Total } \\
\text { Tanks }\end{array}$ & $\begin{array}{c}\text { Total } \\
\text { Leakers }\end{array}$ & $\begin{array}{c}\text { Year of } \\
\text { Multiple } \\
\text { Leakers }\end{array}$ & Number of Multiple Leakers & $\begin{array}{c}\text { Life } \\
\text { Span }\end{array}$ \\
\hline T & 16 & 4 & 1974 & $4(T-107,108,109,111)$ & 50 \\
\hline C & 16 & 6 & 1976 & $4(\mathrm{C}-201,202,203,204)$ & 50 \\
\hline TX & 18 & 8 & 1977 & $5(T X-105,107,110,115,116)$ & 46 \\
\hline B & 16 & 9 & 1978 & $4(\mathrm{~B}-103,105,111,112)$ & 50 \\
\hline
\end{tabular}


Table 4-23. SST Leak Frequency Analysis

SST LEAK EVENTS AND FREQUENCIES

\begin{tabular}{|c|c|c|c|c|c|}
\hline PERIOD & TOTAL LEAKS & $\begin{array}{c}\text { LEAKS WIO } \\
\text { COMMON } \\
\text { CAUSE FAILURE }\end{array}$ & $\begin{array}{l}\text { LEAKS WIO CCF } \\
\text { \& OVERHEAT }\end{array}$ & $\begin{array}{c}\text { TANK } \\
\text { POPULATION }\end{array}$ & $\begin{array}{c}\text { LEAK } \\
\text { FREQUENCY } \\
\text { (ITANKYEAR) }\end{array}$ \\
\hline \multicolumn{5}{|c|}{ ACTIVE OPERATING ERA: } & 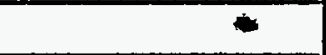 \\
\hline $45-49$ & 0 & 0 & 0 & 106 & $0.00 E+0$ \\
\hline $50-54$ & 0 & 0 & $\overline{0}$ & 139 & $0.00 E+0$ \\
\hline $55-59$ & 3 & 3 & 2 & 142 & $2.82 \mathrm{E}-3$ \\
\hline $60-64$ & 5 & 5 & 4 & 141 & $5.67 \mathrm{E}-3$ \\
\hline $65-69$ & 9 & $\overline{9}$ & 6 & 132 & $9.09 \mathrm{E}-3$ \\
\hline $70-74$ & 18 & 14 & 12 & 114 & $2.11 \mathrm{E}-2$ \\
\hline $75-79$ & 18 & 5 & 3 & 96 & $6.25 \mathrm{E}-3$ \\
\hline Average & 7.57 & 5.14 & 3.86 & 124.29 & $6.41 E-3$ \\
\hline Std. Dev. & 7.76 & 5.01 & 4.18 & & $7.27 \mathrm{E}-3$ \\
\hline \multicolumn{6}{|c|}{ NON-OPERATING ERA: } \\
\hline $80-84$ & 1 & 1 & 1 & 95 & $2.11 E-3$ \\
\hline $85-89$ & 1 & 1 & 1 & 94 & $2.13 \mathrm{E}-3$ \\
\hline $90-94$ & 1 & 1 & 1 & 93 & $2.15 \mathrm{E}-3$ \\
\hline Average & 1 & 1 & 1 & 94 & $2.13 \mathrm{E}-3$ \\
\hline Std. Dev. & 0.00 & 0.00 & 0.00 & & $2.26 \mathrm{E}-5$ \\
\hline
\end{tabular}

FINAL SST LEAK FREQUENCY DISTRIBUTION (PER TANK PER YEAR)

\begin{tabular}{|c|c|c|c|c|c|}
\hline MEAN & 5 th & 20 th & 50 th & 80th & 95th \\
\hline $4.58 \mathrm{E}-03$ & $1.27 \mathrm{E}-3$ & $2.13 \mathrm{E}-3$ & $3.70 \mathrm{E}-3$ & $6.33 \mathrm{E}-3$ & $1.08 \mathrm{E}-2$ \\
\hline
\end{tabular}


Table 4-7. Double-Shell Tank Experience

\begin{tabular}{|l|c|c|c|c|}
\hline $\begin{array}{c}\text { Tank Farm } \\
\text { I.D. }\end{array}$ & $\begin{array}{c}\text { Number of } \\
\text { Tanks }\end{array}$ & $\begin{array}{c}\text { Commission } \\
\text { Year }\end{array}$ & $\begin{array}{c}\text { Tank Age in } \\
1994\end{array}$ & $\begin{array}{c}\text { Total } \\
\text { Tank-Years }\end{array}$ \\
\hline $\mathrm{AY}$ & 2 & 1970 & 24 & 48 \\
\hline $\mathrm{AZ}-101$ & 1 & 1973 & 21 & 21 \\
\hline $\mathrm{AZ}-102$ & 1 & 1977 & 17 & 17 \\
\hline $\mathrm{SY}$ & 3 & 1976 & 18 & 54 \\
\hline $\mathrm{AW}$ & 6 & 1980 & 14 & 84 \\
\hline $\mathrm{AN}$ & 7 & 1981 & 13 & 91 \\
\hline $\mathrm{AP}$ & 8 & 1986 & 8 & 64 \\
\hline & 28 & & & 379 \\
\hline Total & & 1980.5 & 13.5 & \\
\hline
\end{tabular}


Table 4-8. Tank Farms with Active Ventilation Systems

\begin{tabular}{|l|l|}
\hline \multicolumn{1}{|c|}{ Tank Farm } & \multicolumn{1}{|c|}{ Tanks Serviced (Number of Tanks) } \\
\hline AN & All (7) \\
\hline AP & All (8) \\
\hline AW & All (6) \\
\hline AY, AZ $\left(^{*}\right)$ & All $(4)$ \\
\hline SY & All (3) \\
\hline A & $104,105,106$ \\
\hline C & $104,105,106$ \\
\hline SX & 101 through 112,114 \\
\hline *Common ventilation system for AY and AZ tank farms. \\
\hline
\end{tabular}




\begin{tabular}{|c|c|c|}
\hline Peak Acceleration $(\mathrm{g})$ & Site 1 & Site N \\
\hline 0.05 & $1.51 \times 10^{-3}$ & $1.45 \times 10^{-3}$ \\
0.10 & $5.76 \times 10^{-4}$ & $5.68 \times 10^{-4}$ \\
0.15 & $2.94 \times 10^{-4}$ & $2.77 \times 10^{-4}$ \\
0.20 & $1.71 \times 10^{-4}$ & $1.49 \times 10^{-4}$ \\
0.25 & $1.07 \times 10^{-4}$ & $8.47 \times 10^{-5}$ \\
0.30 & $7.02 \times 10^{-5}$ & $4.96 \times 10^{-5}$ \\
0.35 & $4.74 \times 10^{-5}$ & $2.98 \times 10^{-5}$ \\
0.40 & $3.27 \times 10^{-5}$ & $1.81 \times 10^{-5}$ \\
0.50 & $1.62 \times 10^{-5}$ & $6.92 \times 10^{-6}$ \\
0.60 & $8.29 \times 10^{-6}$ & $2.71 \times 10^{-6}$ \\
0.70 & $4.37 \times 10^{-6}$ & $1.08 \times 10^{-6}$ \\
1.00 & $6.91 \times 10^{-7}$ & $4.95 \times 10^{-6}$ \\
\hline
\end{tabular}

Source: Ref.3. 
Table 4-10. Mean Annual Frequencies of Acceleration Ranges

\begin{tabular}{|c|c|c|c|c|}
\hline \multicolumn{5}{|c|}{ Acceleration Range $(\mathrm{g})$} \\
\hline $0.10-0.43$ & $0.43-0.50$ & $0.50-0.60$ & $0.60-0.80$ & $0.80-1.28$ \\
\hline \multicolumn{5}{|c|}{ Designated Acceleration } \\
\hline 0.25 & $\mathbf{0 . 4 5}$ & 0.55 & $\mathbf{0 . 7 0}$ & 1.0 \\
\hline $5.5 \mathrm{E}-04$ & $1.03 \mathrm{E}-05$ & $7.91 \mathrm{E}-06$ & $5.93 \mathrm{E}-06$ & $2.26 \mathrm{E}-06$ \\
\hline
\end{tabular}


Table 4-11. Component Fragilities

\begin{tabular}{|l|c|c|c|c|l|}
\hline \multicolumn{1}{|c|}{ Component } & $\$(\mathrm{~g})$ & $\beta_{\mathrm{R}}$ & $\beta_{\mathrm{U}}$ & HCLPF $(\mathrm{g})$ & \multicolumn{1}{|c|}{ Failure Mode } \\
\hline 1. Offsite Power & 0.30 & 0.25 & 0.50 & 0.10 & $\begin{array}{l}\text { Substation } \\
\text { Transformer Insulators }\end{array}$ \\
\hline 2. Electrical Power & 0.50 & 0.25 & 0.34 & 0.19 & Component Function \\
\hline $\begin{array}{l}\text { 3. Instrument/ } \\
\text { Control Panels }\end{array}$ & 0.80 & 0.25 & 0.17 & 0.40 & Instrument Function \\
\hline 4. Primary Tank & 0.94 & 0.27 & 0.36 & 0.33 & $\begin{array}{l}\text { Shear Buckling and } \\
\text { Cracking at Knuckle } \\
\text { (Dome Collapse } \\
\text { 1.0g) }\end{array}$ \\
\hline 5. Exhaust Ducts & $>1.0$ & & & & \\
\hline 6. Exhaust Fan & $>1.0$ & & & & \\
\hline $\begin{array}{l}\text { 7. Above-Ground } \\
\text { Piping }\end{array}$ & $>1.0$ & & & & \\
\hline 8. Secondary Tank & $>1.0$ & & & & \\
\hline $\begin{array}{l}\text { 9. Single-Shell } \\
\text { Tank }\end{array}$ & .95 & .26 & .22 & .43 & Dome Collapse \\
\hline
\end{tabular}


Table 4-12. Unconditional Component Failure Fractions

\begin{tabular}{|l|c|c|c|c|c|c|}
\hline \multirow{2}{*}{ Components } & \multicolumn{5}{|c|}{ Acceleration Ranges (g) } \\
\cline { 2 - 7 } & $\mathbf{0 . 2 5}$ & $\mathbf{0 . 4 5}$ & $\mathbf{0 . 5 5}$ & $\mathbf{0 . 7 0}$ & 1.0 & Total \\
\hline Offsite Power & $1.01 \mathrm{E}-04$ & $\mathbf{8 . 1 0 \mathrm { E } - 0 6}$ & $6.83 \mathrm{E}-06$ & $5.52 \mathrm{E}-06$ & $2.21 \mathrm{E}-06$ & $1.24 \mathrm{E}-04$ \\
\hline Electrical Panel & $1.47 \mathrm{E}-05$ & $4.41 \mathrm{E}-06$ & $4.62 \mathrm{E}-06$ & $4.54 \mathrm{E}-06$ & $2.09 \mathrm{E}-06$ & $3.04 \mathrm{E}-05$ \\
\hline $\begin{array}{l}\text { Instrument/Control } \\
\text { Panels }\end{array}$ & $1.07 \mathrm{E}-07$ & $3.78 \mathrm{E}-07$ & $8.37 \mathrm{E}-07$ & $1.78 \mathrm{E}-06$ & $1.54 \mathrm{E}-06$ & $4.64 \mathrm{E}-06$ \\
\hline Primary Tank (DST) & $6.44 \mathrm{E}-07$ & $6.13 \mathrm{E}-07$ & $9.15 \mathrm{E}-07$ & $1.41 \mathrm{E}-06$ & $1.12 \mathrm{E}-06$ & $4.70 \mathrm{E}-06$ \\
\hline Tank (SST) & 0.00 & $1.89 \mathrm{E}-07$ & $4.27 \mathrm{E}-07$ & $1.00 \mathrm{E}-06$ & $1.09 \mathrm{E}-06$ & $2.71 \mathrm{E}-06$ \\
\hline
\end{tabular}


Table 4-13. Aircraft Crash Frequency

\begin{tabular}{|c|c|c|c|c|}
\hline \multirow{2}{*}{ Description } & \multicolumn{4}{|c|}{ Annual Frequency (Crashes/Tank-Year) } \\
\cline { 2 - 5 } & Mean & 5th Percentile & $\begin{array}{c}\text { 50th } \\
\text { Percentile }\end{array}$ & $\begin{array}{c}\text { 95th } \\
\text { Percentile }\end{array}$ \\
\hline Aircraft Crash & $3.08 \mathrm{E}-09$ & $3.39 \mathrm{E}-10$ & $1.83 \mathrm{E}-09$ & $1.04 \mathrm{E}-08$ \\
\hline
\end{tabular}




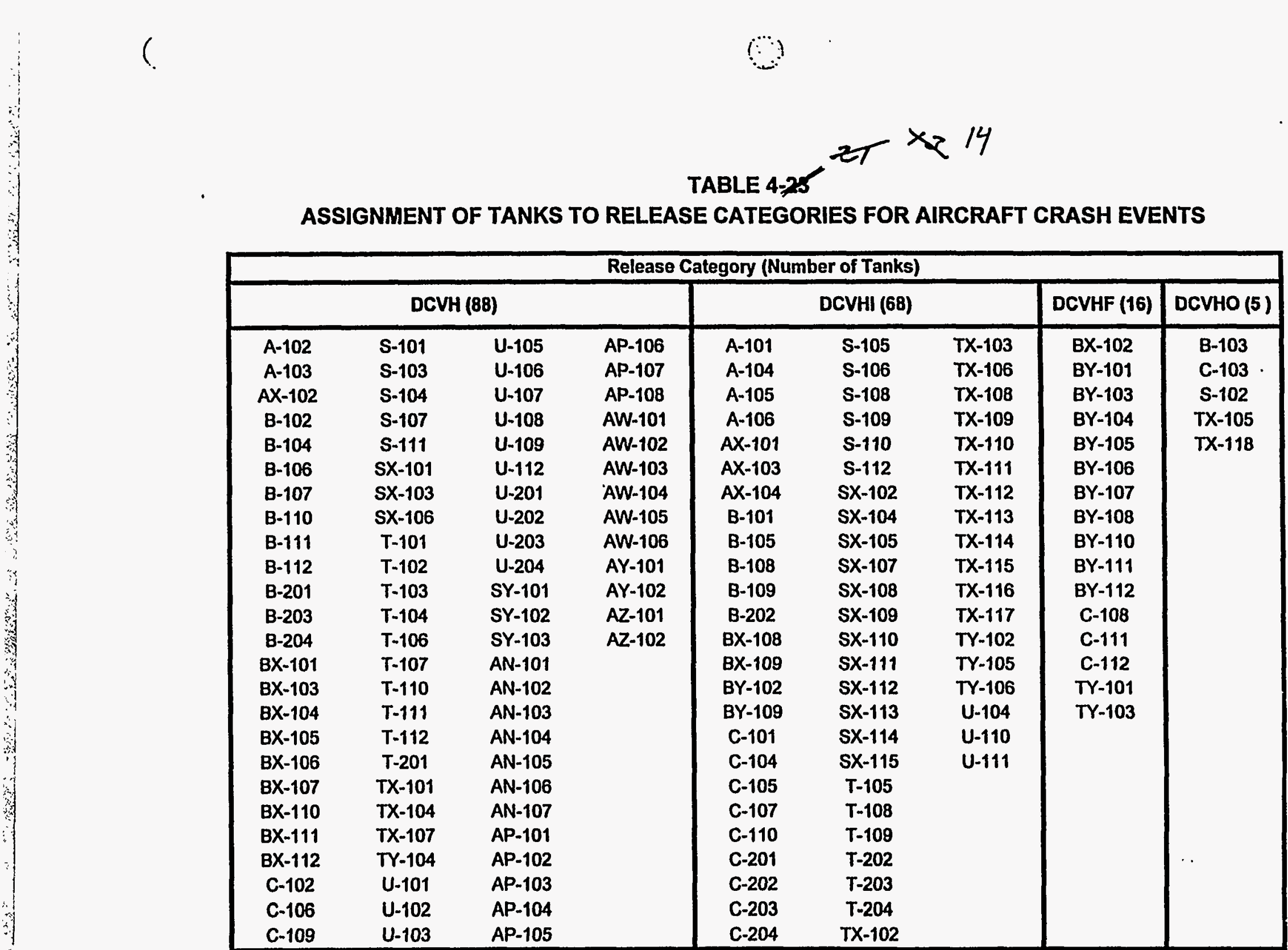


Table 4-15. Annual Release Frequencies for Release Categories DCVH, DCVHO, DCVHF and DCVHI

\begin{tabular}{|l|c|c|c|c|c|}
\hline Description & Number of & \multicolumn{4}{|c|}{ Annual Frequency (Crashes/Year) } \\
\hline $\begin{array}{c}\text { Release } \\
\text { Category }\end{array}$ & Tanks & Mean & 5th Percentile & $\begin{array}{c}50 \text { th } \\
\text { Percentile }\end{array}$ & $\begin{array}{c}\text { 95th } \\
\text { Percentile }\end{array}$ \\
\hline Single Tank & & $3.08 \mathrm{E}-09$ & $3.39 \mathrm{E}-10$ & $1.83 \mathrm{E}-09$ & $1.04 \mathrm{E}-08$ \\
\hline DCVH & 88 & $2.71 \mathrm{E}-07$ & $2.98 \mathrm{E}-08$ & $1.61 \mathrm{E}-07$ & $9.15 \mathrm{E}-07$ \\
\hline DCVHO & 5 & $1.54 \mathrm{E}-08$ & $1.70 \mathrm{E}-09$ & $9.15 \mathrm{E}-09$ & $5.20 \mathrm{E}-08$ \\
\hline DCVHF & 16 & $4.93 \mathrm{E}-08$ & $5.42 \mathrm{E}-09$ & $2.93 \mathrm{E}-08$ & $1.66 \mathrm{E}-07$ \\
\hline DCVHI & 68 & $2.09 \mathrm{E}-07$ & $2.31 \mathrm{E}-08$ & $1.24 \mathrm{E}-07$ & $7.07 \mathrm{E}-07$ \\
\hline
\end{tabular}


TABLE 4.3-T $4=25 / 6$

INITIATING EVENTS USED IN THE HTF PSA

\begin{tabular}{|c|c|c|c|c|c|c|}
\hline \multicolumn{2}{|r|}{ INITIATING EVENT } & \multicolumn{4}{|c|}{ ANNUAL FREQUENCY } & \multirow{2}{*}{$\begin{array}{c}\text { SECTION } \\
\text { REFERENCE }\end{array}$} \\
\hline CODE & DESCRIPTION & MEAN & $5 \%$ & $50 \%$ & $95 \%$ & \\
\hline BURP & Hydrogen Gas Release from Tank SY-101 & $3.51 E+0$ & $2.64 \mathrm{E}+0$ & $3.44 E+0$ & $4.47 E+0$ & $\overline{4.2 .1}$ \\
\hline AX101H2 & Hydrogen Generation and Ignition in SST AX-101 & $6.74 \mathrm{E}-5$ & $0.00 E+00$ & $0.00 E+0$ & $2.00 E-4$ & 4.2 .1 \\
\hline$\overline{A \times 103 \mathrm{H} 2}$ & Hydrogen Generation and lgnition in SST AX-103 & $1.35 \mathrm{E}-6$ & $0.00 E+00$ & $0.00 \mathrm{E}+0$ & $0.00 \mathrm{E}+0$ & 4.2 .1 \\
\hline \begin{tabular}{|l|}
$\mathrm{B} 103 \mathrm{H} 2$ \\
\end{tabular} & Hydrogen Generation and Ignition in SST B-103 & $4.09 E-7$ & $0.00 E+00$ & $0.00 E+0$ & $0.00 E+0$ & 4.2 .1 \\
\hline C103H2 & Hydrogen Generation and Ignition in SST C-103 & $6.38 \mathrm{E}-5$ & $0.00 E+00$ & $0.00 E+0$ & $1.92 E-4$ & $\overline{4.2 .1}$ \\
\hline $\mathrm{S} 102 \mathrm{H} 2$ & Hydrogen Generation and Ignition in SST S-102 & $8.97 E-5$ & $0.00 E+00$ & $0.00 \mathrm{E}+0$ & $2.94 \mathrm{E}-4$ & 4.2 .1 \\
\hline S111H2 & Hydrogen Generation and Ignition in SST S-111 & $4.18 \mathrm{E}-5$ & $0.00 E+00$ & $0.00 \mathrm{E}+0$ & $2.62 \mathrm{E}-4$ & 4.2 .1 \\
\hline $\mathrm{S} 112 \mathrm{H} 2$ & Hydrogen Generation and Ignition in SST S-112 & $8.77 E-5$ & $0.00 \mathrm{E}+00$ & $0.00 E+0$ & $2.91 E-4$ & $\overline{4.2 .1}$ \\
\hline $\mathrm{T} 110 \mathrm{H} 2$ & Hydrogen Generation and Ignition in SST T-110 & $1.76 E-5$ & $0.00 \mathrm{E}+00$ & $0.00 E+0$ & $0.00 \mathrm{E}+0$ & 4.2 .1 \\
\hline TX105H2 & Hydrogen Generation and Ignition in SST TX-105 & $1.91 E-5$ & $0.00 E+00$ & $0.00 E+0$ & $5.09 \mathrm{E}-5$ & 4.2 .1 \\
\hline$\overline{\mathrm{TX} 118 \mathrm{H} 2}$ & Hydrogen Generation and Ignition in SST TX-118 & $7.63 \mathrm{E}-6$ & $0.00 E+00$ & $0.00 E+0$ & $0.00 E+0$ & 4.2 .1 \\
\hline $\mathrm{U} 103 \mathrm{H} 2$ & Hydrogen Generation and Ignition in SST U-103 & $4.82 \mathrm{E}-5$ & $0.00 \mathrm{E}+00$ & $0.00 E+0$ & $3.13 E-4$ & 4.2 .1 \\
\hline $\mathrm{U} 105 \mathrm{H} 2$ & Hydrogen Generation and Ignition in SST U-105 & $1.11 \mathrm{E}-4$ & $0.00 \mathrm{E}+00$ & $0.00 E+0$ & $7.07 E-4$ & 4.2 .1 \\
\hline U106H2 & Hydrogen Generation and Ignition in SST U-106 & $2.55 E-5$ & $0.00 E+00$ & $0.00 E+0$ & $2.28 \mathrm{E}-5$ & 4.2 .1 \\
\hline U107H2 & Hydrogen Generation and Ignition in SST U-107 & $6.19 E-5$ & $0.00 E+00$ & $0.00 E+0$ & $1.79 E-4$ & 4.2 .1 \\
\hline $\mathrm{U} 108 \mathrm{H} 2$ & Hydrogen Generation and Ignition in SST U-108 & $6.97 E-5$ & $0.00 E+00$ & $0.00 E+0$ & $2.13 E-4$ & $\overline{4.2 .1}$ \\
\hline $\mathrm{U} 109 \mathrm{H} 2$ & Hydrogen Generation and Ignition in SST U-109 & $6.33 \mathrm{E}-5$ & $0.00 E+0$ & $0.00 E+0$ & $1.84 E-4$ & 4.2 .1 \\
\hline U111H2 & Hydrogen Generation and Ignition in SST U-111 & $2.99 \mathrm{E}-5$ & $0.00 E+0$ & $0.00 E+0$ & $3.53 \mathrm{E}-5$ & 4.2 .1 \\
\hline \begin{tabular}{|l|} 
DSTSB \\
\end{tabular} & Leak/Breach of the Primary Tank of a Double Shell Tank & $1.28 \mathrm{E}-1$ & $3.63 E-2$ & $1.04 \mathrm{E}-1$ & $2.96 E-1$ & 4.2 .2 \\
\hline SSTSB & Leak/Breach of a Single Shell Tank & $4.26 E-1$ & $1.20 \mathrm{E}-1$ & $3.44 \mathrm{E}-1$ & $9.84 E-1$ & 4.2 .2 \\
\hline DOMEF & Dome Failure Event (Nonseismic) & $3.28 E-2$ & $7.14 E-3$ & $2.09 E-2$ & $7.22 E-2$ & 4.2 .3 \\
\hline RVB & Ventilation Riser or Vent Line Breach & $1.98 E+0$ & $\overline{6.59 E-1}$ & $1.68 E+0$ & $3.54 E+0$ & 4.2 .4 \\
\hline FB & Ventilation Exhaust HEPA Filter Failure & $7.73 \mathrm{E}-1$ & $3.44 E-1$ & $7.00 \mathrm{E}-1$ & $1.22 E+0$ & 4.2 .5 \\
\hline$\overline{\mathrm{VDL}}$ & Active Ventilation System Drainage Leak & $2.24 \mathrm{E}-1$ & $3.88 E-2$ & $1.69 \mathrm{E}-1$ & 4.71E-1 & 4.2 .6 \\
\hline LOTVA & $\begin{array}{l}\text { Loss of Ventilation in Actively Ventilated Tanks (Excluding } \\
\text { Aging Waste Tanks) }\end{array}$ & 4.11E+0 & $3.05 E+0$ & $3.98 E+0$ & $5.03 E+0$ & 4.2.7 \\
\hline
\end{tabular}


TABLE 4.3FT $y-\not 5 / 6$

INITIATING EVENTS USED IN THE HTF PSA

\begin{tabular}{|c|c|c|c|c|c|c|}
\hline \multicolumn{2}{|r|}{ INITIATING EVENT } & \multicolumn{4}{|c|}{ ANNUAL FREQUENCY } & \multirow{2}{*}{$\begin{array}{c}\text { SECTION } \\
\text { REFERENCE }\end{array}$} \\
\hline CODE & DESCRIPTION & MEAN & $5 \%$ & $50 \%$ & $95 \%$ & \\
\hline LOTVAW & Loss of Ventilation in Aging Waste Tanks & $6.54 \mathrm{E}-1$ & $4.74 E-1$ & $6.36 \mathrm{E}-1$ & $8.14 \mathrm{E}-1$ & 4.2 .7 \\
\hline LOTM & Loss of Tank Mixing & $8.23 E-2$ & $1.03 E-2$ & $5.10 \mathrm{E}-2$ & $2.52 E-1$ & 4.2 .8 \\
\hline WIA & Water Intrusion into an Active (in service) Tank & $5.36 \mathrm{E}-1$ & $3.13 E-1$ & $4.99 \mathrm{E}-1$ & $7.60 \mathrm{E}-1$ & 4.2 .10 \\
\hline WIPI & Water Intrusion into a Partially Interim Isolated Tank & $4.95 \mathrm{E}-1$ & $2.76 \mathrm{E}-1$ & 4.67E-1 & $7.08 \mathrm{E}-1$ & 4.2 .10 \\
\hline WIIP & Water Intrusion into an Intrusion Prevented Tank & $1.75 \mathrm{E}-1$ & $1.29 \mathrm{E}-2$ & $1.23 \mathrm{E}-1$ & $4.13 E-1$ & 4.2 .10 \\
\hline WT & Waste Transfer & $1.00 \mathrm{E}+3$ & $8.05 \mathrm{E}+2$ & $1.00 E+3$ & $1.19 \mathrm{E}+3$ & 4.2 .11 \\
\hline SEIS1 & $0.25 \mathrm{~g}$ Seismic Event & $5.50 \mathrm{E}-4$ & Note 1 & & & 4.2 .13 \\
\hline SEIS2 & $0.45 \mathrm{~g}$ Seismic Event & $1.03 \mathrm{E}-5$ & Note 1 & & & 4.2.13 \\
\hline SEIS3 & $0.55 \mathrm{~g}$ Seismic Event & $7.91 E-6$ & Note 1 & & & 4.2 .13 \\
\hline SEIS4 & $0.70 \mathrm{~g}$ Seismic Event & $5.93 E-6$ & Note 1 & & & 4.2 .13 \\
\hline SEIS5 & 1.0g Seismic Event & $2.26 \mathrm{E}-6$ & Note 1 & & & 4.2 .13 \\
\hline$\overline{\mathrm{ACH}}$ & Aircraft Crash (Tanks with Adequate Moisture) & $2.71 E-7$ & $2.98 \mathrm{E}-8$ & $1.61 \mathrm{E}-7$ & 9.15E-7 & 4.2.14 \\
\hline$\overline{\mathrm{ACH}}$ & Aircraft Crash (Dry, Inert Tanks) & $2.09 E-7$ & 2.31E-8 & $1.24 \mathrm{E}-7$ & 7.07E-7 & 4.2 .14 \\
\hline$\overline{\mathrm{ACHF}}$ & Aircraft Crash (Dry Tanks with High Ferrocyanide Content) & 4.93E-8 & 5.42E-9 & 2.93E-8 & $1.66 \mathrm{E}-7$ & 4.2 .14 \\
\hline $\mathrm{ACHO}$ & Aircraft Crash (Dry Tanks with High Organic Content) & $1.54 \mathrm{E}-8$ & $1.70 \mathrm{E}-9$ & $9.15 E-9$ & $5.20 \mathrm{E}-8$ & 4.2 .14 \\
\hline
\end{tabular}

Note 1: Point estimate mean values were used for the discrete seismic initiating event frequencies. 
TABLE 4.3-2 $4-16 / 7$

\section{HFT PRA TOP EVENT SPLIT FRACTION VALUES}

\begin{tabular}{|c|c|c|c|c|c|c|}
\hline \multirow{2}{*}{\multicolumn{2}{|c|}{ TOP EVENT AND SPLIT FRACTION DESCRIPTIONS }} & \multicolumn{4}{|c|}{ SPLIT FRACTION VALUES } & \multirow{2}{*}{$\begin{array}{l}\text { SECTION } \\
\text { REFERENCE }\end{array}$} \\
\hline & & MEAN & 5\%tile & 50\%tile & 95\%tile & \\
\hline \multicolumn{7}{|c|}{ Top Event: ARM } \\
\hline \multicolumn{7}{|c|}{ Description: AREA RADIATION MONITOR ALARM } \\
\hline ARM1 & ARM FAILS TO ALARM DURING LEAK & $1.00 \mathrm{E}-01$ & Note 1 & & & 4.2 .11 \\
\hline ARM2 & ARM FAILS TO ALARM DURING SPARY & $5.00 \mathrm{E}-02$ & Note 1 & & & 4.2 .11 \\
\hline \multicolumn{7}{|c|}{ Top Event: AVI } \\
\hline \multicolumn{7}{|c|}{ Description: ANNULUS VENT INTEGRITY } \\
\hline AVI1 & ANNULUS VENT PIPE FAILED & $5.88 \mathrm{E}-02$ & $2.26 \mathrm{E}-02$ & $5.14 \mathrm{E}-02$ & $1.01 \mathrm{E}-01$ & 4.2 .2 \\
\hline \multicolumn{7}{|c|}{ Top Event: COVER } \\
\hline \multicolumn{7}{|c|}{ Description: DCRT OR PUMP PIT COVER BLOCKS IN PLACE } \\
\hline COVER1 & COVER BLOCK IS NOT IN PLACE & $1.00 \mathrm{E}-01$ & Note 1 & & & 4.2 .11 \\
\hline \multicolumn{7}{|c|}{ Top Event: CRIB } \\
\hline \multicolumn{7}{|c|}{ Description: WASTE IS MISROUTED TO A CRIB } \\
\hline CRIB1 & WASTE IS ROUTED TO CRIB ; GIVEN MISROUTING & $1.60 \mathrm{E}-01$ & $7.39 \mathrm{E}-02$ & $1.44 \mathrm{E}-01$ & $2.55 E-01$ & 4.2 .11 \\
\hline \multicolumn{7}{|c|}{ Top Event: DOME } \\
\hline \multicolumn{7}{|c|}{ Description: DOME INTEGRITY } \\
\hline DOME1 & DOME COLLAPSED DUE TO HYDROGEN BURN & $1.21 E-01$ & Note 2 & & & 4.2 .1 \\
\hline \multicolumn{7}{|c|}{ Top Event: $\mathrm{H} 2 \mathrm{HI}$} \\
\hline \multicolumn{7}{|c|}{ Description: HYDROGEN CONCENTRATION IS $<4 \%$} \\
\hline $\mathrm{H} 2 \mathrm{HII}$ & IH2 IS > 4\% FOLLOWING A BOUND GAS RELEASE (BURP) & $8.85 \mathrm{E}-1$ & Note 2 & & & 4.2 .1 \\
\hline \multicolumn{7}{|c|}{ Top Event: LEAK } \\
\hline \multicolumn{7}{|c|}{ Description: FRACTION OF TANKS THAT ARE LEAKERS } \\
\hline LEAK1 & FRACTION OF ACTIVE TANKS THAT ARE LEAKER & $0.00 \mathrm{E}+00$ & Note 1 & & & 4.2 .10 \\
\hline LEAK2 & FRACTION OF PARTIALLY INTERIM ISOLATED TANKS THAT & $1.57 E-01$ & Note 1 & & & 4.2 .10 \\
\hline LEAK3 & FRACTION OF INTRUSION PREVENTED TANKS THAT ARE LE & 4.90E-01 & Note 1 & & & 4.2 .10 \\
\hline \multicolumn{7}{|c|}{ Top Event: LEVEL } \\
\hline \multicolumn{7}{|c|}{ Description: TANK LEVEL REMAINS WITHIN LIMITS FOLLOWING WATER INTRUSION EVENT } \\
\hline LEVEL1 & LEVEL EXCEEDS TANK LIMITS - WIA INITIATOR & $1.00 \mathrm{E}-01$ & Note 1 & & & 4.2 .10 \\
\hline LEVEL2 & LEVEL EXCEEDS TANK LIMITS - WIPI INITIATOR & 5.12E-02 & Note 1 & & & 4.2 .10 \\
\hline LEVEL3 & LEVEL EXCEEDS TANK LIMITS - WIA INITIATOR & $2.80 E-02$ & Note 1 & & & 4.2 .10 \\
\hline
\end{tabular}


TABLE $4+3-2$ - $4-17$

HFT PRA TOP EVENT SPLIT FRACTION VALUES

\begin{tabular}{|c|c|c|c|c|c|c|}
\hline \multirow{2}{*}{\multicolumn{2}{|c|}{ TOP EVENT AND SPLIT FRACTION DESCRIPTIONS }} & \multicolumn{4}{|c|}{ SPLIT FRACTION VALUES } & \multirow{2}{*}{$\begin{array}{l}\text { SECTION } \\
\text { REFERENCE }\end{array}$} \\
\hline & & MEAN & $5 \%$ tile & $50 \%$ tile & 95\%tile & \\
\hline \multicolumn{7}{|c|}{ Top Event: LI } \\
\hline \multicolumn{7}{|c|}{ Description: TANK LEVEL INDICATION AVAILABLE } \\
\hline LII & LEVEL INDICATION UNAVAILABLE - ACTIVE TANKS & $2.29 \mathrm{E}-01$ & $1.52 \mathrm{E}-01$ & $1.89 \mathrm{E}-01$ & $3.61 \mathrm{E}-01$ & 4.2 .10 \\
\hline $\mathrm{LL}$ & LEVEL INDICATION UNAVAILABLE - PARTILLY INTERIM ISOLA & $1.62 \mathrm{E}-01$ & $7.96 \mathrm{E}-02$ & $1.22 \mathrm{E}-01$ & $3.03 \mathrm{E}-01$ & 4.2.10 \\
\hline$L 13$ & LEVEL INDICATION UNAVAILABLE - INTRUSION PREVENTED & $1.74 \mathrm{E}-01$ & $9.09 \mathrm{E}-02$ & $1.31 \mathrm{E}-01$ & $3.19 \mathrm{E}-01$ & 4.2 .10 \\
\hline \multirow{2}{*}{\multicolumn{7}{|c|}{$\begin{array}{l}\text { Top Event: OP } \\
\text { Descrintion: OPERATOR RESPONDS TO INCREASING TANK LEVEL AND PREVENTS RELEASE }\end{array}$}} \\
\hline & & & & & & \\
\hline OP1 & OOPERATOR FAILS TO PREVENT A RELEASE & $1.30 \mathrm{E}-02$ & $1.42 \mathrm{E}-03$ & $7.07 \mathrm{E}-03$ & $3.32 \mathrm{E}-02$ & 4.2 .10 \\
\hline \multicolumn{7}{|c|}{ Top Event: ORV } \\
\hline \multicolumn{7}{|c|}{ Description: OPERATOR RECOVERS PRIMARY TANK VENTILATION } \\
\hline ORV1 & JOPERATOR FAILS TO TO RECOVER VENTILATION & $1.30 \mathrm{E}-02$ & $1.42 \mathrm{E}-03$ & $7.07 \mathrm{E}-03$ & $3.32 \mathrm{E}-02$ & 4.2 .7 \\
\hline \multicolumn{7}{|c|}{ Top Event: PROP } \\
\hline \multicolumn{7}{|c|}{ Description: NO BURN PROPAGATION FROM VENT LINE TO TANK } \\
\hline PROP1 & H2 BURN PROPAGATES FROM VENT LINE INTO THE TANK & $8.33 E-2$ & Note 2 & & & 4.2 .1 \\
\hline \multicolumn{7}{|c|}{ Top Event: ROUTE } \\
\hline \multicolumn{7}{|c|}{ Description: WASTE TRANSFER ROUTED PROPERLY } \\
\hline ROUTE1 & IWASTE TRANSFER INCORRECTLY ROUTED & $3.99 \mathrm{E}-03$ & $2.78 \mathrm{E}-03$ & $3.79 \mathrm{E}-03$ & $5.22 \mathrm{E}-03$ & 4.2 .11 \\
\hline \multicolumn{7}{|c|}{ Top Event: SIZE } \\
\hline \multicolumn{7}{|c|}{ Description: LEAK SIZE IS LESS THAN 10,000 GALLONS } \\
\hline SIZE1 & ILEAK SIZE GREATER THAN 10 KGAL GIVEN LEAK IN SST & $1.31 \mathrm{E}-01$ & Note 1 & & & 4.2 .2 \\
\hline SIZE2 & LEAK SIZE GREATER THAN 10 KGAL GIVEN DST LEAK & $1.00 E+0$ & & & & 4.2 .2 \\
\hline \multicolumn{7}{|c|}{ Top Event: SPRAY } \\
\hline \multicolumn{7}{|c|}{ Description: NO SPRAY LEAK OCCURS } \\
\hline \begin{tabular}{|l} 
SPRAYI \\
\end{tabular} & TSPRAY LEAK OCCURS IN DCRT OR PUMP PIT & $9.06 \mathrm{E}-05$ & $7.35 \mathrm{E}-06$ & $6.37 \mathrm{E}-05$ & $2.04 E-04$ & 4.2 .11 \\
\hline \multicolumn{7}{|c|}{$\begin{array}{l}\text { Top Event: SSI } \\
\text { Description: SECC }\end{array}$} \\
\hline SSI1 & $\begin{array}{l}\text { SECONDARY TANK SHELL FAILS AFTER PRIMARY TANK } \\
\text { FAILURE }\end{array}$ & 8.54E-02 & $2.28 \mathrm{E}-02$ & $6.53 E-02$ & $1.73 E-01$ & 4.2 .2 \\
\hline
\end{tabular}




\section{HFT PRA TOP EVENT SPLIT FRACTION VALUES}

\begin{tabular}{|c|c|c|c|c|c|}
\hline \multirow[t]{2}{*}{ - TOP EVENT AND SPLIT FRACTION DESCRIPTIONS } & \multicolumn{4}{|c|}{ SPLIT FRACTION VALUES } & \multirow{2}{*}{$\begin{array}{l}\text { SECTION } \\
\text { REFERENCE }\end{array}$} \\
\hline & MEAN & $5 \%$ tile & $50 \%$ tile & $95 \%$ tile & \\
\hline \multicolumn{6}{|l|}{ Top Event: TBRN } \\
\hline \multicolumn{6}{|l|}{ Description: NO HYDROGEN BURN IN TANK } \\
\hline \begin{tabular}{|l|l} 
TBRN1 & H2 BURN IN TANK AFTER BURP IN SY-101 \\
\end{tabular} & $1.28 \mathrm{E}-3$ & Note 2 & & & 4.2 .1 \\
\hline \multicolumn{6}{|l|}{ Top Event: TLL } \\
\hline \multicolumn{6}{|l|}{ Description: NO LEAK IN WASTE TRANSFER LINE } \\
\hline \begin{tabular}{|l|l|} 
TLL1 & TRANSFER LINE LEAK \\
\end{tabular} & $9.28 E-04$ & $5.28 \mathrm{E}-04$ & $8.67 E-04$ & $1.33 \mathrm{E}-03$ & 4.2 .11 \\
\hline \multicolumn{6}{|l|}{ Top Event: VBRN } \\
\hline \multicolumn{6}{|l|}{ Description: NO H2 BURN IN VENT SYSTEM } \\
\hline H2 IGNITION IN VENT DUCT AFTER BURP & $6.60 \mathrm{E}-03$ & Note 2 & & & 4.2 .1 \\
\hline \multicolumn{6}{|l|}{ Top Event: VOP } \\
\hline \multicolumn{6}{|l|}{ Description: VENTILATION CONTINUES TO RUN } \\
\hline \begin{tabular}{|l|l} 
VOP1 & VENTILATION FAILURE WITH ELECTRIC POWER AVAILABLE \\
\end{tabular} & $4.48 E-3$ & Note 3 & & & 4.2 .1 \\
\hline
\end{tabular}

Notes:

1 The mean values of these split fractions were based on engineering judgement or on known empirical data. These split fractions were not important with respect to risk and therefore no uncertainty distributions were developed.

2 This is the mean value of a double della function. The possible values of the function are 0.0 and 1.0. The probability associated with the 1.0 value is equal to the mean value displayed.

3 The mean value for the unavailability of the primary ventilation system was calculated based on the fault tree analysis presented in Appendix D.2 of Reference 4-1. The independent failure of the ventilation system was not a significant contributor to risk, therefore no distribution for Split Fraction VOP1 was required. 
TABLE 43-3 $4-18$

\section{HTF PSA RELEASE CATEGORY FREQUENCIES}

\begin{tabular}{|c|c|c|c|c|c|}
\hline \multicolumn{2}{|r|}{ RELEASE CATEGORY } & \multicolumn{4}{|c|}{ FREQUENCY PER YEAR } \\
\hline CODE & DOMINANT SEQUENCE & Mean & 5.00E-02 & 5.00E-01 & 9.50E-01 \\
\hline$\overline{\mathrm{BPL}}$ & Loss of active ventilation, or breach of a ventilation riser. & $6.84 E+00$ & $5.16 E+00$ & $6.71 E+00$ & $8.97 E+00$ \\
\hline$\overline{\text { SSP }}$ & Transfer line leak during waste transfer operation. & $1.65 E+00$ & $1.05 E+00$ & $1.61 E+00$ & $2.40 E+00$ \\
\hline HEPAL & Ventilation exhaust HEPA filter failure. & 7.92E-01 & $3.70 E-01$ & $7.79 E-01$ & $1.37 E+00$ \\
\hline SLK & Small leak from single shell tank. & 5.33E-01 & 2.32E-01 & 4.67E-01 & $1.05 E+00$ \\
\hline LSP & $\begin{array}{l}\text { Transfer line leak during waste transfer operation and failure of radiation } \\
\text { monitor alarms. }\end{array}$ & 1.57E-01 & $9.64 E-02$ & 1.53E-01 & $2.35 E-01$ \\
\hline LLK & Large leak from single shell tank. & $6.69 E-02$ & $2.28 \mathrm{E}-02$ & $5.64 \mathrm{E}-02$ & $1.47 E-01$ \\
\hline SSPRY & $\begin{array}{l}\text { Small spray leak during waste transfer operation with cover blocks } \\
\text { removed. }\end{array}$ & 8.59E-03 & $1.05 E-03$ & 6.84E-03 & $2.19 E-02$ \\
\hline$\overline{\mathrm{BPH}}$ & Loss of ventilation in aging waste tanks, and operators fail to recover. & $8.52 \mathrm{E}-03$ & 1.03E-03 & $5.22 \mathrm{E}-03$ & $2.64 E-02$ \\
\hline HEPAH & $\begin{array}{l}\text { Hydrogen gass release (BURP) in tank SY-101, burn in tank with no dome } \\
\text { collapse. }\end{array}$ & 5.07E-03 & $3.43 \mathrm{E}-3$ & 4.78E-03 & $7.09 \mathrm{E}-03$ \\
\hline$\overline{\mathrm{DCH}}$ & $\begin{array}{l}\text { Hydrogen gass release (BURP) in tank SY-101, burn in tank and collapse } \\
\text { of the dome. }\end{array}$ & 6.9 & $4.73 E-4$ & -04 & $\overline{1.0}$ \\
\hline DCLLK & Hydrogen generation and ignition with dome collapse. (15 potential tanks) & $6.54 \mathrm{E}-04$ & $0.00 E+0$ & $2.84 E-04$ & $3.06 \mathrm{E}-03$ \\
\hline LSPRY & $\begin{array}{l}\text { Small spray leak during waste transfer operation with cover blocks } \\
\text { removed. }\end{array}$ & 4.52E-04 & $4.34 E-5$ & 3.58E-04 & 1.15E-03 \\
\hline$\overline{\text { DCLLK2 }}$ & Hydrogen generation and ignition in tank S-112 with dome collapse. & 8.77E-05 & $0.00 \mathrm{E}+0$ & $0.00 E+00$ & 2.91E-04 \\
\hline DCHORG & Hydrogen generation and ignition in tank C-103 with dome collapse. & 5.56E-05 & $0.00 \mathrm{E}+0$ & $0.00 E+00$ & 1.92E-04 \\
\hline$\overline{\mathrm{DCL}(4)^{*}}$ & Seismic event $(0.43$ to $0.5 \mathrm{~g})$ causes collapse of 4 SSTs. & $1.03 E-05$ & "** & & \\
\hline$\overline{\mathrm{DCL}(12)^{*}}$ & Seismic event $(0.5$ to $0.6 \mathrm{~g})$ causes collapse of 12 SSTs. & 7.91E-06 & ** & & \\
\hline$\overline{\mathrm{DCL}(45)^{*}}$ & Seismic event $(0.6$ to $0.8 \mathrm{~g})$ causes collapse of 45 SSTs. & 5.93E-06 & 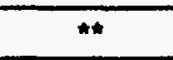 & & \\
\hline $\mathrm{DCL}(122)^{\star}$ & Seismic event $(0.8$ to $1.3 \mathrm{~g})$ causes collapse of 122 SSTs. & $2.26 \mathrm{E}-06$ & ** & & \\
\hline$\overline{D C V H}$ & Aircraft crach with tank collapse and fire (tanks with adequate moisture). & 2.71E-07 & $2.58 \mathrm{E}-08$ & 1.39E-07 & 7.14E-07 \\
\hline DCVHI & Aircraft crach with tank collapse and fire (dry, inert tanks). & 2.09E-07 & 1.99E-08 & $1.08 E-07$ & 5.52E-07 \\
\hline DCVHF & $\begin{array}{l}\text { Aircraft crach with tank collapse and fire (dry tanks with high ferrocyanide } \\
\text { content). }\end{array}$ & 4.93E-8 & 4.69E-09 & $2.53 E-08$ & 1.30E-07 \\
\hline DCVHO & $\begin{array}{l}\text { Aircraft crach with tank collapse and fire (dry tanks with high organic } \\
\text { content). }\end{array}$ & $1.54 \mathrm{E}-8$ & 1.46E-09 & $7.92 E-09$ & $5.56 \mathrm{E}-08$ \\
\hline
\end{tabular}

Notes: Number in parenthesis indicates the number of failed tanks.

** Point estimates were used for the seismic hazard frequency. 


\begin{tabular}{|c|c|c|c|c|c|c|c|c|c|c|c|c|c|c|}
\hline \multirow{3}{*}{$\begin{array}{c}\text { Release } \\
\text { Category } \\
\text { Code } \\
\end{array}$} & \multicolumn{14}{|c|}{ INITIATING EVENTS AND FREQUENCIES } \\
\hline & $\begin{array}{c}\text { Loss of } \\
\text { Active } \\
\text { Ventilation }\end{array}$ & $\begin{array}{c}\text { Hydrogen } \\
\text { Gas } \\
\text { Release } \\
\text { from Tank } \\
\text { SY-101 }\end{array}$ & $\begin{array}{c}\text { Ventilation } \\
\text { Riser or } \\
\text { Vent Line } \\
\text { Breach }\end{array}$ & $\begin{array}{c}\text { Waste } \\
\text { Transfer } \\
\text { (operation } \\
\text { per year) }\end{array}$ & \begin{tabular}{|c|} 
Ventilation \\
Exhaust \\
HEPA Filter \\
Failure
\end{tabular} & $\begin{array}{c}\text { Loss of } \\
\text { Active } \\
\text { Ventliation } \\
\text { (Aging } \\
\text { Waste) }\end{array}$ & \begin{tabular}{|c|} 
Leak/ \\
Breach of a \\
SST
\end{tabular} & \begin{tabular}{|c|} 
Active \\
Ventilation \\
System \\
Drainage \\
Leak \\
\end{tabular} & \begin{tabular}{|c|} 
Water \\
Intrusion \\
into an \\
Intrusion \\
Prevented \\
Tank
\end{tabular} & $\begin{array}{c}\text { Loss of } \\
\text { Tank } \\
\text { Mixing }\end{array}$ & $\begin{array}{c}\text { Water } \\
\text { Intrusion } \\
\text { into a } \\
\text { Partially } \\
\text { Interim } \\
\text { Isolated } \\
\text { Tank }\end{array}$ & $\begin{array}{c}\text { Dome } \\
\text { Fallure } \\
\text { Event } \\
\text { (Non- } \\
\text { selsmic) }\end{array}$ & $\begin{array}{c}\text { Leak } \\
\text { Breach of } \\
\text { the } \\
\text { Primany } \\
\text { Tank of a } \\
\text { DST }\end{array}$ & $\begin{array}{c}\text { Water } \\
\text { Intrusion } \\
\text { Into an } \\
\text { Inservice } \\
\text { Tank }\end{array}$ \\
\hline & $\begin{array}{c}\text { LOTVA } \\
4.11 E+00\end{array}$ & $\begin{array}{c}\text { BURP } \\
3.51 E+00 \\
\end{array}$ & $\begin{array}{c}\text { RVB } \\
1.98 E+00 \\
\end{array}$ & $\begin{array}{c}\text { WT } \\
1.00 E+03\end{array}$ & $\begin{array}{c}\text { FB } \\
7.73 E-01 \\
\end{array}$ & $\begin{array}{l}\text { LOTVAW } \\
6.54 E-01 \\
\end{array}$ & $\begin{array}{c}\text { SSTSB } \\
4.26 E-01 \\
\end{array}$ & $\begin{array}{c}\text { VDL } \\
2.24 E-01 \\
\end{array}$ & $\begin{array}{c}\text { WilP } \\
1.75 E-01 \\
\end{array}$ & $\begin{array}{c}\text { LOTM } \\
8.23 E-02 \\
\end{array}$ & $\begin{array}{c}\text { WIPI } \\
4.95 E-01\end{array}$ & $\begin{array}{l}\text { DOMEF } \\
3.28 E-02 \\
\end{array}$ & $\begin{array}{c}\text { DSTSB } \\
1.28 E-01\end{array}$ & $\begin{array}{c}\text { WIA } \\
5.36 \mathrm{E}-01 \\
\end{array}$ \\
\hline BPL & $4.11 E+0$ & & $1.98 \mathrm{E}+0$ & & & $6.45 \mathrm{E}-1$ & & & & $8.23 \mathrm{E}-2$ & & $3.28 \mathrm{E}-2$ & $6.89 \mathrm{E}-3$ & \\
\hline SSP & & & & $1.41 E+0$ & & & & $2.24 \mathrm{E}-1$ & 4.63E-4 & & $3.71 E-3$ & & & $1.28 \mathrm{E}-2$ \\
\hline HEPAL & & $1.87 \mathrm{E}-2$ & & & 7.73E-1 & & & & & & & & & \\
\hline SLK & & & & & & & 3.70E-1 & & 8.57E-2 & & $7.80 \mathrm{E}-2$ & & & \\
\hline LSP & & & & $1.57 \mathrm{E}-1$ & & & & & & & & & & \\
\hline LLK & & & & & & & $5.59 \mathrm{E}-2$ & & & & & & $1.09 \mathrm{E}-2$ & \\
\hline SSPRY & & & & 8.59E-3 & & & & & & & & & & \\
\hline BPH & & & & & & $8.52 \mathrm{E}-3$ & & & & & & & & \\
\hline HEPAH & & 5.07E-3 & & & & & & & & & & & & \\
\hline DCH & & $6.98 E-4$ & & & & & & & & & & & & \\
\hline \multicolumn{15}{|l|}{ DCLLK } \\
\hline \multicolumn{15}{|l|}{ DCHORG } \\
\hline LSPRY & & & & $4.52 E-4$ & & & & & & & & & & \\
\hline \multicolumn{15}{|l|}{ DCLLK2 } \\
\hline \multicolumn{15}{|l|}{ DCL4 } \\
\hline \multicolumn{15}{|l|}{ DCL12 } \\
\hline \multicolumn{15}{|l|}{ DCL45 } \\
\hline \multicolumn{15}{|l|}{ DCL122 } \\
\hline \multicolumn{15}{|l|}{ DCVH } \\
\hline \multicolumn{15}{|l|}{ DCVHI } \\
\hline \multicolumn{15}{|l|}{ DCVHF } \\
\hline \multicolumn{15}{|l|}{ DCVHO } \\
\hline & & & & & & & & & & & & & & \\
\hline IE Totals & $4.11 E+0$ & $2.45 E-2$ & $1.98 E+0$ & $1.58 \mathrm{E}+0$ & $7.73 \mathrm{E}-1$ & $6.54 \mathrm{E}-1$ & 4.26E-1 & $2.24 \mathrm{E}-1$ & $8.62 E-2$ & $8.23 E-2$ & $8.17 \mathrm{E}-2$ & $3.28 \mathrm{E}-2$ & $1.78 \mathrm{E}-2$ & $1.28 \mathrm{E}-2$ \\
\hline
\end{tabular}




\section{HTF PSA RELEASE CATEGORY FREQUENCIES BY INITIATING EVENT}

\begin{tabular}{|c|c|c|c|c|c|c|c|c|c|c|c|c|}
\hline \multirow[b]{3}{*}{$\begin{array}{c}\text { Release } \\
\text { Category } \\
\text { Code }\end{array}$} & \multicolumn{11}{|c|}{ INITIATING EVENTS AND FREQUENCIES } & \multirow[b]{3}{*}{$\begin{array}{c}\text { Release } \\
\text { Category } \\
\text { Totals } \\
\end{array}$} \\
\hline & \begin{tabular}{|c|} 
Hydrogen \\
Gas Release \\
and lgnition \\
in SSTs (15 \\
tanks)
\end{tabular} & \begin{tabular}{|c|} 
Hydrogen \\
Gas \\
Release and \\
Ignitlon \\
(C-103)
\end{tabular} & $\begin{array}{c}\text { Hydrogen } \\
\text { Gas Release } \\
\text { and Ignition } \\
\text { (S-112) }\end{array}$ & $\begin{array}{c}\text { Seismic } \\
\text { Event } \\
(0.45 g)\end{array}$ & $\begin{array}{c}\text { Seismic } \\
\text { Event } \\
(0.55 \mathrm{~g})\end{array}$ & $\begin{array}{c}\text { Selsmic } \\
\text { Event } \\
(0.70 \mathrm{~g})\end{array}$ & $\begin{array}{c}\text { Seismic } \\
\text { Event } \\
(1.0 \mathrm{~g})\end{array}$ & $\begin{array}{c}\text { Aircraft } \\
\text { Crash } \\
\text { (tanks with } \\
\text { adequate } \\
\text { moisture) }\end{array}$ & $\begin{array}{c}\text { Alrcraft } \\
\text { Crash (dry, } \\
\text { inert tanks) }\end{array}$ & $\begin{array}{c}\text { Aircraft } \\
\text { Crash (dry, } \\
\text { FoCn tanks) }\end{array}$ & $\begin{array}{c}\text { Alicraft } \\
\text { Crash (dry, } \\
\text { organic } \\
\text { tanks) }\end{array}$ & \\
\hline & $\begin{array}{l}\text { ALLH2 } \\
6.54 E-04 \\
\end{array}$ & $\begin{array}{c}\text { C103H2 } \\
6.38 \mathrm{E}-05 \\
\end{array}$ & $\begin{array}{r}5112 \mathrm{H} 2 \\
8.77 \mathrm{E}-05 \\
\end{array}$ & $\begin{array}{c}\text { SEIS2 } \\
1.03 E-05 \\
\end{array}$ & $\begin{array}{c}\text { SEIS3 } \\
7.91 E-06 \\
\end{array}$ & $\begin{array}{c}\text { SEIS4 } \\
5.93 E-06 \\
\end{array}$ & $\begin{array}{c}\text { SEIS5 } \\
2.26 E-06 \\
\end{array}$ & $\begin{array}{c}\mathrm{ACH} \\
2.71 \mathrm{E}-07 \\
\end{array}$ & $\begin{array}{c}\text { ACHI } \\
2.09 E-07 \\
\end{array}$ & $\begin{array}{c}\text { ACHF } \\
4.93 E-08\end{array}$ & $\begin{array}{c}\mathrm{ACHO} \\
1.54 \mathrm{E}-0 \mathrm{~B}\end{array}$ & \\
\hline BPL & & & & & & & & & & & & $6.85 E+0$ \\
\hline SSP & & & & & & & & & & & & $1.65 E+0$ \\
\hline HEPAL & & & & & & & & & & & & $7.92 \mathrm{E}-1$ \\
\hline SLK & & & & & & & & & & & & 5.33E-1 \\
\hline LSP & & & & & & & & & & & & $1.57 \mathrm{E}-1$ \\
\hline LLK & & & & & & & & & & & & $6.69 \mathrm{E}-2$ \\
\hline SSPRY & & & & & & & & & & & & $8.59 \mathrm{E}-3$ \\
\hline BPH & & & & & & & & & & & & 8.52E-3 \\
\hline HEPAH & & & & & & & & & & & & 5.07E-3 \\
\hline DCH & & & & & & & & & & & & $6.98 E-4$ \\
\hline DCLLK & $6.54 \mathrm{E}-4$ & & & & & & & & & & & $6.54 E-4$ \\
\hline DCHORG & & $6.38 \mathrm{E}-5$ & & & & & & & & & & $6.38 \mathrm{E}-5$ \\
\hline LSPRY & & & & & & & & & & & & 4.52E-4 \\
\hline DCLLK2 & & & 8.77E-5 & & & & & & & & & 8.77E-5 \\
\hline DCL4 & & & & 1.03E-5 & & & & & & & & 1.03E-5 \\
\hline DCL12 & & & & & $7.91 \mathrm{E}-6$ & & & & & & & $7.91 E-6$ \\
\hline DCL45 & & & & & & $5.93 E-6$ & & & & & & $5.93 \mathrm{E}-6$ \\
\hline DCL122 & & & & & & & $2.26 E-6$ & & & & & $2.26 \mathrm{E}-6$ \\
\hline DCVH & & & & & & & & 2.71E-7 & & & & 2.71E-7 \\
\hline DCVHI & & & & & & & & & 2.09E-7 & & & 2.09E-7 \\
\hline DCVHF & & & & & & & & & & $4.93 \mathrm{E}-8$ & & 4.93E-8 \\
\hline DCVHO & & & & & & & & & & & 1.54E-08 & $1.54 E-8$ \\
\hline & & & & & & & & & & & & \\
\hline IE Totals & $6.54 E-4$ & $6.38 \mathrm{E}-5$ & 8.77E-5 & $1.03 \mathrm{E}-5$ & $7.91 \mathrm{E}-6$ & $5.93 E-6$ & $2.26 \mathrm{E}-6$ & $2.71 \mathrm{E}-7$ & $2.09 \mathrm{E}-7$ & 4.93E-8 & $1.54 \mathrm{E}-8$ & \\
\hline
\end{tabular}

- Includes the following Single Shell Tanks : AX-101, AX-103, B-103, S-102, S-111, T-110, TX-105, TX-118, U-103, U-105 thru U-109, U-111. 


\section{SOURCE TERMS}

\subsection{QVERVIEW}

The amount of radioactive material released into the atmosphere and/or into the soil column are important factors in the determination of consequences and risk. Along with the timing of the release and parameters that impact the dispersion of these materials in the environment (e.g., release height and the energy associated with the release), these releases are referred to as source terms. Source terms must be developed for each important release category.

As discussed in Chapter 6, the airborne source terms are combined with release category frequencies, meteorological data, and relevant demography to determine the health effects associated with airborne releases. The liquid pathway source terms are input to codes that model ground transport and retention to determine long-term health effects due to releases into the ground. A similar approach is used for economic risk.

There is a basic difficulty in trying to combine the risks of population health consequences via the atmospheric and liquid pathways. Airborne releases typically involve transport times to receptors and exposure times to the passing cloud of minutes to hours. The population at risk and the exposure doses for various accident scenarios can be determined with reasonable accuracy, based on dispersion modeling, current census data, and evacuation (if any) scenarios. In contrast, the releases of liquids into the soil column can involve transport delay times to receptors of hundreds or even thousands of years. These delay times introduce substantial uncertainty in quantifying future health effects since these must be based on projections from current population distributions and lifestyles. In addition, there is considerable uncertainty involved with the current models for vadose zone and ground water transport. This modeling is an essential element in the prediction of health effects involving future generations.

There are also important philosophical questions that arise; e.g., How do you balance the importance of health effects thousands of years in the future against the priorities and concerns of today?

The approach used in this study is to report the long-term doses and risks from the ground transport pathways separate from the doses and risks from the airborne transport pathway. Thus, for those release categories that involve both an airborne release and a liquid release into the soil column, two sets of source terms have been calculated and reported.

As noted earlier, source terms are required for each important release category. A basic premise in this evaluation is that a single source term can be used for a given release category even though the sequences binned to that release category might have originated from accidents involving different tanks. The intent was to develop source terms that are representative of the releases from a variety of tanks.

It should be noted that the radiological source term for a given isotope is the product of the amount of waste material released and the concentration $(\mathrm{Ci} / \mathrm{kg})$ of that isotope. It is 
believed that the distributions developed for the release of material are appropriate for all of the tanks contributing to a given release category. The isotopic concentrations, however, can vary widely from tank to tank.

\subsection{RELEASE CATEGORY DEFINITION}

Release categories are qualitative descriptions of the end states to which each accident sequence is assigned. The definitions of release categories developed for this study are based on the accident sequence modeling presented in Chapter 4 . Detailed descriptions of the representative scenarios for the release categories are presented in Section 4.3 and summarized in Table 4.3-3. As noted earlier, a release category may include either or both airborne and liquid pathway source terms.

Each of the accident sequences defined by the models presented earlier in this report results in a unique release of radioactive and/or toxic materials into the environment. The amount of radioactive or toxic material released is referred to as the "source term" and is used as an input for assessing the potential human health consequences of the release. Because the number of unique sequences is quite large and source term analyses and consequence calculations are costly to perform, it is desirable to group together sequences with similar release characteristics (into bins called release categories) for source term and consequence analysis. The purposes of this section are to identify those factors that can potentially influence the magnitude and timing of radionuclide or toxic gas releases and to define appropriate release categories for accident sequence grouping.

\subsubsection{RELEASE PATHWAYS}

Figure 5-1 graphically portrays the primary pathways for the release of radionuclides or toxic gases from the storage tanks. Radioactive releases can exit the waste tanks directly into the atmosphere in the form of aerosols, seep to the ground as liquids, or both. Toxic gases would disperse directly into the atmosphere. The distinction of an airborne or liquid pathway is especially important because airborne releases could reach onsite or offsite populations in a matter of minutes versus many years for liquid releases.

In the HTF PSA accident sequence model, atmospheric releases result from any failure of the tank dome, risers, ventilation lines, filters (including the deentrainer where appropriate) in the ventilation system, or sprays. Liquid releases can result from failures of the tank primary and secondary shells, transfer leaks, spills, or overflows. The factors discussed in the remainder of this section are important in determining the magnitude and timing of radionuclide and/or toxic gas releases from the HTF tanks.

It is obvious that the use of all possible combinations of the factors discussed above would produce an unmanageably large number of release categories. By identifying likely correlations between the factors and by grouping less severe release categories with more severe ones, the combinations of factors can be reduced to a manageable level for the quantification of risk. All significant release categories are identified by the release pathway and magnitude of the radionuclide release. Table 4.3-3 presents the frequencies of release categories defined using these key factors. 


\subsubsection{VENTILATION SYSTEM CONTRIBUTION TO SOURCE TERMS}

All of the tanks in the HTF are equipped with HEPA filters in the atmospheric vent lines. In addition, tanks with active (i.e., forced flow) ventilation also contain moisture deentrainers to minimize the exposure of the HEPA filters to moisture. In addition to moisture removal, the deentrainers are also very effective in removing particulate matter (including radioisotopes) from the exhaust stream. Thus, the ventilation systems can contain inventories of radioactive material, which could be released into the environment if the filter and/or deentrainer failed in some manner. The integrity of the HEPA filters and deentrainers is explicitly represented by a top event in the accident sequence models.

\subsubsection{RADIONUCLIDE CONTENT OF AEROSOL RELEASED}

Under normal conditions, the radionuclide content of the atmosphere in the tank dome spaces of the tanks is relatively low. If the contents of the tank are disturbed by an energetic event, however, the concentration of radionuclides in the gas mixture available for release could be greatly increased. For example, the radionuclide content of the dome space atmosphere would be expected to increase following a hydrogen burn event, a criticality, or a sustained fire in or above the waste material. Sequences involving sustained fires could provide sufficient energy for significant plume rise and increased dispersion of releases into the atmosphere.

\subsubsection{TOXIC GAS CONTENT OF RELEASED GASES}

Because the HEPA filters and deentrainers (where available) are not effective in trapping gases such as ammonia, the presence of toxic gases in concentrations above levels of concern is assumed to result in a toxic gas release. For tanks such as Tank 101-SY, the normal ventilation exhaust is not toxic. However, on-site toxic gas concentrations could be increased from normal levels during accident situations.

\subsubsection{ELEVATION OF RELEASE}

The dispersion of atmospheric releases of radionuclides and toxic gases is influenced by the elevation at which the release occurs into the atmosphere. For tanks with an active ventilation system, the normal release point into the atmosphere is at the exit of the stack, which is located at Elevation $5 \mathrm{~m}$. Thus, if the tank boundary does not fail and the ventilation system and associated stacks are intact, the elevation of the release into the atmosphere would be $5 \mathrm{~m}$. All other accidental releases are assumed to occur at ground level.

Dispersion calculations indicate that, because of the relatively short stack height (i.e., $5 \mathrm{~m}$ ), the stack release is potentially important only within a distance of approximately $0.5 \mathrm{~km}$ from the release point.

For scenarios in which there is a significant plume rise (e.g., fires), there can be a major impact on downwind dispersion and concentrations. 


\subsubsection{RADIONUCLIDE CONTENT OF LIQUIDS RELEASED}

The significance of liquid releases will be proportional to the volume of waste released and the radionuclide concentration of the liquid released. Estimates of the drainable liquid and radionuclide content are available for many of the tanks. Small leaks are defined as less than 10,000 gallons and can occur from any tank. Large leaks (greater than 10,000 gallons) can only occur from non stabilized tanks.

\subsection{WASTE CHARACTERIZATION}

The concentration of radionuclides in the waste of selected tanks is summarized in Table 51. The data given in this table is derived from various WHC's analyses of tank contents. The airborne source terms consist primarily of materials entrained from the waste surface by the flow of gas. Tables 5-2 and 5-3 list the radioisotope concentrations selected for airborne and liquid releases for each release category, respectively.

Because one of the measures of risk quantified in this PSA is the cost associated with cleanup, decontamination, and repairs after an accident, it is necessary to define a distribution for particle size associated with the airborne source term. When estimating inhalation doses it is conservative to assume that all of the material released into the atmosphere are in the respirable-size range. However, when estimating surface contamination from particle settling (fallout), this approach could underestimate the extent of cleanup that is required since it is primarily the larger particles (above-respirable sizes) that contribute to surface contamination.

The particle size distribution shown in Figure 5-2 is based on Window $C$ (Reference 5-2) and Window $E$ (Reference 5-3) sample analyses. For the dispersion calculations presented in Chapter 6, the particles were binned as follows:

\begin{tabular}{|c|c|c|}
\hline $\begin{array}{c}\text { Physical } \\
\text { Diameter }(\mu \mathrm{m})\end{array}$ & AMAD $(\mu \mathrm{m})$ & $\begin{array}{c}\text { Mass } \\
\text { Fraction }\end{array}$ \\
\hline 3 & 5 & 0.52 \\
\hline 10 & 16 & 0.15 \\
\hline 30 & 47 & 0.07 \\
\hline 60 & 95 & 0.15 \\
\hline 133 & 210 & 0.11 \\
\hline
\end{tabular}

\subsection{AIRBORNE SQURCE TERMS}

This section presents a discussion of the quantities of material released and the source terms developed for each of the release categories involving airborne releases." The release quantities are presented in terms of mean, low (10th percentile), and high (90th percentile) values to reflect the uncertainties involved in deterministic estimates. Estimates of the quantities of material released for each important release category are summarized in Table 5-4. The source terms (i.e., quantities of radioactive materials

\footnotetext{
* A number of these release categories also involve releases of liquids to the soil surrounding or below the tank.
} 
released) used for risk analysis are obtained by multiplying the appropriate concentrations in Tables $5-2$ and $5-3$ by the estimated release quantities in Table 5-4.

\subsubsection{NON BURN SEQUENCES - UNFILTERED RELEASE (BPL)}

The BPL release category represents scenarios in which the HEPA filters and deentrainer are bypassed because of a failure in the ventilation system containment envelope, resulting in an unfiltered release into the atmosphere. As described in Chapter 3, the primary ventilation system removes vapors from the tank head space and maintains a slightly negative internal tank pressure so that all air leaks under normal operations are into the tank. The primary exhaust system of the actively vented tanks, such as those in the SY Tank Farm, consists of a moisture separator (deentrainer), a heater to prevent condensation on the filters, a bank of two HEPA filters, and an induced draft fan. The evaluation of the quantity of material released for this release category is summarized in Figure 5-3. The key issues for this release category are: (1) the time to detect and fix the HEPA

filter/deentrainer leak, and (2) the amount of radionuclides released during this period. The rate of radionuclide release is estimated conservatively, assuming nominal ventilation flow, even though ventilation may fail for certain BPL sequences.

According to published data for 1990, the measured annual radioactivity release from the 241-SY Tank Farm is 3.6E-7 Ci of gross beta activity (Reference 5-4). If it is assumed that this release is primarily $90 \mathrm{Sr}(0.034 \mathrm{Ci} / \mathrm{kg}$ of crust material) and assuming that the other dose-contributing isotopes are present in the same ratios as the tank wastes, this translates to a conservative estimate of the annual release through the HEPA filters (and deentrainer) of $1.06 \mathrm{E}-5 \mathrm{~kg} .++$

Both the deentrainer (actively vented tanks only) and the HEPA filters remove radionuclides from the stream, depending on their operating efficiencies. The HEPA filters are assumed to have a combined mean efficiency of $99.99 \%$ (with a range from $99.95 \%$ to $99.995 \%$; see Figure 5-3). The Plant Specifics Manual (Reference 5-5) lists an individual HEPA filter efficiency of $99.99 \%$ for 0.3 -micron particles. The as-installed efficiency of the combined HEPA filter package is expected to be no less than $99.95 \%$ for 0.5 -micron particles. The deentrainer is assumed to have a mean efficiency of $90 \%$ (with a range from $85 \%$ to $95 \%$ ). It is assumed that the mean time to detect the leak is 8 hours (corresponding to one 8-hour shift). However, it is possible that the leak could be detected earlier (within a few hours) or later (after 1/2 day). Thus, the distribution shown in Figure 5-3 was selected to represent the release duration (or time to detect and fix a leak).

Based on the annual release rates, HEPA filter and deentrainer efficiencies, and the release duration, the amount of radionuclides (aerosols) released can be evaluated by a Monte Carlo simulation. The results of the simulation are also shown in Figure 5-3. The salient point values of the resulting distribution are:

$\begin{array}{lll}- & 10 \% & 3.4 \mathrm{E}-4 \mathrm{~kg} \\ \text { - } & \text { Mean } & 7.0 \mathrm{E}-4 \mathrm{~kg} \\ \text { - } & 90 \% & 2.1 \mathrm{E}-3 \mathrm{~kg}\end{array}$

++ if Cs-137 is also considered, as it should be, the annual release to the environment is only $7.4 \mathrm{E}-7 \mathrm{~kg}$. 
The frequency contributions to Release Category BPL originate with various tanks. Therefore, the values used for the radioisotope concentrations for this release category represent a composite (i.e., a numerical average) of all of the tanks. These concentrations are summarized in Tables 5-2 and 5-3.

\subsubsection{NON BURN SEQUENCES - FILTER BREACHED (HEPAL)}

The HEPAL release category represents those scenarios in which the HEPA filters and deentrainer are breached as a result due to non-burn events such as excessive moisture loading, external events, etc. The radiological source term associated with this scenario results from the release of material entrapped in the deentrainer and HEPA filters during normal operation. The source term evaluation for this release category is summarized in Figure 5-4. The key issues in this source term evaluation relate to estimation of the material entrapped in the deentrainer and HEPA filters and the fraction of this amount released during the scenario.

References 5-6 (p.4-14) and 5-7 suggest that the amount of material entrapped on the deentrainer could be as high as $11.1 \mathrm{~kg}$. Based on a HEPA fiilter "changeout" limit of 200 $\mathrm{mrem} / \mathrm{hr}$ and Tank 241-SY-101 isotopic concentrations, a typical single filter loading would be approximately $1.8 \mathrm{E}-3 \mathrm{Kg}(8.1 \mathrm{E}-3 \mathrm{Ci})$. Depending on when the HEPA filters and the deentrainers are cleaned or replaced, the amount of entrapped material could be relatively low. In any case, however, since the deentrainers are expected to have a removal efficiency of approximately $90 \%$, they would be expected to have approximately ten times the combined loading of the filters. Based on 1990 measurements of the gross beta activity (3.67E-7 Ci/yr) monitored for the 241-SY tank farm, and best estimate deentrainer and filter removal efficiencies, a total deentrainer/HEPA filter loading of 1.49E$2 \mathrm{Kg} / \mathrm{yr}$ can be predicted. Assuming a 20 year interval between cleaning/changeout, the maximum total burden would be approximately $0.3 \mathrm{Kg}$. Arguing that tank-to-tank variations could be as high as a factor of ten, a reference loading of $3.0 \mathrm{Kg}$ can be assumed. The truncated normal distribution depicted in Figure 5-4 for the amount of material entrapped in the deentrainer and HEPA filters has a mean of $3 \mathrm{~kg}$. The upper bound loading of $11.1 \mathrm{Kg}$ was assumed to be the 99 th percentile of that distribution.

Estimating the fraction of the entrapped material released is extremely difficult. Reference 5-6 (p. 4-14) suggests that the release fraction is 0.1 for burn events. Reference 5-11 gives bounding airborne release fractions of 0.01 for HEPA filters for a variety of conditions, including blast effects, pressurized gas release, and the passage of hot gases through the filters. No specific value is given in Reference 5-11 for fires. In this study, the release fraction distribution developed for burns is also applied (conservatively) to Release Category HEPAL. This truncated normal distribution has a mean of 0.05 and a 95th percentile of 0.1 . These parameters were selected in recognition that values used in traditional safety analyses tend to be conservative. Although the values reported in Reference 5-11 suggest that the release fractions for HEPA filters are probably of the order of 0.01 , it is not clear whether these can be applied to the deentrainer which has the preponderance of the loading.

Based on the amount of material entrapped and the fraction released, the source term can be evaluated. Figure 5-4 also depicts the resultant distribution for the amount released for 
HEPAL scenario with a mean release of $0.22 \mathrm{~kg}$. The salient point values for this distribution are:

$\begin{array}{lll}\text { - } & 10 \% & 0.03 \mathrm{~kg} \\ \text { - } & \text { Mean } & 0.22 \mathrm{~kg} \\ \text { - } & 90 \% & 0.48 \mathrm{~kg}\end{array}$

The frequency contributions to Release Category HEPAL originate with various tanks. Therefore, the values used for the radioisotope concentrations for this release category represent a composite (i.e., a numerical average) of all of the tanks. These concentrations are summarized in Tables 5-2 and 5-3.

\subsubsection{BURP/BURN SEQUENCES - FILTER BREACHED (HEPAH)}

The HEPAH release category represents those scenarios in which the HEPA filter and deentrainer are breached because of the overpressure resulting from a burp/burn sequence. The details of the deentrainer and HEPA filter are the same as those described in the previous section. The source term evaluation for this release category is summarized in Figure 5-5.

The key issues in this source term evaluation are: (1) estimation of the material entrapped in the deentrainer and HEPA filters; (2) the fraction of this entrapped amount released during the scenario; (3) the amount of crusted material that is seared due to the burp/burn; and $(4)$ the fraction of this seared amount that is released.

The amount of material entrapped on the deentrainer/HEPA filters could be as high as approximately $11 \mathrm{~kg}$. The loading distribution identified for Release Category HEPAL is used for Release Category HEPAH. This is also true for the release fraction which was developed for a burn type of event. [a very conservative estimate; Reference 5-6 (p. 4-14) and Reference 5-7]. Depending on when the HEPA filters and deentrainers have been cleaned or replaced, the amount entrapped could be much lower.

The amount of material seared/crusted was taken from Reference 5-1 (Appendix E). The distribution shown in Figure $5-5$ has a mean of about $13.4 \mathrm{~kg}$ and depicts the amount seared during a realistic burp/burn (short burn with temperature decay). Due to convection currents generated by fire, some fraction of this seared material could be released into the atmosphere. It is estimated that about $20 \%$ of this seared material may be released (mean $20 \%$, with a range from $5 \%$ to $50 \%$ ) in such a fashion. Based on the amount of material entrapped in the HEPA filter/deentrainer and the amount of material seared along with the individual release fractions, the source term can be evaluated for the HEPAH scenario. Figure 5-5 also depicts the resultant distribution for the amount released for the HEPAH scenario with a mean release of $2.88 \mathrm{~kg}$. The salient point values for this distribution are:

$\begin{array}{lll}- & 10 \% & 0.84 \mathrm{~kg} \\ - & \text { Mean } & 2.88 \mathrm{~kg} \\ - & 90 \% & 5.64 \mathrm{~kg}\end{array}$


As shown in Table 4.3-4, only the Tank SY-101 burp/burn initiator contributes to this release category. Therefore, the radioisotope concentrations listed in Table 5-4 for Release Category HEPAH are based on Tank SY-101 concentrations.

\subsubsection{BURP/BURN SEQUENCES-CATASTROPHIC DOME COLLAPSE (DCH)}

Release Category DCH represents the end state for those scenarios in which a catastrophic tank failure, resulting in collapse of the dome, leaves the tank open to the environment. Tank failure could occur if the burp/burn pressure loads are significant. Dome collapse leaves the tank vulnerable to winds and gusts, which may entrain some material and provide a direct release path. The source term evaluation for this release category is summarized in Figure 5-6.

The key issues in this source term evaluation are: (1) estimation of the material entrapped in the deentrainer and HEPA filters and the fraction of this amount released during the scenario, (2) amount of seared crusted material owing to the burp/burn and the fraction of this amount released, and (3) amount of material entrained and removed by winds or gusts.

The distributions discussed in Section 5.4.2 for the amount of material entrapped in the deentrainer and the HEPA filters (mean of $3.0 \mathrm{~kg}$ ) and the fraction of that materiall which is released to the environment (mean of 0.5 ) were also utilized for Release Category DCH.

The amount of material seared was estimated, as shown in Reference 5-1 (Appendix E). The distribution shown in Figure 5-6 has a mean of about $13.4 \mathrm{~kg}$ and depicts the amount seared during a realistic burp/burn (a short burn with temperature decay). This distribution is same as that selected for the HEPAH scenario in Section 5.3.3. Some fraction of the crust material is prone to be carried upward owing to convection currents and thus will be released into the atmosphere. Because the burp/burn event is much more energetic, it is estimated that about $80 \%$ (as opposed to only $20 \%$ for the HEPAH scenario) of the seared material will be released (mean $80 \%$, with a range from $60 \%$ to $100 \%$ ).

After a dome collapse, the tank contents can be directly exposed to the atmosphere and subjected to wind entrainment. The exposure period for entrainment is the time from dome collapse to the time when the tank is completely covered as a result of post accident recovery operations. This exposure time could vary from $1 / 2$ a day to a week. The distribution shown in Figure 5-6 reflects this range and has a mean exposure time corresponding to 1 day. It has been shown by separate HMS calculations that only winds greater than $20 \mathrm{mph}$ are capable of entraining tank waste materials (see Appendix $E$ of Reference 5-1). Based on meteorological date recorded for the HTF over a 9-year period from 1983 to 1991 , it was determined that the average wind speed during a recording period exceeded $20 \mathrm{mph}$ approximately $5 \%$ of the time. If this result is applied on a daily basis, the time window for entrainment is approximately 1.2 hours per day. The distribution reflecting this time window is shown in Figure 5-6 and has a mean of approximately 1.2 hrs/day.

HMS analysis predicts entrainment rates ranging from 10 to $300 \mathrm{~g} / \mathrm{s}$ for winds from 20 to $70 \mathrm{mph}$. The entrainment rate distribution assumed for this analysis is shown in Figure 5-6. This distribution has a mean of approximately $20 \mathrm{~g} / \mathrm{s}$ with a range from 10 to $50 \mathrm{~g} / \mathrm{s}$ and was judged to be appropriate for the HTF meteorological conditions. 
Based on the amount of material entrapped in the HEPA filters/deentrainer, the amount of material crusted, the release fractions, the wind exposure period, the entrainment time window (fraction), and the wind entrainment rate, the source term can be evaluated for the DCH scenario. Figure 5-6 depicts the resultant distribution for the amount released for the DCH scenario with a mean release of $168.1 \mathrm{~kg}$. The salient point values for this distribution are:

$\begin{array}{llr}\text { - } & 10 \% & 28.4 \mathrm{~kg} \\ \text { - } & \text { Mean } & 168.1 \mathrm{~kg} \\ \text { - } & 90 \% & 374.0 \mathrm{~kg}\end{array}$

As shown in Table 4.3-4, only the Tank SY-101 burp/burn initiator contributes to this release category. Therefore, the radioisotope concentrations listed in Table 5-4 for Release Category DCH are based on Tank SY-101 concentrations.

\subsubsection{LARGE JET AIRCRAFT CRASH AND FUEL FIRE}

Release Categories DCVH, DCVHI, and DCVHO all contain scenarios resulting from a large jet aircraft crashing directly on a waste tank, spilling 5,000 gallons of jet fuel onto the top of the waste. Three distinct release categories were defined for aircraft crash scenarios based on the contents of the impacted tank. A detailed description of each of these release categories is presented in the following sections.

\subsubsection{Aircraft Crash on a Wet. Moist Tank - Dome Collapse (DCVH)}

The aircraft crash scenario has been described in Section 4.2.14. As a result of the aircraft crash, it is postulated, that the dome of the target tank will collapse and jet fuel will be spilled into the tank and then ignited. This subsection describes the details of the source term evaluation for this accident sequence for a target tank that is wet and moist. The major highlights of the calculations for an aircraft crash onto a wet, moist tank are summarized in Figure 5-7.

Release Category DCVH is a scenario in which a large jet aircraft directly impacts the waste tank, spilling 5,000 gallons of jet fuel onto the top of the waste. The resulting 1.8-inch layer of fuel ignites and burns, yielding a total heat release of $5.53 E+08$ Btu over a burn time of approximately 30 minutes (resulting in a release energy rate of $1.11 \mathrm{E}+9$ Btu/hrl. 1 * Due to the convection pattern, most of this heat would be dispersed upwards to the atmosphere. However, some amount of this heat will also be conducted downwards towards the waste. A distribution was assumed to evaluate the fraction of heat conducted to the waste. This distribution shown in Figure 5-7 has a mean of 0.1 and ranges between 0.05 to 0.20 . Assuming that $10 \%$ (corresponding to mean fraction of 0.1 ) of this heat is conducted downward to the waste, $2.56 \mathrm{E}+04 \mathrm{~kg}$ of water would be vaporized. For a convecting liquid waste density of $1.5 \mathrm{~g} / \mathrm{cm}^{3}$, this amount of vaporized water is associated with $1.28 \mathrm{E}+04 \mathrm{~kg}$ of waste-dissolved salts and suspended particulates.

1

* This energy rate is used in plume rise calculations. 
Based on a fire release factor of $1 \%$ for nonvolatile chemical species (Reference 5-8), a lognormal distribution was assumed for the fraction of waste aerosolized. This distribution was created with a mean of 0.01 and a standard deviation of 0.01 . As can be seen from Figure $5-7$, the distribution has a range from 0.0 to 0.02 . This distribution, in conjunction with the estimate of waste-dissolved salts, allows the calculation of the amount of waste aerosolized. For Cs-137, which is soluble, there is some question as to whether the fraction of waste aerosolized should be applied to the mass of liquid which is vaporized rather than or in addition to the associated solids. However, as will be discussed later in this section, the release factor for Cs-137 has been arbitrarily increased by a factor of 10 . This increase should more than compensate for any uncertainty related to the mass of material which is aerosolized.

In addition to the tank contents being aerosolized (and airborne) as a result of fire, high winds also have the potential to entrain the tank contents. High surface winds (> $20 \mathrm{mph}$ ) have been shown to entrain particles at rates 10 to $300 \mathrm{gm} / \mathrm{sec}$. For the purposes of the present calculation, it was assumed that the tank would be exposed to the environment for a finite duration of time, following an aircraft crash. The exposure period for entertainment is the time from dome collapse to the time when the tank is completely covered as a result of post accident recovery operations. This exposure period could be as small as $1 / 2$ day lif the tank can be covered up immediately after the fire) but could also be as large as a week. The week-long exposure is possible if adequate material/manpower/procedures are not in place for such an eventuality. In light of this, a distribution with a mean of 2 days was assumed as shown in Figure 5-7. The exposure duration as shown in the distribution ranges from 0 to 7 days. Analysis of Hanford Meteorological data (Reference 5-9) showed that the winds in excess of $20 \mathrm{mph}$ occurred for about $5.2 \%$ of the time on the average. This corresponds to about $1.25 \mathrm{hr} /$ day of high winds. As these data are based on an multi-year averages, it is likely that, on a given day, the duration of high winds could range from $0.1 \mathrm{hr} /$ day to over $4 \mathrm{hr} /$ day. In light of this, a lognormal distribution with a mean of $1.25 \mathrm{hr} /$ day was chosen with a standard deviation of 1.0 . This allowed the distribution to range from about $0.1 \mathrm{hr} /$ day to over $4 \mathrm{hr} /$ day. The distribution for wind entertainment was chosen to range from 10 to $300 \mathrm{gm} / \mathrm{sec}$ based on separate HMS analysis (Reference 5-10). This distribution for the entertainment rate is shown in Figure 5-7 and has a mean of about $20 \mathrm{gm} / \mathrm{sec}$. The amount of material entrained by the winds is therefore computed by using the exposure period, frequency of high winds, and the entertainment rate.

The total amount of tank content released into the environment for this scenario (DCVH aircraft crash for wet, moist tanks) is computed by combining the mass aerosolized from the burn phenomenon with the mass released as a result of the wind entrainment. The resultant distribution for the total mass released into the environment for this scenario is computed as shown in Figure 5-7. The mean value for this distribution is $257.7 \mathrm{~kg}$. The salient points for this distribution are:

$\begin{array}{lll}- & 10 \% & 79.1 \mathrm{~kg} \\ - & \text { Mean } & 257.7 \mathrm{~kg} \\ - & 90 \% & 479.4 \mathrm{~kg}\end{array}$

It should be noted that these estimates form the basis for the nonvolatile compounds. For the volatile ${ }^{137} \mathrm{Cs}$ fraction, the release factor is assumed to be 10 times greater. 
Therefore, the curies of ${ }^{137} \mathrm{Cs}$ released are obtained by multiplying the product of the release values stated above and in Table 5-7 and the concentration in Table 5-2 by 10 .

\subsubsection{Aircraft Crash on a Dry Inert Tank - Dome Collapse (DCVHIl)}

This subsection describes the details of the source term evaluation for this accident sequence for a target tank that is ory and inert. The major highlights of the calculations for an aircraft crash onto a dry, inert tank are summarized in Figure 5-8.

Following an aircraft crash, about 5,000 gallons of jet fuel are expected to be spilled into the tank. Based on an estimated porosity of 0.5 , about $56,000 \mathrm{~kg}$ of tank contents lof dried tank crust bed/sludgel are expected to be soaked. Upon ignition of the jet fuel, some fraction of this soaked material has the potential to participate in the ensuing fire. A distribution (shown in Figure 5-8) was assumed for this fraction. A normal distribution was created with a mean of $50 \%$ and a standard deviation of $15 \%$. Figure $5-8$ shows that the fraction of the soaked material assumed to participate in the fire ranges from $5 \%$ to $95 \%$ and has a mean of $50 \%$. Use of this distribution in conjunction with the estimate of the mass of soaked material allows the calculation of the mass of dried crust/sludge burned.

Only a fraction of the dried crust/sludge that participates in the burn will be aerosolized. Experimental studies reported by Jofu Mishima (Reference 5-11) predict estimates of release fractions ranging from $3 E-2$ (bounding value for indoors, vigorous burning large pools) to $1 E-2$ (median value for indoors, burning solvent over aqueous phase) to $5 \mathrm{E}-3$ (bounding value for outdoors, aqueous solution or air dried salts under gasoline fire). Based on these references, a distribution was created for the fraction of the mass aerosolized. A normal distribution was created with a mean of $1 E-2$ and a standard deviation of $3 E-3$. The distribution is shown in Figure 5-8 and ranges from $1 \mathrm{E}-3$ to $2 \mathrm{E}-2$. This distribution encompasses the range of values reported by Mishima and is considered to be appropriate for this situation. The amount of tank content aerosolized as a result of the fire is then calculated based on the estimate of mass burned and the distribution of the fraction aerosolized.

In addition to the tank contents being aerosolized (and airborne) as a result of fire, high winds also have the potential to entrain the tank contents. High surface winds (>20 mph) have been shown to entrain particles at rates 10 to $300 \mathrm{gm} / \mathrm{sec}$. For the purposes of the present calculation, it was assumed that the tank would be exposed to the environment for a finite duration of time, following an aircraft crash. The exposure period for entertainment is the time from dome collapse to the time when the tank is completely covered as a result of post accident recovery operations. This exposure period could be as small as $1 / 2$ day lif the tank can be covered up immediately after the fire) but could also be as large as a week. The week-long exposure is possible if adequate material/manpower/procedures are not in place for such an eventuality. In light of this, a distribution with a mean of 2 days was assumed as shown in Figure 5-8. The exposure duration as shown in the distribution ranges from 0 to 7 days. Analysis of Hanford Meteorological data (Reference 5-9) showed that the winds in excess of $20 \mathrm{mph}$ occurred for about $5.2 \%$ of the time on the average. This corresponds to about $1.25 \mathrm{hr} / d a y$ of high winds. As these data are based on an multi-year averages, it is likely that, on a given day, the duration of high winds could range from $0.1 \mathrm{hr} /$ day to over $4 \mathrm{hr} /$ day. In light of this, a lognormal distribution with a mean of $1.25 \mathrm{hr} /$ day was chosen with a standard deviation of 1.0. This allowed the distribution to 
range from about $0.1 \mathrm{hr} /$ day to over $4 \mathrm{hr} /$ day. The distribution for wind entertainment was chosen to range from 10 to $300 \mathrm{gm} / \mathrm{sec}$ based on separate HMS analysis (Reference 5-10). This distribution for the entertainment rate is shown in Figure 5-8 and has a mean of about $20 \mathrm{gm} / \mathrm{sec}$. The amount of material entrained by the winds is therefore computed by using the exposure period, frequency of high winds, and the entertainment rate.

The total amount of tank content released into the environment for this scenario (DCVHI aircraft crash for dry inert tanks) is computed by combining the mass aerosolized from the burn phenomenon with the mass released as a result of the wind entertainment. The resultant distribution for the total mass released into the environment for this scenario is computed as shown in Figure 5-8. The mean value for this distribution is $446 \mathrm{~kg}$. The salient points for this distribution are:

$\begin{array}{lll}\text { - } & 10 \% & 213 \mathrm{~kg} \\ \text { - } & \text { Mean } & 446 \mathrm{~kg} \\ \text { - } & 90 \% & 712 \mathrm{~kg}\end{array}$

It should be noted that these estimates are for the non-volatile compounds. For the volatile $137 \mathrm{Cs}$ fraction, the release factor is assumed to be 10 times greater. Therefore, the curies of ${ }^{137} \mathrm{Cs}$ released are obtained by multiplying the product of the release values in Table 5-8 and the concentration in Table $5-2$ by 10 .

\subsubsection{Aircraft Crash en:a Dry. Organic Tank - Dome Collapse (DCVHO)}

This subsection describes the details of the source term evaluation for this accident sequence for a target tank that is dry and has high organic content. The major highlights of the calculations for an aircraft crash onto a dry, organic tank are summarized in Figure 5-9.

Following an aircraft crash, about 5,000 gallons of jet fuel are expected to be spilled into the tank. Based on an estimated porosity of 0.5 , about $56,000 \mathrm{~kg}$ of tank contents lof dried tank crust bed/sludge) are expected to be soaked. Upon ignition of the jet fuel, some fraction of this soaked material has the potential to participate in the ensuing fire. A distribution (shown in Figure 5-9) was assumed for this fraction. A normal distribution was created with a mean of $50 \%$ and a standard deviation of $15 \%$. Figure 5-9 shows that the fraction of the soaked material assumed to participate in the fire ranges from $5 \%$ to $95 \%$ and has a mean of $50 \%$.

In addition to the gasoline-soaked mass, the rest of the nonsoaked mass can also participate in the combustion process because of the high organic content. The total volume of the organic tank is expressed by the discrete distribution shown in Figure 5-9. This distribution was composed by assigning equal weights to the volumes of all five dry, organic tanks. The tank volumes vary from $59 \mathrm{Kgal}$ to $609 \mathrm{Kgal}$. This tank volume distribution, in conjunction with the density and the amount of gasoline-soaked mass, can be used to determine the mass of nonsoaked material that has the potential to burn. Based on geometry considerations (the dry bed of tank contents would act as a filter bed and try to limit the combustion process) and the non uniform distribution of moisture within the tank (more moisture would be found at the bottom of the tank), all of the tank contents are not likely to participate in the burn process. It is assumed that, on an average, about $20 \%$ 
of this nonsoaked material would participate in the burn. A Weibull distribution ranging from $10 \%$ to $50 \%$ was assumed and is shown in Figure 5-9 to describe the fraction of the nonsoaked mass participating in the burn. Use of these distributions in conjunction with the estimates of the mass of soaked and nonsoaked materials allows the calculation of the mass of dried crust/sludge burned.

Only a fraction of the dried crust/sludge that participates in the burn will be aerosolized. Experimental studies reported by Jofu Mishima (Reference 5-11) predict estimates of release fractions ranging from $3 E-2$ (b.ounding value for indoors, vigorous burning large pools) to $1 E-2$ (median value for indoors, burning solvent over aqueous phase) to $5 E-3$ (bounding value for outdoors, aqueous solution or air dried salts under gasoline fire). Based on these references, a distribution was created for the fraction of the mass aerosolized. A normal distribution was created with a mean of $1 E-2$ and a standard deviation of $3 E-3$. The distribution is shown in Figure 5-9 and ranges from $1 E-3$ to $2 E-2$. This distribution encompasses the range of values reported by Mishima and is considered to be appropriate for this situation. The amount of tank content aerosolized as a result of the fire is then calculated based on the estimate of mass burned and the distribution of the fraction aerosolized.

In addition to the tank contents being aerosolized (and airbornel as a result of fire, high winds also have the potential to entrain the tank contents. High surface winds ( $>20 \mathrm{mph}$ ) have been shown to entrain particles at rates 10 to $300 \mathrm{gm} / \mathrm{sec}$. For the purposes of the present calculation, it was assumed that the tank would be exposed to the environment for a finite duration of time, following an aircraft crash. The exposure period for entertainment is the time from dome collapse to the time that the tank is completely covered as a result of post accident recovery operations. This exposure period could be as small as $1 / 2$ day (if the tank can be covered up immediately after the fire) but could also be as large as a week. The week-long exposure is possible if adequate material/manpower/procedures are not in place for such an eventuality. In light of this, a distribution with a mean of 2 days was assumed as shown in Figure 5-9. The exposure duration as shown in the distribution ranges from 0 to 7 days. Analysis of Hanford Meteorological data (Reference 5-9) showed that the winds in excess of $20 \mathrm{mph}$ occurred for about $5.2 \%$ of the time on the average. This corresponds to about $1.25 \mathrm{hr} / \mathrm{day}$ of high winds. As these data are based on an multi-year averages, it is likely that, on a given day, the duration of high winds could range from $0.1 \mathrm{hr} /$ day to over $4 \mathrm{hr} /$ day. In light of this, a lognormal distribution with a mean of $1.25 \mathrm{hr} /$ day was chosen with a standard deviation of 1.0. This allowed the distribution to range from about $0.1 \mathrm{hr} /$ day to over $4 \mathrm{hr} /$ day. The distribution for wind entertainment was chosen to range from 10 to $300 \mathrm{gm} / \mathrm{sec}$ based on separate HMS analysis (Reference 5-10). This distribution for the entertainment rate is shown in Figure 5-9 and has a mean of about $20 \mathrm{gm} / \mathrm{sec}$. The amount of material entrained by the winds is therefore computed by using the exposure period, frequency of high winds, and the entertainment rate.

The total amount of tank content released into the environment for this scenario (DCVHO aircraft crash for dry organic tanks) is computed by combining the mass aerosolized from the burn phenomenon with the mass released as a result of the wind entertainment. The resultant distribution for the total mass released into the environment for this scenario is computed as shown in Figure 5-9. The mean value for this distribution is $4,222 \mathrm{~kg}$. The salient points for this distribution are: 


$\begin{array}{llr}\text { - } & 10 \% & 900 \mathrm{~kg} \\ \text { - } & \text { Mean } & 4,222 \mathrm{~kg} \\ \text { - } & 90 \% & 8,400 \mathrm{~kg}\end{array}$

It should be noted that these estimates are for the non-volatile compounds. For the volatile ${ }^{137} \mathrm{Cs}$ fraction, the release factor is assumed to be 10 times greater. Therefore, the curies of ${ }^{137} \mathrm{Cs}$ released are obtained by multiplying the product of the release values in Table 5-9 and the concentration in Table $5-2$ by 10 .

\subsubsection{CATASTROPHIC DOME COLLAPSE - NO BURNS (DCL, DCL4, DCL45, AND DCL122)}

These release categories apply to those accidents in which a catastrophic dome collapse occurs, but the failure is not associated with a burn. Following collapse of the dome, the tank is assumed to be open to the environment, but the integrity of the tank shell remains, preventing any significant release via the liquid pathway. As was the case for Release Category $D C H$, the collapse of the dome leaves the damaged tank vulnerable to winds that could entrain material and provide an unfiltered airborne release directly into the environment.

The key issue in the evaluation of the source term for this release category is the amount of material entrained and removed by air movement across the exposed surface of the tanks contents. The amount of deentrainer and HEPA filter material that could become airborne is believed to be minimal in comparison to the burp/burn type events since there is no fire associated with this type of event. Reference 5-11 (page xviii) suggests an upper bound release fraction for the free fall impact of unenclosed HEPA filters of 0.01 . For passively vented tanks, this upper bound release fraction will conservatively be assumed to represent the mean of a lognormal distribution with a range factor of 10 . Tanks with active ventilation systems have moisture deentrainers upstream of the HEPA filters. It is estimated that the deentrainer removes approximately $90 \%$ of the material in the exhaust stream. Reference 5-11 does not include any discussion of the accidental releases from components such as deentrainers. In the absence of any specific evidence, it will be assumed that the release from deentrainers can be characterized by a lognormal distribution with a mean release fraction of 0.2 and an error factor of 5 .

As noted in Section 5.4.4, after the collapse of the dome, the contents of the tank could be directly exposed to the atmosphere and subject to entrainment by wind. The exposure period for entrainment is the time period between dome collapse and when the tank is completely covered. If a single tank fails in this manner le.g., the dome collapses due to loads above the domel, the time duration between the occurrence of the accident and the time at which the tank is covered in some manner is expected to be of the order of $1 / 2$ to 7 days. If multiple tanks fail (e.g., seismic events), this time duration is expected to be significantly longer. Seismic events of sufficient magnitude to cause multiple tank failures will also cause significant damage (e.g., roads, bridges, communications) to the infrastructure as well. In addition, the availability of equipment, materials, and materials will be limited. Therefore, not all of the tanks with collapsed domes can be addressed within the time scale expected for failure of a single tank. Therefore, the distribution of the days of exposure has been broadened for the case of seismic-induced dome tank dome 
collapses. For such common cause events, the following exposure times have been selected:

\begin{tabular}{|l|c|}
\hline $\begin{array}{c}\text { Release } \\
\text { Category }\end{array}$ & $\begin{array}{c}\text { Mean } \\
\text { (Days) }\end{array}$ \\
\hline$D C L$ & 1.82 \\
\hline$D C L 4$ & 3 \\
\hline$D C L 12$ & 6 \\
\hline$D C L 45$ & 23 \\
\hline$D C L 122$ & 60 \\
\hline
\end{tabular}

The remaining distributions governing entrainment are assumed to be identical to those used for Release Category DCH.

Figure 5-10a through 5-10e summarize the release quantity bases and resulting distribution developed for the DCL series of release categories. The resultant distributions for the release of radioactive materials into the atmosphere have the following important parameters:

\begin{tabular}{|l|c|c|c|}
\hline $\begin{array}{c}\text { Release } \\
\text { Category }\end{array}$ & $\begin{array}{c}\text { 10th \% } \\
(\mathrm{kg})\end{array}$ & $\begin{array}{c}\text { Mean } \\
(\mathrm{kg})\end{array}$ & $\begin{array}{c}90 \text { th \% } \\
(\mathrm{kg})\end{array}$ \\
\hline $\mathrm{DCL}$ & 17.2 & 154.1 & 358.4 \\
\hline $\mathrm{DCL4}$ & 36.9 & 261 & 590.6 \\
\hline $\mathrm{DCL} 12$ & 70.5 & 515.9 & 1,173 \\
\hline $\mathrm{DCL45}$ & 274.2 & 1,955 & 4,536 \\
\hline $\mathrm{DCL} 122$ & 691.9 & 5,065 & 11,524 \\
\hline
\end{tabular}

The releases associated with the DCL series of release categories can result from any tank. Therefore, the radioisotope concentrations given in Tables 5-2 and 5-3 represent a composite for the entire tank farm.

\subsubsection{BURP/BURN SEQUENCES WITH DOME COLLAPSE AND SHELL FAILURE (DCLLK)}

This release category (i.e., event tree end state) represents simultaneous failures: dome collapse due to hydrogen burns and loss of tank shell integrity. The magnitude of the airborne release is assumed to be equal to that of Release Category DCH, and the magnitude of the release to the liquid pathway release is assumed to be equal to that of Release Category LLK (see Section 5.5.2).

\subsubsection{BURNS IN PASSIVELY VENTED TANKS (DCLLK2)}

Release Category DCLLK2 is the event tree end state for all burns associated with passively vented Tank S-112. This release category is similar to Release Category DCLLK and has the same airborne and liquid release fractions. However, as shown in Table 5- 1 the concentration of Cs-137 in Tank S-112 is substantially higher than that used in estimating the source term for Release Category DCLLK. Therefore, the radioisotope concentrations given in Tables 5-2 and 5-3 for this release category are unique to Tank S-112. 


\subsubsection{BURNS IN TANKS WITH POTENTIAL FOR POOL FIRES (DCHORG)}

Release Category DCHORG has been identified as the event tree end state for accident sequences involving tanks that are subject to burns in the dome space and contain a floating liquid layer of organic material (i.e., Tank 103-C). Relative to the character of the release into the atmosphere, this release category is somewhat analogous to Release Category DCVH, which was defined for Tank 241-SY-101. For calculating source terms, it is assumed that the floating organic layer is contaminated with radioactive materiais.

It is assumed that it will take approximately 36 minutes for an organic layer of 6000 gals to be consumed by combustion. Based on a mean heat of combustion of the "organic fuel" of $12,500 \mathrm{Btu} / \mathrm{lbm}$, it is estimated that approximately $6.7 \mathrm{E}+8 \mathrm{Btu}$ will be released. These assumptions result in a release energy rate of approximately $1.1 \mathrm{E}+9 \mathrm{Btu} / \mathrm{hr}$. The amount of heat associated with the hydrogen burn which initiates the combustion of the floating organic layer is small in comparison with that of the organic fuel.

Reference 5-11 reports a bounding value of 0.1 and a median value of 0.01 for the release fraction of radioactive material from an organic solvent that is burning on top of an aqueous phase. It was also noted that the rapid evolution of the aqueous phase terminated combustion in many of the experiments that were performed to address this issue. Release Category DCVH also used a fire release factor of 0.01 , however, the basis for this factor was Reference 5-8. For consistency, the lognormal distribution (mean of 0.01 and a standard deviation of 0.01) utilized for Release Category DCVH will also be used for Release Category DCHORG. This release fraction distribution will also be applied to the contaminated organic layer.

Reference 5-11 recommends a bounding value of 0.005 for the release fraction for the suspension of material resulting from the burning of gasoline over aqueous solutions of air-dried salts. Thus, the assumed mean release factor could be somewhat conservative.

For this analysis, the size of the floating organic layer is represented by a lognormal distribution with a mean value of 6000 gallons (see Ref. 5-17) and a 95th percentile value of 14686 gallons. It is assumed that the organic layer participates in the burn. Ignoring other contributions to this source term, the resulting release is:

$\begin{array}{lll}\text { - } & 10 \%: & 51.3 \mathrm{~kg} \\ \text { - } & \text { Mean: } & 461.7 \mathrm{~kg} \\ \text { - } & 90 \%: & 1060.7 \mathrm{~kg}\end{array}$

Figure 5-A describes the distributions and results of the Monte-Carlo simulation for Release Category DCHORG.

The concentration of Pu-239/240 in Tank 103-C is more than an order of magnitude greater than that for the generic source term and more than two orders of magnitude greater than that for Tank 241-SY-101. Thus, the radioisotope concentrations for Release Category DCHORG which are summarized in Tables 5-2 and 5-3 are those of Tank 103-C. As was described for Release Category DCVH, the magnitude of the Cs-137 is increased by a factor of 10 to account for its volatility. 


\subsubsection{UNFILTERED RELEASE FROM AGING WASTE TANKS (BPH)}

Release Category BPH is similar to Release Category BPL except that the magnitude of the release is "enhanced" due.to heatup of the aging waste tank's contents. As noted in Section 4.2.7.3.2, only aging waste tank scenarios in which operator recovery of ventilation fails are mapped to this release category. If operator recovery is successful, the scenarios are mapped to Release Category BPL.

Following extended loss of ventilation, there is the possibility that waste temperatures will rise to a point at which boiling would occur. The boiling process could cause tank waste to become entrained with the vapor and escape into the atmosphere without filtration. Analysis reported in Appendix $F$ of Reference 5-12 estimated a release quantity of $0.347 \mathrm{gal}(1.4 \mathrm{~kg})$ for such events occurring in the aging waste tanks, assuming a heat generation rate of $700,000 \mathrm{Btu} / \mathrm{hr}$. The highest heat generating rate of the aging waste tanks is estimated to be $302,000 \mathrm{Btu} / \mathrm{hr}$. The value calculated in Reference $5-12$ will be used as the median of a lognormal distribution.

Reference 5-11 recommended a bounding value of 0.002 for the fractional release of dissolved matter due to evaporation and bubbling in an aqueous solution. If this release fraction is applied to the quantity of drainable interstitial liquid in Tank 101-AY, the resulting release would be $7,620 \mathrm{~kg}(0.002 \times 3.81 \mathrm{E}+6 \mathrm{~kg}$ ) if all of the liquid was assumed to boil. This bounding estimate appears to be extremely conservative. However, to address the uncertainties involved with making such predictions, a range factor of 10 will be assumed for the lognormal distribution representing this release. Thus, the assumed distribution for the release of radioactive materials to the atmosphere has the following important parameters:

$\begin{array}{lll}\text { - } & 10 \% & 0.087 \mathrm{~kg} \\ \text { - } & \text { Mean } & 1.4 \mathrm{~kg} \\ \text { - } & 90 \% & 3.166 \mathrm{~kg}\end{array}$

\subsubsection{SMALL SPRAY EVENTS (SSPRY)}

Spray events result from leaks in pressurized piping or connections that occur during transfer processes and result in releases into both the atmosphere and to the liquid pathway. Spray leaks are assumed to result from improper jumper installation.

As indicated in Section 4.2.11, if a spray type leak occurs in a pit in which one or more cover blocks has been removed, the leak is binned to either Release Category SSPRY or Release Category LSPRY, depending on whether the area radiation monitors (ARM) detect an increase in radiation and the leak is automatically terminated or terminated by the operator in response to the alarm. Failure to terminate the leak results in assignment to Release Category LSPRY.

The following parameters will control the magnitude of the release into the environment resulting from transfer line leaks that produce sprays:

- Magnitude of the leak. 
Reference $5-13$ provides some insights into the magnitudes of the leaks associated with sprays. Although the estimates provided in Reference 5-13 were calculated for SST salt well pumping, they are assumed to be applicable to all waste transfer events. Based on local line pressures of the order of 50 to 200 psi, typical leaks are expected to be in the 0.5 to 1.0-gpm range. For the evaluation of "small" spray leaks, the magnitude of the leak will be characterized as a lognormal distribution with a median value of $0.75 \mathrm{gpm}$ and a range factor (ratio of 95 th percentile to the median) of 4 .

For sprays that are detected by the ARMs, it is assumed that the leak would be terminated within approximately a 10 to 20-minute time frame. Based on this assumption, the duration of the spray event is assumed to be characterized as a lognormal distribution with a median of 15 minutes and a range factor of 2 .

Reference 5-13 also provides some insights into the airborne source terms associated with sprays. Although the estimates provided in Reference 5-13 were calculated for SST salt well pumping, they are assumed to be applicable to all waste transfer events. For a 0.5-gpm spray-type leak lasting for 8 hours, it was estimated that a total of 44 liters (11.7 gal) of the sprayed liquid would become "aerosolized." This represents a fractional release into the atmosphere of approximately $0.049[11.7 /(0.5 * 60 * 8)]$.

Reference 5-11 (p. 3-2) recommends a bounding value for airborne release fraction of 0.0001 for "venting" of pressurized liquids. This bounding value was based on estimates using the mass fraction of droplets 10 micrometers and less in diameter formed by commercial spray nozzles for conditions that will exceed those for most accidents. Thus, it appears as though the estimate provided in Reference 5-13 appears to be extremely conservative. For this evaluation, the airborne release fraction will also be characterized by a lognormal distribution. The median value for this distribution is assumed to be 0.005 , and the 95 th percentile will be assumed to be equal to 0.049 , yielding a range factor of 9.8.

The difference between the total leakage from the line and the amount that is released into the atmosphere is leaked to the ground. Figure 5-11 summarizes the assumptions and material releases for Release Category SSPRY. The quantities of material released into the environment are as follows:

\begin{tabular}{|l|c|c|}
\hline \multicolumn{1}{|c|}{ Item } & Airborne Release (kg) & Liquid Release (kg) \\
\hline 10th Percentile & 0.07 & 19.81 \\
\hline Mean & 1.26 & 98.17 \\
\hline 90th Percentile & 2.85 & 208.18 \\
\hline
\end{tabular}

Since sprays can originate with a variety of tanks, the composite concentrations for radionuclides was used for this release category (see Tables 5-2 and 5-3).

\subsubsection{LARGE SPRAY EVENTS (LSPRY)}


Release Category LSPRY is very similar to Release Category SSPRY; however, the quantity of sprayed liquid is much larger, producing a larger source term.

For the evaluation of "large" spray leaks, the magnitude of the leak from the pressurized line will be characterized as a lognormal distribution with a median value of $1.0 \mathrm{gpm}$ and a range factor of 5 .

By definition, the leak will not be automatically terminated in response to high radiation readings. Therefore, the time to detection and termination will be significantly longer than that for small spray-type leaks. Typical detection and termination times for large sprays are expected to be in the 8-hour range. This time will be treated as the median of a lognormal distribution with a range factor of 3 ; i.e., the 95 th percentile will be 24 hours.

The distribution developed for small spray events for airborne release fraction is applicable to large sprays as well.

Figure 5-12 summarizes the assumptions and material releases for Release Category LSPRY. The quantities of material released into the environment are as follows:

\begin{tabular}{|l|c|c|}
\hline \multicolumn{1}{|c|}{ Item } & Airborne Release (kg) & Liquid Release (kg) \\
\hline 10th Percentile & 4.12 & 580 \\
\hline Mean & 69.82 & 5,463 \\
\hline 90th Percentile & 149.49 & 12,186 \\
\hline
\end{tabular}

Since sprays can originate with a variety of tanks, the composite concentrations for radionuclides were used for this release category (see Tables 5-2 and 5-3).

\subsection{LIOUID PATHWAY ONLY SOURCE TERMS}

Because Tank 101-SY is currently in an inactive status as far as transferring liquid in or out of it, there are no liquid leaks owing to spills during transfers. However, the occurrences that can lead to liquid spills are (1) a primary tank leak with secondary tank failure, and (2) a water intrusion leading to tank overflow. The corresponding liquid releases, summarized in Table 5-4, are described below. As indicated in Table 5-3, the dissolved radioisotope concentrations in the tank liquids are different from those found in the surface crust material. While the ${ }^{137} \mathrm{Cs}$ is about the same, the ${ }^{90} \mathrm{Sr}$ and transuranics are found to be factors of about 10 and 100, respectively, lower owing to their lower solubilities.

\subsubsection{SMALL LEAK (SLK)}

Release Category SLK contains those scenarios in which there is a breach of tank shell integrity leading to a maximum liquid release of 10,000 gallons $(56,800 \mathrm{~kg})$. * This breakpoint is treated as the high end release; i.e., the 90th percentile. It should be noted that, for such leaks to occur in DSTs, there must be a breach in both the primary and secondary shells.

*All conversions from gallons to $\mathrm{kg}$ assume a density of $5.68 \mathrm{~kg} / \mathrm{gal}$. 
It is assumed that a leak of 6,000 gallons $(34,200 \mathrm{~kg})$ represents the high value, the mean value of the small leak range is assumed to be 3,000 gallons $(17,100 \mathrm{kgl}$, and the low value is assumed to be 2,000 gallons $(11,360 \mathrm{~kg})$.

Since leaks can originate with a variety of tanks, the composite concentrations for radionuclides were used for this release category (see Tables 5-2 and 5-3).

\subsubsection{LARGE LEAK (LLK)}

Release Category LLK contains those scenarios in which there is a breach in tank integrity that results a liquid release greater than 10,000 gallons. Based on evaluations performed for Tank SY-101, the high end release is assumed to be 240,000 gallons $(1,363,200 \mathrm{~kg})$. This release is approximately equal to the quantity of drainable liquid available in Tank 101-SY. A mean value of 120,000 gallons $(681,600 \mathrm{~kg})$ is assumed for the large leak, and the low value is assumed to be 10,000 gallons $(56.800 \mathrm{~kg})$.

Since leaks can originate with a variety of tanks, the composite concentrations for radionuclides was used for this release category (see Tables 5-2 and 5-3).

\subsubsection{SMALL SPILLS (SSP)}

Release Category SSP contains small spill scenarios resulting from waste transfer operations and scenarios in which there is an undetected intrusion of water leading to a tank overflow. The assumed high value is 500 gallons $12,840 \mathrm{~kg}$, the mean value is 300 gallons $(1,700 \mathrm{~kg})$, and the low value is 100 gallons $(570 \mathrm{~kg})$.

The fraction of a liquid spill converted to airborne aerosol for various conditions is given in Reference 5-14 (p. 4.74). Because a waste tank overflow due to water intrusion is non energetic in the sense that there would be no splashing as the liquid impacts a surface, the models in Reference 5-14 probably over predict the aerosol fraction. Using the models suggested in Reference 5-8, the initial fraction aerosolized would be about 1E-6. However, there also would be a contribution due to high wind over the contaminated pool/ground, should the spill be coincident with such a condition. To allow for this, the mean value fraction of the spill converted to aerosol has been assumed to be $1 E-5$ for this analysis. This gives the source terms, listed in Table 5-3, as 5.7E-3, 1.7E-2, and 2.8E-2 for the 10th percentile, mean, and 90 th percentile, respectively.

Since such events can originate with a variety of tanks, the composite concentrations for radionuclides were used for this release category (see Tables 5-2 and 5-3).

\subsubsection{LARGE SPILLS (LSP)}

This release category is similar to Release Category SSP except for the quantity of liquid involved in the spill. Reference 5-15 discusses the magnitude of large spills resulting from leaks during salt well pumping. The values reported in Reference 5-15 are assumed to be applicable for large leaks resulting from any waste transfer operation.

Assuming that the spill is not detected by ARMs and that material balance data are recorded every 8 hours, Reference 5-15 estimated that a slow leak could result in a 
3,000 -gallon $(17,040 \mathrm{~kg}$ ) spill before discovery. A large leak/break could cause a spill of 10,800 gallons $(61,300 \mathrm{~kg})$ before discovery. Reference $5-16$ noted that a recorded spill that occurred prior to installation of ARMs resulted in the release of 8,600 gallons $(48,850 \mathrm{~kg})$ of liquid waste to the soil surface. Based on the above information, the magnitude of large spills has been characterized by a lognormal distribution with a median value of 8,600 gallons $(48,850 \mathrm{~kg})$ and a range factor of 3 .

Based on the above-assumed lognormal distribution, the following source term can be determined:

$\begin{array}{llr}\text { - } & 10 \% & 20,500 \mathrm{~kg} \\ \text { - } & \text { Mean } & 60,975 \mathrm{~kg} \\ \text { - } & 90 \% & 115,900 \mathrm{~kg}\end{array}$

Since such events can originate with a variety of tanks, the composite concentrations for radionuclides was used for this release category (see Tables 5-2 and 5-3).

\subsection{SUMMARY OF RADIOLOGICAL SQURCE TERMS}

The airborne release and liquid release estimates, in terms of kilograms of material released, are summarized in Table 5-4 for each release category. Tables 5-2 (airborne releases) and 5-3 (liquid releases to the ground) provide the isotopic concentrations that have been selected for each release category. Table 5-5 provides a snapshot of the relative risk, in terms of the quantity of material released to the atmosphere, between the various release categories.

The radiological consequences of these releases are presented in Chapter 6 .

\subsection{REFERENCES}

5-1. Tank 241-SY-101 Probabilistic Safety Assessment

5-2. Herting, D. L., "Laboratory Characterization of Samples taken in May 1991 from Hanford Waste Tank 241-SY-101," Westinghouse Hanford Company report WHC-SD-WM-DTR-024, February 10, 1992.

5-3. Herting, D. L., "Laboratory Characterization of Samples taken in Window E from Hanford Waste Tank 241-SY-101," Westinghouse Hanford Company report WHC-SD-WM-DTR-026, August 1992.

5-4. Westinghouse Hanford Company, "Environmental Releases for Calendar Year 1990," WHC-EP-0527, 1992.

5-5. Westinghouse Hanford Company, "Waste Tank Operations Plant Specifics Manual," draft of undated, unnumbered report.

5-6. U.S. Department of Energy, "A Safety Assessment for the Proposed Pump Mixing - Operations To Mitigate Episodic Gas Releases in Tank 241-101-SY: Hanford Site, 
Richland Washington," Los Alamos National Laboratory report LA-UR-92-3196, Rev. 8, March 8, 1993.

5-7. White, J. R., "Filter System Release Accident Analysis," calc note N6-CN-WT-SARAD-1, Rev. 0, January. 4, 1993.

5-8. Ayer, J. E., et al., "Nuclear Fuel Cycle Facility Accident Analysis Handbook," U.S. Nuclear Regulatory Commission report NUREG-1320, Table 4.10, p. 4.35, May 1988.

5-9. Travis, J. R., "An HMS/TRAC Analysis of a High-Level Radioactive Waste Tank Farm," Los Alamos National Laboratory report LA-UR-91-2699, 1991.

5-10. Fax from D. MacFarlane, LANL, "Hanford 200 Area Wind Speed, Stability, and Direction Data at 10 Meters for 1983-1991," May 19, 1994.

5-11. Mishima, J., "Recommended Values and Technical Bases for Airborne Release Fractions (ARFs), Airborne Release Rates (ARRs), and Respirable Fractions (RFs), for Materials from Accidents in DOE Fuel Cycle, Ex-Reactor Facilities," Draft ETM Report, Rev. 2, April 21, 1993.

5-12. Westinghouse Hanford Co., Aging Waste Facility Safety Analysis Report," SD-HS-SAR-010, Rev. 3, Draft, February 1990.

5-13. Westinghouse Hanford Corporation, "Accident Analysis of a Spray Leak for Safety Study on Interim Stabilization of Nonwatchlist Tanks," WHC-SD-WM-RPT-048, Rev. 0, Attachment B.

5-14. Lees, F. P., Loss Prevention in the Chemical Process Industries, Butterworths, London, Vol. I, p. 518, 1986.

5-15. Westinghouse Hanford Corporation, "Estimates of Surface Runoff Volumes and Risk Potential from SST Waste Transfer Line Leaks," WHC-SD-WM-RPT-048, Rev. 0, Attachment $F$.

5-16. SD-WM-SAR-034

5-17 Agnew, S.F., "Analysis of the History of 241-C Farm," LANL Technical Report DOE HQ EM 36, October 1993 
Table 5-1. Radioisotope Concentrations (Ci/kg) for Various Tanks

\begin{tabular}{|c|c|c|c|c|c|c|c|c|c|c|}
\hline \multirow[b]{2}{*}{ Isotope } & \multicolumn{2}{|c|}{ SY-101 * } & \multicolumn{2}{|c|}{ Generic *^ } & \multicolumn{2}{|c|}{ S-112 ** } & \multicolumn{2}{|c|}{$\mathrm{C}-103$ * } & \multicolumn{2}{|c|}{ Tank Farm Max + } \\
\hline & Airborne & Liquid & Airborne & Liquid & Airborne & Liquid & Airborne & Liquid & Airborne & Liquid \\
\hline$\overline{C-14}$ & 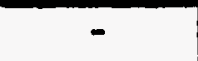 & $7.00 \mathrm{E}-05$ & & & & & & & & \\
\hline Sr-90 & 3.40E-02 & 3.00E-03 & $728 \mathrm{E}=0 \mathrm{O}$ & & 1.37E-01 & & $6.81 E-01$ & & $7.35 E+00$ & \\
\hline TC-99 & 3.00E-04 & 1.30E-04 & & & & & & & & \\
\hline $\mid-129$ & $2.90 E-04$ & 6.00E-07 & & & & & & & & \\
\hline Cs-137 & 4.50E-01 & 4.50E-01 & 4.09E-01 & & $1769 E^{2}=0 \pi$ & & 7.07E-02 & & 4.41E+01 & \\
\hline $\mathrm{Np}-237$ & $5,10 E-4$ & 7.00E-08 & 1.09E-06 & & 1.12E-06 & & & & 2.90E-05 & \\
\hline Pu-239/240 & $1.6 \mathrm{E}-05$ & 1.10E-07 & 4.37E-04 & & 7.37E-06 & & $449=03$ & & & \\
\hline Am-241 & 1.50E-04 & 5.00E-07 & $6978 E=04$ & & $2.75 \mathrm{E}-04$ & & & & $1.28 \mathrm{E}-02$ & \\
\hline
\end{tabular}

Notes: *taken from theTank 241-SY-101 PSA

** taken from Don MacFarlane's spreadsheet

$+\mathrm{Np}-237$ maximum is from MacFarlane spreadsheet. This value is less than that cited for Np-237 in the Tank SY-101 PSA.

Shaded concentrations represent the maximum concentrations for each radioisotope listed among the three specific tanks and the generic concentrations. 
Table 5-2. Isotopic Content of Materials Released to the Atmosphere

\begin{tabular}{|c|c|c|c|c|c|c|c|c|c|}
\hline Release & Representative & & & Concent & ations $(\mathrm{Ci}$ & kg) for Ra & lioisotope & & \\
\hline Category & Tank & C-14 & Sr-90 & Tc-99 & $1-129$ & Cs-137 & Np-237 & Pu-239/240 & Am-241 \\
\hline$\overline{B P L}$ & Generic & - & $7.28 \mathrm{E}-01$ & - & - & $4.09 E-01$ & 1.09E-06 & 4.37E-04 & 6.18E-04 \\
\hline BPH & & - & & & & & & & \\
\hline HEPAL & Generic & - & $7.28 \mathrm{E}-01$ & - & - & 4.09E-01 & 1.09E-06 & 4.37E-04 & 6.18E-04 \\
\hline HEPAH & 101-SY & -- & 3.40E-02 & 3.00E-04 & 2.90E-04 & 4.50E-01 & 5.10E-04 & $1.60 E-05$ & 1.50E-04 \\
\hline $\mathrm{DCH}$ & 101-SY & - & $3.40 E-02$ & 3.00E-04 & 2.90E-04 & 4.50E-01 & 5.10E-04 & 1.60E-05 & 1.50E-04 \\
\hline $\mathrm{DCL}$ & Generic & - & $7.28 E-01$ & -- & -- & 4.09E-01 & 1.09E-06 & 4.37E-04 & 6.18E-04 \\
\hline DCVH & Generic & -- & 7.28E-01 & - & - & 4.09E-01 & 1.09E-06 & 4.37E-04 & $6.18 E-04$ \\
\hline DCVHI & Generic & - & $7.28 E-01$ & - & -. & 4.09E-01 & 1.09E-06 & 4.37E-04 & 6.18E-04 \\
\hline DCVHF & Generic & - & 7.28E-01 & -- & $\cdots$ & 4.09E-01 & 1.09E-06 & 4.37E-04 & $6.18 E-04$ \\
\hline DCVHO & & & & & & & & & \\
\hline DCLLK & Generic & $-\infty$ & $7.28 E-01$ & - & - & 4.09E-01 & $1.09 E-06$ & 4.37E-04 & 6.18E-0. \\
\hline DCLLK2 & $112-S$ & $\cdots$ & 1.37E-01 & - & - & 7.69E-01 & 1.12E-06 & 7.37E-06 & 2.75E-04 \\
\hline DCHORG & $103-C$ & - & 6.81E-01 & - & - & 7.07E-02 & - & 4.79E-03 & - \\
\hline SSPRY & Generic & - & 7.28E-01 & -- & - & 4.09E-01 & 1.09E-06 & 4.37E-04 & 6.18E-04 \\
\hline LSPRY & Generic & -- & 7.28E-01 & - & - & 4.09E-01 & 1.09E-06 & 4.37E-04 & $6.18 E-04$ \\
\hline SLK & Generic & - & 7.28E-01 & - & - & 4.09E-01 & 1.09E-06 & 4.37E-04 & 6.18E-04 \\
\hline LLKK & Generic & - & 7.28E-01 & - & - & 4.09E-01 & 1.09E-06 & 4.37E-04 & 6.18E-04 \\
\hline SSP & Generic & - & 7.28E-01 & - & - & 4.09E-01 & 1.09E-06 & 4.37E-04 & 6.18E-04 \\
\hline LSP & Generic & - & 0.728 & $=$ & - & 0.409 & $1.09 \mathrm{E}-06$ & 0.000437 & 0.000618 \\
\hline
\end{tabular}

Notes:

Release Category DCL concentrations are used for Release Categories DCL4, DCL12, DCL45, and DCL122 
Table 5-3. Isotopic Content of Liquids Released to the Ground

\begin{tabular}{|c|c|c|c|c|c|c|c|c|c|}
\hline \multirow{2}{*}{$\begin{array}{l}\text { Release } \\
\text { Category }\end{array}$} & Representative & \multicolumn{8}{|c|}{ Concentrations (Ci/kg) for Radioișotope } \\
\hline & Tank & C-14 & Sr-90 & Tc-99 & $1-129$ & Cs-137 & $\mathrm{Np}-237$ & Pu-239/240 & Am-241 \\
\hline BPL & Generic * & - & $7.28 \mathrm{E}-01$ & $\overline{-}$ & - & $4.09 E-01$ & 1.09E-06 & 4.37E-04 & $6.18 E-04$ \\
\hline BPH & & & & & & & & & $618=-04$ \\
\hline HEPAL & Gèneric * & $\ddot{-}$ & $7.28 E-01$ & - & - & $4.09 E-01$ & 1.09E-U0 & 4.31E-U4 & $0.105-U 4$ \\
\hline HEPAH & 101-SY & $7.00 E-05$ & 3.00E-03 & 1.30E-04 & 6.00E-07 & 4.50E-01 & 7.00E-08 & 1.10E-07 & 5.00E-07 \\
\hline $\mathrm{DCH}$ & $101-S \gamma$ & 7.00E-05 & 3.00E-03 & 1.30E-04 & 6.00E-07 & 4.50E-01 & 7.00E-08 & 1.10E-07 & 5.00E-07 \\
\hline DCL & Generic * & -- & 7.28E-01 & - & -- & 4.09E-01 & 1.09E-06 & 4.37E-04 & $6.18 E-04$ \\
\hline DCVH & Generic ${ }^{\bullet}$ & - & 7.28E-01 & - & - & 4.09E-01 & $1.09 E-06$ & 4.37E-04 & 6.18E-04 \\
\hline DCVHI & Generic • & - & 7.28E-01 & - & - & 4.09E-01 & 1.09E-06 & 4.37E-04 & $6.18 E-04$ \\
\hline DCVHF & Generic * & - & 7.28E-01 & -- & - & 4.09E-01 & 1.09E-06 & 4.37E-04 & 6.18E-04 \\
\hline DCVHO & & & & & & & & & \\
\hline DCLLK & Generic • & $-\infty$ & 7.28E-01 & -- & $\cdots$ & $4.09 E-01$ & 1.09E-06 & 4.37E-04 & $6.18 E-04$ \\
\hline DCLLK2 & $112-S$ * & -- & 1.37E-01 & - & - & 7.69E-01 & 1.12E-06 & 7.37E-06 & 2.75E-04 \\
\hline DCHORG & $103-C$ * & - & 6.81E-01 & - & - & 7.07E-02 & - & 4.79E-03 & - \\
\hline SSPRY & Generic * & - & 7.28E-01 & - & - & $4.09 \mathrm{E}-01$ & 1.09E-06 & 4.37E-04 & $6.18 \mathrm{E}-04$ \\
\hline LSPRY & Generic & - & 7.28E-01 & -- & -- & 4.09E-01 & 1.09E-06 & 4.37E-04 & 6.18E-04 \\
\hline SLK & Generic ${ }^{\bullet}$ & - & 7.28E-01 & - & - & 4.09E-01 & 1.09E-06 & 4.37E-04 & 6.18E-04 \\
\hline LLK & Generic * & - & 7.28E-01 & - & - & 4.09E-01 & 1.09E-06 & 4.37E-04 & 6.18E-04 \\
\hline SSP & Generic * & - & 7.28E-01 & - & - & 4.09E-01 & 1.09E-06 & 4.37E-04 & 6.18E-04 \\
\hline LSP & Generic * & - & 0.728 & - & - & 0.409 & 1.09E-06 & 0.000437 & 0.000618 \\
\hline
\end{tabular}

Notes:

Release Category DCL concentrations are used for Release Categories DCL4, DCL12, DCL45, and DCL122

- from Don MacFarlane FAX dated 06/21/94 
Table 5-4. Total Quantities of Material Released to the Environment

\begin{tabular}{|c|c|c|c|c|c|c|}
\hline $\begin{array}{l}\text { Release } \\
\text { Calegory }\end{array}$ & $\begin{array}{c}\text { Low Value } \\
\text { (10/h Percentile) }\end{array}$ & $\begin{array}{l}\text { Irbome Release (kg) } \\
\text { Mean Value }\end{array}$ & $\begin{array}{c}\text { High Value } \\
\text { (90th Percentile) }\end{array}$ & $\begin{array}{c}\text { Low Value } \\
\text { (10th Percenlile) }\end{array}$ & $\begin{array}{l}\text { uid Release }(\mathrm{kg}) \\
\text { Mean Value }\end{array}$ & $\begin{array}{c}\text { High Value } \\
\text { (90Ih Percentile) }\end{array}$ \\
\hline BPL & 3.40E-04 & 7.00E-04 & 2.10E-03 & - & - & - \\
\hline BPH & 0.087 & 1.4 & 3.166 & - & - & - \\
\hline HEPAL & 0.3 & 0.22 & 0.48 & - & - & - \\
\hline HEPAH & 0.84 & 2.9 & 5.6 & - & $\bar{i}$ & - \\
\hline $\mathrm{DCH}$ & 28.4 & 168.1 & 374 & - & - & - \\
\hline DCL & 17.2 & 154.1 & 358.4 & - & - & - \\
\hline DCL4 & 36.9 & 261 & 590.6 & - & - & - \\
\hline DCL12 & 70.5 & 515.9 & 1173 & - & - & - \\
\hline DCL.45 & 274.2 & 1955 & 4536 & - & - & - \\
\hline DCL122 & 691.9 & 5065 & 11524 & - & - & - \\
\hline DCVH & 79.1 (Cs Enhanc) & 257.7 (Cs Enhanc) & 479.4 (Cs Enhanc) & - & - & - \\
\hline DCVHI & 213 (Cs Enhanc) & 446 (Cs Enhanc) & 712 (Cs Enhanc) & - & - & -- \\
\hline DCVHF & 213 (Cs Enhanc) & 446 (Cs Enhanc) & 712 (Cs Enhanc) & $-\bullet$ & - & - \\
\hline DCVHO & 900 (Cs Enhanc) & 4222 (Cs Enhanc) & 8400 (Cs Enhanc) & - & - & - \\
\hline DCLLK & 24.2 & 170.1 & 521.9 & 56800 & 681600 & 1363200 \\
\hline DCLLK2 & 24.2 & 170.1 & 521.9 & 56800 & 681600 & 1363200 \\
\hline DCHORG & 51.3 (Cs Enhanc) & 461.7 (Cs Enhanc) & 1060.7 (Cs Enhanc) & 56800 & 681600 & 1363200 \\
\hline SSPRY & 0.07 & 1.26 & 2.85 & 19.81 & 08.17 & 208.18 \\
\hline LSPRY & 4.12 & 69.82 & 149.49 & 580 & 5463 & 12186 \\
\hline SLK & - & - & - & 11360 & 34200 & 56800 \\
\hline LLK & - & - & - & 56800 & 681600 & 1363200 \\
\hline SSP & 5.70E-03 & 0.02 & 0.03 & 570 & 1700 & 2840 \\
\hline LSP & 0.21 & 0.61 & 1.15 & 20738 & 61052 & 115070 \\
\hline
\end{tabular}

Note: The total release of each radionuclide I is equal to the product of the numbers

listed in this table and the concentration (Ci/kg) of radionuclide i in the material released. 
Table 5-5. Point Estimate of Risk from Airborne Releases

\begin{tabular}{|c|c|c|c|}
\hline $\begin{array}{c}\text { Release } \\
\text { Category }\end{array}$ & $\begin{array}{c}\text { Release } \\
\text { Category } \\
\text { Freq(1/yr) }\end{array}$ & $\begin{array}{c}\text { Mean Value } \\
\text { of Release } \\
\text { (kg) }\end{array}$ & $\begin{array}{c}\text { Mean } \\
\text { Risk } \\
\text { (kg/yr) }\end{array}$ \\
\hline DCL45 & $5.93 \mathrm{E}-04$ & 1955 & $1.16 \mathrm{E}+00$ \\
DCL & $1.55 \mathrm{E}-03$ & 154.1 & $2.39 \mathrm{E}-01$ \\
HEPAL & $7.92 \mathrm{E}-01$ & 0.22 & $1.74 \mathrm{E}-01$ \\
DCH & $6.98 \mathrm{E}-04$ & 168.1 & $1.17 \mathrm{E}-01$ \\
DCELK & $6.55 \mathrm{E}-04$ & 168.1 & $1.10 \mathrm{E}-01$ \\
LSP & $1.57 \mathrm{E}-01$ & 0.61 & $-9.58 \mathrm{E}-02$ \\
LSPRY & $4.52 \mathrm{E}-04$ & 69.82 & $3.16 \mathrm{E}-02$ \\
DCHORG & $6.38 \mathrm{E}-05$ & 461.7 & $2.95 \mathrm{E}-02$ \\
SSP & 1.65 & 0.02 & $2.81 \mathrm{E}-02$ \\
DCLLK2 & $8.77 \mathrm{E}-05$ & 170.1 & $1.49 \mathrm{E}-02$ \\
HEPAH & $5.07 \mathrm{E}-03$ & 2.88 & $1.46 \mathrm{E}-02$ \\
BPH & $8.52 \mathrm{E}-03$ & 1.4 & $1.19 \mathrm{E}-02$ \\
DCL122 & $2.26 \mathrm{E}-06$ & 5065 & $1.14 \mathrm{E}-02$ \\
SSPRY & $8.59 \mathrm{E}-03$ & 1.26 & $1.08 \mathrm{E}-02$ \\
BPL & 6.84 & $7.00 \mathrm{E}-04$ & $4.79 \mathrm{E}-03$ \\
DCL12 & $7.91 \mathrm{E}-06$ & 515.9 & $4.08 \mathrm{E}-03$ \\
DCL4 & $1.03 \mathrm{E}-05$ & 261 & $2.69 \mathrm{E}-03$ \\
DCVHI & $2.09 \mathrm{E}-07$ & 446 & $9.32 \mathrm{E}-05$ \\
DCVH & $2.71 \mathrm{E}-07$ & 258 & $6.99 \mathrm{E}-05$ \\
DCVHO & $1.54 \mathrm{E}-08$ & 4222 & $6.50 \mathrm{E}-05$ \\
DCVHF & $4.93 \mathrm{E}-08$ & 446 & $2.20 \mathrm{E}-05$ \\
SLK & $5.34 \mathrm{E}-01$ & 0 & $0.00 \mathrm{E}+00$ \\
LLK & $6.69 \mathrm{E}-02$ & 0 & $0.00 \mathrm{E}+00$ \\
\hline
\end{tabular}


. 7 rig5_.AF2

3

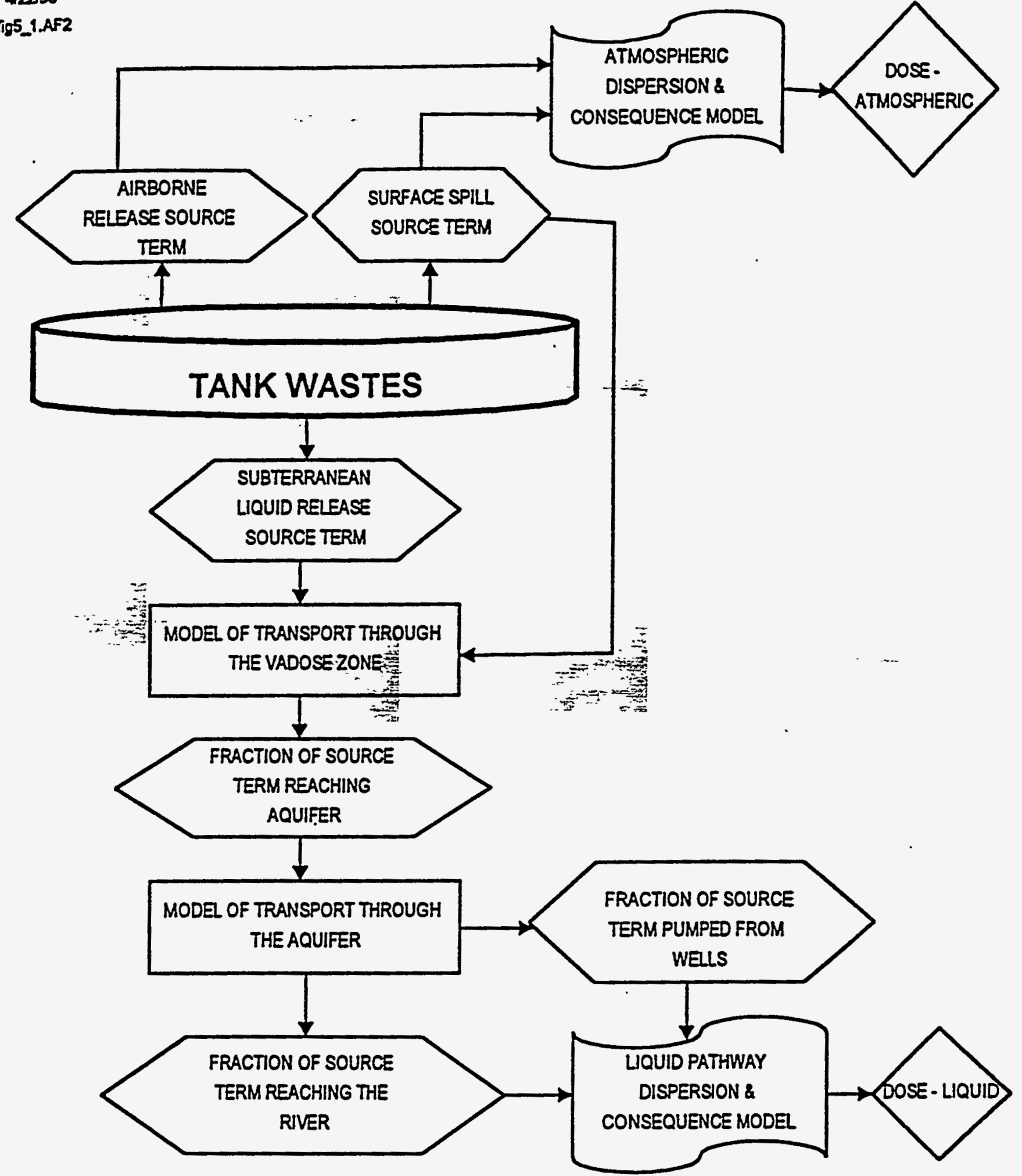

\section{FIGURE 5.1 HANFORD TANK FARM SOURCE TERM AND CONSEQUENCE MODEL STRUCTURE}


.

$\therefore$.

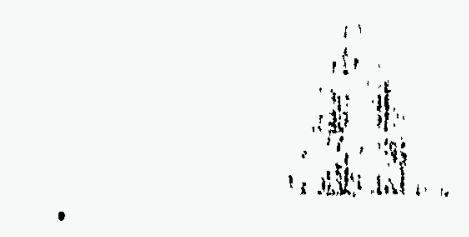

Averago Dlsirlbullon (Somples 5C+3E)

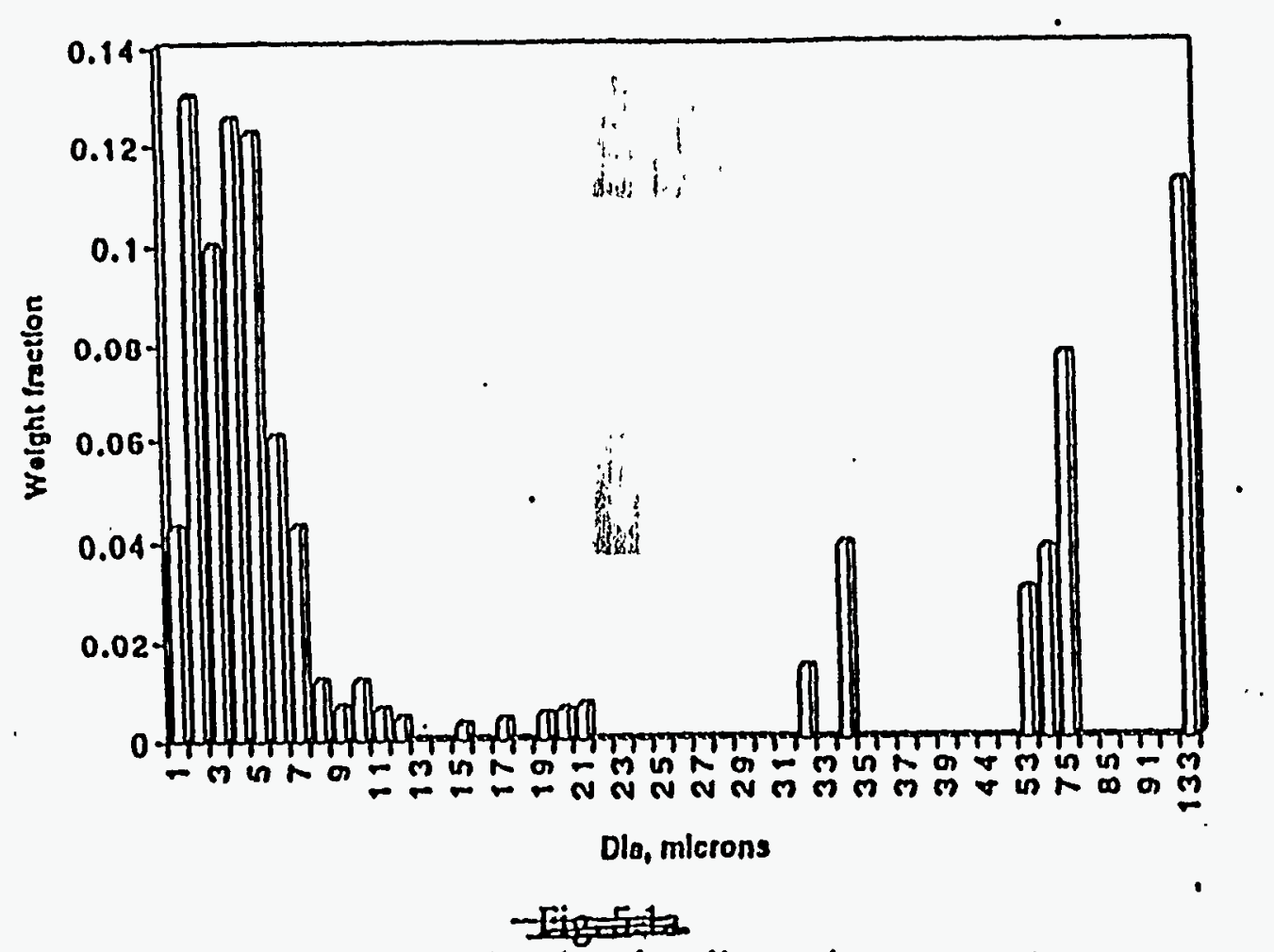

Figure 5.2. Particle size distribution for dispersion source term. 


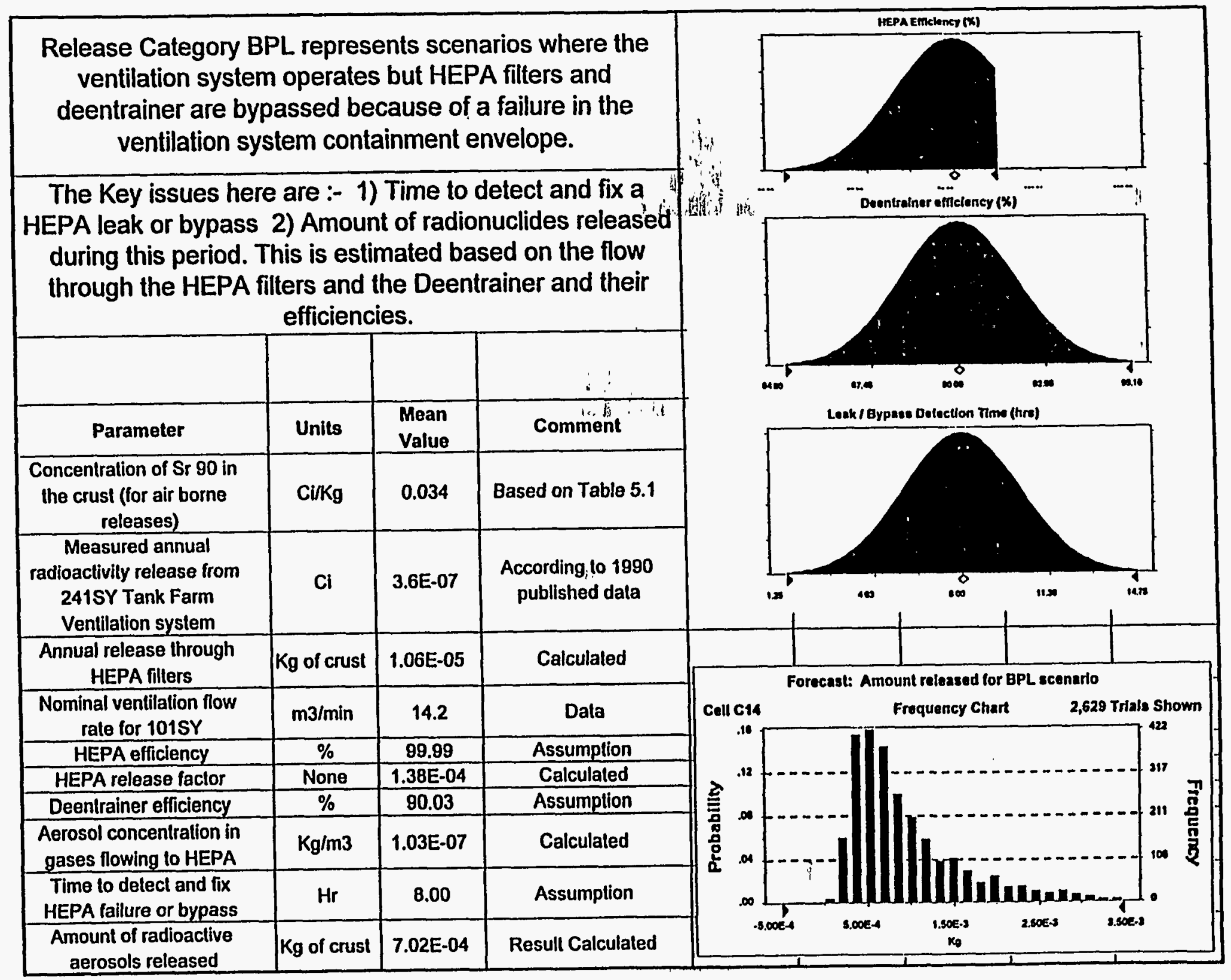

Figure 5-3 Source Term Summary for Release Category BPL 




Figure 5-4 Source Term Summary for Release Category HEPAL 
Release Category HEPAH represents those scenarios where HEPA filters and deentrainer are breached because of overpressure resulting from a burp/burn sequence.

The key issues are :( 1$)$ the amount of material entrapped in the HEPA filters/ deentrainer and the fraction of this amount that is released, and (2) the amount of material seared due to burp/burn and the fraction of this amount that is released.

\begin{tabular}{|c|c|c|c|}
\hline Parameter & Units & Value & Comment \\
\hline $\begin{array}{c}\text { Amount of malerial } \\
\text { entrapped in deentrainer } \\
\text { and HEPA fillers }\end{array}$ & $\begin{array}{c}\mathrm{Kg} \text { of crust } \\
\text { material }\end{array}$ & 3.00 & Assumplion (see texl) \\
\hline $\begin{array}{c}\text { Fraclion of entrapped } \\
\text { material released to } \\
\text { almosphere }\end{array}$ & None & 0.05 & Assumplion (see texi) \\
\hline $\begin{array}{c}\text { Amount of crust material } \\
\text { released during } \\
\text { BURP/burn }\end{array}$ & Kg & 13.35 & $\begin{array}{c}\text { From Appendix E for } \\
\text { (emperalistic burn with }\end{array}$ \\
\hline $\begin{array}{c}\text { Burnt Fractlon released to } \\
\text { atmosphere }\end{array}$ & None & 0.20 & Assumplion \\
\hline $\begin{array}{c}\text { Amount released for } \\
\text { HEPAH scenario }\end{array}$ & $\begin{array}{c}\text { Kg of crust } \\
\text { malerial }\end{array}$ & 2.83 & Resull / Calculation \\
\hline
\end{tabular}

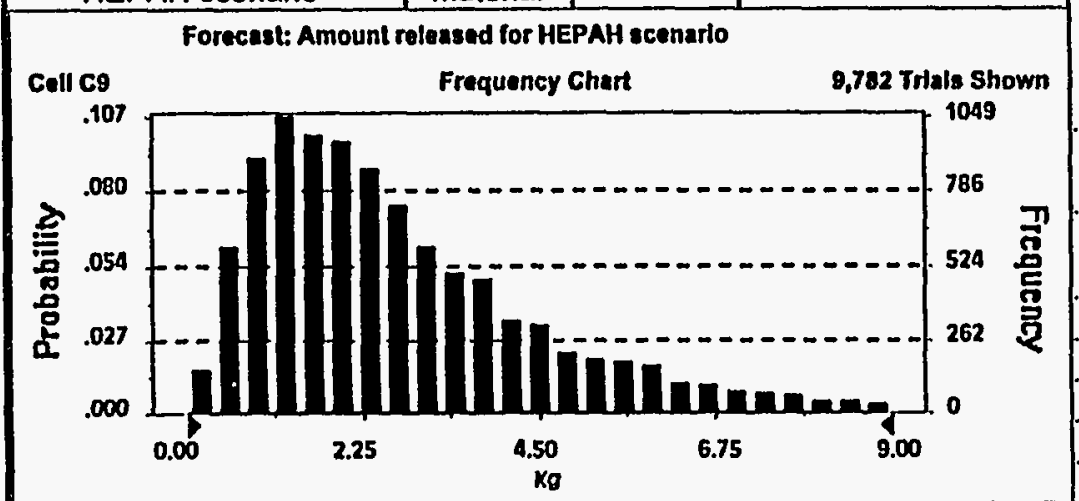

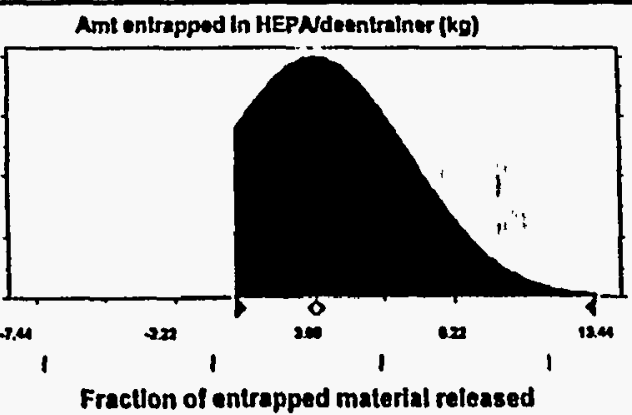


Bumt fraction reloased

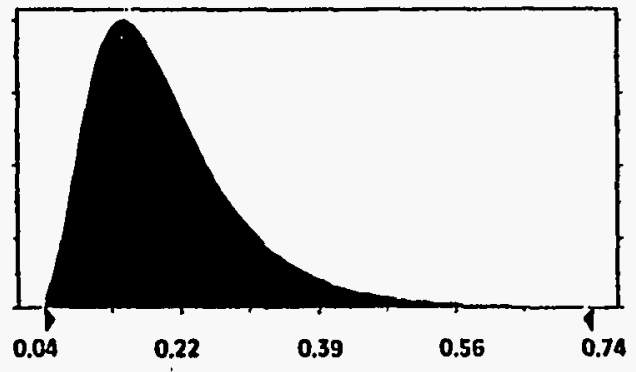

Figure 5-5 Source Term Summary for Release Category HEPAH 


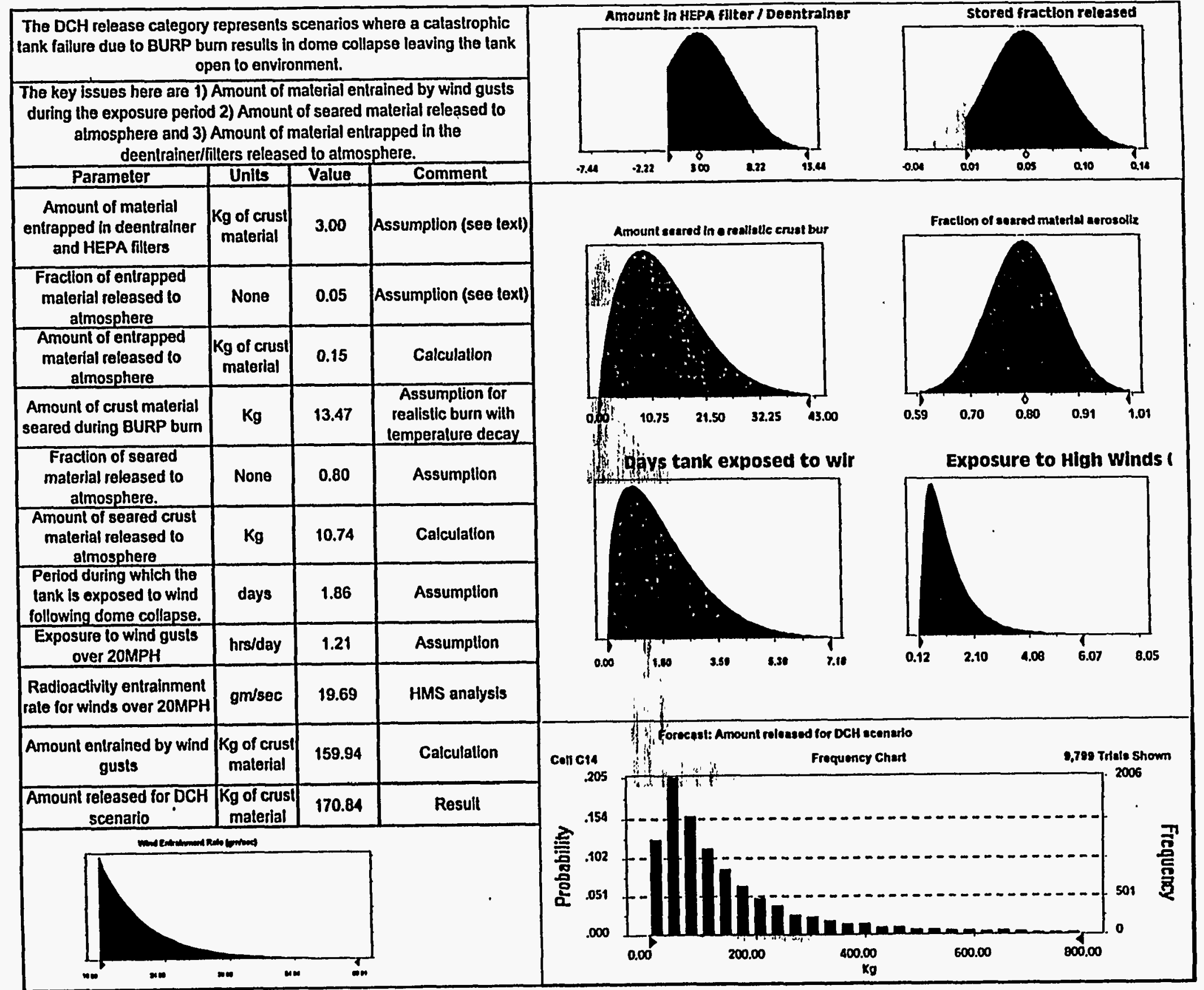

Figure 5-6. Source Term Summary for Release Category DCH 
C. Fugue $5^{\circ}$

\begin{tabular}{|c|c|c|c|}
\hline Paramaler & Unils & Value & Comment \\
\hline $\begin{array}{c}\text { Amount of fuel spilled on } \\
\text { lop of Tank } 1015 Y \text { after } \\
\text { an aircraft crash } \\
\end{array}$ & Gallons & 5000 & Assumption \\
\hline $\begin{array}{l}\text { Amount of Heat relessed } \\
\text { Irom Fuel burn } \\
\end{array}$ & BTU & & Back Calculation \\
\hline Duration of Burn & Minutes & $B 30$ & Assumption \\
\hline $\begin{array}{l}\text { Fraction of Heat conducted } \\
\text { downward to the Wasto }\end{array}$ & Nono & & Assumption. \\
\hline $\begin{array}{c}\text { Latent heat of Water } \\
\text { Evaporation }\end{array}$ & BTUKKg . & 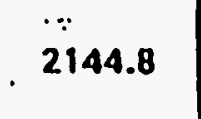 & $\begin{array}{l}\text { Data Appendix E } \\
\text { (540.5 cal/gm) }\end{array}$ \\
\hline $\begin{array}{c}\text { Amount of Water } \\
\text { Vaporized }\end{array}$ & $\mathbf{K g}$ & $2.56 E+04$ & Calculation \\
\hline Density of Waste & $\mathrm{gm} / \mathrm{cc}$ & 1.5 & dota \\
\hline $\begin{array}{l}\text { Amount of Weste } \\
\text { essociated with the } \\
\text { amount of Water } \\
\text { eveporated }\end{array}$ & $\mathbf{K g}$ & 12784.25 & Calculation \\
\hline $\begin{array}{l}\text { Fraction of this wasta } \\
\text { aerosolized }\end{array}$ & none & 7.70E-03 & Assumption \\
\hline $\begin{array}{c}\text { Amount of waste } \\
\text { aerosolized } \\
\end{array}$ & $\mathbf{K g}$ & 98.44 & Calculation \\
\hline $\begin{array}{c}\text { Period the Tank is exposed } \\
\text { to wind following aircraft } \\
\text { cresh }\end{array}$ & deys & 1.82 & Assumption \\
\hline $\begin{array}{c}\text { Exposure to wind gusts } \\
\text { over } 20 \mathrm{MPH}\end{array}$ & hrs/dey & 1.21 & Assumption \\
\hline $\begin{array}{l}\text { Radioactivity entrainment } \\
\text { rato for winds over } 20 \mathrm{MPH}\end{array}$ & $\mathrm{om} / \mathrm{sec}$ & 19.82 & HMS analysis \\
\hline $\begin{array}{c}\text { Amount entrained by wind } \\
\text { gusts }\end{array}$ & $\begin{array}{l}\text { Ko of crust } \\
\text { material }\end{array}$ & 157.58 & Calculation \\
\hline $\begin{array}{l}\text { Amount released for DCVH } \\
\text { scensrio }\end{array}$ & $\mathbf{K g}$ & 256.02 & $\begin{array}{c}\text { Aesull / } \\
\text { Calculation } \\
\end{array}$ \\
\hline
\end{tabular}
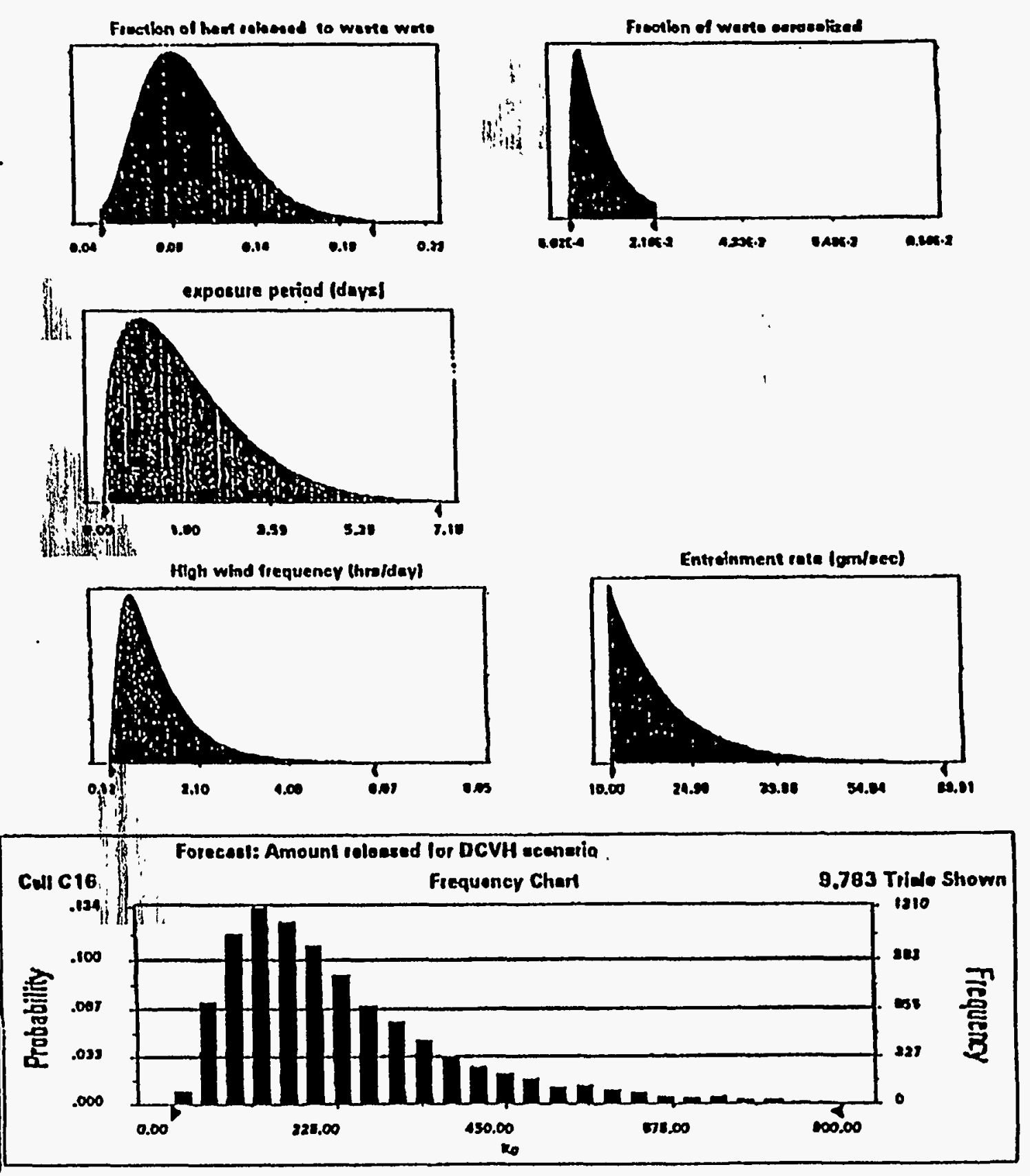
Figure 5-8. Source Term Summary for Release Category DCVHI

\begin{tabular}{|c|c|c|c|}
\hline Parameter & Units & Value & Comment \\
\hline $\begin{array}{l}\text { Amount of fuel spilled on } \\
\text { top of Tank after an } \\
\text { aircraft crash }\end{array}$ & Gallons & 5000 & Assumption \\
\hline $\begin{array}{c}\text { Porosity of the Dried } \\
\text { Sludge }\end{array}$ & & 0.5 & Assumption \\
\hline $\begin{array}{l}\text { Amount of Sludge } \\
\text { soaked with fuel }\end{array}$ & m3 & 37.85 & Calculation \\
\hline Density of Waste & $\mathrm{gm} / \mathrm{cc}$ & 1.5 & data \\
\hline $\begin{array}{c}\text { Mass of Sludge soaked } \\
\text { with fuel }\end{array}$ & $\mathrm{Kg}$ & 56775 & Calculation \\
\hline $\begin{array}{c}\text { Fraction of soaked mass } \\
\text { participating in fire }\end{array}$ & none & $50 \%$ & Assumption \\
\hline Mass of sludge burned & $\mathrm{Kg}$ & $2.85 E+04$ & Calculation \\
\hline $\begin{array}{l}\text { Fraction of burned } \\
\text { sludge aerosolized }\end{array}$ & none & $1.00 \mathrm{E}-02$ & Assumption \\
\hline $\begin{array}{l}\text { Mass of sludge } \\
\text { aerosolized }\end{array}$ & $\mathrm{Kg}$ & 286.48 & Calculation \\
\hline $\begin{array}{l}\text { Period the Tank is } \\
\text { exposed to wind } \\
\text { following aircraft crash }\end{array}$ & days & 1.82 & Assumption \\
\hline $\begin{array}{l}\text { Exposure to wind gusts } \\
\text { over } 20 \mathrm{MPH}\end{array}$ & hrs/day & 1.22 & Assumption \\
\hline $\begin{array}{l}\text { Radioactivity entrainment } \\
\text { rate for winds over } \\
20 \mathrm{MPH} \\
\end{array}$ & $\mathrm{gm} / \mathrm{sec}$ & 20.00 & HMS analysis \\
\hline $\begin{array}{l}\text { Amount entrained by } \\
\text { wind gusts }\end{array}$ & $\begin{array}{l}\mathrm{Kg} \text { of } \\
\text { crust } \\
\text { material }\end{array}$ & 159.42 & Calculation \\
\hline $\begin{array}{l}\text { Amount released for } \\
\text { DCVHI (Dry Inert tank) } \\
\text { scenario }\end{array}$ & $\mathrm{Kg}$ & 445.90 & $\begin{array}{c}\text { Result / } \\
\text { Calculation }\end{array}$ \\
\hline
\end{tabular}
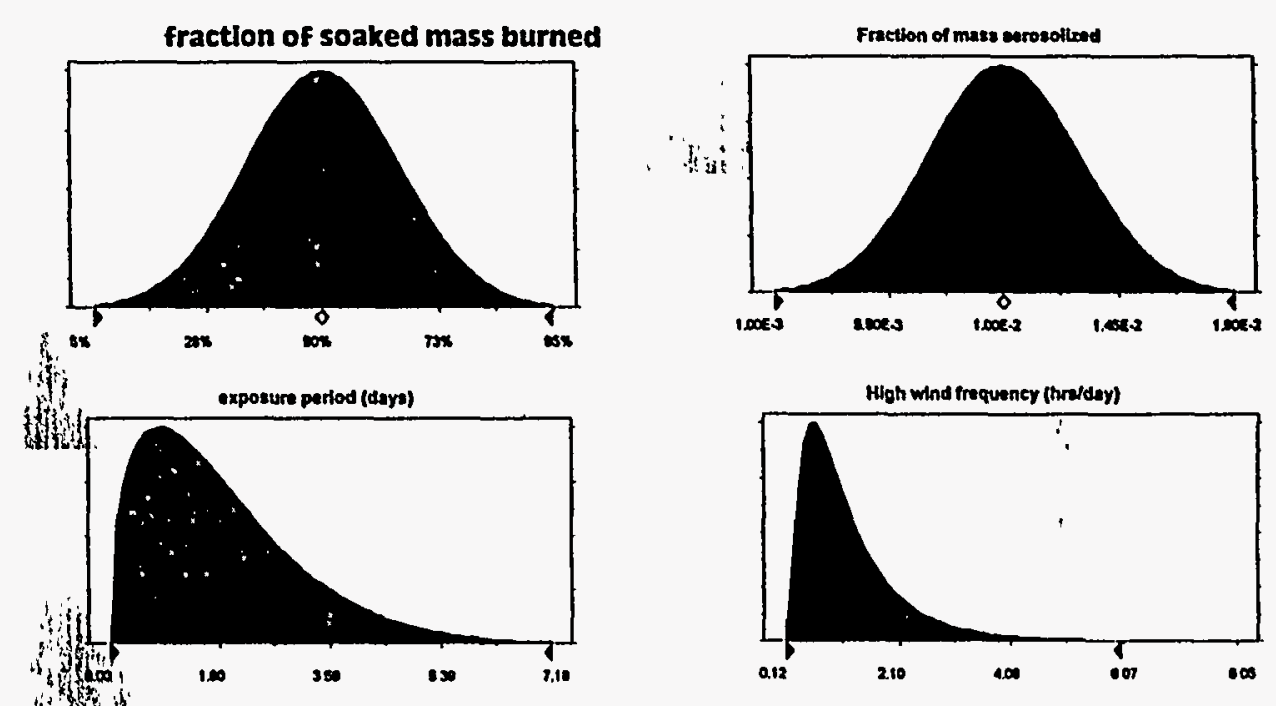

High wind frequeney (hredday)



\begin{tabular}{|c|c|c|c|}
\hline Parameter & Units & Value & Comment \\
\hline $\begin{array}{c}\text { Amount of fuel spilled on } \\
\text { top of Tank after an } \\
\text { aircraft crash }\end{array}$ & Gallons & 5000 & Assumption \\
\hline $\begin{array}{l}\text { Porosity of the Dried } \\
\text { Sludge }\end{array}$ & none & 0.5 & Assumption \\
\hline $\begin{array}{l}\text { Amount of Sludge } \\
\text { soaked with fuel }\end{array}$ & m3 & 37.85 & Calculation \\
\hline Density of Waste & gm/cc & 1.5 & data \\
\hline $\begin{array}{c}\text { Mass of Sludge soaked } \\
\text { with fuel }\end{array}$ & $\mathrm{Kg}$ & 56775 & Calculation \\
\hline $\begin{array}{l}\text { Tolal Volume of Tank } \\
\text { contents }\end{array}$ & Kgallons & 354.511 & Data \\
\hline $\begin{array}{c}\text { Total mass of Tank } \\
\text { Contents } \\
\end{array}$ & Kg & 2012736 & Calculation \\
\hline $\begin{array}{c}\text { Fraction of soaked mass } \\
\text { participating in fire }\end{array}$ & none & $50 \%$ & Assumption \\
\hline $\begin{array}{l}\text { Fraction of non-soaked } \\
\text { dry organic tank mass } \\
\text { particpating in burn }\end{array}$ & none & $19 \%$ & Assumplion \\
\hline Mass of sludge burned & $\mathrm{Kg}$ & 4.06E+05 & Calculation \\
\hline $\begin{array}{l}\text { Fraction of bumed } \\
\text { sludge aerosolized }\end{array}$ & none & $1.00 \mathrm{E}-02$ & Assumption \\
\hline $\begin{array}{l}\text { Mass of sludge } \\
\text { aerosolized }\end{array}$ & Kg & 4062.54 & Calculation \\
\hline $\begin{array}{l}\text { Period the Tank is } \\
\text { exposed to wind } \\
\text { following aircraft crash }\end{array}$ & days & 1.82 & Assumplion \\
\hline $\begin{array}{l}\text { Exposure to wind gusts } \\
\text { over 20MPH }\end{array}$ & hrs/day & 1.22 & Assumption \\
\hline $\begin{array}{l}\text { Radioactivity } \\
\text { entrainment rate for } \\
\text { winds over 20MPH }\end{array}$ & $\mathrm{gm} / \mathrm{sec}$ & 20.04 & HMS analysis \\
\hline $\begin{array}{l}\text { Amount entrained by } \\
\text { wind gusts }\end{array}$ & $\begin{array}{c}\mathrm{Kg} \text { of } \\
\text { crust } \\
\text { malerial }\end{array}$ & 159.72 & Calculation \\
\hline $\begin{array}{l}\text { Amount released for } \\
\text { DCVHO (Dry Organic } \\
\text { tank) scenario }\end{array}$ & $\mathrm{Kg}$ & 4222.26 & $\begin{array}{c}\text { Result I } \\
\text { Calculation }\end{array}$ \\
\hline
\end{tabular}
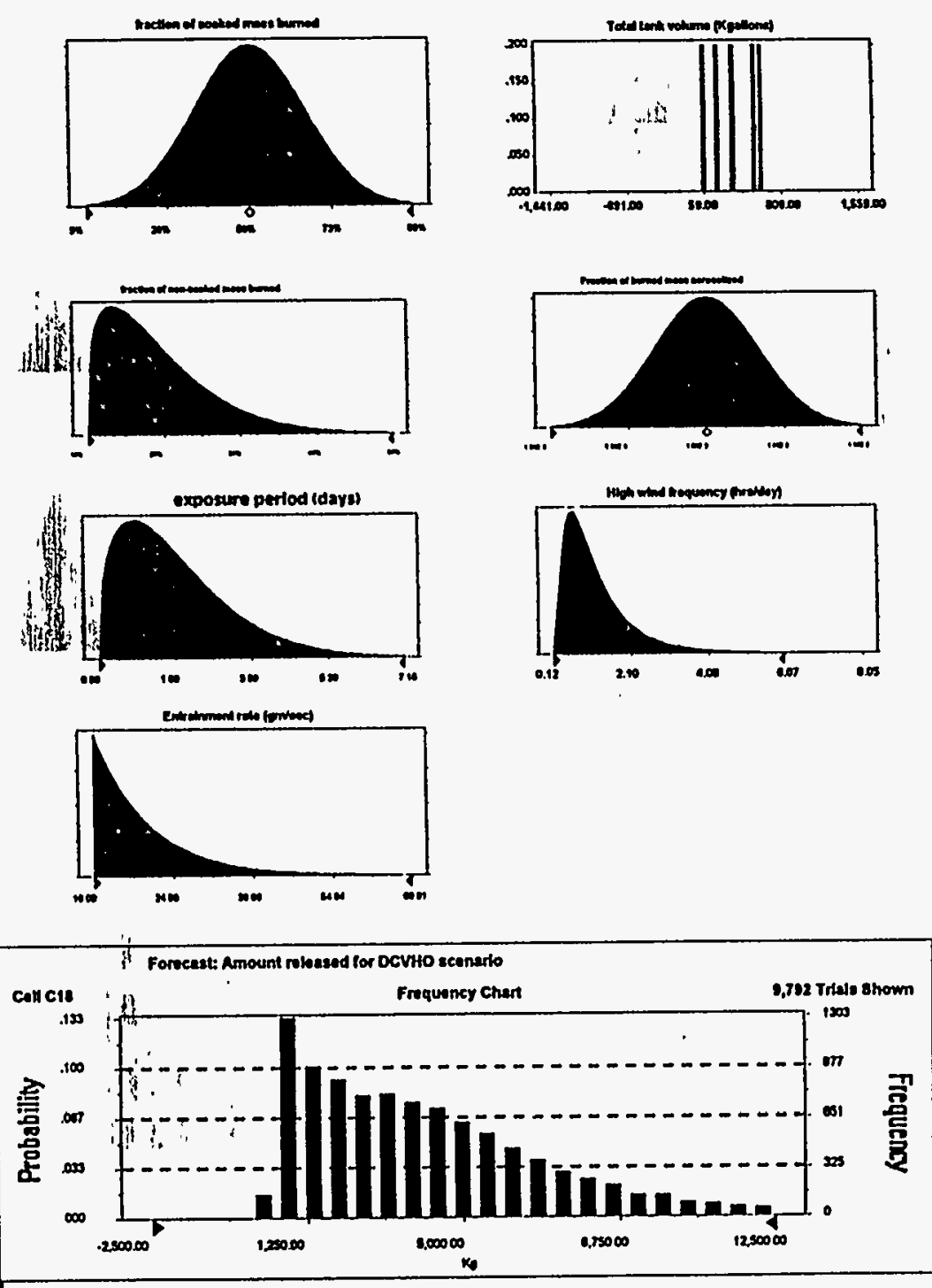


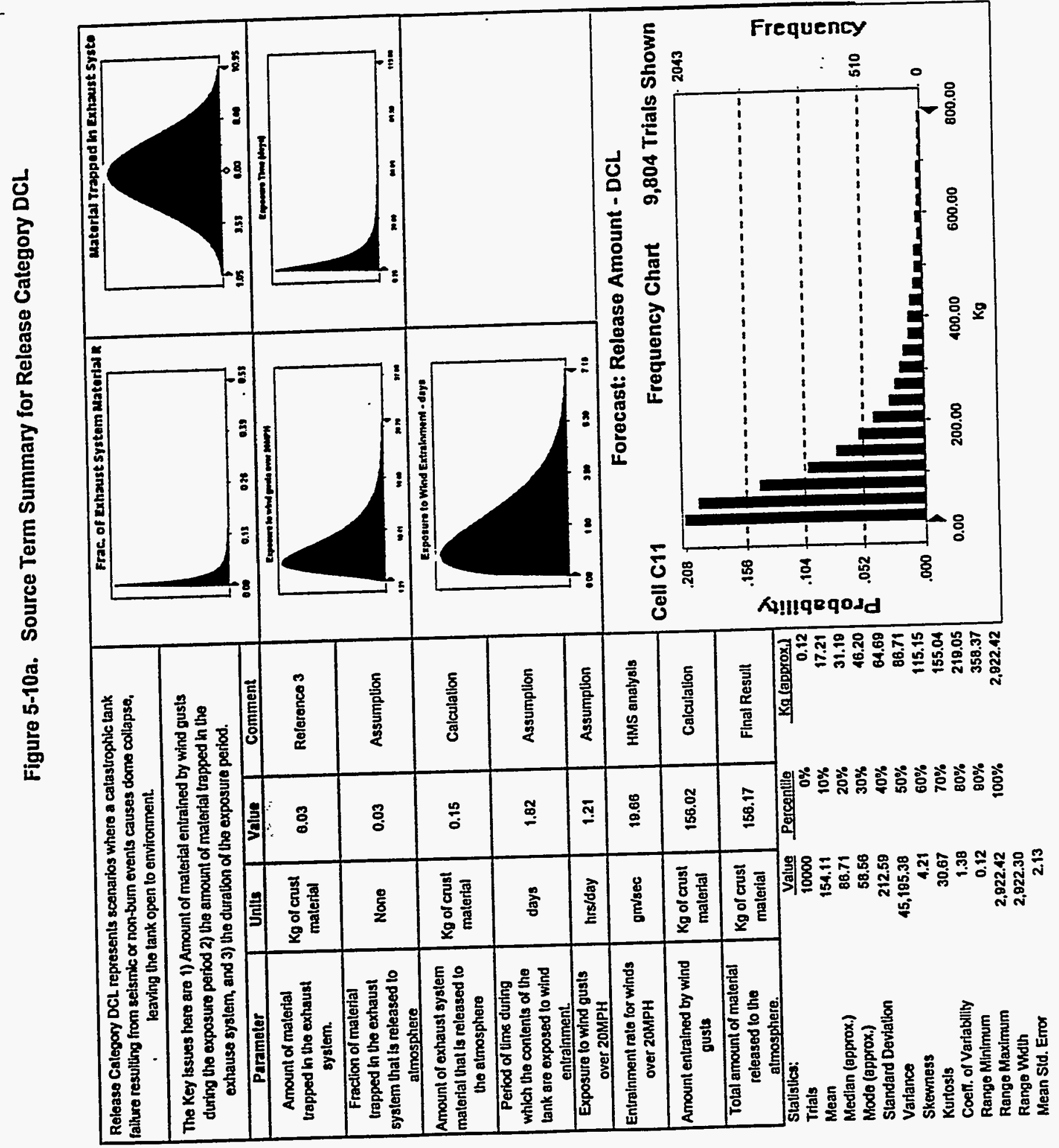




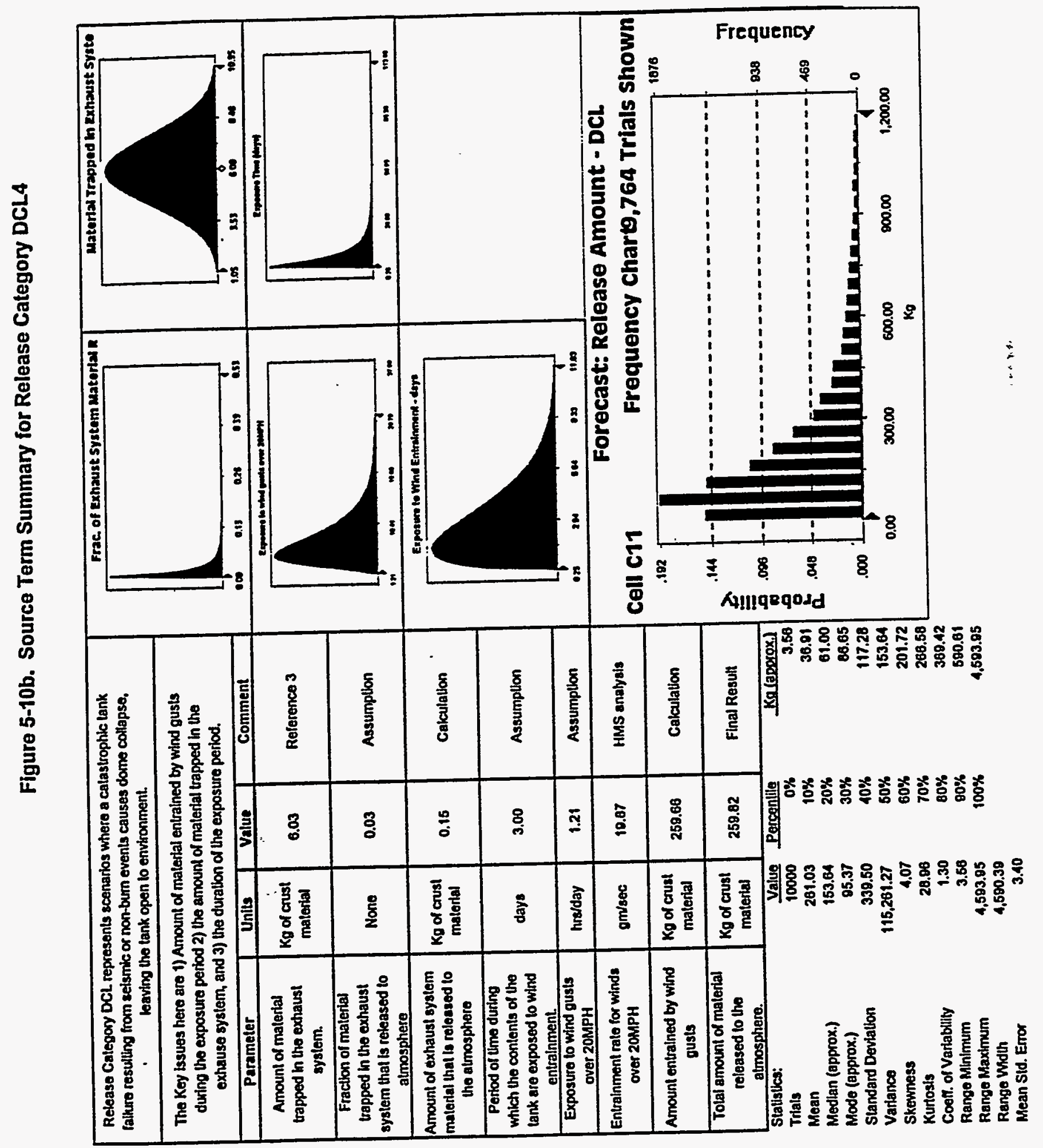


Figure 5-10c. Source Term Summary for Release Category DCL12




Figure 5-10d. Source Term Summary for Release Category DCL45




Figure 5-10e. Source Term Summary for Release Category DCL122




Figure 5-11. Source Term Summary for Release Category SSPRY



FIG5_11.XLS 
Figure 5-12. Source Term Summary for Release Category LSPRY

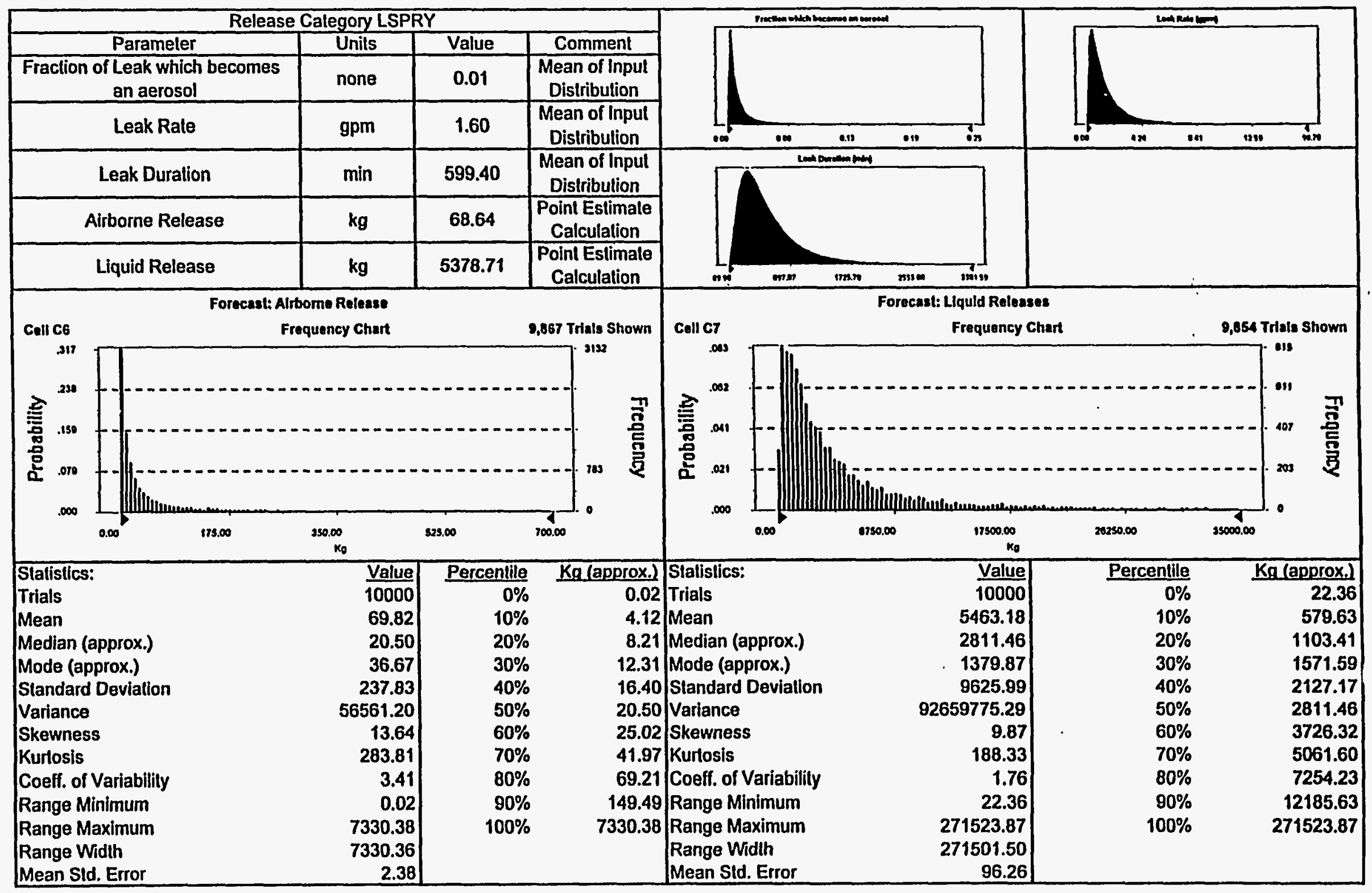


Figure 5-A. Airborne Source Terms for Release Category DCHORG

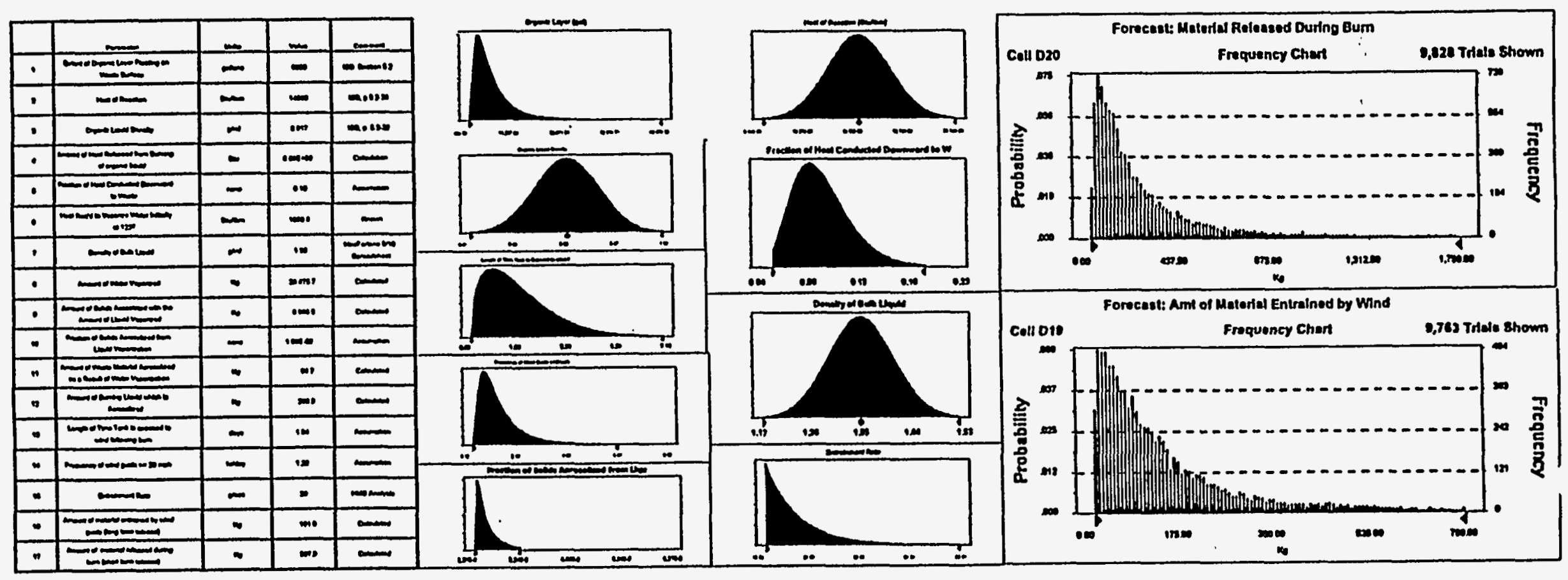




\title{
PLG MEMORANDUM
}

\author{
TO: $\quad$ J.P. Kindinger \\ $R \times O$ \\ FROM: $\quad$ R. Kenneth Deremer/Wade Lardner \\ SUBJECT: ECONOMIC RISKS ASSOCIATED WITH POTENTIAL TANK 24.1-SY-101 \\ A.CCIDENTS
}

DATE: $\quad$ March 11, 1994

The purpose of this memo is to transmit a revised draft of Section 6.5, ECONOMIC RISK for the Tank 241-SY-101 PSA. The cnclosed draft section addresses the cconomic risk associated with accidents that have already been identified and quantified in the PSA and supersedes the draft scction transmitted to you by our memorandum dated March 9, 1994.

In addition to the revisions discussed in our March 9, 1994 memorandum, the attached document incorporates the results of discussions with Don MacFarlane on this date regarding the size (gallons) of the water intrusion/overflow cvents (SSP) and the onsite cleanup/decontamination costs associated with Release Category BPL. It was agreed that the mean size of the intrusion/overflow events would be set at 300 gallons instcad of 3000 gallons as used for small leaks (i.c., Release Category SLK). It was also agreed that the distribution used for Release Categories HEPAL and HEPAH for onsite clcanup/dccontamination was inappropriate for Rclcase Category BPL. For Release Category $B P L$, a new lognormal distribution was assumed, using a median value of $\$ 1$ million as opposed to the distribution with a median value of $\$ 5$ million which is being used for Relcase Catcgorics HEPAL and HEPAH.

Both the text and figures have been revised accordingly.

Electronic files (WORDPERFECT and EXCEL) for the attached section can be provided.

cc: Dave Bidwell Mike Emerson

Karl Fleming

Wei He

Clicnt File - 3098 


\section{- DRAFT -}

\subsection{ECONOMIC RISK}

\subsubsection{Introduction}

The economic risks resulting from accidents associated with Tank 241-SY-101 will be strongly influenced by the political and economic environments prevailing at the time of such accidents. These considerations will dictate the extent of remediation to be performed. In addition, the current database for remediation costs is extremely limited. This database will expand dramatically as data from ongoing remediation activities at DOE and other facilities becomes available. With these limitations in mind, the remainder of this section discusses a framework for calculating the cconomic risks associated with Tank 24l-SY-101 accidents and provides estimates for these risks using this framework and available data.

\subsubsection{Mcasures of Economic Damage}

To assess the cconomic risk associated with the Tank 241-SY-101 accidents identificd carlier in this PSA, it was first necessary to qualitativcly identify the measures of cconomic damage associated with the sequences representing cach of the release categorics. Table 6.5-1 summarizes the various types of cconomic damage expected for each of the representative sequences/release categories. Based on this qualitative evaluation, the following four measures of cconomic damage were sclected.

\section{Ground Contamination}

\section{Tank Replacement}

\section{Cleanup of Soil Contaminated by Tank Leaks}

\section{Ventilation System Repair}

The tank replacement costs includes an cstimate for the transfer of the contents remaining in Tank 241-SY-101 to a new tank and stabilization of the damaged tank.

As shown in Table 6.5-1, some of the above damage measures appear in morc than one relcase category and individual relcase catcgorics gencrally contain more than one damage measure. Although some damage measures arc qualitatively similar between release calcgorics, the matcrials relcased to the cuvironment (i.c., the source terms) are different. Thus, to obtain an overall measure of economic risk, all damage measures within a given release category must be summed and the risk from cach rolease category nust be summed.

The following sections provide a brief discussion of the above damage measures including the basis for the probabilistic cstimates for various remediation activitics, results for the important relcase catcgorics, and results for the ovcrall cconomic risk (summed over all of the release categorics 
considered) associaled with the Tank 241-SY-101 accidents identified carlicr in this report.

\subsubsection{Ground Contamination}

For any release category involving an airborne release of material, there will be some level of ground (i.e., surface) contamination. Since the amount of material released through airborne pathways varies from release category to relcase category, this measure of economic risk must be addressed for each release category which has a unique airborne source term.

The important parameters associated with generating the economic risk curves associated with ground contamination are as follows:

1. The area of land that is decmed to be contaminated and thus subject to some form of remediation activity.

2. The unit costs $\left(\$ / \mathrm{m}^{2}\right)$ associated with lowcring the extent of contamination to "acceptable" lcvels.

Probabilistic cstimates of the land which becomes contaminated for a particular release category were determined by LANL using existing dispersion codes using site meteorological data and predicted source terms for the various rcicasc categorics. The extent of such contamination for Relcase Categories DCVH, DCH, HEPAH, and HEPAL and low, medium and high cstimates for the source terms is summarized in Tables 6.5-2 through 6.5-5. As indicated in these tables, the total area of ground contamination is subdivided into arcas corresponding to various levels of contamination. The extent of contamination is implied by the amount of decontamination require to restore the land to an acceptable level. The decontamination factors shown in these tables are based on restoring the land to complete public use, including the possibility that residents will use the land to grow crops and these crops will be consumed by those residents.

The unit costs involved with decontamination depend on the procedure(s) selected to accomplish the decontamination. Reference $6.5-1$ discusses a varicty of techniques to decontaminate land and their associated costs. Figure 2.5.7 of Reference 6.5-1 contains a plot of decontamination costs (in 1982 $\$$ ) as a function of decontamination factor (i.c., the level of contamination). As the level of contamination increases, the methods for decontamination change somcwhat. The various decontamination operations portrayed in Figure 2.5.7 of Reference 6.5-1 are defined as follows, along with their representative costs:

\begin{tabular}{clc} 
Method & Definition & Cost $\left(1982 \$ / \mathrm{m}^{2}\right)$ \\
\cline { 3 - 3 } L & Leaching with $\mathrm{FcCl}_{3}$ & 0.052 \\
W & Low pressurc watcr & 0.0219 \\
$\mathrm{X}$ & Scrapc 4" to 6" & 0.31 \\
$\mathrm{x}$ & Double scrapc & $0.62(2 \times 0.31)$ \\
$\mathrm{G}$ & Cover with 6" soil & 0.371 \\
$\mathrm{~T}$ & Surface scalcr, fixative & 0.2061 \\
$\mathrm{~N}$ & Clear, harvest & 0.026
\end{tabular}




\section{- DRAFT -}

As noted in Reference 6.5-1, a scquence of decontamination operations could be required rather than a single operation. In fact, sequences of operations form the basis for the plot shown in Figure 2.5.7 of Reference 6.5-1. For example, for a level of contamination corresponding to a decontamination factor of 1000 the cost is based on the "string" of decontamination methods denoted as TNxX. As indicated by the above table, this string involves three scrapings $(\mathrm{xX})$, the application of a surface sealer/fixative (T), and clcaring of the dccontaminated land $(N)$. A detailed review of Figure 2.5.7 indicates that the following strings of decontamination operations can be applied to the ranges of decontamination factors associated with the contaminated land areas.

$\begin{array}{ll}\begin{array}{c}\text { DF } \\ \text { Range }\end{array} & \begin{array}{c}\text { Operations } \\ \text { String }\end{array} \\ 1-3.3 & \text { L - WWWW } \\ 3.3-10 & \text { WWWW }- \text { XG } \\ 10-33 & \text { XG }- \text { TNx } \\ 33-100 & \text { TNX } \\ 100-330 & \text { TNX } \\ 330-1000 & \text { TNX }- \text { TNxX } \\ 1000-3300 & \text { TNXX }\end{array}$

An investigation of the basis for Figure 2.5.7 of Reference 6.5-1 indicated that the identified decontamination actions were intended to reduce ground shine (external dose) to acceptable levels and would not necessarily climinate the potential for internal dose due to ingestion (i.e., restore the land for unlimited agricultural usc). Thus, it was assumed that the contaminated soil must be removed after scraping. It was assumed that cach scraping would remove 6" of soil and that this soil would be transported 5 milcs (a round trip of 10 miles) where it again would be covered. Based on Table 2.4.11.1 of Reference 6.5-1 and the above assumptions, the representative costs for hauling werc assumed to be $\$ 4.15 / \mathrm{m}^{3}$ or $\$ 0.63 / \mathrm{m}^{2} /$ scraping. In addition, it was assumed that the hauled matcrial would be covered at the point of storage at a cost of $\$ 0.371 / \mathrm{m}^{2}$ regardless of the number of scrapings. Furthermore, Reference 6.5-2 notes that pre-cleanup and post-cleanup radiation surveys (at $\$ 480 /$ acre/survcy) would be required in any decontamination activity. The costs of these surveys were also included as they did not seem to be included in the costs associated with the decontamination operation strings identificd above. All costs identificd above are in 1982 dollars.'

Based on the assumptions and base costs discussed above, cstimates for the total costs of dccontamination for the various decontamination factor ranges were determined. These estimates are provided in Table 6.5.6. In addition to best cstimatc calculations, "Jow" and "high" cstimates are provided. Each of the cstimates are assigned a probability; 0.1 for low, 0.8 for best cstimate, and 0.1 for high.

\footnotetext{
'The radiation survey costs were actually given in 1981 dollars but were treated as 1982 dollars. 


\section{- DRAFT -}

The mean annual frequency of the cost excceding various levels of damage (i.e., dollars) due to ground contamination for the four release categories identified above are shown in Figure 6.5-1. As indicated in this figure, the costs associated with restoring contaminated land are not significant.

\subsubsection{Tank Replacement}

The total cost of tank replacement is equal to the sum of the costs associated with construction of a new tank and the remediation costs associated with the old tank, including transfer of the remaining contents of the old tank to the new tank.

\section{Cost of a New Tank:}

The costs associated with the cost of a new tank are based on Reference 6.5-3. This reference divides the costs associated with construction of a double shelled tank farm into the following: tcchnology, (2) design, (3) construction, (4) startup, (5) regulatory compliancc, and (6) project management. The estimates were stated to be accurate within plus or minus 30 percent.

Although no specific definition of "technology costs" was provided, for the purpose of this cvaluation, it was assumed that such costs werc not appropriate for a "replicated" tank.

Thus, the cost of a new tank can be expressed as follows:

$$
\text { Total Cost }=\text { Design Costs }+ \text { Construction Costs }+ \text { Startup Costs }+
$$

Regulatory Compliance Costs + Project Management Costs

The design costs discussed in Reference 6.5-3 include conceptual and preliminary design costs. These costs were also deemed to be inappropriate for a replicated tank. The detailed design (\$2 million) and field engincering ( $\$ 3$ million) costs, however, wcre considered appropriate for this cvaluation.

With the exception of the costs for the ventilation and cnclosure buildings and a "discount" for site preparation and restoration, all of the construction costs identified in Reference 6.5-3 were included in this evaluation. It was assumed that 50 percent of the site preparation and restoration costs were rclated to the buildings and $50 \%$ ( $\$ 3$ million) to the tank itself. The cost of constructing the tank itself is $\$ 16.5$ million. Although it was assumed that no ncw buildings would be necessary, the cntirc cost of major cquipment ( $\$ 5.8$ million) was included in this cvaluation. All of the construction costs were assumed to be accuratc within $+/-30$ percent. Construction management costs were assumed to be 10 percent of the total of the other costs identified as construction costs.

The full value of the Reference $6.5-3$ costs associated wilh startup (\$2.4 million) and regulatory compliance ( $\$ 3.6$ million) were included in this evaluation. These costs were also assumed to be accuratc to $+/-30$ percent. 
Substituting the above cstimales and solving the two equations simultancously results in $A=$ $\$ 610,000$ and $B=\$ 92.36 /$ gallon. These values werc treated as the medians of two probability distributions. For A, the $95^{\text {th }}$ percentilc was arbitrarily set at $\$ 1.0$ million and for $B$ the $95^{\text {th }}$ percentilc was arbitrarily sct at $\$ 150$ /gallon.

By definition (see Section 5.5.1 of Refcrence 6.5-6), Rclcase Category SLK represents leaks of 5000 gallons or less with a mean of 3000 gallons. The distribution for small leaks was assumed to be lognormal with a mean of 3000 gallons and the $99.99^{\text {th }}$ percentile equal to 5000 gallons. The stated mean value for large leaks (per Section 5.5.2 of Reference 6.5-6) is 120,000 gallons. The large leak distribution was also assumed to be lognormal with a $90^{\text {th }}$ percentile of 240,000 gallons. For Relcase Category SSP, the mean value of the water intrusion/overflow is taken as 300 gallons (see Scction 5.5.3 of Reference 6.5-6) and the "low" value is assumed to be 100 gallons. The low value was assumed in this evaluation to correspond to the $20^{\text {th }}$ percentile.

Figure 6.5-4 displays the cconomic risk CCDFs associated with the relcase catcgorics involving leaks and watcr intrusion/overflow.

\subsubsection{Ventilation System Repair}

A number of the release categories involve onsite (i.c., the immediate vicinity of the tank) contamination and possibly damage to the ventilation system but not tank failure or leakage. The degree of damage resulting from hydrogen burns is extremely difficult to cstimate and thereforc, the costs associated with the repair of such damage are even more difficult to estimate. For Release Categories HEPAL and HEPAH (both of which involve hydrogen burns), the cost of ventilation system repair was represented by the sum of lognormal distribution for equipment replacement (identical to that for "major equipment" in the tank replacement algorithm) and a lognomal distribution for clcanup/contamination of the cquipment and area affected by the event. The lognormal distribution for new equipment had a median value of $\$ 5.8$ million and an error spread of 1.3. The assumed lognormal distributions for cleanup/decontamination had median values of $\$ 5.0$ million for Release Categories HEPAL and HEPAH and \$1.0 million for Release Category BPL. An error spread of 2.0 was used for both of these distributions. Since Release Category BPL did not involve a hydrogen burn, only its distribution for onsite cleanup/decontamination was considercd.

Figure 6.5-5 shows the CCDFs for this measure of cconomic damage for Relcase Categorics BPL, HEPAL, and HEPAH.

\subsubsection{Relcase Category Total Costs}

Figures 6.5-6 through 6.5-12 show the total economic risk, in terms of CCDFs for the mean annual frequency of excecding various damage levels for all of the relcase categorics.

As.shown in Figurc $6.5-10$, the cost associated with remediating ground contamination is only 


\section{- DRAFT -}

Based on the Reference 6.5-3 percentage, the costs associated with project management were assumed to be 2 percent of all other costs.

The costs discussed above were represcnted by truncated (the minimum cstimale was not allowed to be 20 percent lower than the median value) lognormal distributions with the medians set equal to the values tabulated in Refcrence $6.5-3$ and the $90^{\text {th }}$ percentiles set equal to 1.3 times the medians.

A distribution for the total cost of a new tank was gencrated with the Crystal Ball ${ }^{\otimes}$ software. The results of this calculation are expressed as a cumulative distribution function as shown in Figure 6.52. This distribution was used as input to the STADIC program to reflect the cost of a new tank.

\section{Remediation Costs Associated With Damaged Tank:}

Figure 6.5-2 docs not include the costs associated with remediation activities associated with the failed tank and the transfer of its remaining contents to the new tank. To account for such costs, a second distribution (identical to that for the cost of a ncw tank) was included in the STADIC model.

Although the second distribution liad identical parameters, the distribution associated with remediation activitics involving the damaged tank was assumed to be completely independent of the costs associated with the new tank. Thus, for any given sample, the total cost was the sum of the independently sampled distributions for the ncw tank and for remediation of the old tank.

\section{Total Costs:}

Figure 6.5-3 shows the CCDFs for the costs associated with replacement and remediation of a damaged tank for Relcasc Catcgories DCH, DCLLK, and DCVH.

\subsubsection{Clcanup of Contamination Caused by Tank Leaks}

The costs associated with the cleanup of contamination caused by tank lcaks is based on information supplied in References 6.5-4 and 6.5-5, and leak size distributions for both large leaks (Release Catcgorics LLK and DCLLK), small leaks (Release Catcgory SLK), and water intrusion/overflow cvents (Rclease Catcgory SSP).

The costs associated with leak tcrmination arc not included in this mcasure of cconomic damage.

Reforence $6.5-5$ stalcs that it would cost $\$ 656,200$ to clcan up (including cxcavating, washing, vitrification, temporary storage on site, transportation to a final repository, and backfilling) 500 gallon lcak. The estimate for a 100,000 gallon leak is $\$ 9,846,000$. An evaluation of these estimates indicates that there is some "cconomy of scale," and therefore, the cost to process a leak of $x$ gallons could be represcnted by

Tolal cost $(\$)$ to process $X$ gallons $=A+B * X$ 
"significant" for Rclease Category DCVH. Since this release category has a mean annual frequency of occurrence of approximately $3.1 \times 10^{-09} / \mathrm{yr}$, one can conclude that ground contamination is not a major concem for accidents associated with Tank 241-SY-101.

The release category totals are also shown in Figurc 6.5-13.

\subsubsection{Total Economic Risk for All Relcasc Catcgories}

1

The total cconomic risk for Tank 241-SY-101 accidents represented by the release categories discussed above is shown in Figure 6.5-13. Bascd on current interpretations of existing remediation cost data and assuming that remediation would be required and performed, the economic consequences of Tank SY-101 accidents could be substantial (more than $\$ 100$ million at a frequency greater than $1 \times 10^{-04} / \mathrm{yr}$ ). The results displaycd in Figure 6.5-13 for damage levels less than approximatcly $\$ 20$ million arc dominated by Release Catcgory HEPAL, which in turn, is dominated by the costs associated with replacement and decontamination of the ventilation system and cquipment. The mean frequency of Relcase Category HEPAL is approximately $1.2 \times 10^{-01}$ per year. Therefore, it is not surprising that this relcase category dominates the low end of the CCDF for total costs.

In the damage level range of approximatcly $\$ 20$ to $\$ 130$ million, Release Category DCH (mean annual frequency of $6.7 \times 10^{-04} / \mathrm{yr}$ ) is the major contributor, indicating the significance of the costs associated with the construction of a new tank and remediation of the damaged tank. Beyond $\$ 130$ million and at frequencies less than approximately $5 \times 10^{-06} / \mathrm{yr}$, Rclease Category DCLLK appcars to be the dominant contributor. This relcase catcgory involves activitics associated with the remediation of a large leak as wcll as tank damagc.

\subsubsection{References}

6.5-1. Tawil, J.J., et al, "Off-Site Conscquences of Radiological Accidents: Methods, Costs and Schedules for Decontamination," prepared by the Pacific Northwest Laboratory for U.S. Nuclear Regulatory Commission, NUREG/CR-3413, August 1985

6.5-2. Los Alamos National Laboratory, "Supplementary Documcntation for an Environmental Impact Statement Regarding the Pantex Plant, Decontamination Methods and Cost Estimates for Postulated Accidents," Report No. LA-9445-PNTX-N

6.5-3. Mike Butner FAX dated 5/21/93

6.5-4. "Draft. Environmental Impact Statement (EIS) for Disposal of Hanford Defense High-Level, Transuranic, and Tank Wastes," Department of Energy Report DOE/EIS-0113, March 1986

6.5-5. Mike Butner Memo dated 4/15/93

C:IWPSILANLITTIECORISK.RVI:03/09/94 


\section{- DRAFT -}

6.5-6 MacFarlane, D.R., ct al, "Risk Assessment for Hanford High-Lcvel Waste Tank 241-SY101," Draft Los Alamos National Laboratory Report, July 1993 
Table 6.5-1. Economic Damage Measures

\begin{tabular}{|c|c|c|c|c|c|c|c|c|c|c|c|c|c|c|}
\hline \multirow[b]{2}{*}{$\begin{array}{c}\text { Release } \\
\text { Category }\end{array}$} & \multicolumn{7}{|c|}{ Damage To } & \multicolumn{7}{|c|}{ Excessive Contamination to } \\
\hline & $\begin{array}{c}\text { Primary } \\
\text { Tank }\end{array}$ & $\begin{array}{c}\text { Secondary } \\
\text { Tank }\end{array}$ & $\begin{array}{l}\text { Vent } \\
\text { System } \\
\text { Ducting } \\
\end{array}$ & Deent. & $\begin{array}{l}\text { HEPA } \\
\text { Filters } \\
\end{array}$ & Inst. & Fan & Ground & Bldgs. & $\begin{array}{l}\text { Vent } \\
\text { System } \\
\text { Ducting } \\
\end{array}$ & Deent. & $\begin{array}{l}\text { HEPA } \\
\text { Filters. } \\
\end{array}$ & Inst. & Fan \\
\hline BPL & No & No & Yes & No & No & No & No & No & No & No & No & No & No & No \\
\hline HEPAL & No & No & Possible & Possible & Breached & Breached & Possible & Yes & Yes (?) & Yes & Breached & Breached & Yes & Yes \\
\hline HEPAH & No & No & Possible & Possible & Breached & Breached & Possible & Yes & Yes (?) & Yes & Breached & Breached & Yes & Yes \\
\hline $\mathrm{DCH}$ & Yes & Yes & Yes & Yes & Yes & Yes & Likely & Yes & Yes (?) & Yes & Yes & Yes & Yes & Yes \\
\hline $\mathrm{DCVH}$ & Yes & Yes & Yes & Yes & Yes & Yes & Likely & Yes & Yes (?) & Yes & No (?) & No $(?)$ & No (?) & No (?) \\
\hline SLK & Small Leak & Failure & No & No & No & No & No & Small Leak & No & No & No & No & No & No \\
\hline LLKK & Large Leak & Failure & No & No & No & No & No & Large Leak & No & No & No & No & No & No \\
\hline SSP & No & No & No & No & No & No & No & \begin{tabular}{|c|} 
Water \\
Intrusion I \\
Overflow \\
\end{tabular} & No & No & No & No & No & No \\
\hline $\begin{array}{l}\text { DCLLK } \\
\text { (DCH + } \\
\text { LLKK) }\end{array}$ & Yes & Yes & Yes & Yes & Yes & Yes & Líkely & $\begin{array}{c}\text { Airborne \& } \\
\text { Leak }\end{array}$ & Yes (?) & Yes & Yes - & Yes & Yes & Yes \\
\hline
\end{tabular}

NOTE: SLK \& LLK result in below grade leakage (considerable excavation required before contaminated soil can be reached) 
Table 6.5-2 Ground Contamination Levels - Release Category DCVH

\begin{tabular}{|c|c|c|c|c|c|c|}
\hline \multicolumn{2}{|c|}{ Release Category DCVH } & & & & & \\
\hline \multicolumn{5}{|c|}{ DECONTAMINATION LEVELS REQUIRED TO MEET PAG FOR } & & \\
\hline \multicolumn{6}{|c|}{ LAND WITHIN DOWNWIND DISTANCES $(M): 1.20 E+02-2.60 E+04$} & \\
\hline & \multicolumn{4}{|c|}{ (WEATHER WEIGHTED) } & \multirow{2}{*}{\multicolumn{2}{|c|}{$283 \mathrm{~kg}$}} \\
\hline & $57 \mathrm{~kg}$ & & $113 \mathrm{~kg}$ & & & \\
\hline $\begin{array}{l}\text { Decontamination } \\
\text { factor range }\end{array}$ & $\begin{array}{l}\text { Area } \\
\text { within this } \\
\text { range (sq } \\
\text { meters) }\end{array}$ & $\begin{array}{l}\text { Area with } \\
\text { this DF or } \\
\text { higher }\end{array}$ & $\begin{array}{l}\text { Area } \\
\text { within this } \\
\text { range (sq } \\
\text { meters) }\end{array}$ & $\begin{array}{l}\text { Area with } \\
\text { this DF or } \\
\text { higher }\end{array}$ & $\begin{array}{l}\text { Area } \\
\text { within this } \\
\text { range (sq } \\
\text { meters) }\end{array}$ & $\begin{array}{l}\text { Area with } \\
\text { this DF or } \\
\text { higher }\end{array}$ \\
\hline & & & & & & \\
\hline & & & & & & \\
\hline & & & & & & \\
\hline $1.0 \mathrm{E}+07 \cdot 3.3 \mathrm{E}+06$ & $0.00 E+00$ & $0.00 E+00$ & $0.00 E+00$ & $0.00 E+00$ & $0.00 E+00$ & $0.00 E+00$ \\
\hline $3.3 E+06 \cdot 1.0 E+06$ & $0.00 E+00$ & $0.00 E+\infty 0$ & $0.00 E+00$ & $0.00 E+00$ & $0.00 \mathrm{E}+00$ & $0.00 E+00$ \\
\hline $1.0 E+06 \cdot 3.3 E+05$ & $0.00 E+00$ & $0.00 E+00$ & $0.00 E+00$ & $0.00 E+00$ & $0.00 E+00$ & $0.00 E+00$ \\
\hline $3.3 E+05-1.0 E+05$ & $0.00 E+00$ & $0.00 \mathrm{E}+00$ & $0.00 \mathrm{E}+00$ & $0.00 E+00$ & $0.00 E+00$ & $0.00 E+00$ \\
\hline $1.0 E+05 \cdot 3.3 E+04$ & $0.00 E+00$ & $0.00 E+00$ & $0.00 E+00$ & $0.00 E+00$ & $0.00 E+00$ & $0.00 E+00$ \\
\hline $3.3 E+04 \cdot 1.0 E+04$ & $0.00 E+00$ & $0.00 E+00$ & $0.00 E+00$ & $0.00 E+00$ & $0.00 E+00$ & $0.00 E+00$ \\
\hline $1.0 \mathrm{E}+04-3.3 \mathrm{E}+03$ & $0.00 E+00$ & $0.00 E+00$ & $0.00 E+00$ & $0.00 E+00$ & $0.00 E+00$ & $0.00 E+00$ \\
\hline $3.3 \mathrm{E}+03-1.0 \mathrm{E}+03$ & $0.00 E+00$ & $0.00 E+00$ & $0.00 E+00$ & $0.00 E+00$ & $9.10 E+02$ & $9.10 E+02$ \\
\hline $1.0 E+03-3.3 E+02$ & $0.00 E+00$ & $0.00 E+00$ & $1.69 E+03$ & $1.69 E+03$ & $4.45 \mathrm{E}+03$ & $5.36 \mathrm{E}+03$ \\
\hline $3.3 \mathrm{E}+02 \cdot 1.0 \mathrm{E}+02$ & $3.30 E+03$ & $3.30 E+03$ & $6.01 E+03$ & $7.70 E+03$ & $1.27 \mathrm{E}+04$ & $1.81 E+04$ \\
\hline $1.0 \mathrm{E}+02 \cdot 3.3 \mathrm{E}+01$ & $7.34 E+03$ & $1.06 E+04$ & $1.15 E+04$ & $1.92 E+04$ & $3.83 \mathrm{E}+04$ & $5.64 E+04$ \\
\hline $3.3 \mathrm{E}+01-1.0 \mathrm{E}+01$ & $2.80 E+04$ & $3.87 E+04$ & $4.64 E+04$ & $6.55 E+04$ & $1.31 E+05$ & $1.88 E+05$ \\
\hline $1.0 \mathrm{E}+01 \cdot 3.3 \mathrm{E}+00$ & $6.01 E+04$ & $9.88 E+04$ & $1.36 E+05$ & $2.01 E+05$ & $2.33 \mathrm{E}+05$ & $4.21 E+05$ \\
\hline $3.3 E+00 \cdot 1.0 E+00$ & $1.30 E+05$ & $2.28 E+05$ & $2.26 E+05$ & $4.27 E+05$ & $4.97 E+05$ & $9.18 E+05$ \\
\hline
\end{tabular}




$$
\text { DC1015 XLS }
$$

Table 6.5-3 Ground Contamination Levels - Release Category DCH

\begin{tabular}{|c|c|c|c|c|c|c|}
\hline Release category DCH & & & & & & \\
\hline \multicolumn{7}{|c|}{ DECONTAMINATION LEVELS REQUIRED TO MEET PAG FOR } \\
\hline \multicolumn{7}{|c|}{ LAND WITHIN DOWNWIND DISTANCES $(M): 1.20 E+02 \cdot 2.60 E+04$} \\
\hline & \multicolumn{4}{|c|}{ (WEATHER WEIGHTED) } & & \\
\hline & $14.7 \mathrm{~kg}$ & & $32.8 \mathrm{~kg}$ & & $55.2 \mathrm{~kg}$ & \\
\hline $\begin{array}{l}\text { Decontamination } \\
\text { factor range }\end{array}$ & $\begin{array}{l}\text { Area } \\
\text { within this } \\
\text { range (sq } \\
\text { meters) }\end{array}$ & $\begin{array}{l}\text { Area with } \\
\text { this DF or } \\
\text { higher }\end{array}$ & $\begin{array}{l}\text { Area } \\
\text { within this } \\
\text { range (sq } \\
\text { meters) } \\
\end{array}$ & $\begin{array}{l}\text { Area with } \\
\text { this DF or } \\
\text { higher }\end{array}$ & \begin{tabular}{|l|} 
Area \\
within thls \\
range (sq \\
meters) \\
\end{tabular} & $\begin{array}{l}\text { Area with } \\
\text { this DF or } \\
\text { higher }\end{array}$ \\
\hline & & & & & & \\
\hline & & & & & & \\
\hline $1.0 E+07 \cdot 3.3 E+06$ & $0.00 E+00$ & $0.00 E+00$ & $0.00 E+00$ & $0.00 E+00$ & $0.00 E+00$ & $0.00 E+\infty 0$ \\
\hline $3.3 E+06 \cdot 1.0 E+06$ & $0.00 E+00$ & $0.00 E+00$ & $0.00 \mathrm{E}+00$ & $0.00 E+00$ & $0.00 E+00$ & $0.00 E+00$ \\
\hline $1.0 E+06-3.3 E+05$ & $0.00 E+00$ & $0.00 \mathrm{E}+00$ & $0.00 E+00$ & $0.00 E+00$ & $0.00 E+00$ & $0.00 E+00$ \\
\hline $3.3 E+05 \cdot 1.0 E+05$ & $0.00 E+00$ & $0.00 \mathrm{E}+00$ & $0.00 \mathrm{E}+00$ & $0.00 E+00$ & $0.00 E+00$ & $0.00 E+00$ \\
\hline $1.0 E+05-3.3 E+04$ & $0.00 \mathrm{E}+00$ & $0.00 E+00$ & $0.00 \mathrm{E}+00$ & $0.00 E+00$ & $0.00 E+00$ & $0.00 E+00$ \\
\hline $3.3 E+04-1.0 E+04$ & $0.00 E+00$ & $0.00 E+00$ & $0.00 E+00$ & $0.00 E+00$ & $0.00 E+00$ & $0.00 E+00$ \\
\hline $1.0 E+04 \cdot 3.3 E+03$ & $0.00 E+00$ & $0.00 E+00$ & 7.94E.01 & $7.94 \mathrm{E} \cdot 01$ & $6.95 E+00$ & $6.95 E+00$ \\
\hline $3.3 E+03 \cdot 1.0 E+03$ & $5.80 E+00$ & $5.80 \mathrm{E}+00$ & $1.80 \mathrm{E}+01$ & $1.88 \mathrm{E}+01$ & $2.80 E+01$ & $3.50 E+01$ \\
\hline $1.0 E+03 \cdot 3.3 E+02$ & $2.33 E+01$ & $2.91 E+01$ & $2.86 E+01$ & $4.74 \mathrm{E}+01$ & $4.50 E+01$ & $8.00 E+01$ \\
\hline $3.3 E+02-1.0 E+02$ & $4.33 E+01$ & $7.24 \mathrm{E}+01$ & $1.16 E+02$ & $1.64 E+02$ & $1.93 E+02$ & $2.73 E+02$ \\
\hline $1.0 \mathrm{E}+02 \cdot 3.3 \mathrm{E}+01$ & $1.32 E+02$ & $2.04 E+02$ & $2.34 E+02$ & $3.98 \mathrm{E}+02$ & $3.02 \mathrm{E}+02$ & $5.75 \mathrm{E}+02$ \\
\hline $3.3 E+01 \cdot 1.0 E+01$ & $3.35 E+02$ & $5.39 E+02$ & $6.41 E+02$ & $1.04 E+03$ & $1.19 E+03$ & $1.77 E+03$ \\
\hline $1.0 E+01 \cdot 3.3 E+\infty 0$ & $9.04 E+02$ & $1.44 \mathrm{E}+03$ & $1.65 E+03$ & $2.69 E+03$ & $2.48 E+03$ & $4.24 E+03$ \\
\hline $3.3 E+00 \cdot 1.0 E+\infty 0$ & $2.10 E+03$ & $3.55 E+03$ & $5.21 E+03$ & $7.89 E+03$ & $8.05 E+03$ & $1.23 E+04$ \\
\hline
\end{tabular}


Table 6.5-4 Ground Contamination Levels - Release Category HEPAH

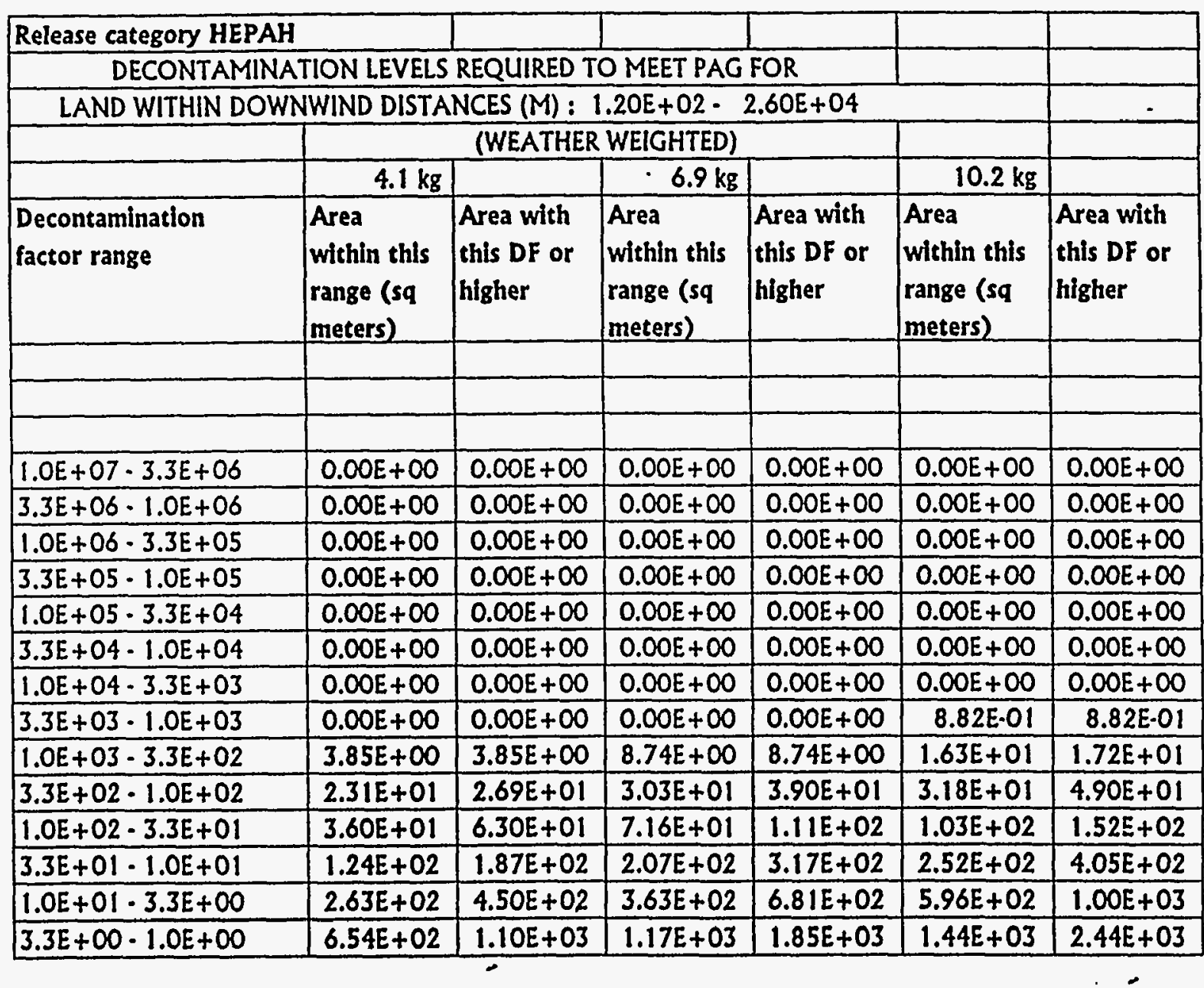


Table 6.5-5 Ground Contamination Levels - Release Category HEPAL

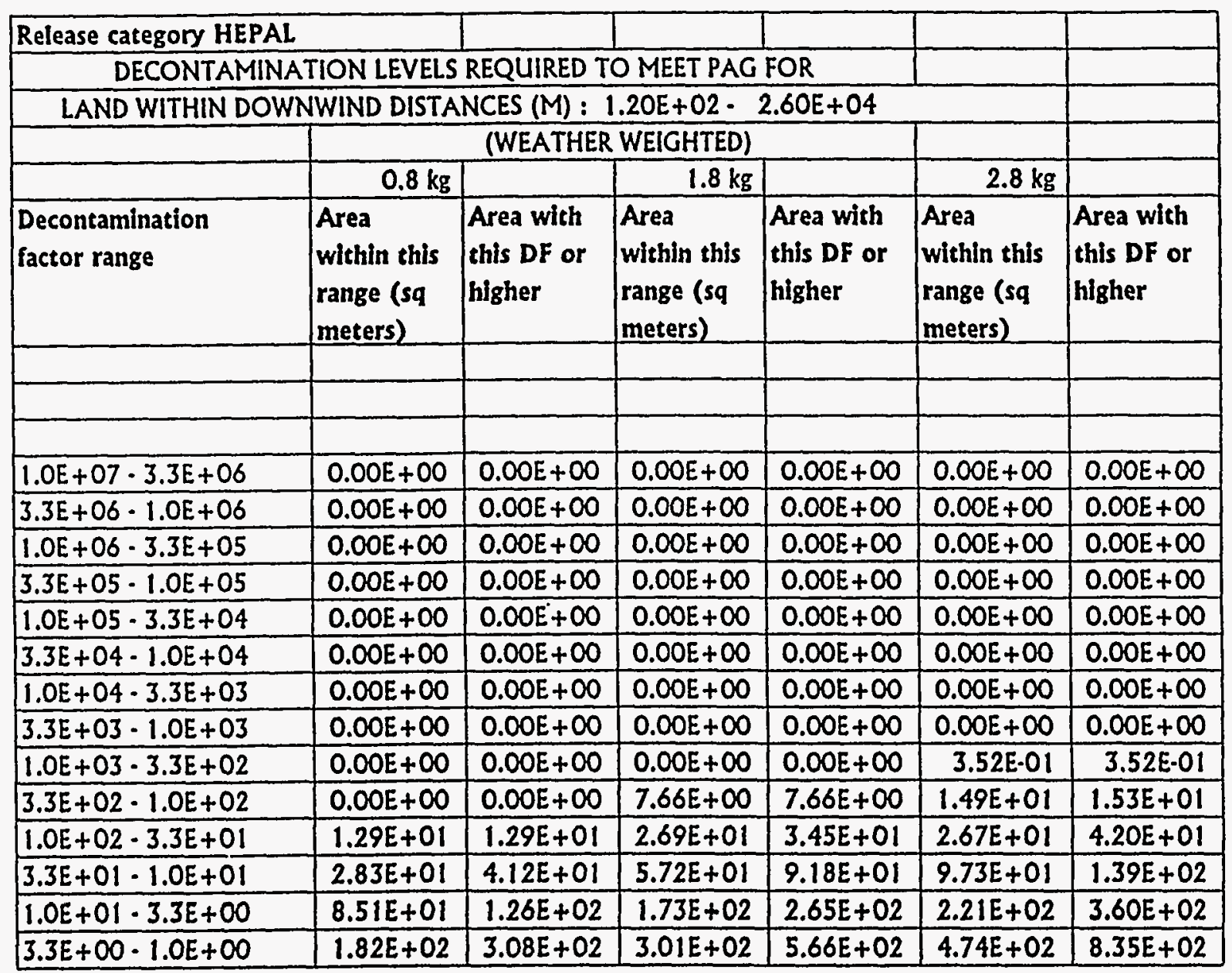




\section{Table 6.5-6. Assumed Ground Decontamination Costs}

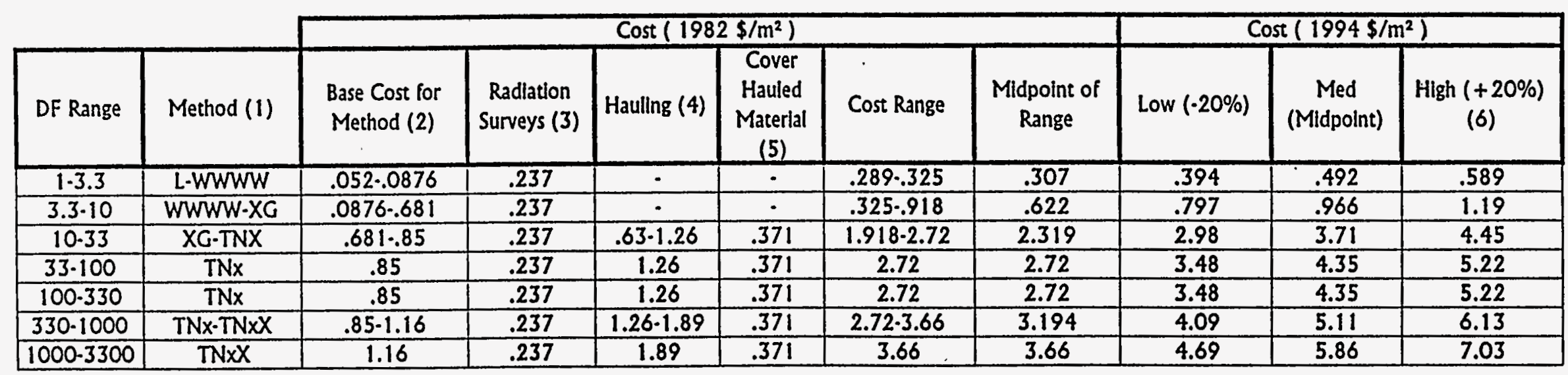

Notes:
(1) See Figure 2.5.7, NUREG /CR.3413
(2) See Table 2.4.4.1, NUREG /CR-3413
(3) See Table A.1, LANL-3098-DOC-38
(4) See Table 2.4.11.1, NUREG /CR.3413 ( $10 \mathrm{ml}$ round trip, $6^{\text {n }}$ per scraping
(5) See Table 2.4.4.1, NUREG /CR.3413
(6) Costs escalated at $4 \% / y r$ 


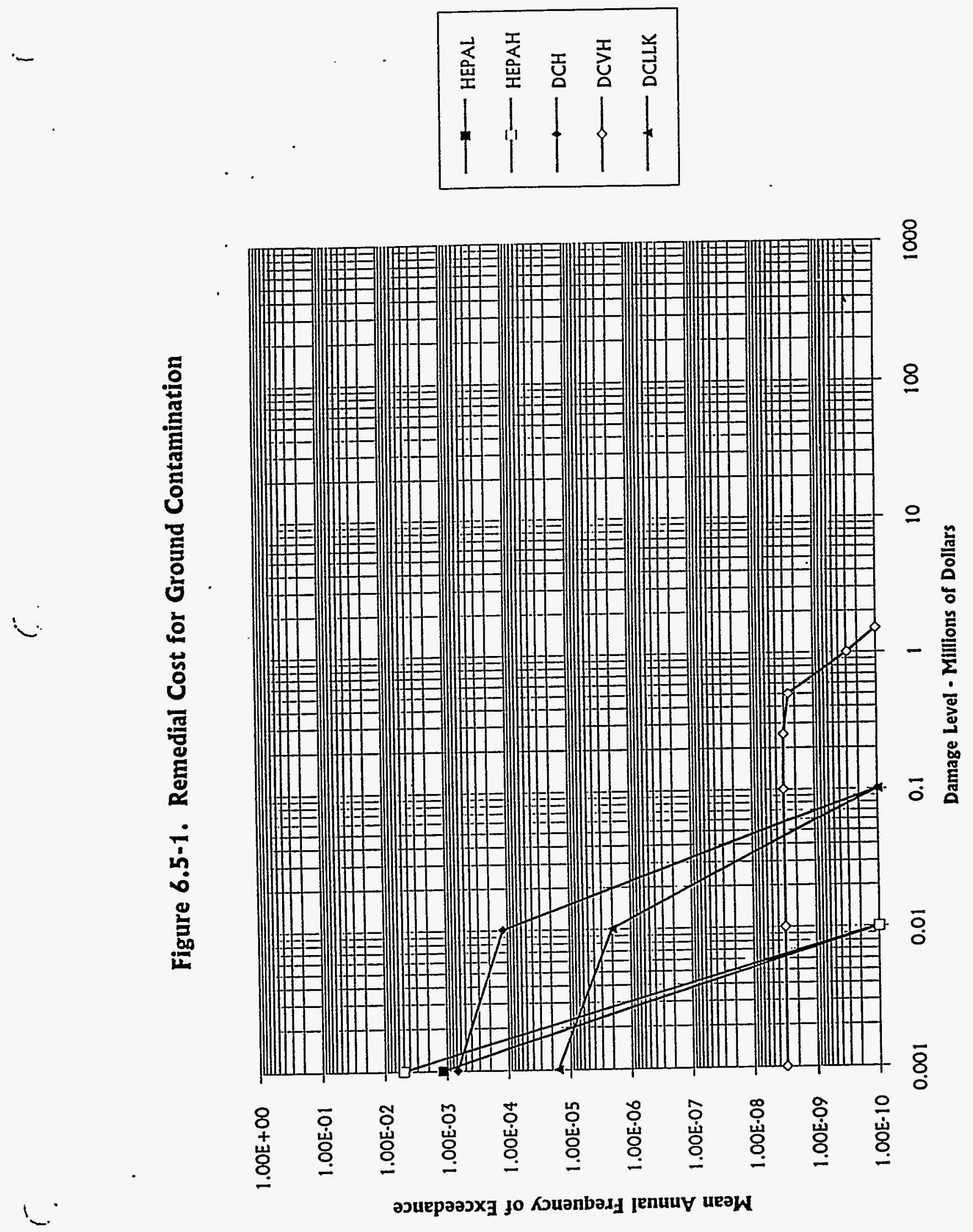

$\frac{⿱ 亠}{\equiv}$ 


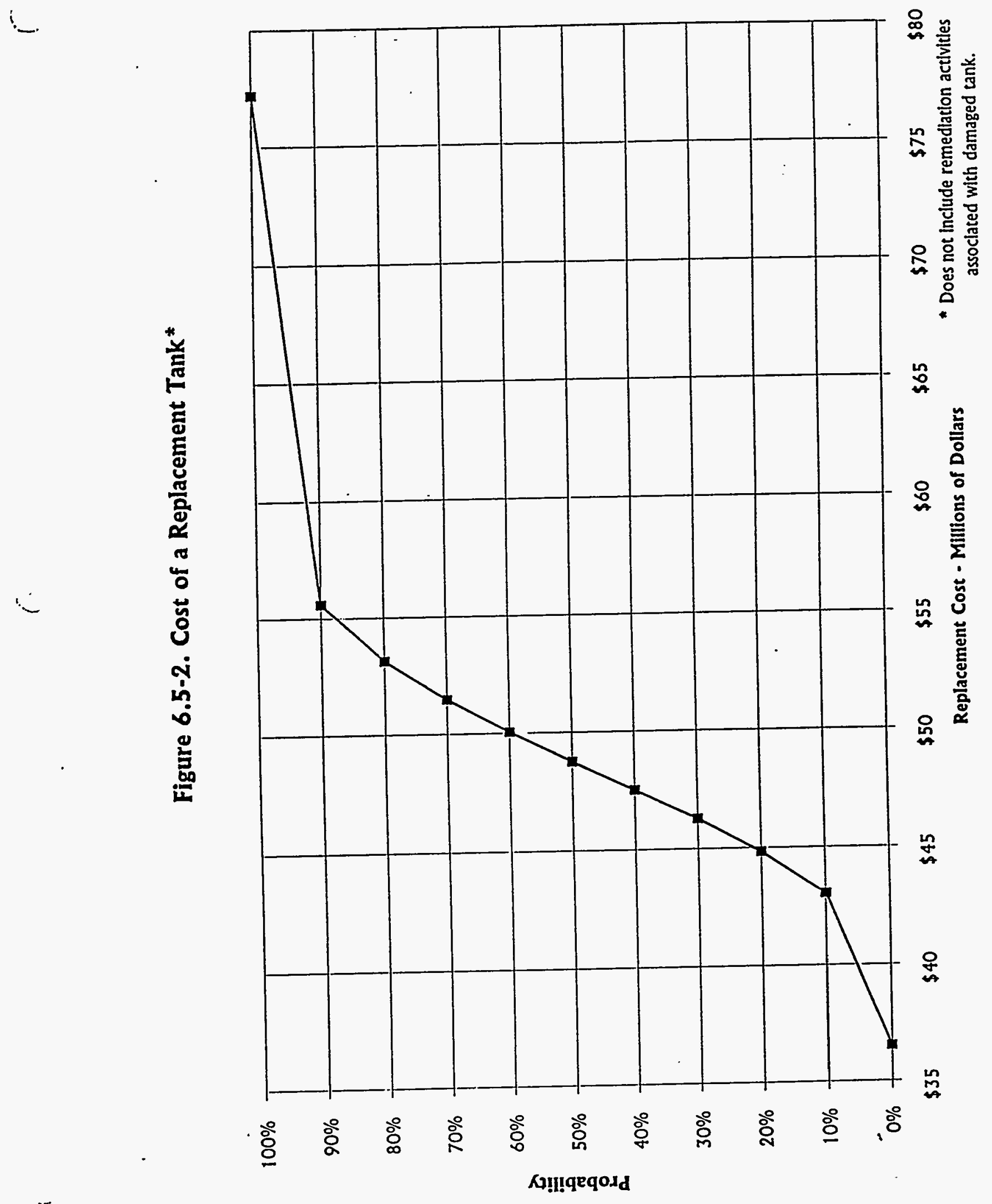




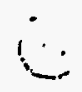



高

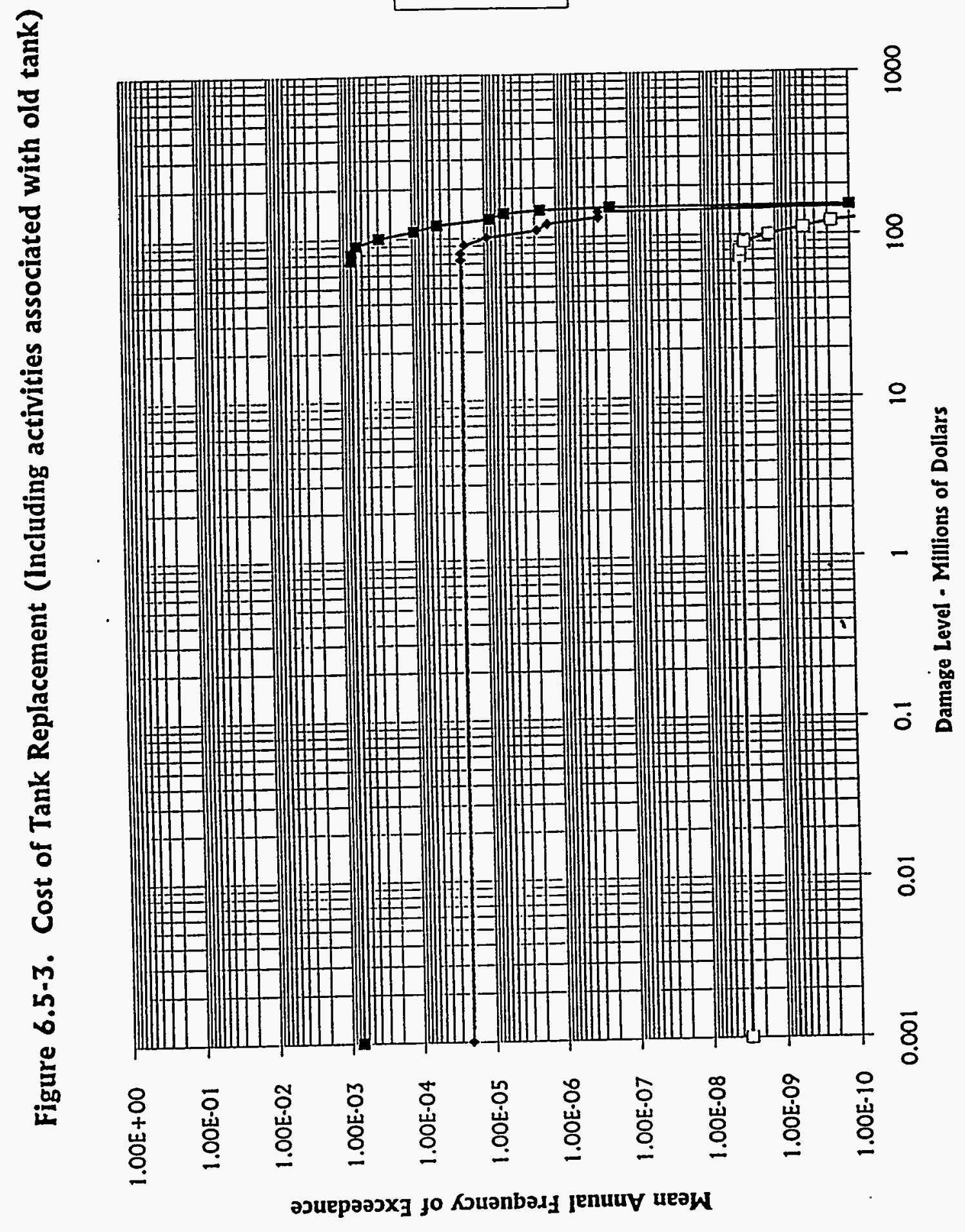


6
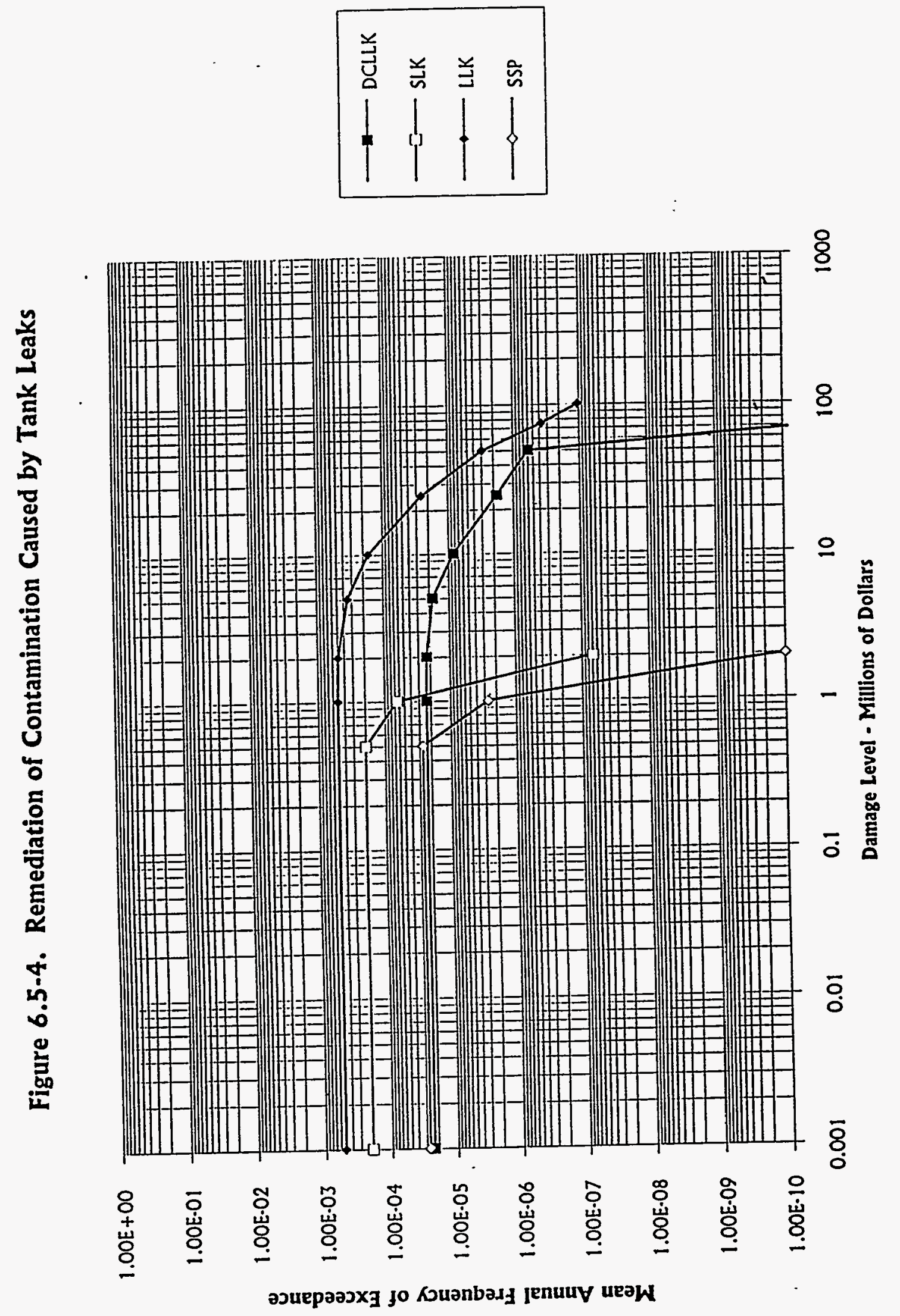

喜 


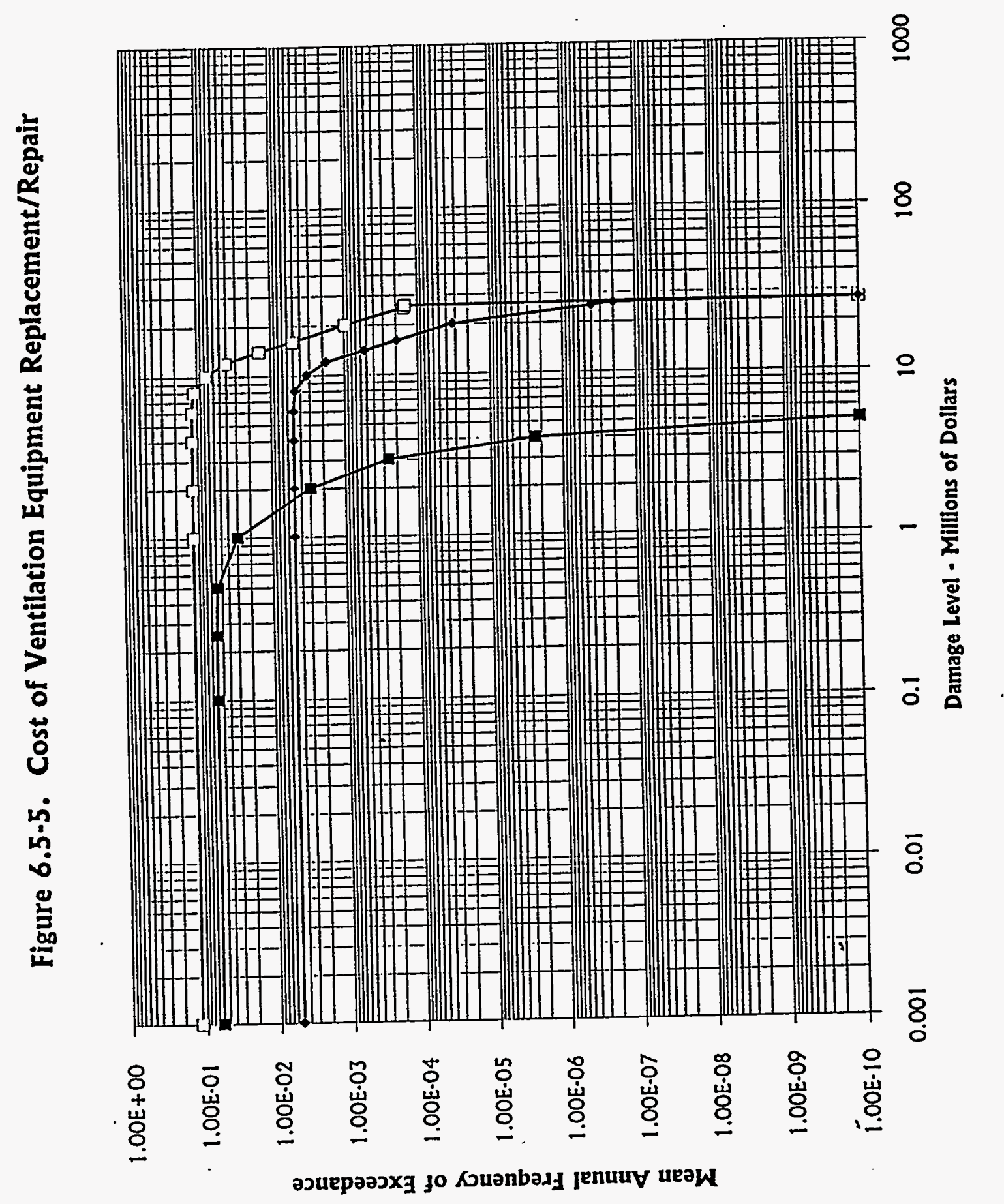




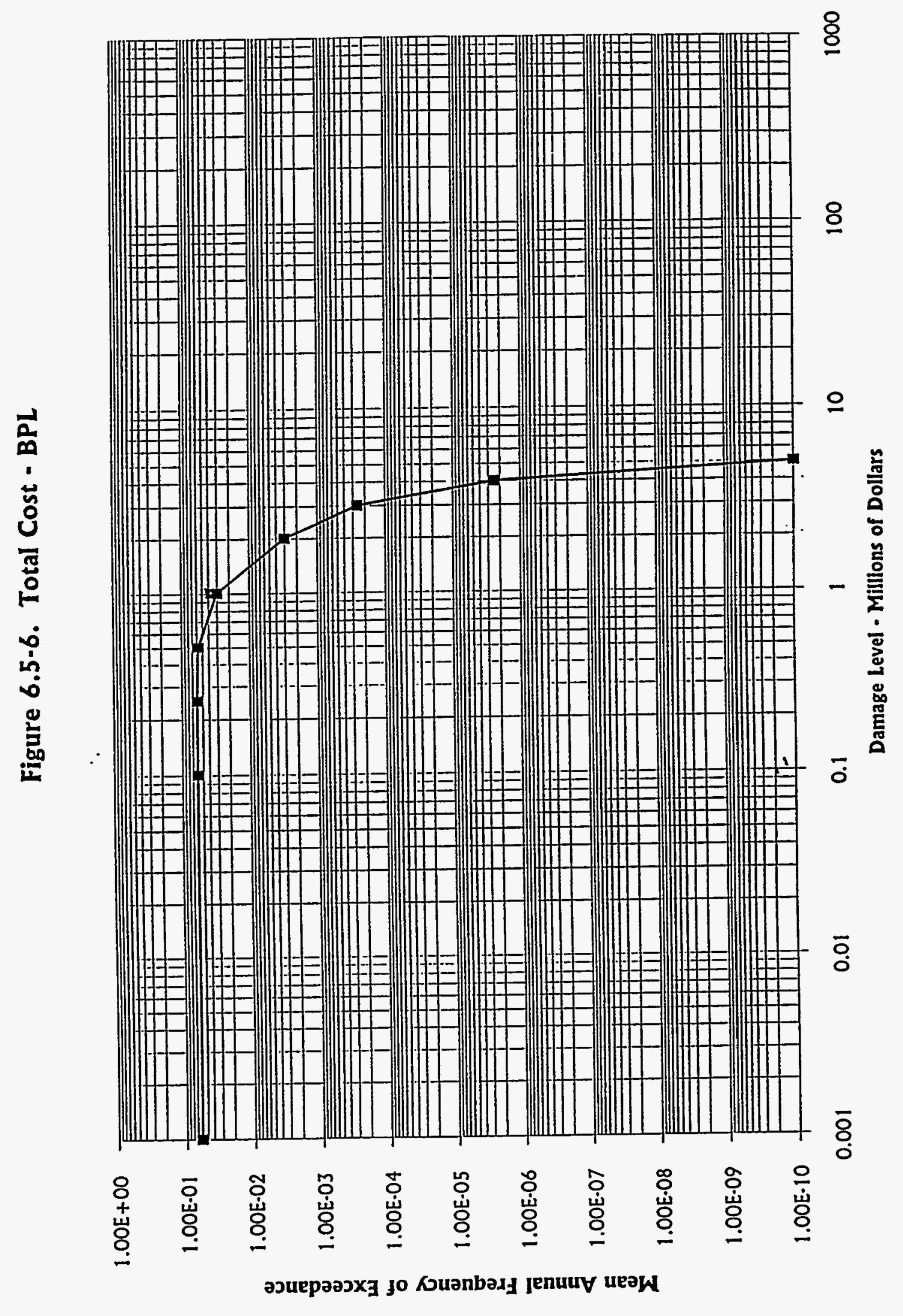




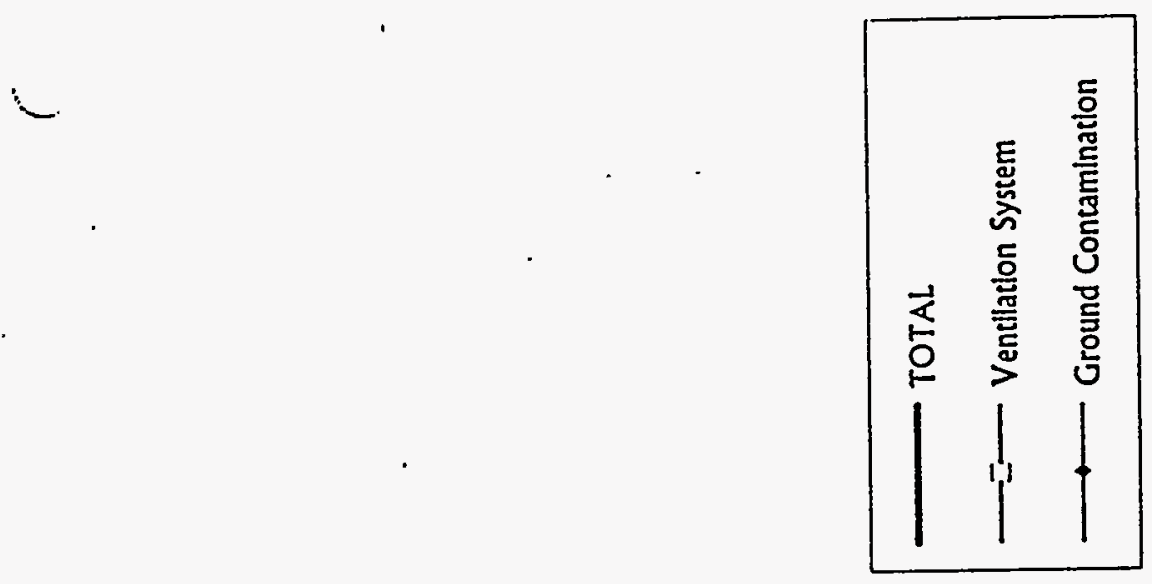

$\frac{ \pm}{2}$

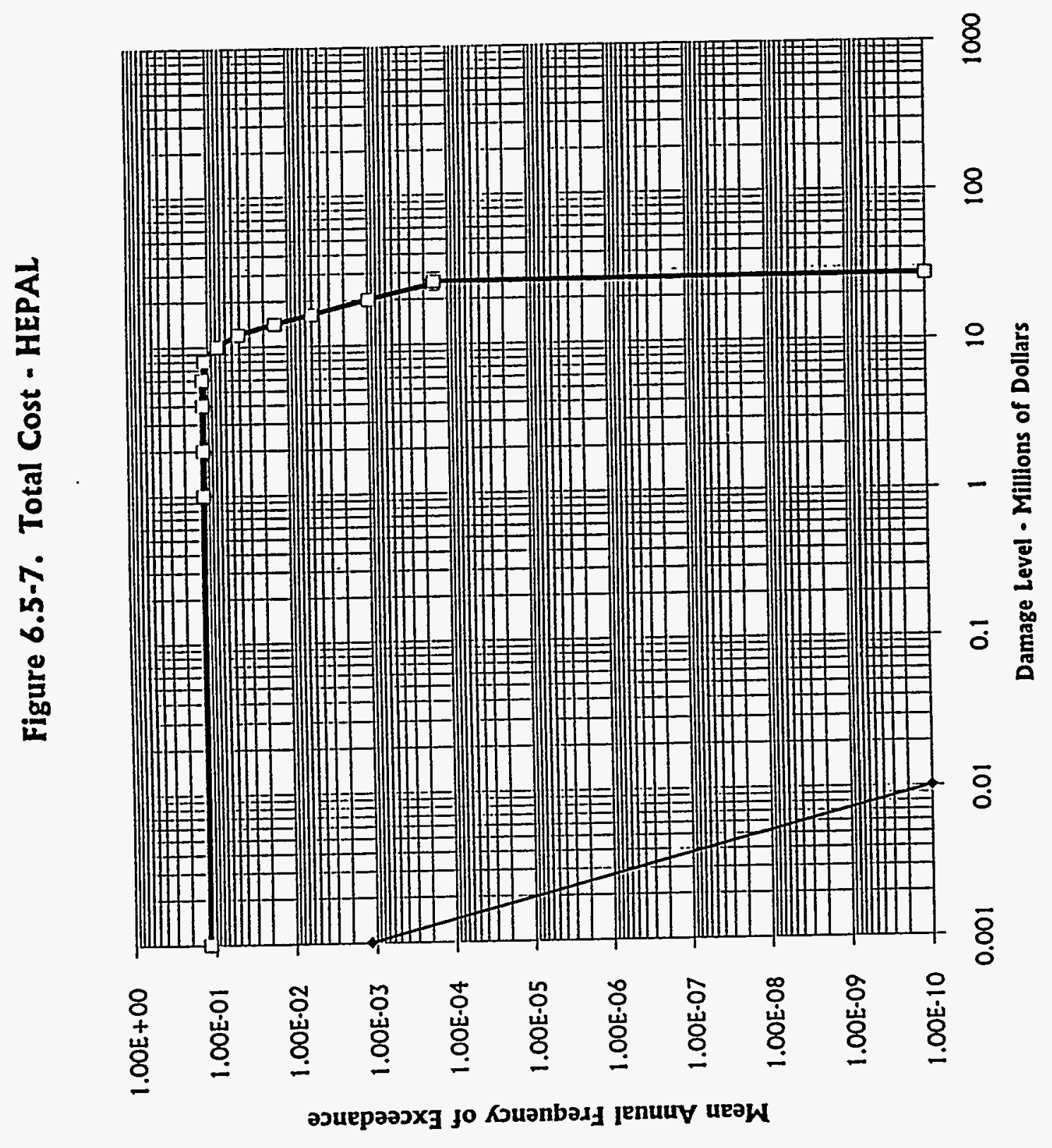




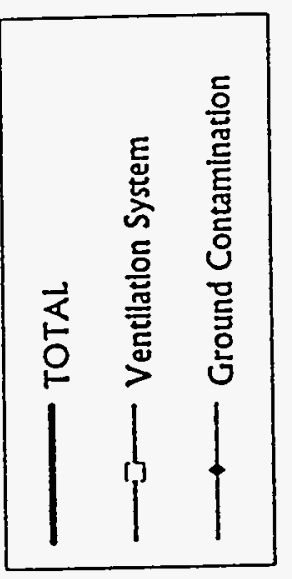

$\stackrel{\Xi}{\equiv}$
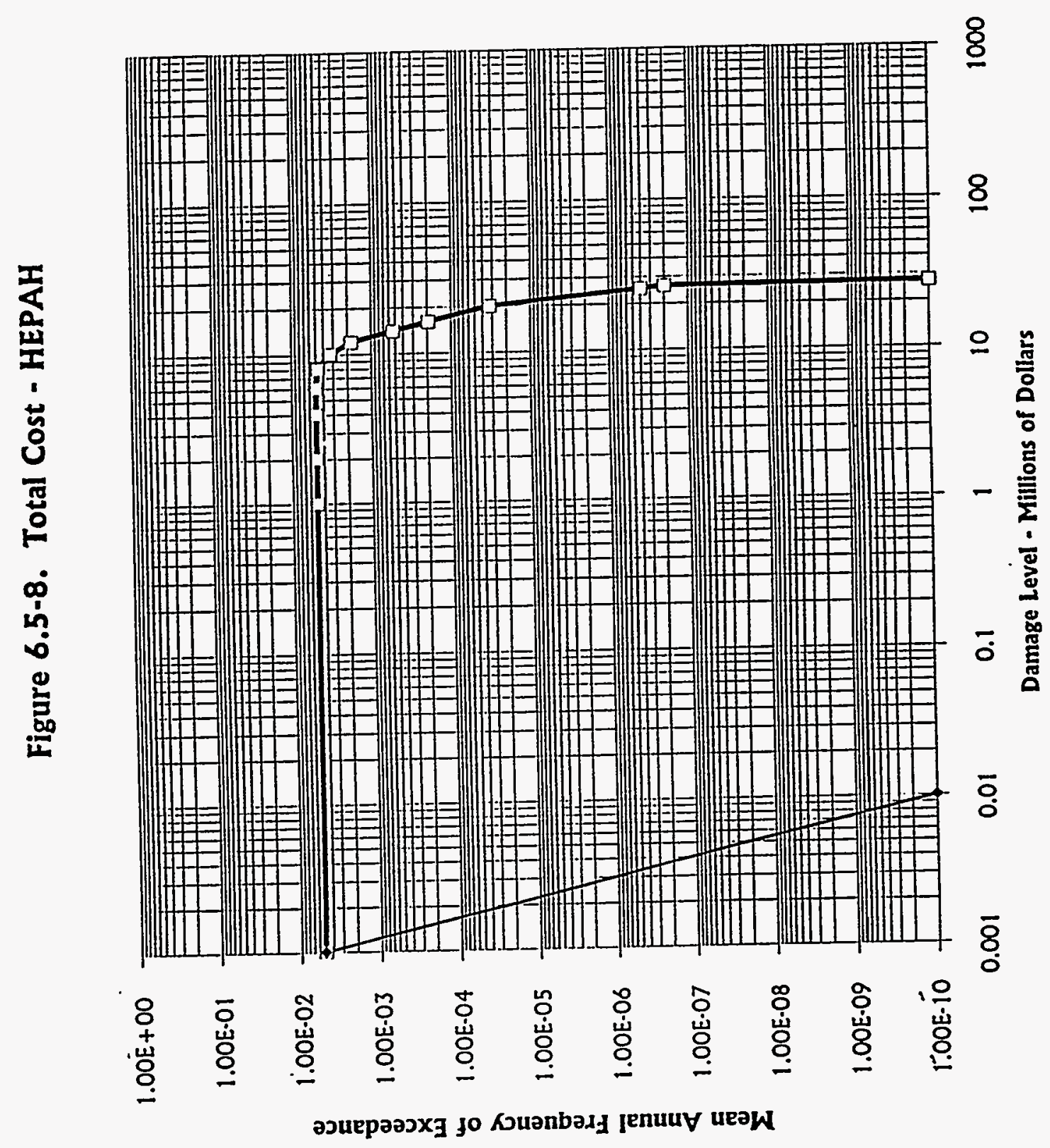

总 
1



$\stackrel{⿱ 亠 乂}{\vdots}$

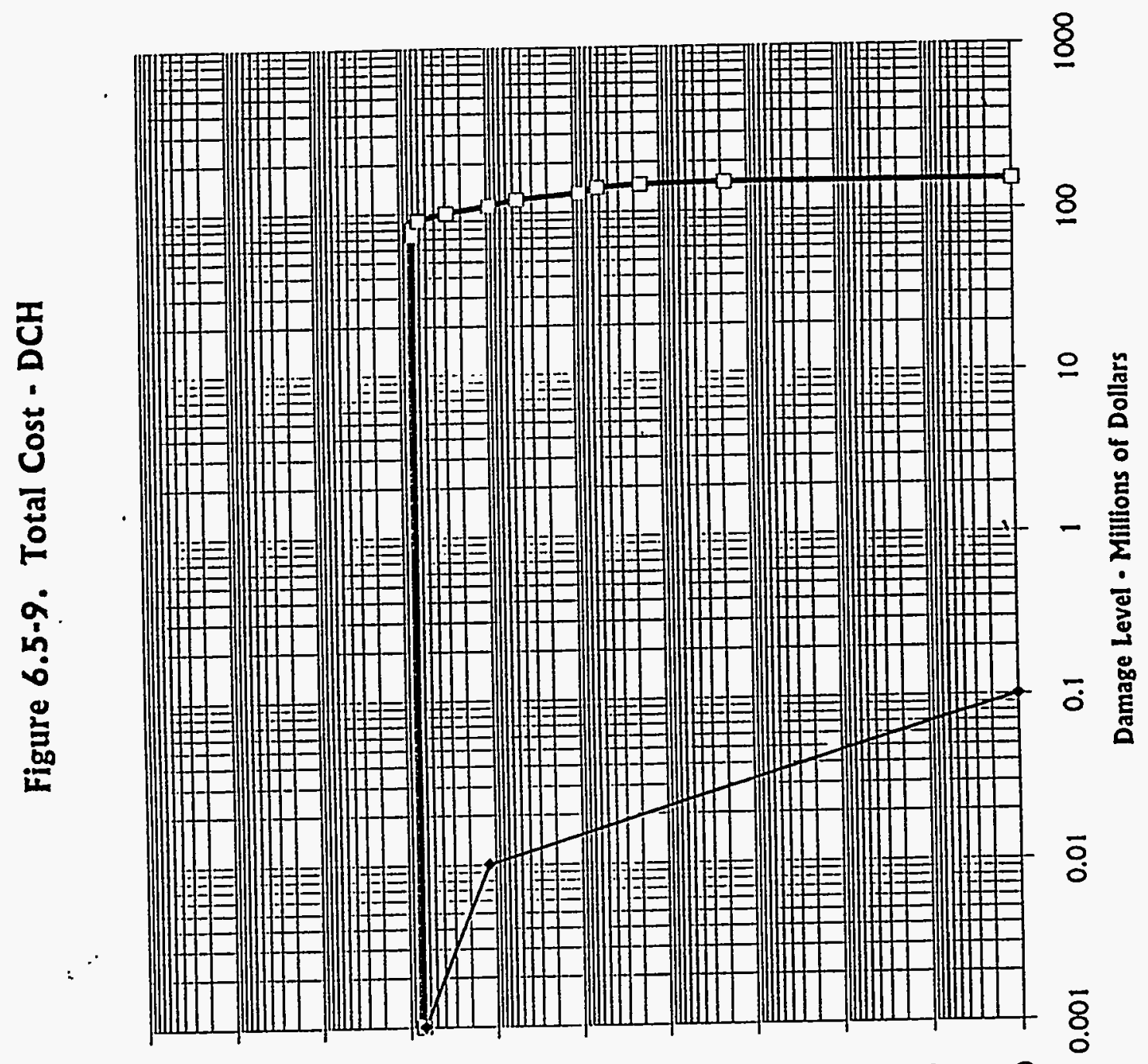

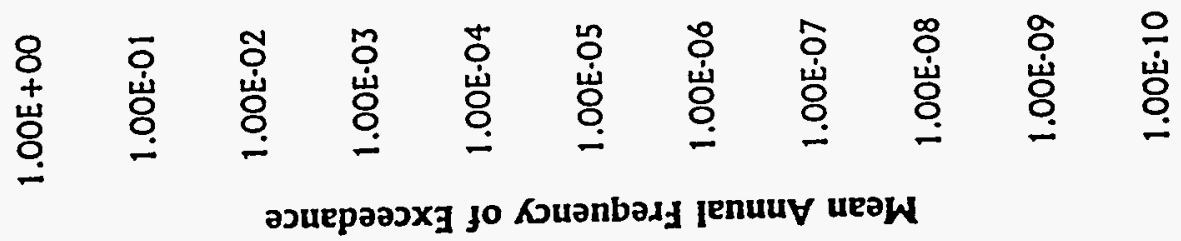



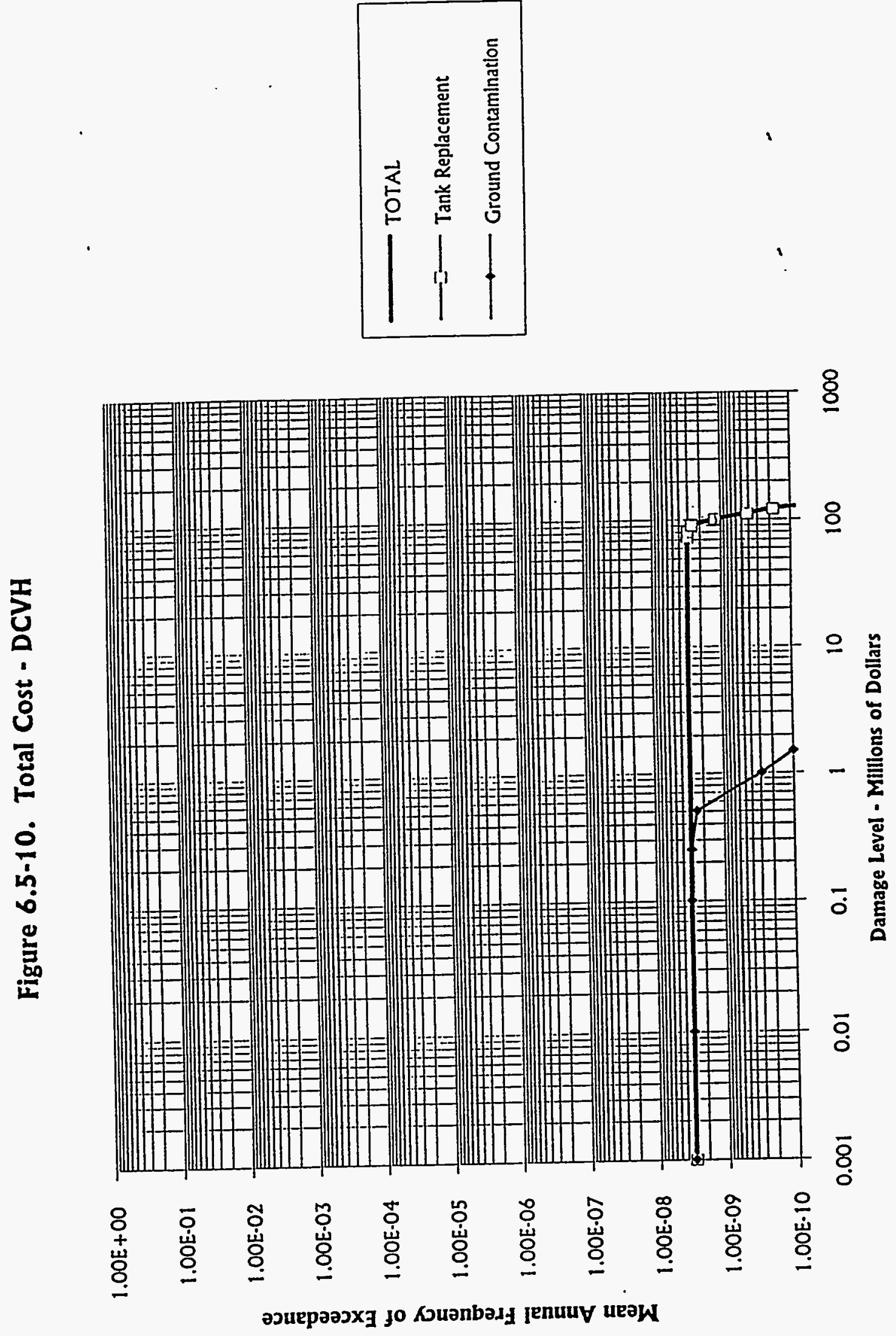





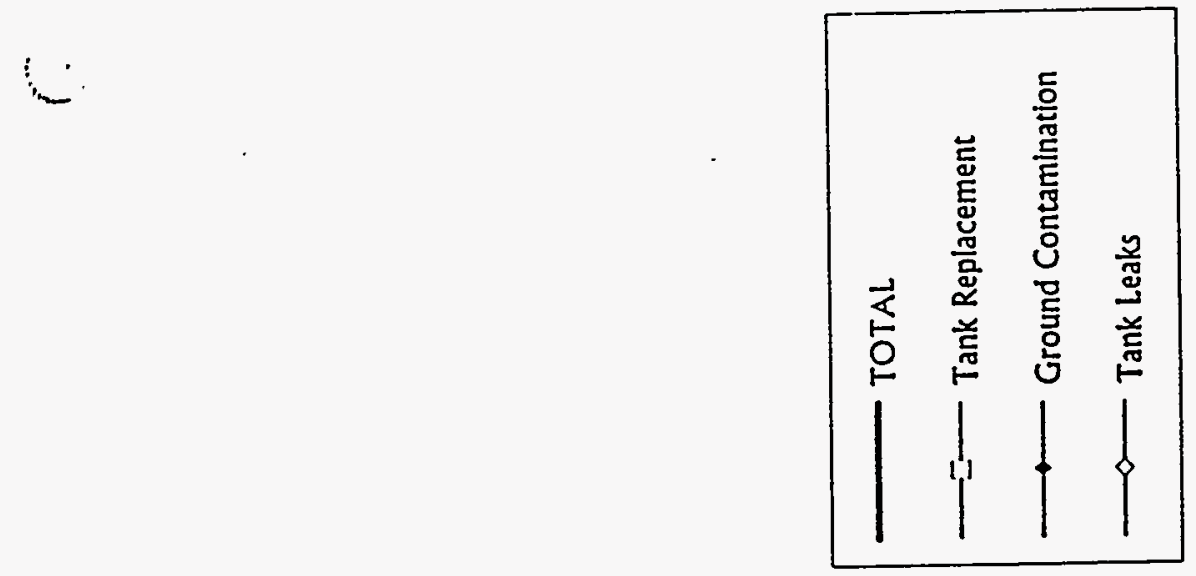

$\stackrel{+}{=}$

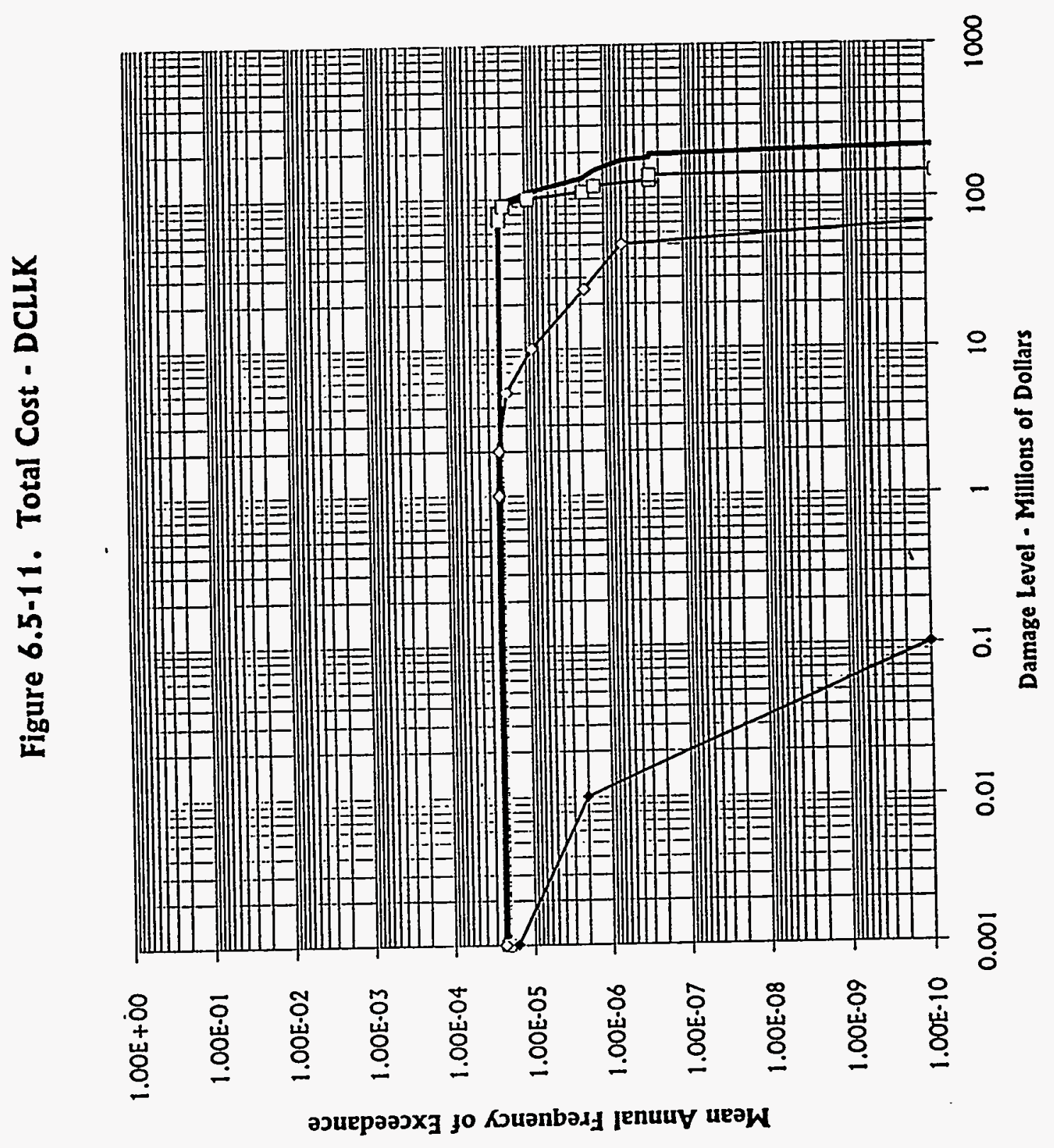




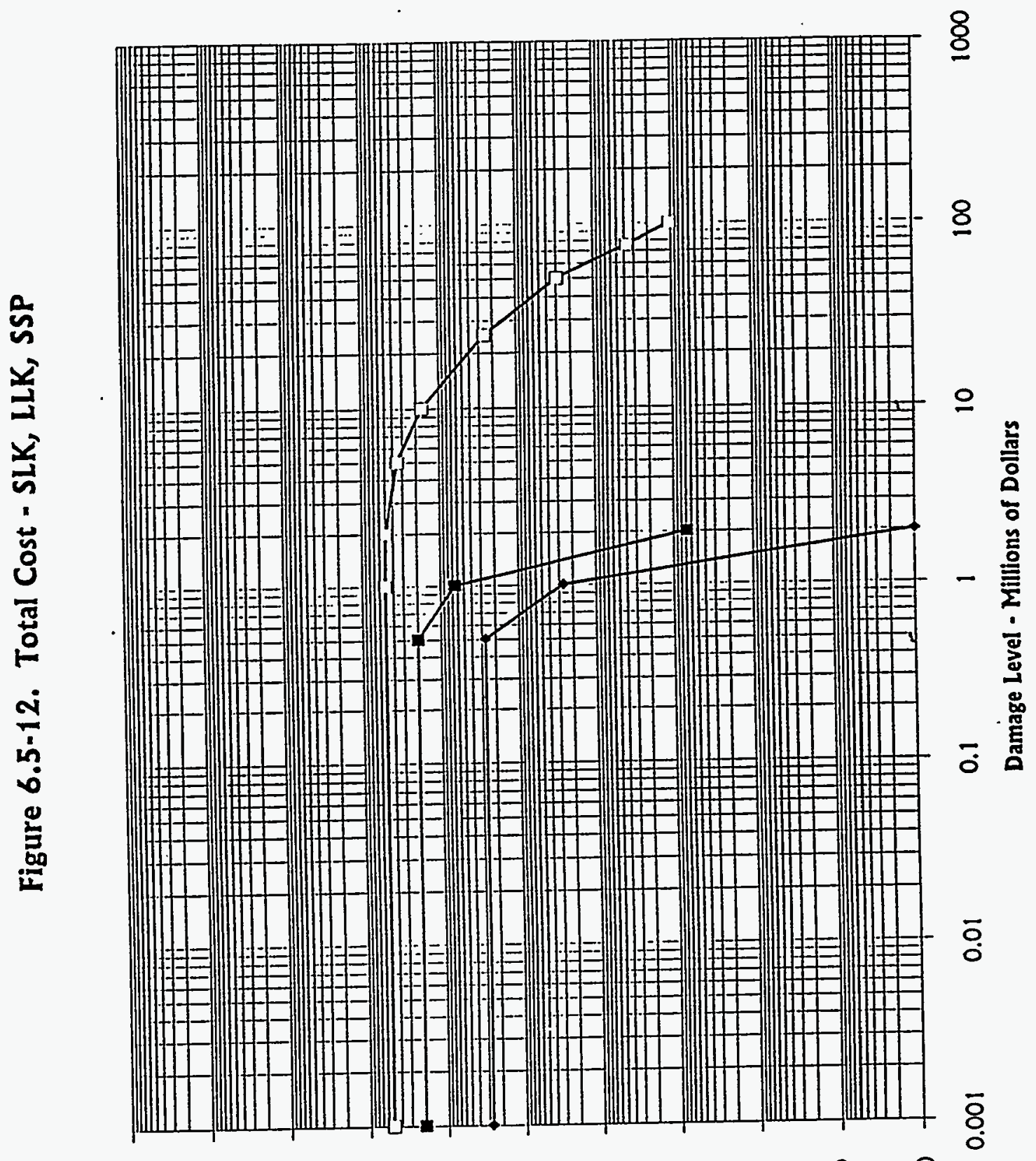

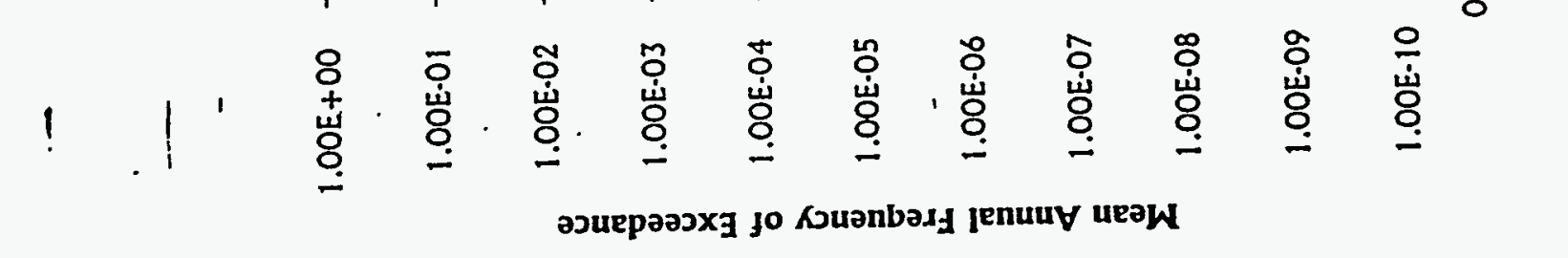





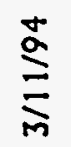

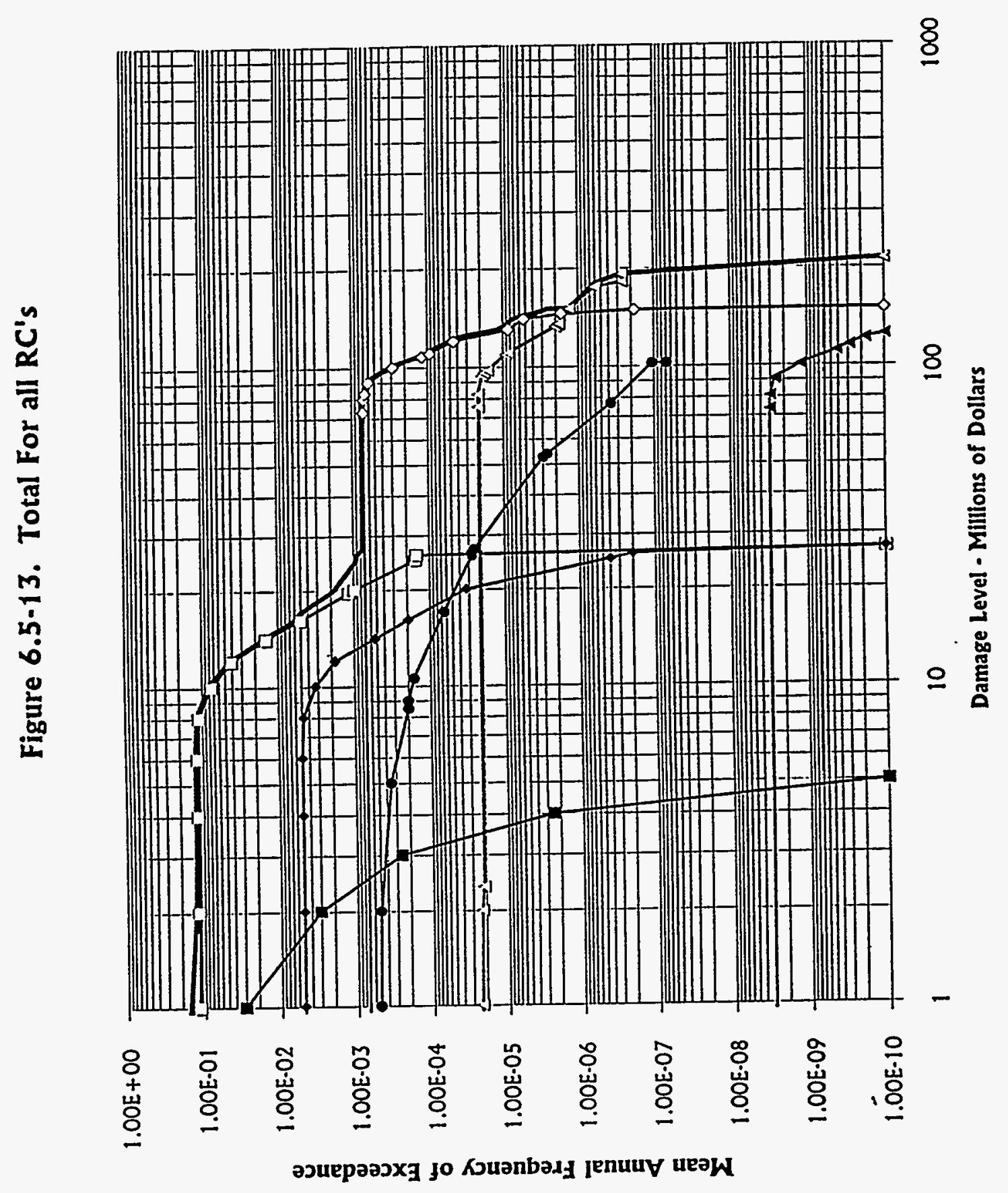

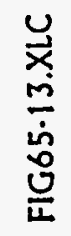



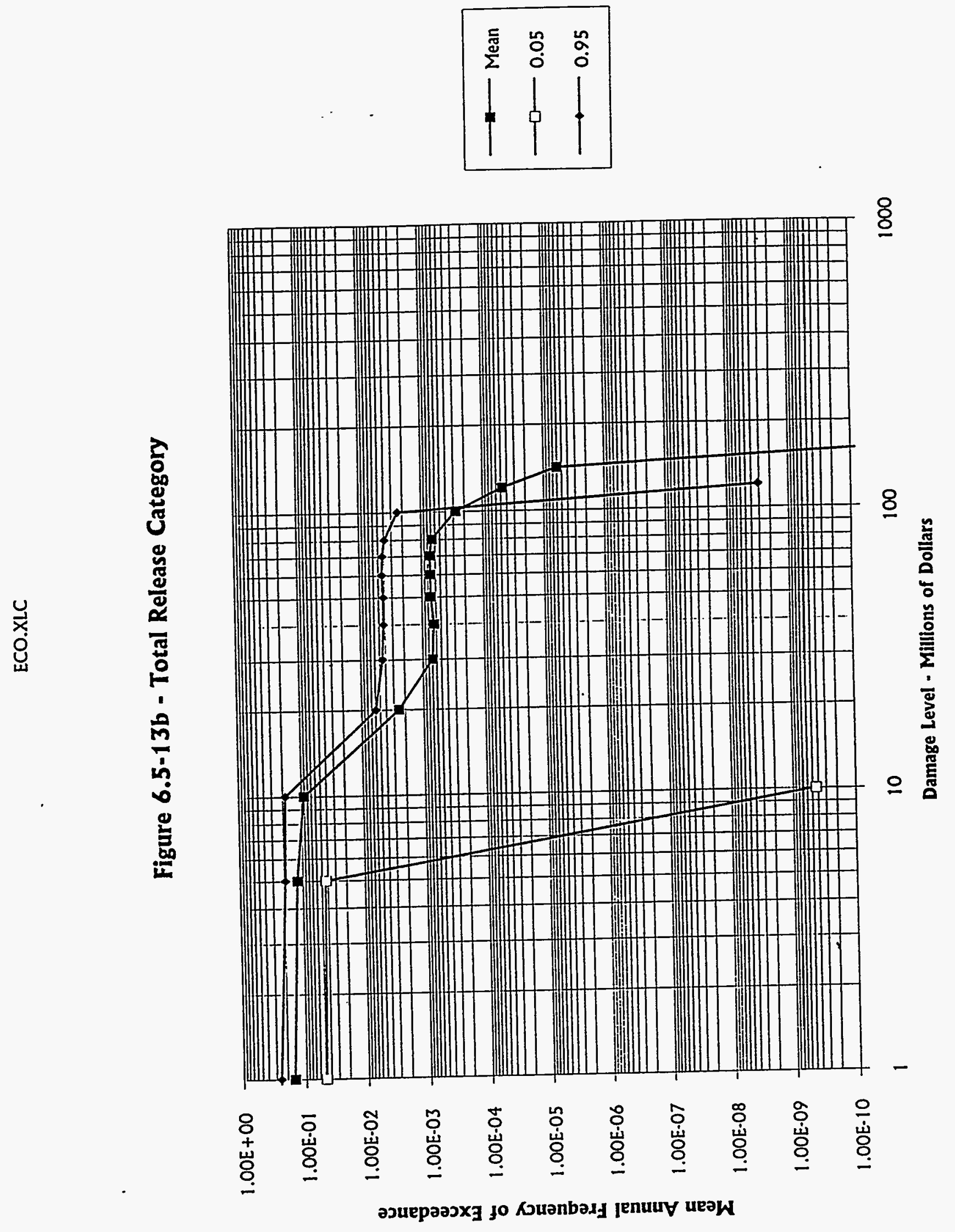


\section{PLG}

ENGINEERS• APPUIED SCIENTISTS • MANAGEMENT CONSULTANTS
PLG, Inc., 4590 MacArthur Boulevard, Suite 400, Newport Beach. California 92660-2027

Tel. 714-833-2020 - Fax 714-833-2085

Washington, D.C.. Oflice

Tel. 202-659-1122 - Fax 202-296-0774

JPKindinger

RKDeremer

January 27, 1994

LANL-3098-PLG-14

MAEmerson

DABidwell

GABrosche

Client File

Mr. Donald R. MacFarlane

Los Alamos National Laboratory

SM30 Bikini Road, MS-K557

Los Alamos, NM 87545

Dear Don:

\section{HANFORD TANK STATUS DATABASE}

Enclosed is the draft tank status database of all 177 tanks for the Hanford Tank Farm (HTF). This database and its supporting notes will be incorporated as an appendix into the HTF risk assessment report for all tanks. Please return any comments or suggestions on this document to me.

Please note that data on tank leak dates and volumes have not been revised to incorporate the recent information obtained from Mr. Steve Agnew. It is our intent to report the "official record" in this database. In our later analysis of tank leaks, we will detail how the official record should be updated based on the new data from Mr. Agnew. This approach should leave a clear record of how all available information was used.

Finally, this document, along with the previously transmitted update of the master logic diagram and initiating events analysis, constitutes completion of item \#3 for this contract (6617K0013-95). I will instruct our accounting department to proceed with invoicing for this milestone $(\$ 73,861)$.

Very truly yours,



John P. Kindinger

\section{Enclosures}

JPK/jhp

L309814.JPK 


\section{HANFORD TANK FARM DATABASE}

The Hanford Tank Farm database consists of four documents. First is the tank database spreadsheet (TANKLEAK.XL'S).

The second document (INFOSORC.XLS) is a table that links the data in the database to the source document. This table references the column in the database and indicates the specific table and page where the information originates. It was originally created as a map to aid in verifying each entry in the table. The table should be very useful in the future for comparing old document sources with new updated ones. It will help to avoid comparing values tankby-tank in updates to the database. In addition, anyone using the database now has a resource to find more detailed information.

The third document (DBWRTUP.DOC) is a fully detailed description of each subject or column in the tank database.

The fourth document is a list of definitions for the abbreviations used in the database (TKFOOTNT.DOC). 


\section{Hanford Tank Farm Data Base Abbreviations and Terms}

Tank I.D.: The identifier is composed of a letter followed by a number. The letter refers to the farm area. The number is either a 200 series or a 100 series. This refers to the tank type (see below).

Tank Type:

. 100 - 75 foot diameter single shell tanks.

200 - 20 foot diameter single shell tanks.

DST - 75 foot Double Shell Tanks.

Stabilized:

IS - Interim Stabilized. A tank which contains less than 50,000 gallons of drainable liquid and less than 5,000 gallons of supernatant liquid. If the tank was jet pumped, this criteria was achieved when the flow rate dropped below $0.05 \mathrm{gpm}$.

Supernatant Liquid:

AGING -

Aging waste. High level, first cycle solvent extraction waste from the Plutonium-Uranium Extraction plant. Neutralized current acid waste (NCAW).

CC - Concentrated complexant. Concentrated product from the evaporation of dilute complexed waste.

CP - Concentrated phosphate waste. Waste originating from the decontamination of $100 \mathrm{~N}$ Area reactor.

DC - Dilute complexed waste. This is characterized by a high content of organic carbon including organic complexants.

DN - Dilute non-complexed. Low activity liquid waste originating from $T$ and $S$ Plants, 300 and 400 Areas, Plutonium-Uranium Extraction facility (decladding supernatant and miscellaneous wastes), $100 \mathrm{~N}$ Area (sulfate waste), B Plant, saltwells, and Plutonium Finishing Plant (supernatant).

DSSF - $\quad$ Double shell slurry feed. Waste evaporated just before reaching the sodium aluminate saturation boundary or $6.5 \underline{\mathrm{M}}$ hydroxide in the evaporator. This form is not as concentrated as DSS.

EMPTY - Contains no contents.

NCPLX - Non-complexed. General waste term applied to all site liquors not identified as complexed.

PD - $\quad$ Plutonium-Uranium Extraction plant decladding or Neutralized Cladding Removal Waste (NCRW). It is the solids portion of the Plutonium-Uranium 
PT -

Extraction plant neutralized cladding removal waste stream, received into tanks as a slurry. It is classified as transuranic waste.

Plutonium Finishing Plant transuranic solids which originate from West Area operations.

NA - Not applicable.

Isolated:

IP -

Interim Prevention. The administrative designation reflecting the completion of the physical effort required to minimize the addition of liquids into an inactive storage tank. Under no circumstances are electrical or instrumentation devices disconnected or disabled during the intrusion prevention process (except for electrical pumps). This term was adopted in June 1993.

PI - $\quad$ Partially interim isolated. The administrative designation indicating the completion of all of the physical efforts required to minimize the addition of liquids into an inactive storage tank except for the isolation of risers and piping. The exception is required for jet pumping or for other stabilization methods.

Watch Lists: Tanks that have met the criteria for Watch List Tanks defined in Public Law 101510, Section 3137, "Safety Measures for Waste Tanks at Hanford Nuclear Reservation,"(1990).

FECN - $\quad$ Tanks containing $>1000$ gram mole of ferrocyanide $(\mathrm{FeCN})$.

H2 - Tanks with the potential for hydrogen or flammable gas accumulation above the flammability limit.

ORG - Tanks containing concentrations of organic salts $>3 \%$ weight TOC.

Heat - $\quad$ Single shell tanks with heat loads $>40,000$ BTU/Hr.

Level Measurement: Each tank is periodically measured for liquid. All of the single shell tanks are measured by one of 3 different methods. The measurements are either taken automatically (A), by intrusion (I) or manually (M). The frequency of level measurement varies by tank. The frequencies can either be daily (D), weekly (W), monthly (M) or quarterly (Q).

Ventilation: There are two basic types of tank ventilation systems employed: an active powered system and a passive "breather filter" system. The active powered system takes two forms. One system is a portable, skid mounted system. The other is a permanent piped ventilation system that serve a farm. The following designators are used. 702-A - Farms $A Y$ and $A Z$ are serviced by ventilation building 702-A. 
AN - Permanent piped system servicing the AN farm.

AP - Permanent piped system servicing the AP farm.

$A W$ - Permanent piped system servicing the AW farm.

BF - Passive breather filter system.

P - Portable, skid mounted, active powered system.

SY - Permanent piped system servicing the SY farm. 


\section{Units of Measurement}

BTU/Hr - British Thermal Units per hour.

g mol - Gram molecules, or moles. The quantity of a chemical compound that has a weight in grams numerically equal to the molecular weight of the compound.

Kgal - $\quad$ Thousands of gallons, e.g. 55,900 gallons $=55.9 \mathrm{Kgal}$.

Temperature - Temperature measured in degrees fahrenheit.

Yr - $\quad$ Calendar year with the first 2 digits removed, e.g. 1955 is represented as 55.

Yrs - Number of years.

\section{Other Terms}

Total Waste - $\quad$ Solids volume plus supernatant liquid.

Supernatant Liquid - Supernatant liquid is usually derived by subtracting the solids level measurement from the liquid level measurement. Drainable liquid remaining minus drainable interstitial liquid.

Drainable Interstitial - Drainable interstitial liquid is calculated based on the saltcake and sludge volumes, using average porosity values or actual data for each tank, when available. It is the drainable liquid remaining minus the supernatant liquid.

Drainable liquid - That liquid remaining in the tank which is drainable. It is comprised of the supernatant and the drainable interstitial liquid.

Sludge -

Solids formed during sodium hydroxide $(\mathrm{NaOH})$ additions to waste. Sludge usually was in the form of suspended solids when the waste was originally received in the tank from the waste generator. In tank photographs may be used to estimate the volume.

Saltcake -

Results from crystallization and precipitation after concentration of liquid waste, usually in an evaporator. If saltcake is layered over sludge, it is only possible to measure total solids volume. In tank photographs may be used to estimate the volume.

DSS - $\quad$ Double shell slurry. Waste evaporated nearly to its sodium aluminate saturation boundary or $6.5 \mathrm{M}$ hydroxide in the evaporator. For reporting purposes, DSS is considered a solid. 


\section{Hanford Tank Farm Data Base}

Most of the important Hanford Tank Farm data has been collected and placed in Table X. This table has been created from several Westinghouse Hanford Company documents (see references) which have been approved for release to the public. The documents are summary reports which are promulgated on a regular basis in order to track the inventory of radioactive waste, and the behavior of the tanks and their contents.

The goal of this table or data base is to be able to provide sufficient information in order to systematically create groups of tanks that have similar behavior. The groups would be based upon criteria such as various measurable parameters and known facts about each tank. By sorting the table based on the criteria, the groups can be constructed and analyzed.

The table is composed of one record for each of the 177 tanks. Each record begins with a line number in the first column, and the unique tank identifier in the second column. The third column indicates the type of tank: 100 denotes a single shell tanks of $75 \mathrm{ft}$ diameter, 200 denotes a single shell tank of $20 \mathrm{ft}$ diameter, and DST indicates a double shell tank of $75 \mathrm{ft}$ diameter. All of the tanks are located in the 200 area and the relative east or west location is indicated by the fourth column.

Within a farm, each tank was constructed at approximately the same time. It is assumed that the tank was placed in service at the end of the construction period for the farm. Column 5, labeled Start Date, is the last 2 digits of the year in which the farm construction ended. The adjacent column labeled Age is the age of the tank in years.

Because of various circumstantial pieces of information, many tanks have been administratively labeled "Assumed Leakers." These tanks have been labeled with a Y (yes) or N (no) as appropriate in the column titled Leaker No/Yes. The year in which the decision was made to categorize the tank as a leaking tank is found in parenthesis following the "Y." If sufficient information became available to declare a tank a leaking tank, there was also sufficient information to determine the size of the leak. The size of the leak is found in the column labeled Leak Size. All values are given in thousands of gallons.

One of the most effective ways of limiting the size of a potential leak is to limit the available inventory of liquid. Those tanks that have had much of their liquid inventory removed have been labeled Interim Stabilized (IS). The designation applies to those tanks that have less than 50,000 gal of drainable liquid (interstitial liquid plus supernatant liquid) and less than 5,000 gal of supernatant liquid. The term also applies if the tank was jet pumped and the flow rate dropped below a specific level. If the jet pump flow rate dropped below $0.05 \mathrm{gpm}$, the tank met the Interim Stabilized criteria.

Tanks that have met either of these criterion have an IS in the column labeled Stabilized. The year the tank was Interim Stabilized follows IS in parenthesis.

Each tank contains a mixture of liquids and solids. The liquid that resides above the solids and precipitate on the bottom of the tank is the supernatant. The volume of supernatant found in each tank is found in the column Supernatant Liquid, Kgal, and the adjacent column, under Type, describes the category of liquid. The string of characters used to define the categories of liquid is defined as follows: 

AGING - $\quad$ Aging waste. High level, first cycle solvent extraction waste from the Plutonium-Uranium Extraction plant. Neutralized current acid waste (NCAW).
CC - Concentrated complexant. Concentrated product from the evaporation of dilute complexed waste.
CP - $\quad$ Concentrated phosphate waste. Waste originating from the decontamination of $100 \mathrm{~N}$ Area reactor.
DC - Dilute complexed waste. This is characterized by a high content of organic carbon including organic complexants.
DN - Dilute non-complexed. Low activity liquid waste originating from $T$ and $S$ Plants, 300 and 400 Areas, Plutonium-Uranium Extraction facility (decladding supernatant and miscellaneous wastes), $100 \mathrm{~N}$ Area (sulfate waste), B Plant, saltwells, and Plutonium Finishing Plant (supernatant).

DSSF - Double shell slurry feed. Waste evaporated just before reaching the sodium aluminate saturation boundary or $6.5 \mathrm{M}$ hydroxide in the evaporator. This form is not as concentrated as DSS.

EMPTY - Contains no contents.

NCPLX - Non-complexed. General waste term applied to all site liquors not identified as complexed.

PD - $\quad$ Plutonium-Uranium Extraction plant decladding or Neutralized Cladding Removal Waste (NCRW). It is the solids portion of the Plutonium-Uranium Extraction plant neutralized cladding removal waste stream, received into tanks as a slurry. It is classified as transuranic waste.

PT - $\quad$ Plutonium Finishing Plant transuranic solids which originate from West Area operations.

Found within the solids and precipitate below the supernatant is (interstitial) liquid. This is a drainable volume whose quantity is based on either average porosity values for the solid constituents, or actual data. The column labeled Inter. Liquids indicates the measured or calculated volume. The next column, Total Liquids, is the sum of the supematant volume and the interstitial volume. The resultant amount is also known as the drainable volume.

The other major constituent of the tanks is solids. Solids have been categorized into 3 main groups which are double-shell slurry, sludge, and saltcake. These terms are defined as follows:

DSS - $\quad$ Double shell slurry. Waste evaporated nearly to its sodium aluminate saturation boundary or $6.5 \underline{\mathrm{M}}$ hydroxide in the evaporator. For reporting purposes, DSS is considered a solid. 
saltcake - $\quad$ Results from crystallization and precipitation after concentration of liquid waste, usually in an evaporator. If saltcake is layered over sludge, it is only possible to measure total solids volume. In-tank photographs may be used to estimate the volume.

sludge -

Solids formed during sodium hydroxide $(\mathrm{NaOH})$ additions to waste. Sludge usually was in the form of suspended solids when the waste was originally received in the tank from the waste generator. In-tank photographs may be used to estimate the volume.

The column labeled Solids with Interstitial is subdivided into the above 3 categories. The quantity indicated is the volume of solids inciuding the interstitial liquid. The quantity of solids without the interstitial liquid volume included is the column labeled Solids. This is the volume attributed to solely the solids as if all of the interstitial liquid had been removed.

The measure of all of the waste in a tank can be found in the column titled Total Waste. This is a calculated field in that it is the sum of the Total Liquids column and the Solids column. In other words, the total waste is the sum of all of the liquids (supernatant and interstitial) and all of the solids (DSS, sludge, and salt).

All of the single shell tanks have been isolated to some degree in order to minimize the further addition of waste. Two degrees of isolation have been established: partially interim isolated, and interim isolated. Interim isolated $(I)$ means that all of the physical efforts needed to minimize the further addition of waste to a tank has been completed. Partially interim isolated (P) means that all of the efforts to minimize the further addition of waste to a tank has been performed, except that risers and piping needed for tank stabilization have not been isolated. The column titled Isolated indicates which degree of isolation has been performed for each tank. Double shell tanks have not been isolated.

Several parameters other than level are being monitored for many tanks. One important parameter is tank temperature which translates into heat load. The values for several dates can be found in the column titled High Temperature Reading. The associated heat load, if calculated, can be found in the column titled Heat Load.

Many tanks have detectable levels of ferrocyanide ( $\mathrm{FeCN}$ ), and this value is given in the column titled FECN. Those tanks that contain greater than 1000 gram-mole of ferrocyanide are placed on the Watch List. The column titled Watch List and with the sub-column title FECN has an "X" for those tanks on the watch list. Other criteria for the Watch List includes hydrogen levels above the flammability limit (denoted by the sub-column title $\mathrm{H} 2$ ), organic salts (sub-column title $\mathrm{ORG}$ ) and heat (sub-column title HEAT).

Each tank is periodically measured for liquid. This is an important measurement because it is not only used to track the inventory of liquid waste at the site, it provides evidence as to whether a tank has been leaking. All of the single shell tanks are measured by one of 3 different methods and these methods are listed in the column titled Level Measurement. The measurements are either taken manually $(M)$, automatically $(A)$ or by intrusion (I). The frequency of level measurement varies by tank. The frequencies can either be daily (D), weekly (W), monthly (M) or quarterly (Q). 
As the tank volume expands or contracts due to temperature fluctuations or the release of gases, a ventilation system maintains the gas space above the liquid volume constant. There are two basic types of tank ventilation systems employed: an active powered system and a passive "breather filter" system. The active powered system takes two forms. One system is a portable, skid mounted system. The other is a permanent piped ventilation system that serve a farm. The following designators are used.

702-A - Farms $A Y$ and $A Z$ are serviced by ventilation building 702-A. AN - Permanent piped system servicing the AN farm.

AP - Permanent piped system servicing the AP farm.:

AW - Permanent piped system servicing the AW farm.

BF - Passive breather filter system.

P - Portable, skid mounted, active powered system.

SY - Permanent piped system servicing the SY farm.

The source of each column of information in data base (TANKLEAK.XLS) can be tracked back to the original document via the table of references (INFOSORC.XIS). 
Tank Data Reference Chart

\begin{tabular}{|c|c|c|c|c|}
\hline Subject & Column: & Table(s) & Page: & Comment \\
\hline Tank type & 1 & Fig B-8 & $\mathrm{B}-15 / 16$ & $\begin{array}{l}200 \text { type tanks are smaller radius } \\
\text { circles; double shell tanks (DST) are } \\
\text { concentric circles; remainder are } 100 \\
\text { type. }\end{array}$ \\
\hline Location E/W & 2 & Fig B-8 & $B-15 / 16$ & \\
\hline In service date & 3 & Fig B-8 & $B-15 / 16$ & $\begin{array}{l}\text { Assume the tank was placed in service } \\
\text { at the end of the construction period. }\end{array}$ \\
\hline Agge (years) & 4 & - & - & Calculated field. \\
\hline Leaker (year) & 5 & $\mathrm{H}-1$ & $\mathrm{H}-3$ to $\mathrm{H}-6$ & Column 2. \\
\hline Leak size (kgal) & 6 & $\mathrm{H}-1$ & $\mathrm{H}-3$ to $\mathrm{H}-6$ & Column 3. \\
\hline \multirow[t]{3}{*}{ Stabilized method (year) } & 7 & $\overline{\mathrm{H}-1}$ & $\mathrm{H}-3$ to $\mathrm{H}-6$ & Column 5 is the date source. \\
\hline & & $\overline{C-5}$ & C-9 thru C-18 & $\begin{array}{l}\text { Column } 4, \text { first } 2 \text { characters for the } \\
\text { status. }\end{array}$ \\
\hline & & $2,3,4,5$ & $11,14,15,16$ & Addition sources for year. \\
\hline Supernatant liquid (kgal) & $8 \mathrm{~A}$ & $C-4,5$ & C-6 thru C-18 & 8th and 6th column respectively. \\
\hline Supernatant liquid (type) & $8 \mathrm{~B}$ & $\mathrm{C}-4,5$ & $C-6$ thru $C-18$ & 2nd column. \\
\hline Interstitial liquid (kgal) & 9 & $C-4,5$ & C-6 thru $C-18$ & 9th and 7th column respectively. \\
\hline Total liquids (kgal) & 10 & - & - & $\begin{array}{l}\text { Calculated: sum of supernatant and } \\
\text { interstitial liquid. }\end{array}$ \\
\hline \multirow[t]{3}{*}{$\begin{array}{c}\text { Solids (kgal) with Interstitial } \\
\text { DSS }\end{array}$} & $11 \mathrm{~A}$ & $C-4$ & C-6 thru C-8 & $\begin{array}{l}\text { 14th column. Applicable to double shell } \\
\text { tanks only. }\end{array}$ \\
\hline & $11 \mathrm{~B}$ & $\mathrm{C}-4,5$ & $\mathrm{C}-6$ thru $\mathrm{C}-18$ & 15th and 12 th column respectively. \\
\hline & $11 \mathrm{C}$ & $\mathrm{C}-4,5$ & $C-6$ thru $C-18$ & 16th and 13 th column respectively. \\
\hline \multirow[t]{2}{*}{ Solids (kgal) } & 12 & $B-5, B-6$ & $\mathrm{~B} 9 / 10, \mathrm{~B} 11 / 12$ & $\begin{array}{l}\text { Data for single shell tanks. Calculated } \\
\text { by subtracting the Total Liquids from } \\
\text { the Total Waste Volume [(solids }+ \\
\text { supernatant)-(drainable interstitial }+ \\
\text { supernatant)] found on figure. }\end{array}$ \\
\hline & & C-4 & C-6 thru C-8 & $\begin{array}{l}\text { Data for double shell tanks. This is the } \\
\text { sum of DSS, sludge, and saltcake } \\
\text { subtracted by the drainable interstitial } \\
\text { quantity (columns } 14+15+16-9 \text { ) - all } \\
\text { found on table. }\end{array}$ \\
\hline Total Waste & $\sqrt{13}$ & - & - & $\begin{array}{l}\text { Calculated field. Is the sum of the Tota } \\
\text { Liquids column and the Solids column. }\end{array}$ \\
\hline Isolated (5) & 14 & $\widehat{D-5, D 6}$ & $\begin{array}{l}\mathrm{D}-9 / 10, \mathrm{D}- \\
11 / 12\end{array}$ & $\begin{array}{l}\text { The status is indicated under the figure } \\
\text { for each tank. }\end{array}$ \\
\hline
\end{tabular}


Tank Data Reference Chart

\begin{tabular}{|c|c|c|c|c|}
\hline Subject i & Column:* & Table(s) & Page. & Comment \\
\hline \multicolumn{5}{|l|}{ High temp. reading: } \\
\hline Sept $-91(3)$ & $15 \mathrm{~A}$ & $2,3,4,5$ & $5-8$ & 2nd column of each. \\
\hline Dec-91 & $15 \mathrm{~B}$ & $2,3,4,5$ & $11,14,15,16$ & 2nd column of each. \\
\hline July-92(1) & $15 \mathrm{C}$ & 9 & $19-21$ & Column 6. \\
\hline Ferrocyanides $(1000 \mathrm{~g} \mathrm{~mol})$ & & & & \\
\hline Dec-91 & 16 & 2 & 11 & Column 6. \\
\hline Heat load (Btu/hr) & & & & \\
\hline Dec-91 & $17 \mathrm{~A}$ & 2,5 & 11,16 & Column 7 and 6 respectively. \\
\hline July-92 (1) & $\overline{17 B}$ & 2,5 & 6,12 & Column 7 and 6 respectively. \\
\hline Watch lists & & & & \\
\hline hydrogen & $18 \mathrm{~A}$ & 1 & 10 & Columns 2, 4, and 6. \\
\hline organic salts & $18 \mathrm{~B}$ & 1 & 10 & Columns 2,4 , and 6. \\
\hline fertocyanide & $18 \mathrm{C}$ & 1 & 10 & Columns 2, 4, and 6. \\
\hline heat & $18 \mathrm{D}$ & 1 & 10 & Columns 2,4 , and 6. \\
\hline Level Measurement (4) & $19 \mathrm{~A}, \mathrm{~B}$ & $1-25$ & $1-349$ & $\begin{array}{l}\text { Column } 2 \text { is the method, column } 3 \text { is } \\
\text { the frequency. }\end{array}$ \\
\hline Ventilation (5) & 20 & \begin{tabular}{|l|} 
Hanford \\
Tank \\
Farm \\
Facilities \\
200 West \\
and East
\end{tabular} & $\begin{array}{l}D-13 / 14, D- \\
15 / 16\end{array}$ & $\begin{array}{l}\text { The designator is located at 4-o'clock } \\
\text { on each tank. }\end{array}$ \\
\hline Ventilation (4) & & \begin{tabular}{|l|} 
Figures 3- \\
71,77 \\
$78,79,81$
\end{tabular} & $\begin{array}{l}\text { Volume } 2 \text { of } \\
\text { ISB }\end{array}$ & $\begin{array}{l}\text { These figures depict the configuration } \\
\text { of the ventilation systems for farms AN } \\
\mathrm{AP}, \mathrm{AW} \text {, and SY. }\end{array}$ \\
\hline
\end{tabular}

Notes:

* - column number of tank data table (TANKLEAK.XIS) beginning with Tank Type.

All data is from Ref. 2. except as noted in parenthesis. 


\section{Tank Data Reference Chart}

\section{References}

1. Hanlon, B. M., Tank Farm Surveillance and Waste Status Summary Report for July 1992, Westinghouse Hanford Company, WHC-EP-0182-52.

2. Hanlon, B. M., Tank Farm Surveillance and Waste Status Summary Report for December 1991, Westinghouse Hanford Company, WHC-EP-0182-45, March 1992.

3. Hanlon, B. M., Tank Farm Surveillance and Waste Status Summary Report for September 1991, Westinghouse Hanford Company, WHC-EP-0182-42.

4. Hanford Site Tank Farm Facilities Interim Safety Basis, August 1993, Westinghouse Hanford Company, WHC-SD-WM-ISB-001, Revision 1.

5. Hanlon, B. M., Tank Farm Surveillance and Waste Status Summary Report for June 1993, Westinghouse Hanford Company, WHC-EP-0182-63. 


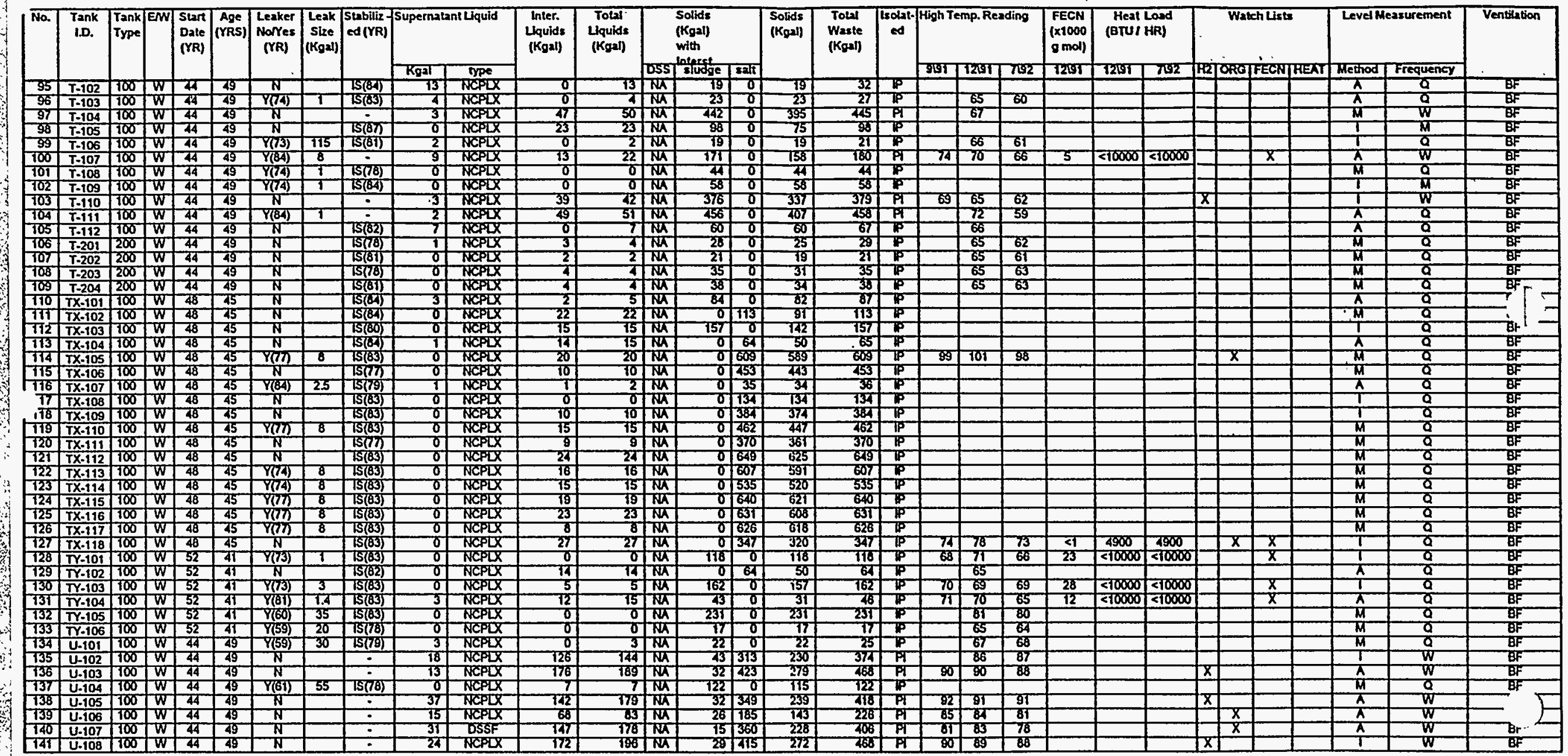




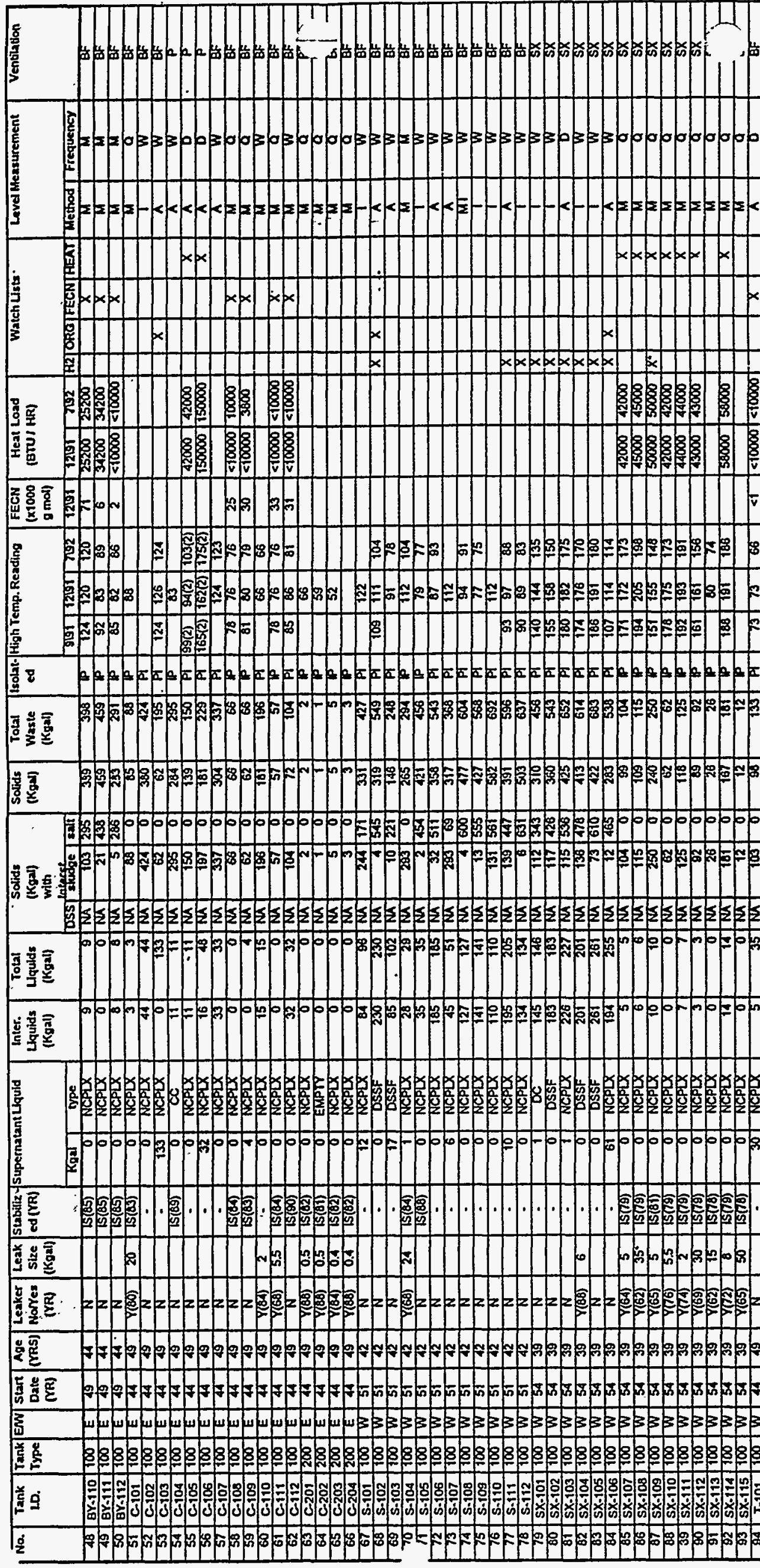


Hanford Tank Farm Data Base

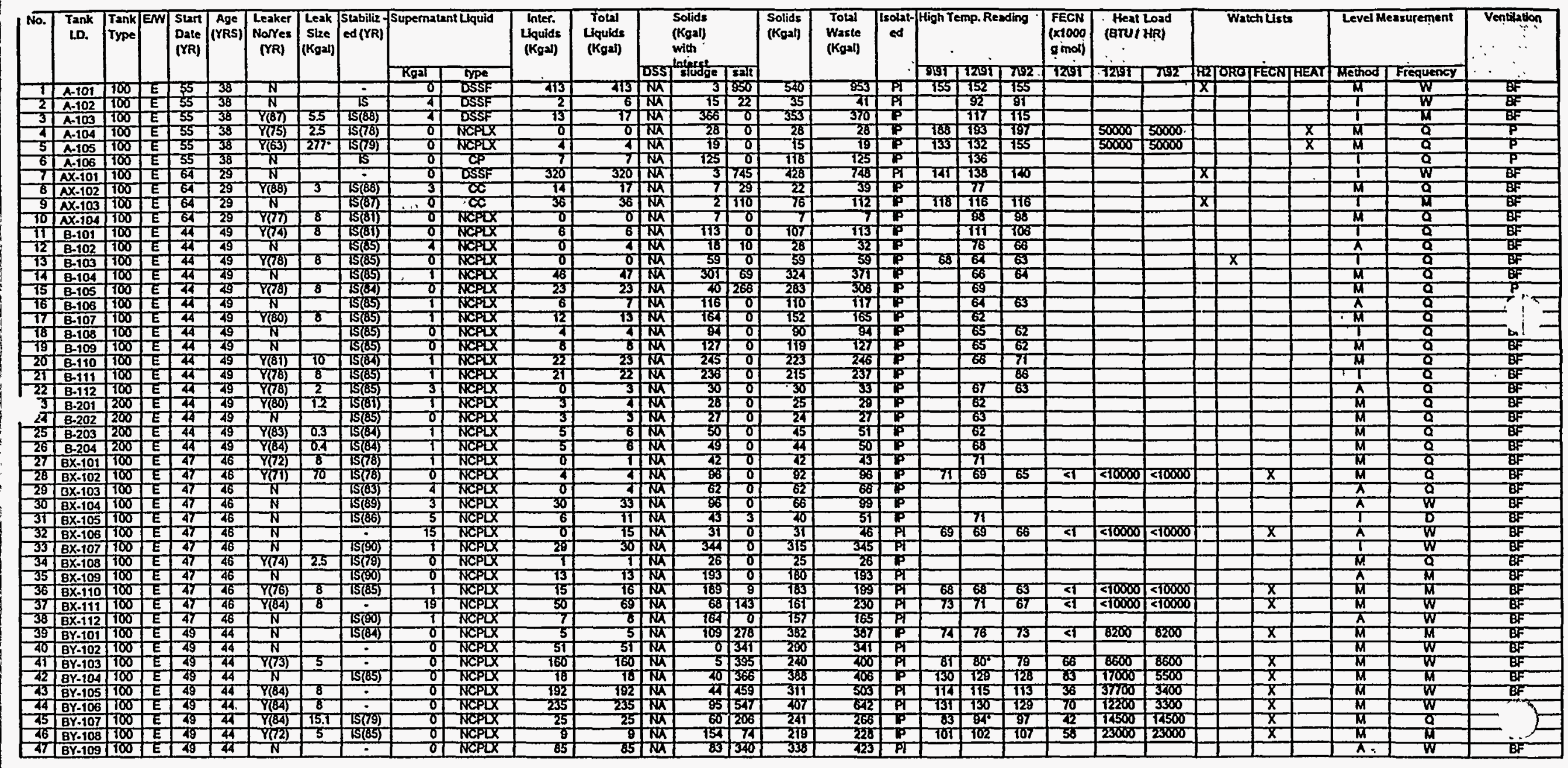

TANKLEAK. XLS 